\title{
Investigation and Development of Exhaust Flow Rate Estimation Methodologies for Heavy-Duty vehicles
}

\author{
Chakradhar Reddy Vardhireddy \\ cv0008@mix.wvu.edu
}

Follow this and additional works at: https://researchrepository.wvu.edu/etd

Part of the Automotive Engineering Commons, Mechanical Engineering Commons, and the Other Computer Engineering Commons

\section{Recommended Citation}

Vardhireddy, Chakradhar Reddy, "Investigation and Development of Exhaust Flow Rate Estimation Methodologies for Heavy-Duty vehicles" (2019). Graduate Theses, Dissertations, and Problem Reports. 7423.

https://researchrepository.wvu.edu/etd/7423

This Thesis is protected by copyright and/or related rights. It has been brought to you by the The Research Repository @ WVU with permission from the rights-holder(s). You are free to use this Thesis in any way that is permitted by the copyright and related rights legislation that applies to your use. For other uses you must obtain permission from the rights-holder(s) directly, unless additional rights are indicated by a Creative Commons license in the record and/ or on the work itself. This Thesis has been accepted for inclusion in WVU Graduate Theses, Dissertations, and Problem Reports collection by an authorized administrator of The Research Repository @ WVU. For more information, please contact researchrepository@mail.wvu.edu. 


\title{
Investigation and Development of Exhaust Flow Rate Estimation Methodologies for Heavy-Duty vehicles
}

\author{
Chakradhar Reddy Vardhireddy \\ Thesis submitted to the \\ Benjamin M. Statler College of \\ Engineering and Mineral Resources \\ at West Virginia University \\ in partial fulfillment of the requirement \\ for the degree of \\ Masters of Science in \\ Mechanical Engineering
}

Committee members:

Marc Cyrill Besch, PhD., Committee Chairperson

Arvind Thiruvengadam, PhD

Ross Ryskamp, PhD.

Saroj Pradhan, PhD.

Department of Mechanical and Aerospace Engineering

Morgantown, West Virginia

2019

Keywords: Exhaust Flow Estimation, Raw Exhaust Flow, Artificial Neural Network, Diesel Particulate Filter Differential Pressure Copyrights 2019 Chakradhar Reddy Vardhireddy 


\section{ABSTRACT \\ Investigation and Development of Exhaust Flow Rate Estimation Methodologies for Heavy-Duty vehicles Chakradhar Reddy Vardhireddy}

Exhaust gas flow rate from a vehicle tailpipe has a great influence on emission mass rate calculations, as the emission fractions of individual gases in the exhaust are calculated by using the measured exhaust flow rate. The development of high-end sensor technologies and emission pollutant measurement instruments, which can give instantaneous values of volume concentration of pollutants flowing out of the engine are gaining importance because of their ease of operation. The volume concentrations measured can then be used with the instantaneous exhaust flow rate values to obtain mass flow rates of pollutants.

With the recent promulgation of real world driving (RDE) emissions, it is of significance to gain a real-time measurement or estimation of fuel consumption and mass emission numbers for the tailpipe constituents. Adhering to the packaging complexity and cost involved in affixing the vehicles with accurate flow meters, the methodologies to predict the same using existing vehicle infrastructure has been constantly evolving and investigated. Towards realizing such an effort, the present work is directed towards investigating a few improved approaches towards estimating exhaust flow values, including the challenging vehicle operation regimes such as, light load activity and start-stop idle conditions which is prone to fluctuations in the flow behavior. Also, the fact that the exhaust gas flow rate plays a key role in determining actual amounts of mass flow rates of pollutants, provides scope for the development of new methods to estimate exhaust flow rates. 
In this report, three different methodologies to estimate the exhaust flow rate from the vehicle tailpipe have been developed and investigated. The estimations were obtained by using the on-board diagnostics (OBD) data collected from the engine control unit (ECU). Mass flow rate of fuel and other parameters necessary to calculate the intake flow rate to the engine, and parameters which can be used directly for estimation of exhaust flow rate, were obtained from the ECU. Based on these values the exhaust gas flowing out of vehicle tailpipe was estimated and corrected.

The estimations made by methodologies under study were found to match the measured exhaust flow, measured using an industry standard Portable Emissions Measurement System (PEMS) exhaust flow device, in its best within 1\% along Regional and Port: Local routes and the least accurate estimations were observed to be happening in vehicle activity along Highway route with highest difference of $13.3 \%$ respectively. However, the developed methods serve as alternative methodologies, as the exhaust flow rate values are calculated without usage of any additional flow meters and flow sensors, and by just using the ECU data, eventually providing a reliable means to help in calculating the mass flow rates of pollutants flowing out of vehicle tailpipe. 


\section{ACKNOWLEDGEMENTS}

I would take genuine pleasure in expressing my deepest indebtedness to my committee chair, Professor Dr. Marc Cyrill Besch, who has the attitude and substance of a genius; he has continually and convincingly conveyed a spirit of adventure to me with regard to research. Without his persistent guidance and help this dissertation would have not been possible. His dedication and keen interest, and above all his overwhelming desire to support his students, has been solely responsible for the completion of my work. His timely advice, meticulous scrutiny, scholarly advice and scientific approach have been essential in helping me to accomplish this project. Apart from these, his kindness, enthusiasm and dynamism have made him my inspiration. And I am indebted to him for providing me with this most valuable opportunity.

I would like to thank my committee member, Professor Dr. Arvind Thiruvengadam, whose research work inspired me to apply for admission at West Virginia University. I thank him for providing me with consistent guidance and advice, and for pointing me in the right career direction. I truly respect him for his great character, and as a noble human being who has stood for and supported many international students in finding jobs and helping them when needed. I am inspired by his great deeds and will try every moment of my life to live up to the great standards set by him.

I am deeply indebted to Dr. Berk Demigork, PhD, and Zach Layhew for laying the basic foundation from which I started, for sharing their dissertation work with me, and for providing me a clear perspective about the importance of the work that I would be involved with and working on. 
I would like to thank Daniel Carder, Dr. Ross Ryskamp, Dr. Saroj Pradhan and my fellow lab mates and employees who supported my work in the best possible way and for helping me collect high quality data which enabled me to get the best possible results. I have a deep sense of gratitude and owe special thanks to the doctoral students Vishnu Padmanaban, Rasik Pondicherry, Anirudh Trius, Mehar Baba Bade and Dr. Sai Satish Guda, for generously sharing their knowledge with me, and for laying down the right path before me with their guidance, which has been essential in helping me to succeed in my career. I am also deeply grateful to them for their patience and support in helping me to overcome the numerous obstacles I have been faced with through the course of my research.

I wish to profusely thank my friends and my fellow master's students; Filiz Khazan, for being a source of constant emotional support and for her consolidative speeches. I thank, Jordan, the boy from the 'Maryland Fire department' for all his caring support and help, my big Mexican friend Diego, for his never-ending friendship and Beti, 'the daughter of CAFEE', for her engaging conversations and for her unflattering willingness to lend a helping hand. Finally, I would like to express my heartiest thanks to Sri Satya Ravi, Ranjith Reddy Kalluri, Sashank jammalamadaka, Hemanth Kumar, Vivek Kommarina, Pushpitha, Rahul Kooragayala, Saavan Suri and Anveeksh koneru for their profuse love and affection, and for making my life at WVU a lot easier.

I would like to thank my parents; whose love and guidance are with me in whatever I pursue. They are my ultimate role models. Nobody has been more important to me in the pursuit of this project than the members of my family. Most importantly, I thank my loving and supportive friend, Prerna Singh, for showering me with everlasting love and for motivating me to finish my dissertation successfully. 


\section{Table of Contents}

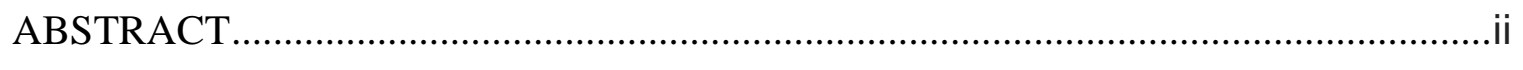

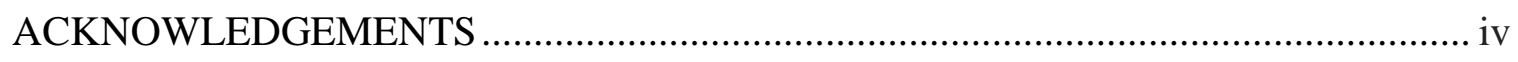

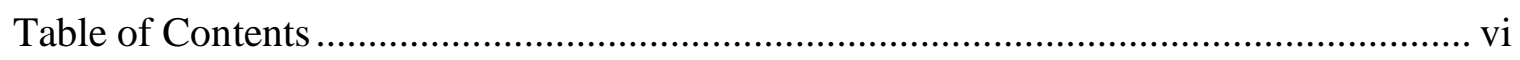

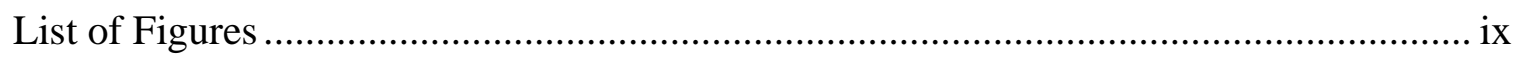

List of Tables ...................................................................................................... xii

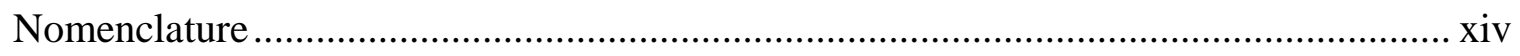

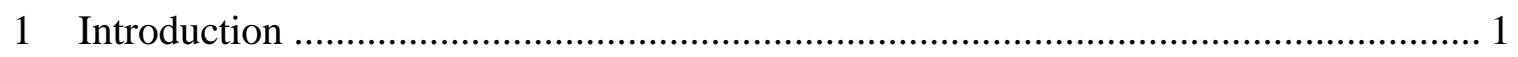

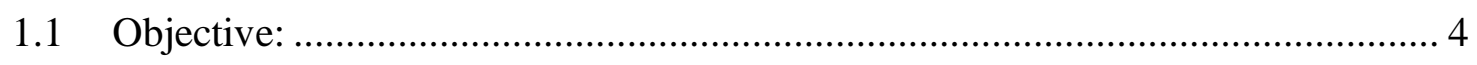

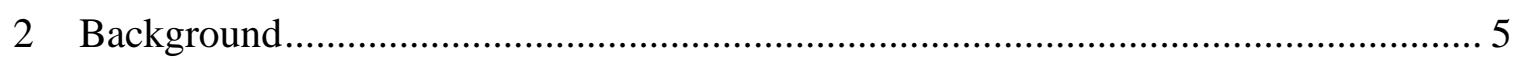

2.1 Exhaust flow measurement methodologies: ............................................... 5

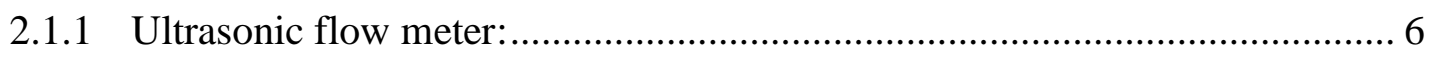

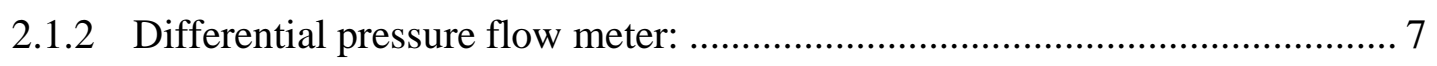

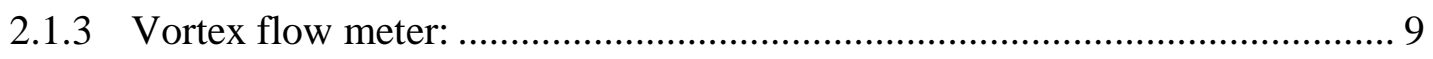

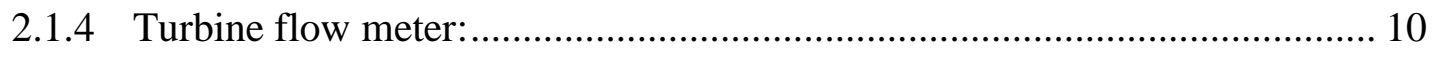

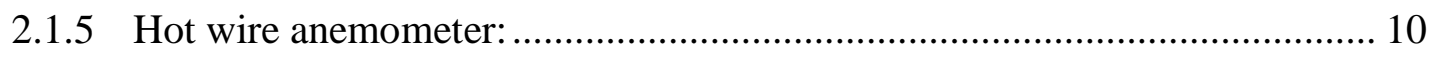

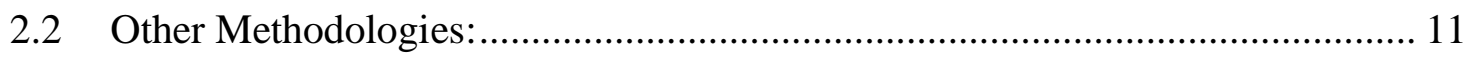

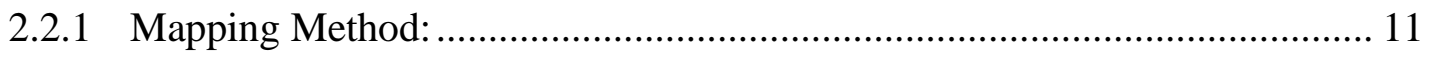

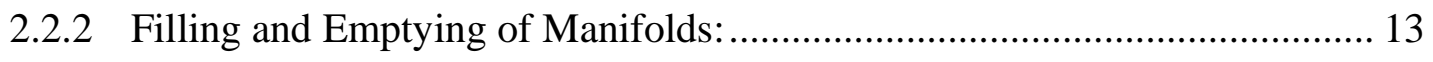

2.2.3 Polytropic Process Method: ............................................................... 14

2.3 Intake Flow Measurement using Intake Speed-Density Method: ...................... 14

2.4 Fuel Flow \& Air-Fuel Ratio Measurement Methods: ...................................... 16

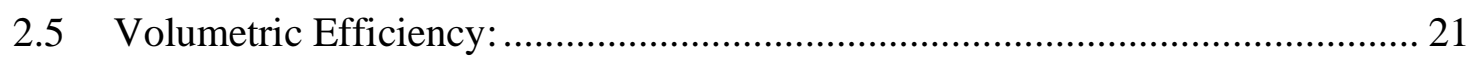

2.6 Diesel Particulate Filters: ..................................................................... 23 
2.7 LFE for EFM calibration:

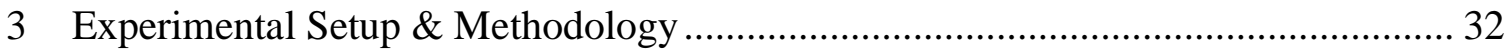

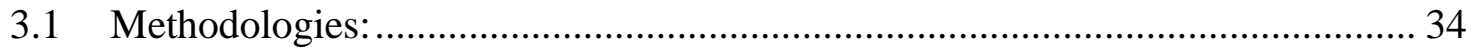

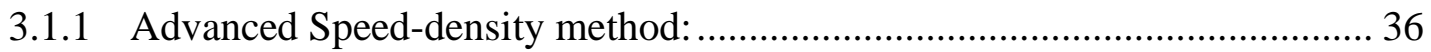

3.1.2 Artificial neural network method: ................................................... 40

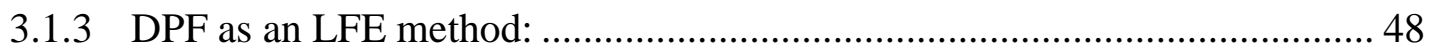

3.2 Experimental Test Vehicles and Data Collection Equipment: .........................52

3.3 Artificial Neural Network Training Data: .................................................... 56

3.4 Routes Used for Validating the Developed Methodologies:.............................58

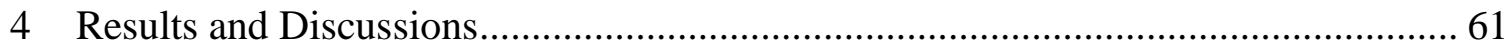

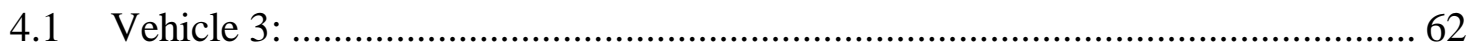

4.1.1 Correction Coefficients of Vehicle-3 speed density method - 1 a ...............62 62

4.1.2 Regression Plots of Vehicle-3 speed density method - 1 a: .......................... 64

4.1.3 Quartile-Quartile Plots Vehicle-3 speed density method - 1 a:....................65

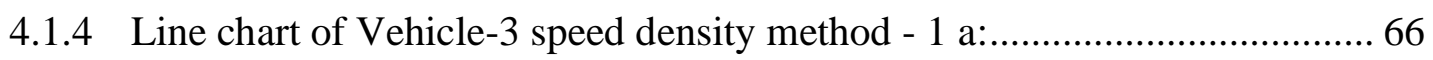

4.1.5 Regression Plots of Vehicle-3 speed density method - 1 b:......................... 68

4.1.6 Quartile-Quartile Plots Vehicle-3 speed density method - 1 b: ................... 69

4.1.7 Line chart of Vehicle-3 speed density method - 1 b: ............................. 70

4.1.8 ANN Training Performance Results of Vehicle-3: ............................... 71

4.1.9 Regression Plots of Vehicle-3 ANN Method:......................................... 72

4.1.10 Quartile-Quartile plots of Vehicle-3 ANN Method: ................................. 73

4.1.11 Line chart of Vehicle-3 ANN Method: ................................................... 74

4.1.12 Regression plots of Vehicle-3 DPF-DP Method:................................. 76

4.1.13 Quartile-Quartile plots of Vehicle-3 DPF-DP Method: ............................ 77

4.1.14 Line chart of Vehicle-3 DPF-DP Method: ............................................ 78 
4.1.15 Combined Line chart of Vehicle-3 all Methods:

4.2 Numerical Results of Vehicle-1: ................................................................ 83

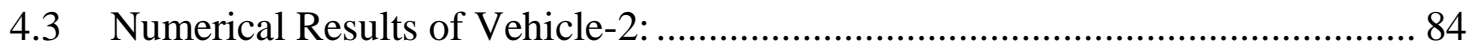

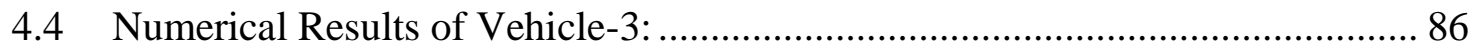

4.5 Numerical Results of Vehicle-4: ........................................................... 88

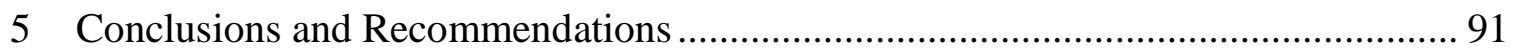

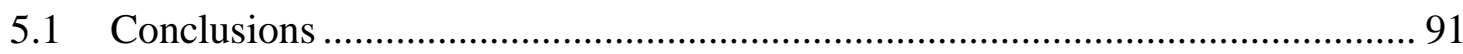

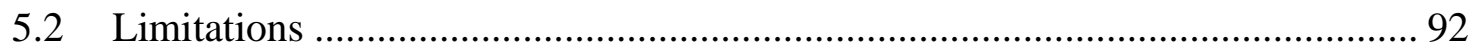

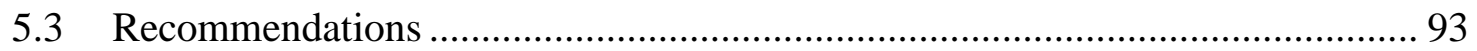

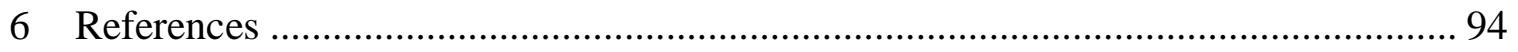

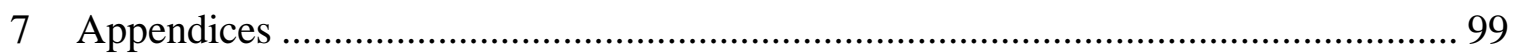

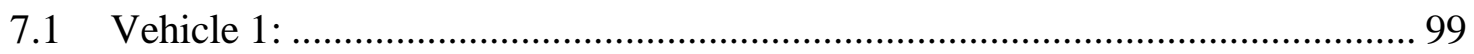

7.1.1 Correction Coefficients of Vehicle-1 speed density method - 1 a: ...............99

7.1.2 Regression Plots of Vehicle-1 speed density method - 1 a: ..................... 101

7.1.3 Quartile-Quartile Plots Vehicle-1 speed density method - 1 a:.................. 102

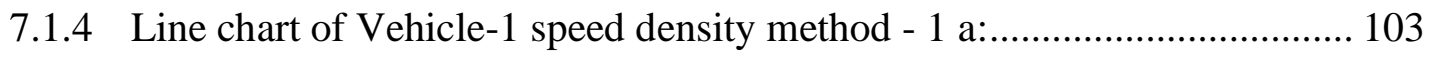

7.1.5 Regression Plots of Vehicle-1 speed density method - 1 b:...................... 105

7.1.6 Quartile-Quartile Plots Vehicle-1 speed density method - 1 b: ................. 106

7.1.7 Line chart of Vehicle-1 ANN Method: ................................................. 107

7.1.8 ANN Training Performance Results of Vehicle-1: ................................ 108

7.1.9 Regression Plots of Vehicle-1 ANN Method:......................................... 109

7.1.10 Quartile-Quartile Plots Vehicle-1 ANN Method: ................................. 110

7.1.11 Line chart of Vehicle-1 ANN Method: ............................................... 111

7.1.12 Combined Line chart of Vehicle-1 all Methods:.................................. 113 


\section{List of Figures}

Figure 1 - Structure of Biological Neural Network and Artificial Neural Network ......... 41

Figure 2 - Multi-layer Artificial Neural Network ..................................................... 42

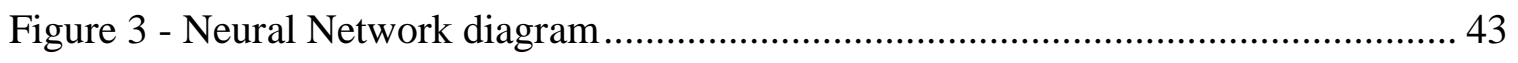

Figure 4 - parameters used for training the Neural Network ...................................... 43

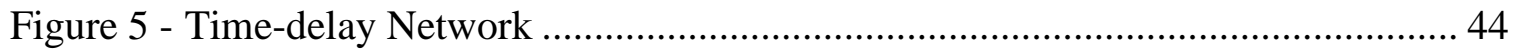

Figure 6 - Semtech measured flow (vs) estimated flow without any correction ............. 46

Figure 7 - Enlarged view of Semtech flow (vs) estimated flow without any correction .. 46

Figure 8 - Correction factors used in the training data set ........................................ 47

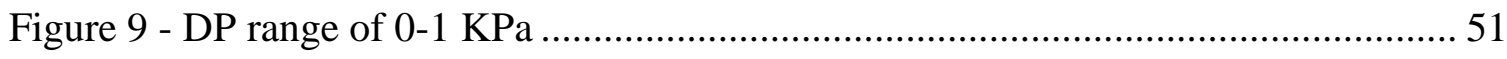

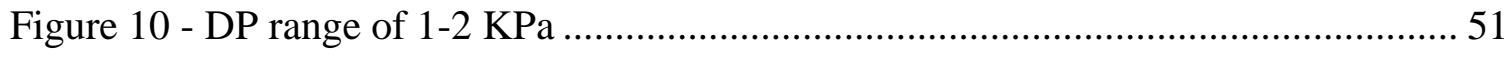

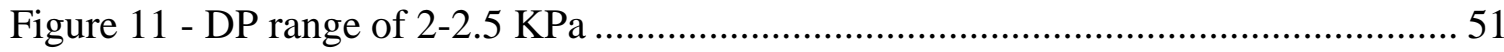

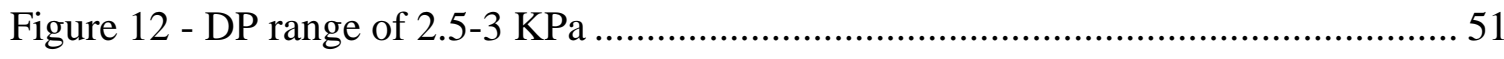

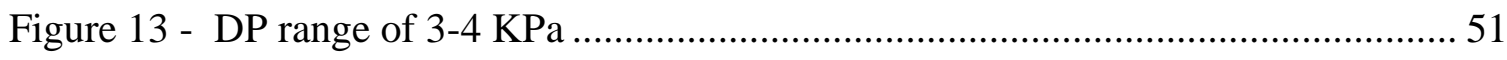

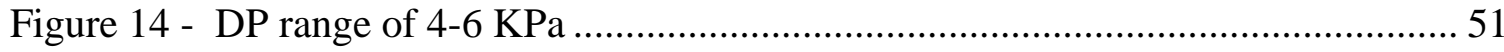

Figure 15 - Semtech exhaust gas flow meter connected to exhaust pipe........................52

Figure 16 - Semtech instrument mounted inside the driver cabin ................................. 53

Figure 17 - Components of Semtech exhaust gas flow tube.......................................... 53

Figure 18 - Inside the Semtech exhaust gas flow tube box.......................................... 54

Figure 19 - Trip summary of vehicle-1 training data set .......................................... 56

Figure 20 - Trip summary of vehicle-2 training data set .......................................... 56

Figure 21 - Trip summary of vehicle-3 training data set ......................................... 57

Figure 22 - Trip summary of vehicle-4 training data set ........................................... 57

Figure 23 - Vehicle-1; Validation routes .............................................................. 58

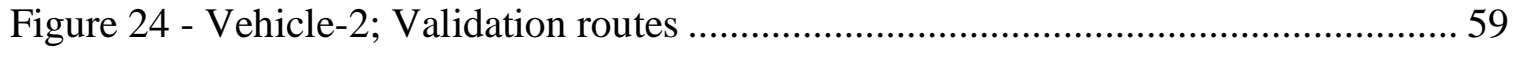

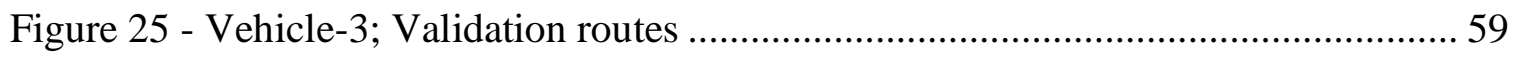

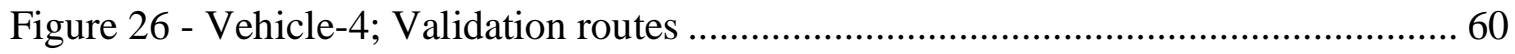

Figure 27 - Correction Coefficients of Regional Route of Vehicle-3 ............................. 62

Figure 28 - Correction Coefficients of Highway Route of Vehicle-3 ........................... 62

Figure 29 - Correction Coefficients of Regional Route of Vehicle-3 ............................ 63 
Figure 30 - Correction Coefficients of Highway Route of Vehicle-3 ........................... 63

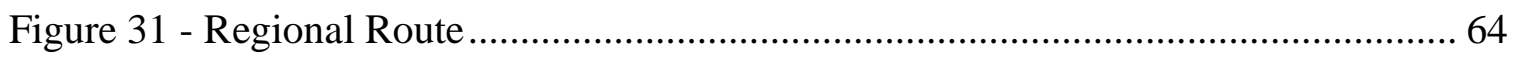

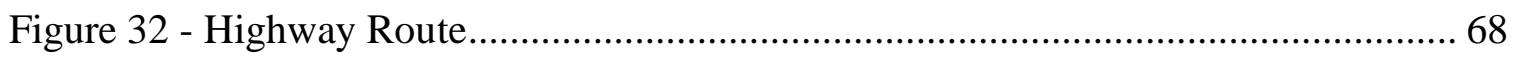

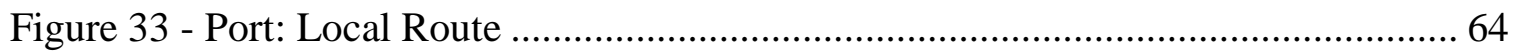

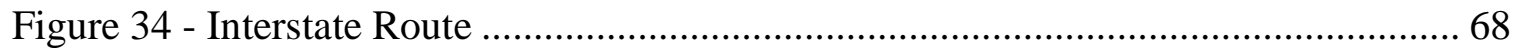

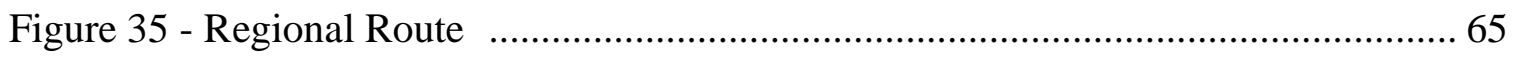

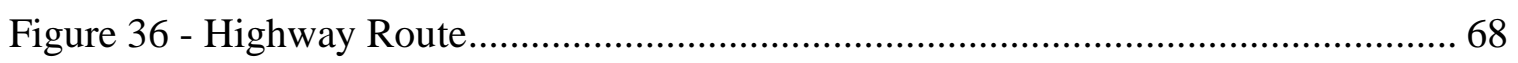

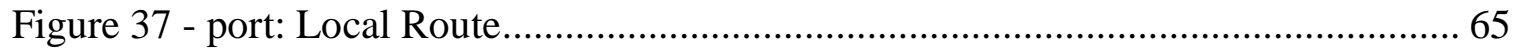

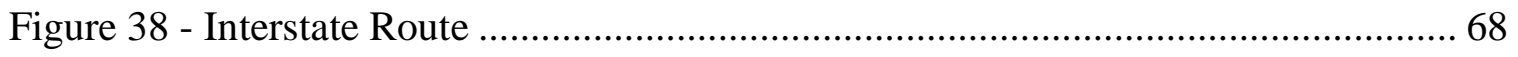

Figure 39 - Regional Route of Vehicle-3 speed density method - 1 a ............................. 66

Figure 40 - Highway Route of Vehicle-3 speed density method - 1 a............................... 66

Figure 41 - Port: local Route of Vehicle-3 speed density method - 1 a........................... 67

Figure 42 - Interstate Route of Vehicle-3 speed density method - 1 a ........................... 67

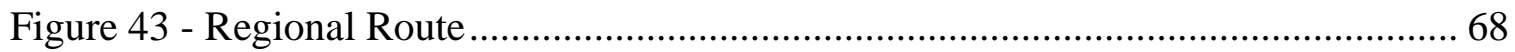

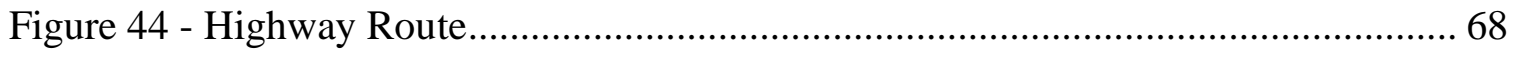

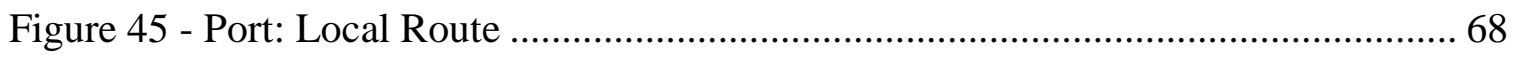

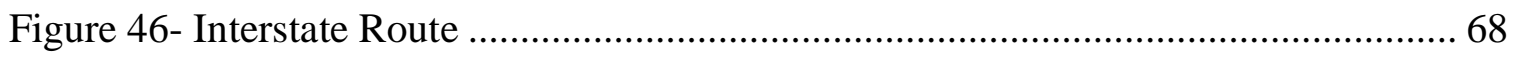

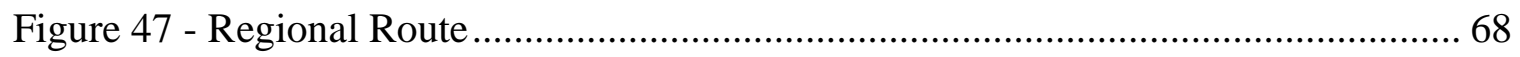

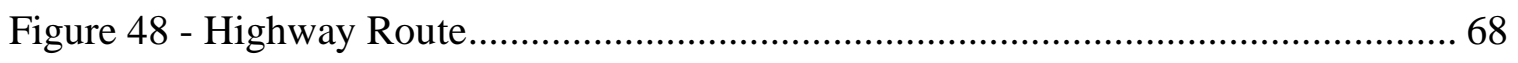

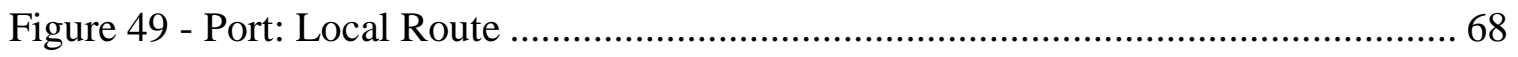

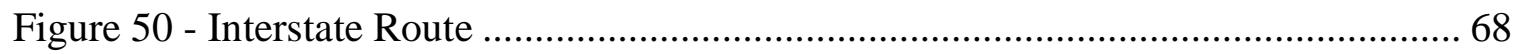

Figure 51 - Combined plot of Vehicle-3 speed density method - 1 b ............................ 70

Figure 52 - Enlarged combined plot of Vehicle-3 speed density method - $1 \mathrm{~b}$............... 70

Figure 53 - Training performance of Vehicle-3 data ............................................. 71

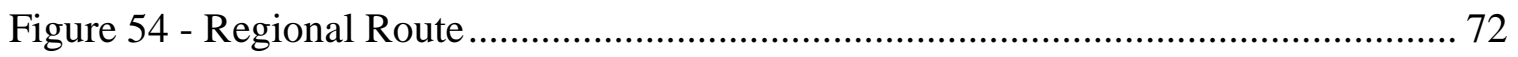

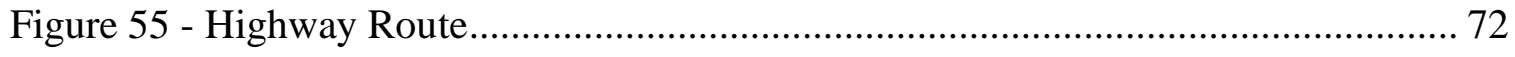

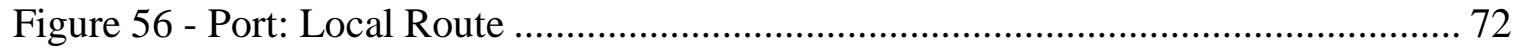

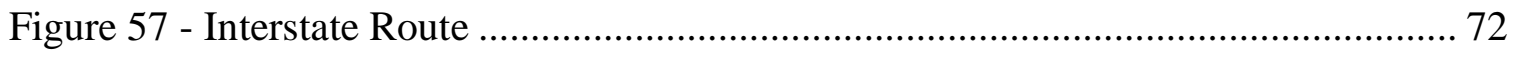

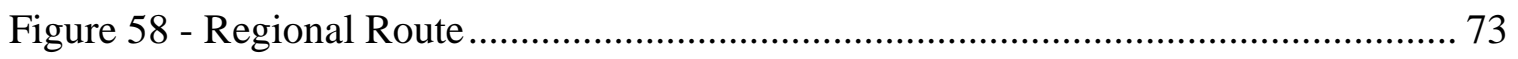

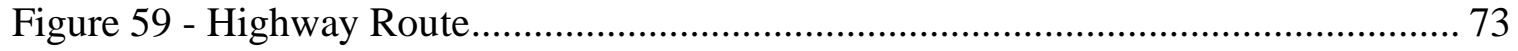

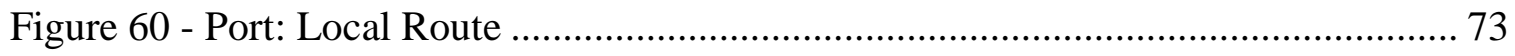




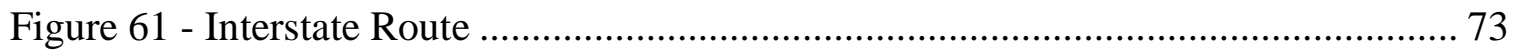

Figure 62 - Regional Route of Vehicle-3 ANN method .................................................. 74

Figure 63 - Highway Route of Vehicle-3 ANN method ................................................. 74

Figure 64 - Port: local Route of Vehicle-3 ANN method ............................................... 75

Figure 65 - Interstate Route of Vehicle-3 ANN method................................................... 75

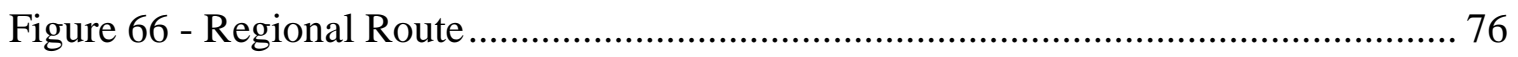

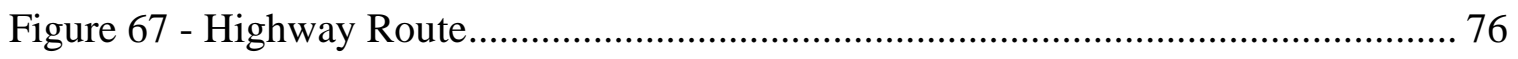

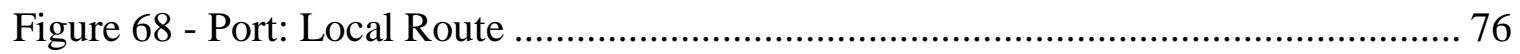

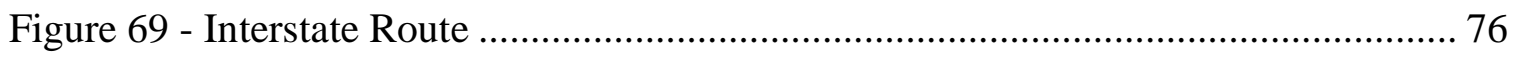

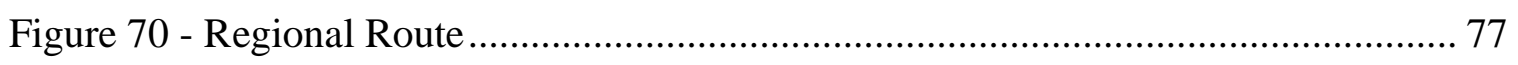

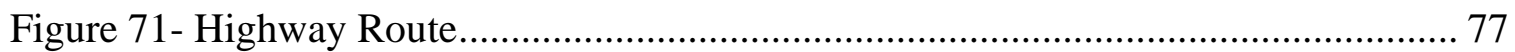

Figure 72 - Port: Local Route …………………………………………………...... 77

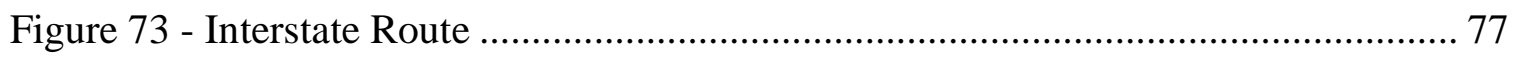

Figure 74 - Regional Route of Vehicle-3 DPF-DP method ............................................. 78

Figure 75 - Highway Route of Vehicle-3 DPF-DP method............................................... 78

Figure 76 - Port: local Route of Vehicle-3 DPF-DP method:............................................ 79

Figure 77 - Interstate Route of Vehicle-3 DPF-DP method ........................................... 79

Figure 78 - Regional Route of Vehicle-3 all methods .................................................. 80

Figure 79 - Highway Route of Vehicle-3 all methods ..................................................... 80

Figure 80 - Port: local Route of Vehicle-3 all methods ................................................... 81

Figure 81 - Interstate Route of Vehicle-3 all methods.................................................. 81

Figure 82 - Correction Coefficients of Regional Route of Vehicle-1 ............................... 99

Figure 83 - Correction Coefficients of Highway Route of Vehicle-1 .............................. 99

Figure 84 - Correction Coefficients of port: Local Route of Vehicle-1 ......................... 100

Figure 85 - Correction Coefficients of Interstate Route of Vehicle-1 …....................... 100

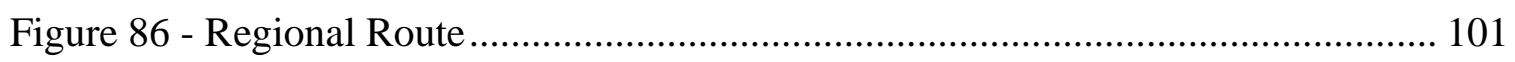

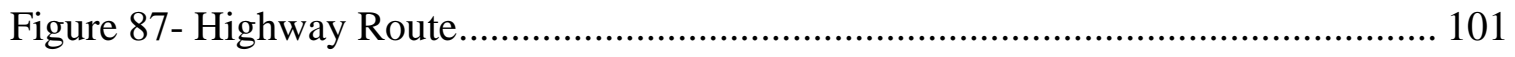

Figure 88 - Port: Local Route ................................................................................. 101

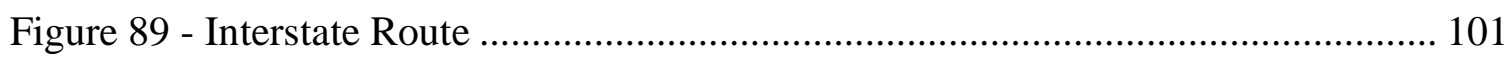

Figure 90 - Regional Route ..................................................................................... 101

Figure 91 - Highway Route...................................................................................... 101 


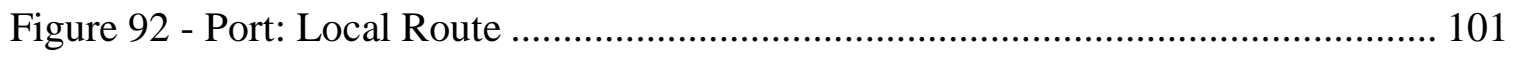

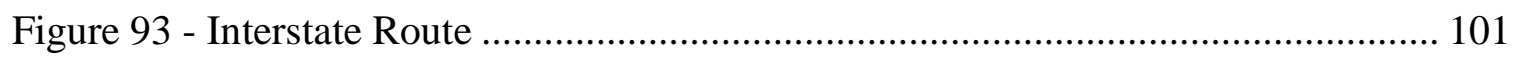

Figure 94 - Regional Route of Vehicle-1 speed density method - 1 a _............................ 103

Figure 95 - Highway Route of Vehicle-1 speed density method - 1 a............................. 103

Figure 96 -Port: local Route of Vehicle-1 speed density method - 1 a........................... 104

Figure 97 - Interstate Route of Vehicle-1 speed density method - 1 a ........................... 104

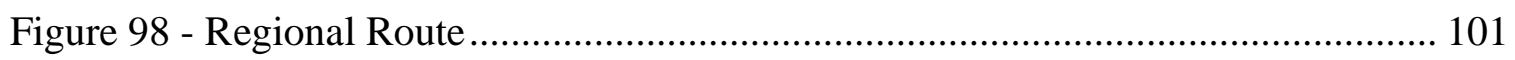

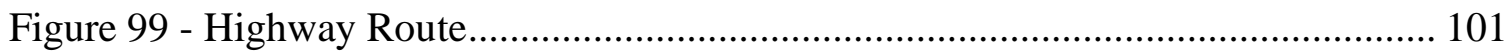

Figure 100 - Port: Local Route ................................................................................ 101

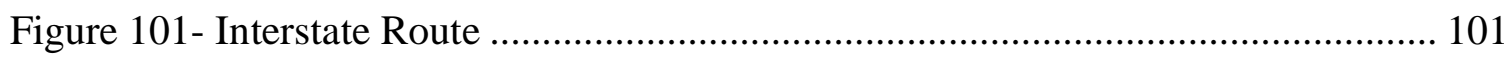

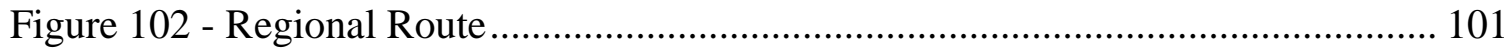

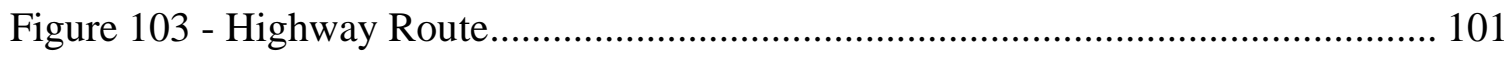

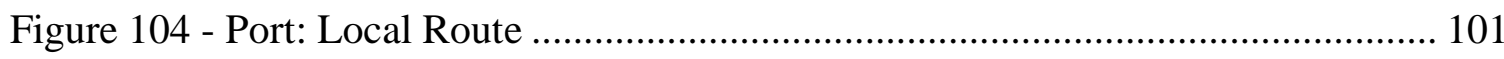

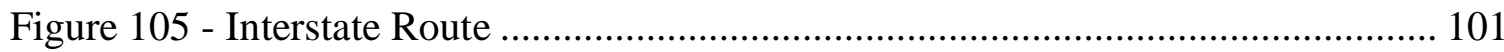

Figure 106- Combined plot of Vehicle-1 speed density method - $1 \mathrm{~b}$............................ 107

Figure 107- Enlarged combined plot of Vehicle-1 speed density method - 1 b ............. 107

Figure 108 - Training performance of Vehicle-1 data .................................................. 108

Figure 109 - Regional Route ..................................................................................... 101

Figure 110 - Highway Route...................................................................................... 101

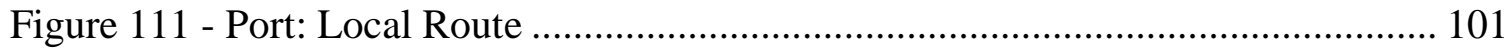

Figure 112 - Interstate Route ……………………………......................................... 101

Figure 113 - Regional Route .................................................................................. 101

Figure 114 - Highway Route...................................................................................... 101

Figure 115 - Port: Local Route .................................................................................. 101

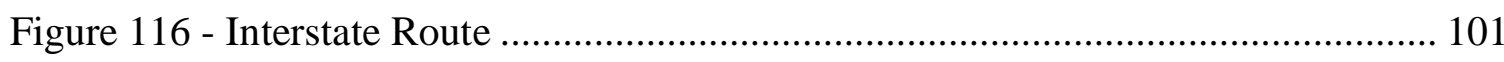

Figure 117 - Regional Route of Vehicle-1 ANN method ............................................ 111

Figure 118 - Highway Route of Vehicle-1 ANN method................................................. 111

Figure 119 - Port: local Route of Vehicle-1 ANN method ............................................ 112

Figure 120 - Interstate Route of Vehicle-1 ANN method............................................... 112

Figure 121 - Regional Route of Vehicle-1 all methods ................................................... 113

Figure 122 - Highway Route plot of Vehicle-1 all methods.......................................... 113 


\section{List of Tables}

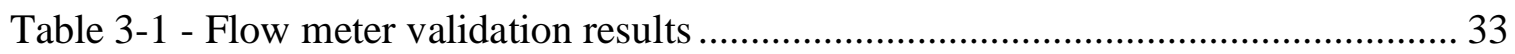

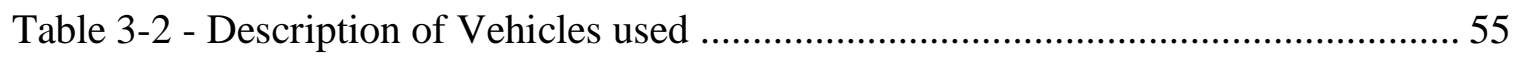

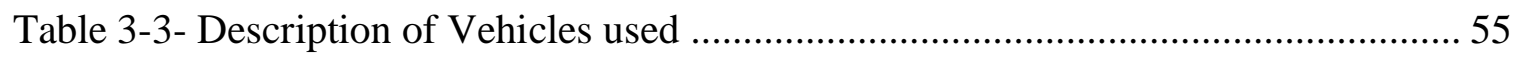

Table 3-4 - Information on application of validation methodologies ............................... 60

Table 4-1 - Training performance of Vehicle-3 data ………………………………...... 71

Table 4-2 - Results of Vehicle-1 speed density method - 1 a .......................................... 83

Table 4-3 - Results of Vehicle-1 speed density method - 1 b........................................ 83

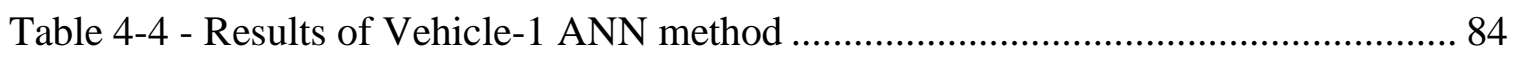

Table 4-5 - Results of Vehicle-2 speed density method - 1 a .......................................... 84

Table 4-6 - Results of Vehicle-2 speed density method - 1 b......................................... 85

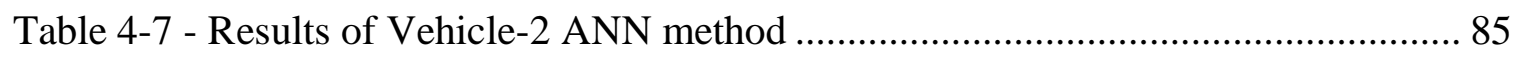

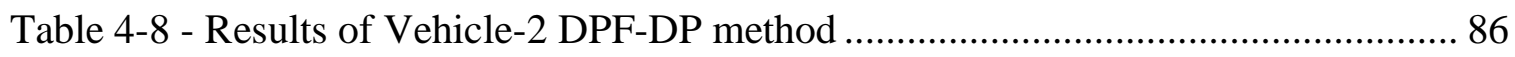

Table 4-9 - Results of Vehicle-3 speed density method - 1 a .......................................... 86

Table 4-10 - Results of Vehicle-3 speed density method - 1 b....................................... 87

Table 4-11 - Results of Vehicle-3 ANN method ............................................................. 87

Table 4-12 - Results of Vehicle-3 DPF-DP method …………………………………..... 87

Table 4-13 - Results of Vehicle-4 speed density method - 1 a .......................................... 88

Table 4-14 - Results of Vehicle-4 speed density method - 1 b........................................ 89

Table 4-15 - Results of Vehicle-4 ANN method .............................................................. 89

Table 7-1 - Training performance of Vehicle-1 data ..................................................... 108 


\title{
Nomenclature
}

\author{
OBD - On-Board Diagnostics \\ EGR - Exhaust Gas Recirculation \\ CVS - Constant Volume Sampler
}

EPA - Environmental protection Agency

BMD - Bag Mini Diluter

PID - Parameter ID

ECU - Engine Control Unit

DPF - Diesel Particulate Filter

DP - Differential Pressure

LFE - Laminar Flow Element

SCFM - Standard Cubic Feet per Minute

CFM- Cubic Feet per Minute

CFR - Code of Federal Regulations

ANN - Artificial Neural Network

Q-Q - Quartile-Quartile

MAP - Manifold Absolute Pressure 
PEMS - Portable Emissions Measurement system

UEGO-O2 - Universal Exhaust Gas Oxygen - Diatomic Oxygen Sensor 


\section{Introduction}

Vehicular pollution has become a global problem (Bai, Wang and Ma 2018). With an increase in the number of automobiles used for both for personal and commercial purposes, the vehicle population has been amplified dramatically over the past decade (Gordon 2009). As each vehicle tends to release a certain amount of pollutant into the atmosphere, it is raising a globalscale concern as billions of automobiles are now being operated, resulting in release of huge amounts of pollutants which require some stabilization time and reactant atmosphere for them to be transformed into harmless gases. However, the continuous operation of automobiles is making the natural procedure of conversion of these pollutants difficult. Hence, the automobile industry is trying to minimize the release of these pollutants, and taking deliberate measures to improve on and harness the customers' requirements on one end and implement stringent environmental protection policies on the other (Yamazaki, et al. 2003).

Engine manufacturers started incorporating the OBD (On Board Diagnostics) tool to keep emissions under compliance and so far, have succeeded in meeting the requirements. The sole purpose of OBD II is emission compliance and it has evolved over the years and has now become a comprehensive system which monitors entire vehicle operations and all the vehicles manufactured after 1996 are OBD II equipped (California Air Resources Board n.d.). In simple words in OBD equipped vehicles the onboard computer monitors the performance of each and every component related to emissions compliance, it ensures that the emission control component is working and vehicle maintains low emissions while in-use; may it be an engine misfire causing more hydro-carbon emissions or if there is any fault in the exhaust gas recirculation (EGR) system resulting in increased NOx emissions, etc. If any of the emission control devices fail or any key 
sensors fail, then the engine malfunction light turns on, indicating the user to get the vehicle inspected by a professional (Baltusis 2004).

The measuring instruments measure the volume concentration of pollutants of a particular gas in a given sample of exhaust gas, and these concentration values can be used in relation with exhaust flow rate to get the actual mass rates of pollutants flowing out of the engine. In order to answer the issue of pollution, we need to start with accurate measurement of the most significant thing, which is the exhaust flow rate (Czerwinski, Zimmerli and Butler 2016). Precisely measured exhaust flow plays a key role in accurately quantifying levels of Nitrogen oxides (NOx), hydrocarbons $(\mathrm{HC})$, carbon monoxide $(\mathrm{CO})$, carbon dioxide $\left(\mathrm{CO}_{2}\right)$ and other exhaust pollutants.

A vehicles tailpipe exhaust flow is a highly unsteady flow, which can be characterized by high pulsations, high moisture content and extremely high temperatures. Accurate prediction of the exhaust gas flow rate has always been of major importance to measure the gaseous emissions as well as particulate matter emission, as a small change in the exhaust flow calculated over a specific time interval can bring large changes in the calculated emission values of various gases and particulates.

The CVS (Constant Volume Sampler) system, helped to appropriately address the difficulties that existed during exhaust flow measurement, the CVS measurement approach involved proportional sampling of the exhaust gas at a constant flow rate with variable dilution technique (Caretto 1998). The CVS system resolved all the problems associated with measurement of exhaust flow, because of this it was considered as the standard testing procedure and has been approved by EPA (Environmental Protection Agency) for the vehicular certification process (Chase 1999). On the other hand, during warm operation conditions of the ultra-low emission vehicles and near-zero emission vehicles, the produced emission concentrations are less than those 
of dilution air background levels and in such a situation usage of typical full-flow CVS dilution tunnel where varying dilution ratios are used, is likely to account for more errors in the measured concentrations (Guenther, Henney, et al. 2000).

With the development of super ultra-low emission vehicles which meet more stringent emission regulations, the partial flow system is no longer the effective way to accurately measure the super ultra-low pollutant concentrations (Hornreich and Seifert 2003). The BMD (Bag MiniDilution) system has become the new trend in the automotive industry which aids in the precise measurement of low emission levels and accounted for lesser standard deviation in the measured values when compared to those measured by CVS system (Ohtsuki, Inoue and Namiyama 2002). The BMD system relies on measured exhaust flow rate values to calculate integrated emission masses over each phase of the emission test cycle, and this system requires precise measurement of exhaust flow, as with a BMD system, a direct correlation exists between exhaust flow measurement accuracy and fuel economy/emission accuracy (Mark Guenther 2000). However, this method is also limited to laboratory testing.

For the development of engine strategies which aid in reducing engine-out emissions and for designing engines which offer high efficiency and improved fuel economy, it was extremely imperative for the automobile and engine manufacturers to develop new methods that can give out the correct and exact pollutant concentrations flowing out from the vehicle tailpipe, and if possible allow capturing of even minor changes in amounts of exhaust pollutants concentrations, which can be achieved with a high level of accuracy by measuring raw exhaust flow, and using it to calculate pollutant concentration in the exhaust. Also, measuring and using raw exhaust flow to find emission fractions helps to overcome minor variations in measured pollutant concentrations, which are likely to incur if the dilution-measurement method was adopted. 


\subsection{Objective:}

- The measurement of raw exhaust flow rates without influencing the normal engine operating conditions, without using additional equipment and accounting for lesser errors while being used for on-road (or) real-world testing of vehicles has always been a difficult task. So, the invention of a measuring methodologies which can efficiently estimate exhaust flow were needed.

- $\quad$ The objective of this study was to develop new methodologies which can accurately estimate exhaust flow values without need of any additional instrumentation, by making use of information available from OBD of the vehicles, and which can be implemented on all heavy-duty vehicles equipped with an ECU. 


\section{Background}

\subsection{Exhaust flow measurement methodologies:}

To identify the methods which offer optimum capability in achieving closer predictions of the exhaust gas flow rate values by overcoming the problems arising, like the reverse flow phenomena during low speed engine operation, excess moisture contents and particle contents, continuously fluctuating flow with rapid chemical changes alongside offering minimal error in the calculated value, various existing methodologies used for exhaust flow rate prediction were reviewed. The outcome of it, was to come up with a method which reduces the complexity in measurement procedure, and which can aid in further increasing the prediction efficiency.

Over the recent years large number of flow meters are devised to measure raw exhaust gas flow rate, such as ultrasonic flow meter, flow measuring devices like the vortex and turbine type, differential pressure flowmeter, pitot tube type flowmeter, (Akita and Nevius 2011) (Laurantzon 2010) (Hebrard and Strzelecki 1992) (Stoltenkamp 2007). Annubar Flow meter, Hot wire anemometer flow meter and head-type flowmeter Apart from these, some methodologies were also developed for flow measurement, such as mapping method, pressure wave analysis method, UEGO-O2 (Universal Exhaust Gas Oxygen - Diatomic Oxygen Sensor) sensor-based analysis method (Gonzalez, Kindelan and Martinez n.d.) (Sato, et al. 2007) (Silvis, et al. 2007). Overall, each of the above-mentioned instruments or methodologies are equally accurate and have their own advantages and associated disadvantages as discussed below. 


\subsubsection{Ultrasonic flow meter:}

Ultrasonic meters are the best-known flow meters in industry to accurately measure realtime undiluted exhaust gas flow. They operate by measuring the sound propagation in a flowing fluid, as the fluid flow causes 'entrainment and braking effects' of ultrasonic pulses which cause shortening or lengthening in run-time of the sound pulses at the receiver modules. The piezo electric transducer generates high magnitude sound pulse which are of the order of tens of megahertz. The travel time of ultrasonic pulses from transmitter to the receptor is shorted along the gas flow direction as it overlaps with the ultrasonic pulse, it becomes longer if the flow is in the opposite direction to the generated sound pulses (Akita and Nevius 2011).

The run-time difference is then analyzed, and the gas speed is determined using intelligent signal algorithm. The measurements are simultaneously made at four location which further improves the measurement ability and lessens susceptibility of flow meters to fluctuations, facilitating it to measure highly dynamic flows with high measurement ability (Schroder, et al. 2006). Ultrasonic flowmeters are known to work effectively under pulsating conditions at low loads and can handle measurement during backflow conditions. (Hakansson and Delsing 1994) (J.E.Heritage 1989) (Nevius, et al. 2017)

Akita and Nevius developed a new high temperature resistant ceramic ultrasonic transducer which can be adapted for exhaust flow measurement in heavy duty vehicles and is also designed to handle temperatures during regeneration event. The newly developed flow meter was tested with a 3.8L V6 gasoline engine, where the accuracy specifications of $<1 \%$ for flow rates greater than 15 scfm, and an accuracy of less than $2 \%$ for flow rate of 5-15 scfm and less than $5 \%$ for lower flow rate 
range of $5 \mathrm{scfm}$ and lower, with an average flow error of around $0.2 \%$ were observed (Akita and Nevius 2011).

\subsubsection{Differential pressure flow meter:}

These are the most commonly employed meters in industry to measure flow rates, as they account for less restriction in the flowing duct. They have a limited operation range because of the limited maximum pressure ratio across the cross section of the device. These devices can be used for either point measurement or averaged velocity measurement and provides good estimate of the bulk flow rates (Laurantzon 2010). In its simplest form, the operation of these instruments dependent on measurement of pressure drop across the device due to flow area restriction, alongside using Bernoulli's theory and diameter of pipe to estimate the velocity of the fluid from the measured Differential and stagnation pressures (Santhosh K V 2012) (Laurantzon 2010).

With recent technological advancements came the Averaging Pitot tube differential pressure flow meters, which can be used to obtain average velocity of flow over the entire cross section of the device instead of a point measurement. It employs a measuring tube with holes distributed over the entire length which facilitate to take multiple samples across pipe section and to obtain averaged differential pressure encountered allowing them to consider, the pressure variation across entire length of the pipe section. The instantaneous pressure difference can also be obtained by employing separate absolute pressure transducers along with a static pressure sensor, which further helps to determine density, if a measured temperature reading is available (Lee and Hoon 2011). Choong Hoon Lee, conducted research on averaging Pitot tube differential flow meters to identify the changes in the differential pressure signal and the change in estimated flow rate with changes in cross section of the inner shape of the averaging Pitot tube and discovered that it's important to choose the shape of flowmeter depending on the conditions that pertain during the study (Hoon and Lee 2017). 
In a study conducted by Natalia fonesca, Gonzalez etc. al, they came up with a MIVECO averaging differential Pitot tube flow meter technology combined with an off-line theoretical approach, which classifies the pressure waves generated during pulsation into two types. One is an oscillating higher frequency wave, caused by the sudden opening of the exhaust valve and other is a normal flow wave, which develops as the exhaust flows out of the engine (Gonzalez, Kindelan and Martinez n.d.).

The theoretical approach employed here is used for developing equations for pressure and velocity as a function of engine speed and number of cylinders, additionally considering the averaged amplitude of pressure waves and their speeds. The main assumption was the pressure waves can be modeled using continuity equation, momentum equation and the derived flow equation resembles a one-dimensional wave equation for a fluid whose motion is inviscid compressible flow condition. The paper improves one's understanding about the relationship between pressure waves generated in exhaust manifold during various engine operating conditions and the rate at which the exhaust flow changes in relation to the changing pressure conditions (Gonzalez, Kindelan and Martinez n.d.).

From the results, it was evident that the developed methodology was able to predict exhaust flow rates accurately. For a diesel car operated over the New European Driving Cycle, the observed instantaneous average error value was $-1.12 \%$ and the standard deviation was $1.53 \%$. Whereas for a gasoline vehicle the averaged instantaneous error and standard deviation were $-0.32 \%$ and $2.2 \%$. Furthermore, understandings from the paper include, usage of correction factors and the procedures that need to be adopted while dealing with the response frequency of data collection, which helps in obtaining the average values of various parameters (Gonzalez, Kindelan and Martinez n.d.). 


\subsubsection{Vortex flow meter:}

Vortex flow meter working principle is based on the measurement of frequency of pressure fluctuations or impact stresses created by flow separation which cause development of vonKarman vortex stress, the periodic separation of flow happens when the fluid in motion comes across obstructions like sharp edges (bluff body). In case of uniform flow conditions, the shedding frequency of separated flow is proportional to flow velocity. The frequency is a function of pressure, temperature and density of fluid flowing. These meters cannot be used for exhaust flow measurement, where fluid is subjected to high pressure and density variations occurring during pulsations (Laurantzon 2010) (Hebrard and Strzelecki 1992).

Gandhi, Singh etc. al (Gandhi, et al. 2004), investigated to find out the influence of bluff body shape on the coefficient of drag and permanent pressure loss which can be related to the shedding frequency and came up with the concluding results that, for better prediction of flow rate a vortex flowmeter requires stable vortex shedding frequency which can be achieved by sharp edged bluff bodies and the accuracy of Vortex Shedding flow meter can be improved by choosing the right bluff body shape based on particular operation range of the test. For Further elaboration on analyzing the flow rate from the shedding frequency signal, the reader is encouraged to go through (Hu, Miau and Chen 2006). 


\subsubsection{Turbine flow meter:}

Turbine flow meters use electromagnetic sensor to record the rotating frequency of the rotor. A linear representation between recorded rotor frequency values and flow rate values exists when these meters are used for flow measurement of incompressible fluids with steady state flowing conditions. When they are used for exhaust flow measurement with highly pulsation flow condition, the occurrence of continuous pressure variations in flow results in slower mass flow variations which leads to overestimation of flow rate, and the magnitude of error induced depends on pulsation frequency and amplitude, physical design of turbine meter, flow properties like density and flow rate (Laurantzon 2010) (Stoltenkamp 2007).

\subsubsection{Hot wire anemometer:}

Hot Wire anemometers are electrically heated wires, which are placed in the flow of stream. As, the gas flows over the hot surface of wire, the heat gets transferred from wire to gas and the temperature of the wire starts to reduce, which eventually causes the resistance of wire to. The resistance of the wire is dependent on the rate of gas flow and changes with changing gas flow rates. In the hot wire anemometers, the recorded flow value is a local representative of flow speed and the recorded value belong to and is valid within a small region around the anemometer probe (Laurantzon 2010). Fluctuations in flow velocities that occur in the wake of the pipe cross-section absorbed away from the location of hot wire probe may not be considered during flow calculation, which may lead to huge measurements errors in flow rate values. Also, the hot wire anemometers are not suitable for diesel engine equipped vehicles because of particulate matter getting deposited on the hot wire, which affects its operation causing a drift in the measured values (Comte-Bellot 2007). 


\subsection{Other Methodologies:}

\subsubsection{Mapping Method:}

Sato, Yamamoto etc. al (Sato, et al. 2007), Investigated on the exhaust flow rate measurement from a three-way catalyst built-in gasoline passenger vehicle by employing the MAP Method. The main principle adopted in his study is based on the concept of establishing correction coefficient determined during Map method which can be used in relation with other measured parameters to give out the Exhaust flow rate values.

Exhaust gas flowing out of an engine can be better estimated, if direct measurement method is employed, direct measurement requires expensive equipment and also lacks in its measurement ability when used for higher flow rates of exhaust mass flow. Other method for estimating exhaust gas flow, is the one in which estimation is based on incoming "Air and Fuel Flow", it is widely used for heavy duty engines equipped with turbochargers and EGR recirculation loops. During dynamic operation of engines, a correlation can be used to simplify the relation between intakes and exhaust flow.

In the research conducted, a Laminar flow meter which gives the actual intake air flow rate was connected to the gasoline vehicle, and it is used to established a correction correlation which is multiplied with the estimated flow rate value, measured using parameters like the intake air pressure (boost pressure), engine speed, atmospheric pressure, intake air temperature, engine displacement volume and by usage of Air-Fuel ratio value obtained from the engine ECU directly, which was calculated by the Lambda sensor. Additionally, variable venturi flow meter was employed to measure the actual exhaust flow rate, whose values in turn are used for comparison with the predicted exhaust flow values. The vehicle was tested on a 4WD chassis dynamometer 
and the intake and exhaust flow rates were measured during wide range of engine operation conditions.

The test was conducted in a way to obtain the wide range of engine operating conditions, to achieve this the tests were conducted by operating the vehicle under Overdrive on and off conditions and third condition using two speeds. As, the correction coefficient differs even when the operating conditions of engine speed and intake boost pressure remain the same, using a single correction factor for entire range doesn't account for any improvement in accuracy for the predicted measurements. So, multiple correction coefficient models were adopted in which correction coefficients were developed for differentiated transient conditions, in correspondence to the rate of change of engine speed.

The multiple correction coefficients model helps to attain more accurate prediction, as the correction coefficients are not averaged over the entire range of operation, it results in offset value of error to reduce. As the correction coefficients differ based on speed range, the usage of these coefficients will also help in the attainment of closer values. For a three-way catalyst equipped sparkignited vehicles the air to fuel ratio of gasoline engine remains close to stoichiometric ratio the $\mathrm{O} 2$ sensor signal data can be used directly. Diesel engines are typically lean burn engines the air to fuel ratio can vary from 12:1 to 70:1, hence certain modifications to this model are needed to successfully implement it for the case of Diesel engines. 


\subsubsection{Filling and Emptying of Manifolds:}

In the model developed by William Silvis, Steigerwald etc. al (Silvis, et al. 2007), they took into consideration the influence of filling and emptying of the manifold phenomenon while measuring exhaust flow, based on intake air and fuel flows. As the gas flows through the exhaust manifolds there are chances that the gas pressure inside manifold increases, the volume of a manifold is a constant parameter so the increase in pressure may be associated because of more exhaust gas being accumulated in the manifolds. This leads us to the phenomenon of filling and emptying of engine manifolds, which is going to create a delay and should be considered for precise flow measurement.

The Procedure employed by (Silvis, et al. 2007) involves dividing the sections of the intake and exhaust circuits into volume regions I.e. volume on the intake side, volume between External HWA and compressor is considered as V1, volumes before and after intercooler V2 \& V2s, on the exhaust side $\mathrm{v} 3$ represent volume of exhaust manifold and V4 accounts for part of exhaust piping after turbine. The final exhaust flow calculation is based on the amount of airflow, fuel flow and the accumulated gas quantities within different manifolds.

Based on the study conducted, it has been determined that the percentage error in emissions doesn't deviate much by using air and fuel flow, instead of modeled Exhaust flow. From this study, it is evident that there is no significant difference in the value of exhaust flow measured using exhaust flow meter and the value calculated based on intake Air and fuel rate, except that the measured flow is time aligned with the one obtained from Standard measurement method. By adopting the method of exhaust flow prediction which makes use of intake pressure, intake temperature and Fuel flow data logged by ECU, better prediction accuracies can be achieved. 


\subsubsection{Polytropic Process Method:}

(Shin n.d.), In their study developed a model to predicted instantaneous exhaust flow rates by assuming the exhaust process as a polytropic process, where the polytropic index was obtained making of the measured in-cylinder pressure. In the case of reciprocating engines, the behavior of unburnt mixture and burnt gases is known to be isentropic, and also the compression and expansion process were well defined by the polytropic relation $\mathrm{P} . \mathrm{V}_{\mathrm{n}}=\mathrm{C}$. The only difference here is, the polytropic exponent ' $\mathrm{n}$ ' is affected by heat loss and the residual gas fractions within the cylinder. So, the polytropic index was predicted using the logarithmic-scale plot of in-cylinder pressure. In this research the mass flowrate following the blow-down phase of piston was used to predict the exhaust flow rate values. During the blow-down phase the mass flow rates is at maximum state which appears near 150 crank angle after top dead center, from there it starts reducing till the pressure drop reaches the atmospheric pressure. Once the flow starts to kick in, the pressure curve pattern becomes a replica of the pressure wave pattern in the exhaust system, the blow-down

process and the displacement flow are known to characterize the exhaust flow rate. The instantaneous flow rate values calculated from the compressible blow-down process were within a limit of \pm 5 percent.

\subsection{Intake Flow Measurement using Intake Speed-Density Method:}

As, all the engines are tightly packed with various components leaving no space for installation of external flow meters or sensors. (Vojtisek and Kotek 2014), developed a method to estimate intake air flow from the available ECU broadcasted engine out parameters like engine 
speed, intake boost pressure and temperature, engine displacement, volumetric efficiency and air composition, which has been classified as speed-density method.

The test data was collected from both naturally aspirated and turbocharged diesel and gasoline engines. The mass flow was estimated using the speed-density equation as mentioned in (Vojtisek and Kotek 2014). From the study, it was evident that the recirculation of EGR accounted for considerable differences in estimated measurements made, by up to a factor of 2 when EGR was operational. During EGR non-operating condition, the results were either underestimated or overestimated in correspondence to the engine operation state. Overall, the difference between estimated and actual measured values of Intake mass flow accounted for not more than $10 \%$ error for engines which had no higher EGR rates.

Hussain, Palaniradja etc. al (J, et al. 2012), conducted a study to evaluate the effects of exhaust gas recirculation on the performance of compression ignition engines. In this study the change of exhaust temperature at the inlet to the intake manifold in relation to the changing EGR rates was evaluated, it was observed that the temperatures of exhaust gas at the inlet to the intake manifold under no-load condition with 0\% EGR and 25\% EGR rates differed by more than 40 $(0 \mathrm{C})$. Whereas, at full load, the difference was around $60(0 \mathrm{C})$.

In the speed-density method (Vojtisek and Kotek 2014), no provisions were made to account for this higher temperature at the entrance to Intake Manifold, which might be one of the reasons for deviation of estimated values from those of measured for the two engines equipped with turbochargers. In this current study, all the possible parameters which have an influence on exhaust flow rate were taken into considerations to attain accurate prediction, and to eliminate any discrepancies that may occur as discussed in above paragraphs. 


\subsection{Fuel Flow \& Air-Fuel Ratio Measurement Methods:}

Emissions from vehicles are the main sources of atmospheric pollution. The greenhouse gases like carbon monoxide, nitrogen oxides, and other harmful gases have a direct effect on human beings and other living organisms. The emission flow rates of these pollutants are dependent on the amount of fuel being burnt, reduction of these pollutants is possible by monitoring and delivering the right amount of fuel which can possibly be achieved using advanced engine strategies and by using feedback system with high response frequency (Battermanb 2013).

Fuel flow measurement can be done by volumetric measurement method, gravimetric flow measurement method, and carbon balance method. For volumetric flow measurements, a wide variety of flow devices are available (i.e. like the AVL KMA flow meter, Coriolis flow meter). For volumetric flow rate measurement, the engines are fed fuel from the fuel metering unit, which gives the volume of fuel flowing into the engine instantaneously. Gravimetric method of fuel flow measurement involves mounting the fuel tank on a weighing scale and is mainly used in laboratory testing. Whereas, the volumetric flow rate method can be used during on-road testing. In the end, for the validation of any developed method for fuel flow measurement, it is necessary to use a validated and established method which is the carbon balance method. Carbon balance method uses the amount of carbon flowing out of the engine, where fuel consumption is back-calculated using the pollutant emissions date i.e. hydrocarbons (HC), carbon monoxide (co) and carbon dioxide (co2), which are dependent on the amount of fuel burnt in the engine. To employ carbon balance method a good exhaust gas analyzer is required to measure accurate concentrations of exhaust gases (Taubert and Majerczyk 2013).

Fuel flow rate, on the other hand, can be controlled by accurately monitoring the air-fuel ratio, as the air-fuel ratio influences the amount of fuel being used in relation to the air and has a 
great impact on the effective reduction of emissions. Air and fuel need to be at the desired proportion to completely burn the fuel, it there is an exactly correct amount of air present to completely burn all the air then it is referred to as stoichiometric mixture. If there is less air the mixture is considered "rich". Rich mixtures are associated with the production of higher power but are less efficient. In contrary, if the stoichiometric ratio is higher it is considered a lean mixture, lean mixtures account for higher temperatures, higher levels of Nitrogen oxide pollutants, but offer higher efficiencies. So, air-fuel ratio plays a key role in determining the performance efficiency of an engine and helps in controlling the pollutant formation and needs to be predicted or estimated correctly (Hillier and Pittuck 1966).

A bulk of research work has been conducted on this subject, different approaches based on both classical and modern methods were developed over the years. A study was conducted to review different processes of fuel flow measurements, and to evaluate the process which is economical and involves less instrumentation, alongside accounting for less error percentage.

Alex Pink, Adam Ragatz etc. al (Pink, et al. 2017), in their study assessed the accuracy of fuel flow rate data broadcasted by the vehicle ECU, by comparing the obtained values against those measured by precise and standard instruments. To determine the extent to which one can rely on the CAN-broadcasted data, a different analysis was conducted.

Firstly, a quantitative total fuel consumption analysis comparing the overall percentage differences between CAN measured and precisely measured fuel flow rate. Secondly, qualitative real-time analysis to identify the operating conditions under which the discrepancies arise. Finally, an analysis which relatively compares the fuel consumption of vehicle reported fueling and laboratory measurement over the entire length of the drive cycle was conducted. Simultaneously, measurements were recorded using instruments, data logger recorded standard CAN signals and 
for on-road tests, measurements were made by a fuel scale installed on vehicles. For, every test data recorded included, integration of fuel estimates data and second-by-second data estimate.

The percentage difference obtained during quantitative total fuel consumption analysis vary from $-6.81 \%$ to $16.91 \%$, with corresponding standard deviations ranging from $0.20 \%$ to $2.62 \%$ and indicates that some CAN fueling rates are accurate compared to others and proves that there is no fixed trend across various datasets. Similarly, the quantitative real-time analysis also says that fuel rates are under-reported in few cases and over reported for the other. It requires a compensation algorithm which can eliminate these discrepancies by compensating CAN fuel estimates based on the operating condition of that particular vehicle or engine. But it seems to universally adopt this as the compensation algorithm needs to be developed separately for each vehicle or engine model. Drive cycle analysis indicates that the averaged fuel estimates share relatively similar trend with the gravimetric fuel measurements. A highest relative difference of $3.95 \%$ was observed between gravimetric measurements and CAN estimate. However, CAN fuel estimates obtained from the vehicles seems to provide fuel consumption rates with a difference of $\pm 4 \%$ for some vehicle classes and even as low as $\pm 2 \%$ for the most vehicle, from which it can be determined that we can rely on Vehicle-broadcasted Fuel consumption rates to some extent.

Timothy etc. al (DeFries, et al. 2014), worked on light duty gasoline engine vehicles (portfuel \& direct injection), equipped with On-board diagnostic systems (OBD 11 systems) and manufacturers specific PIDs (enhanced PIDs) in an effort to obtain the fuel economy data and developed two methods. One is based on the information obtained from the $\mathrm{O} 2$ sensor and mass airflow sensor data, which are then used to calculate Fuel consumption by employing the basic combustion balance equation. The other method is used in the absence of $\mathrm{O} 2$ sensor, in place of 
O2 sensor data, the information from enhanced PIDs is used, which involves using injector fuel rate or injection pulse width along with the MAP data obtained by the speed-density method.

Test data was obtained from two different vehicles (Vehicle_1: Camry, Vehicle_2: Prius) equipped with OBD and those that contained the enhanced PID data, then comparisons were made between injector calculated instantaneous values (Enhanced PID) and standard PIDs. The average difference in percentage was $151 \%$ for vehicle- 1 and it was $22 \%$ for vehicle-2. The coefficient of determination values for the two comparisons was around 0.81 and 0.98 . The reasons for vehicle_1 lesser coefficient of determination value was the slow response of fuel injector signal, the injection fuel rate value remaining at higher rates even when the vehicle is coasting down or slowing accounted for higher percentage errors. This was not observed in the case of Vehicle_2, which resulted in a higher agreement between the enhanced PID and standard PID which imply that a system with good data acquisition is needed to get accurate estimates of the flow values.

On the other hand, the volumetric fuel flow rate calculated from standard PIDs obtained from a single vehicle were compared with the carbon balance measurements of volumetric fuel flow rate obtained from dynamometer chassis testing. A set of modifications and alignments were made to smoothen the OBD data which needs to match with the delayed carbon balance estimated values. Before, processing the data there existed a discrepancy between the two fuel rates which was assumed to occur because of fuel cut off events. Employing OBD MAF correction algorithm to compensate for fuel cut off events and non-stoichiometric operation conditions, helped to correct the standard PIDs values and attain an improved accuracy of about $3 \%$, and with a coefficient of determination of 0.993 against the dynamometer measured fuel flow rate values.

Robert Howlett, Simon Walters etc. al (Robert.J.Howlett, et al. n.d.), Came up with an innovative methodology for air-fuel ratio measurement, which uses the combination of time- 
varying waveforms generated at spark plug in combination with a neural network methodology to measure air-fuel ratio. The approach is to record the spark plug voltage waveform, whose characteristic shape is of predictable form, and use it in combination with a pattern-recognition method which can trim out the uncertainties and noise to maintain consistency in measured waveform and then train the neural network by correlating the spark plug voltage waveforms with the Air-fuel ratio.

Before the occurrence of spark inside the combustion chamber, a spark pulse is generated by the ignition system, suddenly huge potential difference occurs raising the coil voltage from 6 volts to 22,000 volts across the electrodes, and then it is accompanied by a sudden breakdown of voltage. This voltage waveform signal is used in conjunction with the neural network pattern recognition model to predict the lambda value as this waveform has a number of predictable phases. The voltage waveform is influenced by the engine speed, engine load, and engine operating conditions. So, it is necessary that the data recorded be tailored to remove any discrepancies which are achieved by a pattern recognition neural network model.

In case of compression ignition engines, we don't have an ignition coil. In that case, the voltage signal sent to solenoid activation valve in injector can be used in place of a voltage waveform of the spark pulse. Some manufacturers publish this data and in case of other engines, this data can be obtained by using enhanced PID's and can be used along with a neural network method. Some engine manufacturers have designed things in a way that ECU receives information from all these parameters and it publishes a single output, which is the mass flow rate of fuel flowing into the engine. However, there will be a considerable difference between actual fuel flowing in and the one commanded by the ECU. 


\subsection{Volumetric Efficiency:}

Volumetric efficiency can be defined as the breathing ability of the engine. It is the ratio between the volumes of air (or) air-fuel mixture that has been drawn into the cylinder to the volumetric displacement of the cylinder itself. For modern engines with increasing regulations for emissions and fuel consumption, the control of fuel is highly important and to achieve it all parameters should be taken into consideration and volumetric efficiency value which has a greater influence should be definitely made part of it.

The efficiency of the engine to move air and fuel into and out is directly dependent on the intake pressure and temperature condition. If we want to control engine-out emissions, we need to burn a sufficient amount of fuel only, which is dependent on the amount of air flowing into the cylinder. Intake air flow can be calculated using mass flow sensors, but they need volumetric efficiency for accurate estimation of intake flow. Prediction of correct breathing efficiency of the engine helps to calculate intake and exhaust flow rates precisely.

Due to the developments in emission control strategies like recirculating the exhaust flow or increasing the intake boot pressure using a turbocharger, which have an influence on the properties of intake air flowing into engine cylinder, their effects on engine operation conditions need to be considered, if it was a naturally aspirated engine the volumetric efficiency value could have been neglected as it doesn't account for huge errors in calculated values. But with modern engines, it's not the case and needs some attention. One of the key parameters, which can bring considerable changes in the predicted intake flow rate is the volumetric efficiency of the engine. By employing accurate volumetric ratios in calculations, air-fuel ratio and eventually torque of the engine can be effectively controlled leading to supply of a right amount of fuel, eventually reducing the exhaust gas pollutant emissions. 
Jamil, Guillaume Colin etc. al (Hadef, et al. 2013), employed a multilayer perceptron and radial basis function neural network model for predicting volumetric efficiency, by considering all the parameters that are believed to have an influence on the volumetric efficiency value. (I.e. burnt gases flowing into the engine, scavenging ability, intake and exhaust temperature \& pressure conditions). Using a physical-model requires usage of parameters which are prohibitive by some manufacturers and require arduous test bench experiments, whereas in the study by using neural network models and by using data obtained from a set of steady state tests the prediction difficulty of volumetric efficiency was resolved, overcoming the time-consuming difficulties which exist with usage of lookup table method.

In the study, a Single neuron perceptron model with sigmoidal function in the hidden layer, and linear function at the outlet was employed and the number of neurons were varied depending on the output accuracy and error attained. Based on the findings from the report, input temperature values have much less influence on the predicted values and also less amount of training data is needed for obtaining volumetric efficiency values with minimal error.

Zackery Layhew (Layhew 2017) worked with Neural Networks to predict NOx values. In his study for prediction of transient data, he implemented a time series network, with the Nonlinear Input-Output Neural network model. In order to increase the prediction efficiency of the neural network addition parameters which are derivatives of actual engine parameters were considered. The training dataset was obtained during in-use vehicle operation and was created by combining data sections from various tests to cover all the operating conditions and to improve the training ability by covering as much operation conditions as possible. This study indicates the various considerations that need to be adopted to improve the efficiency of a neural network for prediction of transient data. 
Additionally, the simplicity of the neural network model used and the accuracy of them in prediction gives the incentive to readily adopt the neural networks model for prediction of Volumetric Efficiency instead of look-up table method or any other physical-model. The model's accuracy can be further improved by increasing the training data (i.e. using data obtained during transient operation) and by taking into consideration, the time response frequency of various sensors used to collect input data values, the only trade-off here is it requires higher training \& processing time.

\subsection{Diesel Particulate Filters:}

Diesel engine vehicles account for the highest portion in the heavy-duty transportation field, as large number of vehicles are used for transporting goods across the country and were needed to be cleaner during their operation. Deliberate procedures were being adopted by environmental protection agencies on one end to come up with stringent environmental protection policies and manufacturers on the other end are trying their best to develop new technologies that meet the new regulations and the customer's requirements at the same time. To either check the compliance of the diesel engines in meeting the emission regulations or for the development of new engine strategies which aid in reducing engine-out and tail pipe out emissions, it was necessary to study a huge fleet of diesel engine equipped vehicles and conduct wide range of testing, most of which needs to be conducted while the vehicle is being operated in the real-world scenario. With the development of super ultra-low emission vehicles which meet more stringent emission regulations, it was extremely imperative to develop new methods that can reduce the exact pollutant concentrations flowing out from the vehicle tailpipe and if possible, allow in capturing of even minor concentrations of pollutants from the exhaust. 
To achieve the filtering of particulates in the diesel engine exhaust manufacturers developed the particulate filter technology. The particulate filters are made up of long porous channels and are available in two variants, flow through type and wall flow type. The wall flow type of particulate filters has higher filtration efficiency and are used extensively in the heavy-duty vehicle Industry. The wall flow filter has a substrate made up of long porous channels that are plugged alternatively, one at each end forming a honeycomb arrangement and resembles a checkerboard pattern. The exhaust gas entering the inlet channel finds its way through the porous substrate into the outlet channel with an open exit end, the particulate matter gets deposited on the porous wall by allowing only the gas to flow into the outlet channel. The accumulated particulate matter over time results in formation of a sooth cake layer that further improves the filtering efficiency of the filter and this along with other operation and design parameters accounts for a considerable pressure drop across the filter. Over the years, a lot of research has been going on to improve the efficiency of this technology and the Diesel particulate filters underwent a lot of changes in the last decade.

(Masoudi 2002), in their study investigated on the parameters that influence the pressure drop and developed a clear understanding on the hydrodynamics of the filter pressure drop. It can be understood from the study that the filter pressure drop depends on the exhaust flow parameters like the temperature of exhaust flow, rate of flow and the rate at which particulates are being emitted and also depend on the filter parameters like permeability, length and diameter of the pores and plug length. Pressure drop starts accounting from the entry of flow to the filter and experiences various changes till the flow exits the channels, the influence on the pressure drop is a result of flow contraction at the entrance and exit, shear losses as the flow forms frictional boundary layers with the walls of the plug, pressure losses due to flow through porous membrane and through the 
sooth cake layer (particulate layer) observed in case of a loaded filter, and the plug exit losses, where the flows emerging out from each cell experience shearing action against each other which results in formation of small scale eddies.

The flow regime across the DPF was classified into four regimes namely Darcy flow (includes flow through porous membrane and particulate layer), wall-friction flow, contraction and expansion regime occurring at entrance and exit to the filter. The type of pressure loss becomes significant based on the state of the filter, whether it is fully loaded or if it is a clean filter or if it is partially loaded, they discovered that motion of flow through porous membrane and through particulate sooth cake layer accounts for a major pressure loss compared to the inlet compression and outlet expansion losses. In the case of a clean or lightly loaded filter, the entrance and exit flow regimes were observed to account for about $1 / 4$ and $1 / 2$ of total pressure drop and in a heavily loaded filter they account for $10 \%$ or less and the remaining pressure loss was observed due to the porous wall and the soot cake layer built up. From this literature it was clear that the exhaust gas flowing through the walls is the most important cause for pressure drop where Darcy's law can be used to determine the pressure drop caused by the flowing gas. The next component that accounts for a significant pressure drop is because of the inertial effect at higher wall-flow velocities.

As the back pressure across the diesel particulate filter reaches a certain predefined value, the vehicle undergoes regeneration event, during which the temperatures of the DPF is increased and reaches around $600-650 \circ \mathrm{C}$. The particulates along with all the ash deposited on the walls of porous filter substrate burn away, making the filter clean again. (Seller 2008) In their report, worked with undamaged and damaged particulate filters and identified that, during regeneration the differential pressure values are at their maximum, as the exhaust flow and exhaust gas temperature starts to increase. As the regeneration reaches the end, the pressure signal drops 
rapidly and immediately after regeneration event the pressure decreases due to high availability of filter space. Also, from the damaged filters tested to check for the drift in the measured differential pressure signal, a thermally damaged filter didn't account for any higher error percentages, whereas a mechanically damaged filter had a deviation in the pressure signal by a max value of 10 mbar over a transient load cycle where the pressure signal was observed to vary non-linearly with the flow rate.

(Changpu Zhao 2017), worked with hexagonal and square celled particulate filters to investigate the influence of cell structure on pressure drop across the filter element. Geometrically viewing, in the case of hexagonal cell DPF, the gas has three pathways to transport gas from inlet to outlet cell, whereas in the squared celled DPF the gas flow can happen in four directions. Hence, compared to square cell structure the hexagonal cell structure results in higher filtration efficiency by faster formation of sooth cake layer and at the higher sooth loading for a given amount of sooth load, the hexagonal filter has higher inlet flow area and lower velocity which results in a lower pressure drop compared to the square cell. For same mass flow rates, the pressure drop is higher for a hexagonal filter. Also, the hexagonal filter has a smaller outlet aperture ratio than that of square celled DPF which results in an serious pressure loss across the hexagonal cell DPF.

Further investigations to identify the ash loading effects on the pressure drop characteristics revealed that the ash deposits mostly accumulate at the channel end plugs, and in case of continuously regenerated filters the channel ash deposits are higher compared to the end-plug deposits, which results in higher pressure loss for a hexagonal cell DPF, as it has smaller outlet aperture compared to that of square cell. (sappok and Wong 2010), worked on the pressure drop considering ash loading effect, indicated that the DPF with ash and soot behaves differently compared to a DPF with no ash and just sooth load. In a filter substrate with no ash, the depth 
filtration and sooth cake filtration can be clearly identified and the slopes of which remain linear with respect to the flow rate. Whereas, in the ash accumulated filter, the ash gets deposited on the pores and acts as a physical barrier restricting the sooth from reaching the filter pores, which yields in non-linear behavior of pressure drop.

This literature review conducted on particulate filters helps to identify the various parameters that have influence on the differential pressure signal, which if needs to be corrected or compensated for while working with the particulate filter differential pressure signal.

\subsection{LFE for EFM calibration:}

In the recent years, several exhaust flow meters were developed which helped to address complexities and offered a promising solution to exhaust flow measurement. These flow meters are subjected to dynamic flow conditions over the period of testing. They need to be periodically tested, to evaluate their performance efficiency, accuracy and drift characteristics and should be calibrated accordingly to eliminate any flow difference which they might have developed over a period of time (TetraTec 2016).

Besides this, the main standard component used for calibrating the exhaust flow device by simultaneously measuring flow should offer a reasonably low-pressure drop, this condition can be achieved by a laminar flow measuring element, which can operate at higher flow speeds accounting for less pressure drop. According to Merriam Industries, LFE can be calibrated to accuracies of $\pm 1 \%$ and have $\pm 0.1 \%$ repeatability. So, the calibration of Exhaust flow meters can be accomplished by using Laminar Flow Elements, a standard flow measurement device which can be operated in the flow ranges that are expected during actual vehicle testing. 
Laminar Flow element is made up of numerous parallel capillary passages, as the LFE is designed to induce a laminar flow condition, its principle of operation involves generation of differential pressure which maintains a nearly linear relationship with the volumetric flow rate. The construction of LFE involves a matrix of individual stainless-steel tubes or windings of stainless-steel foils which are long enough relative to their inside diameter to produce laminar flow conditions. According to Hagen-Poiseuille relationship, which states that the differential pressure measured across inlet and outlet of an element is linearly proportional to the volumetric flow rate if the length of the flow tube is relatively much larger compared to the inside diameter of the tube. LFE is designed perfectly to reduce pressure loss and produce pressure difference which is no greater than 8 " water column, even under maximum flow conditions and the differential pressure across the matrix element responds very quickly with respect to changing flow conditions. For effective measurement of the pressure difference between the inlet and outlet a pressure transducer is used, as well as inlet temperature and pressure conditions need to be obtained which helps to correct the measurements to standard pressure and conditions from that of a specific gas state. Another advantage of LFE is, it is available at for lesser cost than other standard flow devices and is robust in design with no moving parts (Meriam Instruments Inc. n.d.)

Mark Guenther etc. al (Guenther, Polster and Wroza, Exhaust Flow Meter Calibration 2004), worked on creating an automatic calibration system to generate new calibration curves for flow meters, to routinely verify accuracy and access drift characteristics of the exhaust flow meters. Some import consideration that can be observed in this study were, the first consideration was the system was set up in a way to push air through the exhaust meter creating a pressure head similar to that when a meter is used on a vehicle test, instead of pulling air through by applying a vacuum. The second consideration was about the placement if flow standard, whether it needs to be placed 
before or after exhaust flow meter since there exist micro leaks in the flow meter it was decided that flow standard be placed before the flow meter. The third consideration was to keep the flow element clean of dust, small particles, oil, etc. so it is important to filter the flow media before it enters the flow standard instrument.

As the exhaust flow meter is insensitive to different gas mixtures their calibration system did not include the capability to operate with different gas mixtures. Since most flow transfer standard instruments are designed to operate with a flow media temperature close to atmospheric temperature, ambient temperature room air was used as the flow media. For accurate calibration of exhaust flow meter, the temperature was elevated downstream of flow standard simulating the conditions of actual vehicle test as much as possible thus making the exhaust meter insensitive to flow media temperature. In order to obtain proper flow conditioning upstream and downstream of the meter, ten pipe lengths of the meter with the same diameter piper was used.

The automatic calibration procedure was designed to control the calibration cart flow rate and was designed to progress through 25 distinct calibration points, starting from a higher flow rate of $95 \mathrm{scfm}$ and ending at the lowest flow rate of $3.5 \mathrm{scfm}$. To achieve this, they developed a calibration system which can be operated in the flow ranges that are experienced during actual vehicle testing conditions. Based on their past testing experience with flow meters, a range of 3$100 \mathrm{scfm}(1.42-47.2 \mathrm{l} / \mathrm{sec})$ where the majority of their vehicle products were operated was selected, and to compensate for some special higher flow calibrations to be performed when needed, an upper limit of $300 \mathrm{scfm}$ was selected. At each point, the flow was allowed to stabilize for a minute and the data was collected in the next minute. The automatic calibration system is designed to generate a completely new calibration and can be used to just verify the meter's calibration. 
In order to determine the ability of exhaust flow meter for temperature compensation differences, which can be studied by running calibrations with the heater on and off conditions, the calibrations were run at $17 \mathrm{scfm}$ and $35 \mathrm{scfm}$ where the first calibration is performed with the heater off, second with the heater on. A difference of $0.5 \%$ was observed between the calibrations with the air heater on and off working condition.

Yassine etc.al (Yassine, et al. 2004), developed a vehicle exhaust flow meter calibration device, to accurately and reliably calibrate exhaust flow measurement equipment such as E-Flow. The calibration device has a main flow path with diverter valve and provisions to mount two laminar flow elements in parallel. A $40 \mathrm{cfm}$ and $400 \mathrm{cfm}$ LFE were utilized to calibrate the flow meters and mostly cover the entire range of flows observed during actual vehicle testing. The blower pushes the air through the main path and based on the flow rate it is then diverted into the desired LFE flow path by manual diverter valve controls.

The calibration of the $500 \mathrm{cfm}$ E-flow was done with a higher flow range of $400 \mathrm{cfm}$ and then the flow was decreased in increments of $33 \mathrm{cfm}$ to $67 \mathrm{cfm}$. The main path is then diverted toward the $40 \mathrm{cfm}$ LFE and calibration intervals decreased from $40 \mathrm{cfm}$ to $15 \mathrm{cfm}$ in increments of $5 \mathrm{cfm}$ and then from $15 \mathrm{cfm}$ to $1 \%$ of the range of E-flow, frequency was brought down to 2 cfm with observed error reading while calibrating $500 \mathrm{cfm}$ range E-flowmeter being less than $2 \%$ except for flows below $15 \mathrm{cfm}$. The error value spiked to $13 \%$ as the flow range lowered from 15 $\mathrm{cfm}$ to $5 \mathrm{cfm}$ with a critical flow around $7 \mathrm{cfm}$ beyond which noise levels in flow measurement account for higher error percentage as the E-flow signal gets too much smoothed out by the software for eliminating noise and pulsations as meters sensitivity gets affected greatly at much lower flow rates accounting for higher error percentage. 
Literature study conducted on all the existing methods involving both theoretical procedures and the approaches based on usage of various instrument methodologies has helped to understand the principle procedure employed and their achievements to exhaust flow measurement. Based on the literature study conducted and considering all the various cases, a new methodology which is simple, more efficient and which just makes use of already existing sensor data to determine the end result without any additional equipment and which gives end values which are in good agreement with those of originals, or at least which are in the acceptable error range to those measured by external instruments was developed. 


\section{Experimental Setup \& Methodology}

To evaluate the exhaust flow meters accuracy and repeatability, ambient air was chosen as the flow media and laminar flow element (LFE) was chosen as the standard flow measuring instrument. With the literature review conducted it was understood that, for creating a system which replicates the actual testing conditions, the flow meter being calibrated should be placed downstream of the reference measuring instrument, the reason for this being the accountability of exhaust flow meters for temperature increments and micro-leaks which may affect the operation of the standard measuring instrument. Also, it is necessary to push the compressed air through the system instead of pulling it, as pushing air through the system helps in creating pressure differences similar to those experienced when actual exhaust flows out of vehicle tail-pipe. The measurements made can then be corrected to standard conditions using the data from pressure and temperature sensors that have been incorporated into the system.

Intake air flow rate to the system was controlled using a restriction plate in the flow circuit, which is operated manually by a hand chain. As, the flow restriction slightly increases the pressure and temperature of the air, stabilized flow conditions were achieved at each point and the data was then collected for a period of 30 seconds. The flow meter being a low pressure drop flowmeter, requires maintenance of gradual flow conditions upstream and downstream. To achieve the stabilized intake flow condition, a pipe length greater than ten diameters of the pipe being used was employed ahead of the standard measuring instrument, and a pipe whose length was equal to five times the diameter of the inlet pipe was connected on the outlet side of the flow meter.

Linearity tests were conducted under four different configurations. In all the tested configurations, the flows system inlet is connected to a standard measuring instrument, then the flow meter under test is connected in series downstream of the measuring instrument. The first 
configuration was a straight pipe configuration, where the flow meter is placed after the reference flow device with only a straight pipe separating them. Second is an elbow configuration, where a straight pipe was connected to a 900 bend and the flow meter was immediately connected to the other end of the elbow. The third and fourth configurations are also elbow configurations, but with a pipe length of 6,12 inches placed between the elbow and the flow meter.

The linearity verification results of the flow rates obtained by comparing the measurements recorded by the standard flow measuring instrument and the flow meter under test imply that the calculated uncertainty, slope and regression values as shown in Table 3-1 - Flow meter validation results, under the straight flow and Elbow plus 12" configuration are in compliance with CFR requirements of linearity criteria. Whereas, the other two configurations fail because of the slope value falling slightly out of the prescribed range. So, from the calibration results it is evident that the flow meter stays within the CFR linearity criteria even with a 90o bend if a sufficient length of straight pipe is installed ahead of it for stabilizing the flow. During real world testing it is very difficult to always connect the exhaust flow meters in a straight line and the use of bends which don't influence the measured values are needed.

\section{Table 3-1 - Flow meter validation results}

\begin{tabular}{|l|l|l|l|l|l|}
\hline \multirow{2}{*}{$\begin{array}{l}\text { Measurement } \\
\text { Configuration }\end{array}$} & \begin{tabular}{l} 
Linearity Criteria \\
\cline { 2 - 6 }$(\leq 1 \% \cdot \mathrm{nmax})$
\end{tabular} & $\begin{array}{l}\mathrm{a} 1 \\
(0.98-1.02)\end{array}$ & $\begin{array}{l}\text { SEE } \\
(\leq 2 \% \cdot \mathrm{nmax})\end{array}$ & $\begin{array}{l}\mathrm{R} 2 \\
(\geq 0.990)\end{array}$ & Pass/Fail \\
\hline $\begin{array}{l}\text { Straight Pipe } \\
(\text { after 10D })\end{array}$ & 0.00204 & 0.98100 & 0.06319 & 0.9996 & Pass \\
\hline Elbow & 0.00159 & 1.1459 & 0.08411 & 0.9991 & Fail \\
\hline Elbow + 6” & 0.00121 & 1.0787 & 0.04174 & 0.9998 & Fail \\
\hline Elbow + 12” & 0.00066 & 1.0102 & 0.03570 & 0.9998 & Pass \\
\hline
\end{tabular}


Once, the exhaust flow meter was calibrated using the laminar flow element, it was used for collecting the exhaust flow rate measurement values during on-road real world in-use emission testing of heavy-duty trucks.

\subsection{Methodologies:}

In this study, three major different methodologies were developed to help predict the exhaust flow rate using the OBD data. In the first two methods, the intake flow was calculated using the basic flow equation and then the measured fuel flow and estimated correction coefficients were used in relation to the measured intake flow to get the estimates of exhaust flow. Whereas, in the third method, exhaust flow was estimated directly using the differential pressure signal observed across the engine Diesel particulate filter, which is discussed in detail in the further sections. Thus, in all the three developed methods the flow was predicted by just using the OBD data.

The Intake flow rate was estimated making use of the basic flow equation and the OBD data from engine control unit i.e. intake boost pressure, intake temperature, ambient air temperature, ambient pressure, engine and engine speed. By using the mass flow rate formula based on delivery ratio, the intake air flow rate is calculated, and from the literature review conducted it was believed that the OBD fuel flow rate estimates lie in good correlation with actual fuel flow values, so the fuel rate broadcasted by ECU was used. The intake flow is added to the fuel flow rate data obtained from OBD of ECU, and finally the result of intake plus fuel flow rate is multiplied by a correction coefficient calculated by one of the methods developed, which are discussed in the further sections. The correction coefficient when used in relation with the 
measured intake flow rate and fuel flow, gives the actual estimates of exhaust gas leaving the engine cylinder.

$$
\dot{m}_{\text {lnt }}=\frac{P_{I M}}{R_{A} T_{I M}} \cdot V_{d} \cdot Z \cdot \frac{n}{30 \cdot \tau} \cdot \mathrm{T}_{d}
$$

$m_{\text {lnt }}:$ Intake air flow rate $(\mathrm{Kg} / \mathrm{sec})$

$P_{I M}:$ Intake Boost Pressure $(\mathrm{kPa})$

$T_{I M}$ : Intake manifold temperature $(\mathrm{K})$

$R_{A}$ : Characteristic Gas constant $(\mathrm{J} / \mathrm{g} \mathrm{K})$

$V_{d}$ : Cylinder displacement (m3)

$Z$ : Number of cylinders

$n$ : Engine speed (1/min)

$\tau$ : Number of strokes

$\mathrm{T}_{d}$ : Delivery ratio

$$
\dot{m}_{e x h}=\dot{m}_{\text {lnt }}+\dot{m}_{f u e l}
$$

Where:

$$
\begin{aligned}
& \dot{m}_{e x h}=\text { Exhaust flow rate uncorrected }(\mathrm{g} / \mathrm{min}) \\
& \dot{m}_{\text {tnt }}=\text { Intake flow rate }(\mathrm{g} / \mathrm{min}) \\
& m_{f u e l}=\text { Fuel flow rate }(\mathrm{g} / \mathrm{min})
\end{aligned}
$$




\subsubsection{Advanced Speed-density method:}

The first methodology used for generating correction coefficients is a speed density method, where an overall correction coefficient is calculated taking into consideration the Baseline volumetric efficiency, engine coolant temperature correction, intake and ambient air density correction. Each of the correction factors used, have a significant effect on the overall correction and eventually on the amount of estimated exhaust flow. It was desired that even during low speed and idling conditions the correction coefficient method helps in producing better estimation of exhaust flow values.

Firstly, a correction factor for density differences is considered, as the usage of engine exhaust gas recirculation brings in a huge temperature difference between intake air and the ambient air, which results in density differences across the engine intake and cylinder intake conditions, the actual air taken into the cylinder varies and needs to be corrected. As the intake flow rate is being used to get estimates of exhaust flow rate, a correction factor which compensates for density differences has been taken into consideration.

$$
\begin{gathered}
\rho_{\text {int }}=\frac{P_{\text {int }} \cdot M_{a}}{R_{u} \cdot T_{\text {int }} \cdot 1000} \\
\rho_{a m b}=\frac{P_{a m b} \cdot M_{a}}{R_{u} \cdot T_{a m b} \cdot 1000} \\
K_{\rho}=\frac{\rho_{a m b}}{\rho_{\text {int }}}
\end{gathered}
$$

Where:

$\rho_{\text {int }}=$ Density of air in the intake manifold $(\mathrm{kg} / \mathrm{m} 3)$ 


$$
\begin{aligned}
& \rho_{i n t}=\text { Density of ambient air }(\mathrm{kg} / \mathrm{m} 3) \\
& P_{a m b}=\text { ambient Pressure }(\mathrm{kPa}) \\
& T_{a m b}=\text { ambient temperature }(\mathrm{K})
\end{aligned}
$$

Equation- (3) (4) (5) represents the calculation for density correction factor. The engine cooling rate is believed to have some influence on the overall volumetric efficiency of the engine as it can cause significant effects on the exhaust gas scavenging, which needs to be corrected for accurate prediction of flow, it is compensated by incorporating a correction factor which is based on coolant temperatures. Equation- (6) represents the calculation of the correction factor based on engine coolant temperatures recorded by the engine ECU.

$$
K_{E C}=\frac{1450}{T_{E C}+1110}
$$

Where:

$T_{E C}=$ Engine coolant temperature $(\mathrm{K})$

Finally, based on the density correction factor the delivery ratio of engine is varied. As most of the engines are turbo charged and are high speed engines, it was assumed that all the engines have a varying delivery ratio or a charging efficiency which ranges from $0.8-1.2$, during entire engine operation conditions. The delivery ratio was made varied based on the mean of calculated density correction factor. 
For $0.51 \leq$ mean $\left(K_{\rho}\right) \leq 0.6$

$$
K_{d}=1.2
$$

For $0.61 \leq$ mean $\left(K_{\rho}\right) \leq 0.7$

$$
K_{d}=1.1
$$

For $0.91 \leq$ mean $\left(K_{\rho}\right) \leq 1.0$

$$
K_{d}=0.8
$$

Where:

$K_{d}=$ Delivery Ratio

$$
K_{O}=\operatorname{mean}\left(K_{\rho}\right) \cdot K_{d} \cdot K_{E C}
$$

Where:

$K_{O}=$ Overall correction Factor

$K_{d}=$ Delivery ratio

$K_{\rho}=$ Density correction Factor

$K_{E C}=$ Coolant correction Factor

$$
\dot{m}_{\text {exh }}=\left(\dot{m}_{\text {lnt }}\right) * K_{O}+\left(m_{\text {fuel }}\right)
$$


The density correction coefficient values that were developed across the entire engine operation range were then averaged and used as represented in Equation- (7), along with varying delivery ratio and instantaneous engine coolant correction factor. Then the overall correction factor is used along with Intake and fuel flow rate to obtain estimates of exhaust flow as shown in Equation-(8). By comparing the speed density estimated exhaust flow rates with those of the exhaust flow rate values measured using an external flow meter, it was revealed that, better estimation of flow can be achieved by using an averaged density correction factor across the entire range instead of using instantaneous correction coefficients. So, an average value was calculated for each test, based on the instantaneous correction coefficients and then used with other correction factors, which helped to obtain better estimates of exhaust flow that matched the actual measured flow rate values, by better correcting the estimated flow rate values across the entire test range irrespective of the vehicle operation condition.

To overcome the problem of in-accurate predication of correction coefficient in case of shorter tests and to further improve the efficiency of the above estimation model, a new method which could be classified as a sub model of speed density method was also investigated. In this method, at least two or more test routes are combined together and then an overall correction factor which is an average of correction coefficient values was obtained from the combined data set. When this combined data set correction factor was used for correcting estimated flow it improved the estimation ability of the speed density method which resulted in reasonable estimation of exhaust flow rate values. 


\subsubsection{Artificial neural network method:}

The second method used to estimate the correction coefficients was by using an artificial neural network prediction model. Artificial neural networks (ANN), due to their ability in accurately predicting the estimates of time-varying unobservable components, are gaining importance in data prediction and being used extensively in the automobiles as black box models. The literature study conducted helped to understand the simplicity of using neural networks, which can learn and recognize the data patterns just like a human brain and generalize the estimates based on the training data provided. Therefore, an attempt was made to estimate the exhaust flow rate data by using artificial neural networks in combination with the OBD data.

Artificial neural networks are developed learning systems that can mimic the operations of brains functions. ANN models were inspired and developed from the biological neural networks. The developed ANN models were widely useful in technological applications and helped to develop a new information processing paradigm. ANN have the capability to approximate continuous functions if the domains of the dependent and the independent variables are known and when enough input-output data is available for training. To estimate an unobservable data, the structure of the network should be finalized first, and then the internal parameters can be adjusted by means of training algorithms. Once the training and pattern recognition of data based on the available input-output data (training data) is completed, the weighted average of correction factors is calculated, and accordingly the activation functions are used to produce output values of the new time series data by just receiving the inputs. 


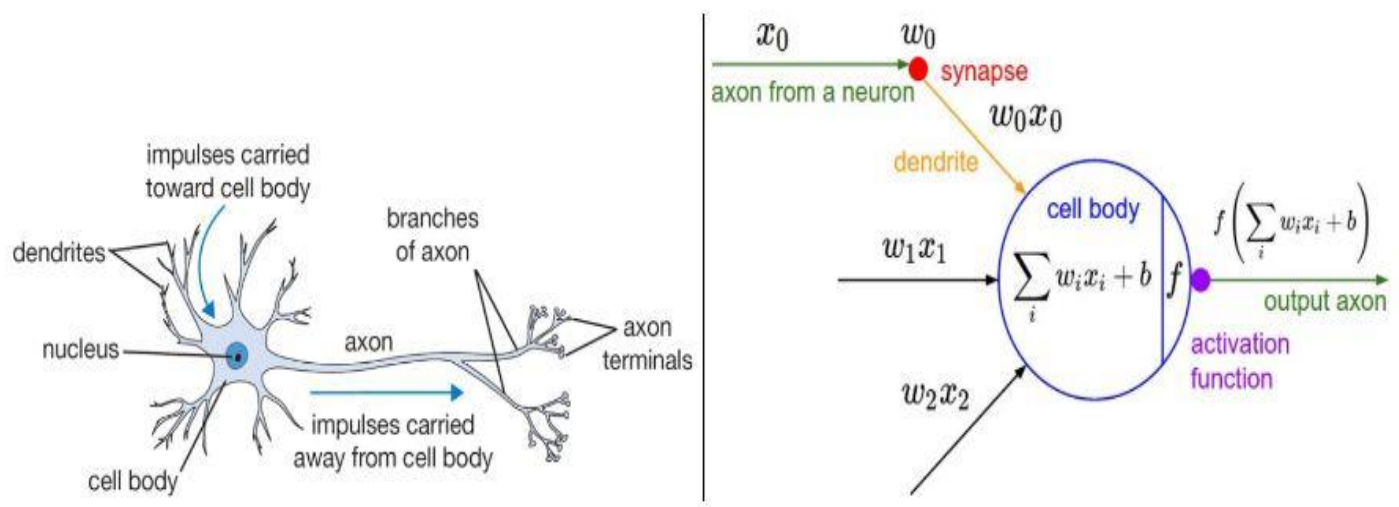

Figure 1 - Structure of Biological Neural Network and Artificial Neural Network (Willems n.d.)

Figure 1, represents the correspondence between the biological neural component and mathematical model (or) ANN model component that was developed from the biological networks. A generic neuron ' $\mathrm{j}$ ' receives inputs from the exterior paths modeling the dendrites and produces an output that passes on to other neurons or to the exterior of the network through an axon path. The output, also called activation or excitation, is computed by weighted sum of inputs modified by an activation function $\Psi$, and is represented in equation form as:

$$
o(t)=\Psi\left[\sum_{i=1}^{n} w_{i} a_{i}+\theta\right]
$$

Where $\left[\mathrm{a}_{1}, \mathrm{a}_{2} . . . \mathrm{an}\right]$ are the inputs $\left[w_{1}, w_{2} \ldots w_{n}\right]$ are the weights of the synapses and ' $o$ ' is the output. The adjustment of synapses weights occurs as part of the "learning" process. Within an ANN, the artificial neurons can be further divided into three types. Input units or neurons, output units or neurons and hidden or intermediary neurons. The input neurons form the input layer of the network and receive information from outside the network, the output units send the information to exterior and possibly back to inside of the network and the hidden neurons that communicate with the elements inside the network. Depending on the existence of hidden layers, 
ANN are said to be of single layer type or multiple layer type. The performance of the network is greatly dependent on the number of layers and neurons present in it. For any given application there is no procedure to determine the layer or neuron count, although optimal configuration exists and totally depends on the input data size, type and number of outputs and internal complexities of the model. Figure 2, Represents a multi-layer neural network model with an input array of $\mathrm{p}$ elements and outputs array consisting of m elements.

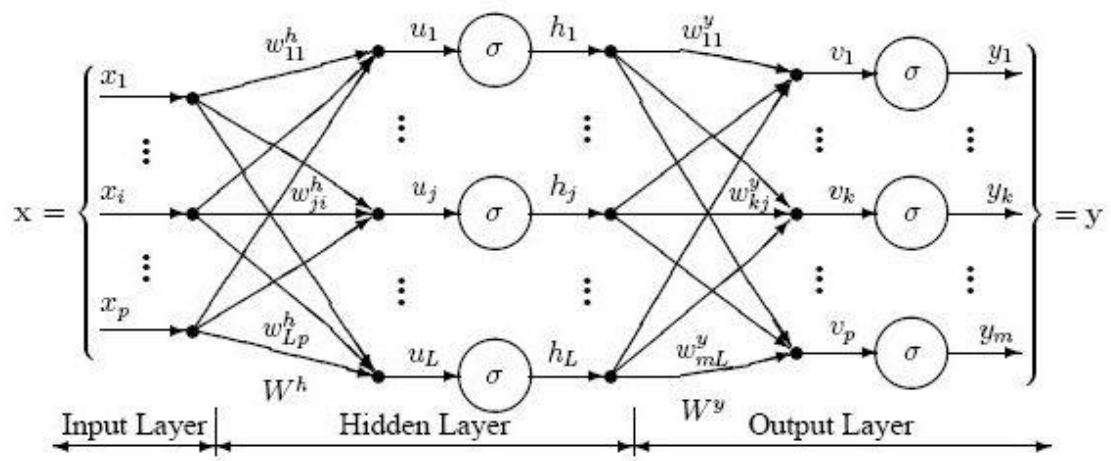

Figure 2 - Multi-layer Artificial Neural Network

There are a wide Variety of Neural Networks being used in engineering application, where each network has their own usage applications, advantages and disadvantages. For this particular application a 'Dynamic Time Series Network' was adopted. These are used where predictions have to be made by dynamic filtering and where past values of large time series transient data are used to predict the future data during the training process. The dynamic neural networks help in nonlinear filtering and in the prediction of model patterns. As long as there is a large and diverse training data set, which helps in obtaining stable weight estimates, relatively stable output predictions can also be obtained. 'Non-linear Autoregressive with Extraneous Input' (NARX), 'Non-linear Autoregressive' (NAR), and 'Non-linear Input-Output' are the three types of dynamic time series prediction models available. Since, we need to predict the values of new data based on 
previous input-output data, a 'Non-linear Input-Output' back propagation neural network model with provision for time delay was adopted for this study.

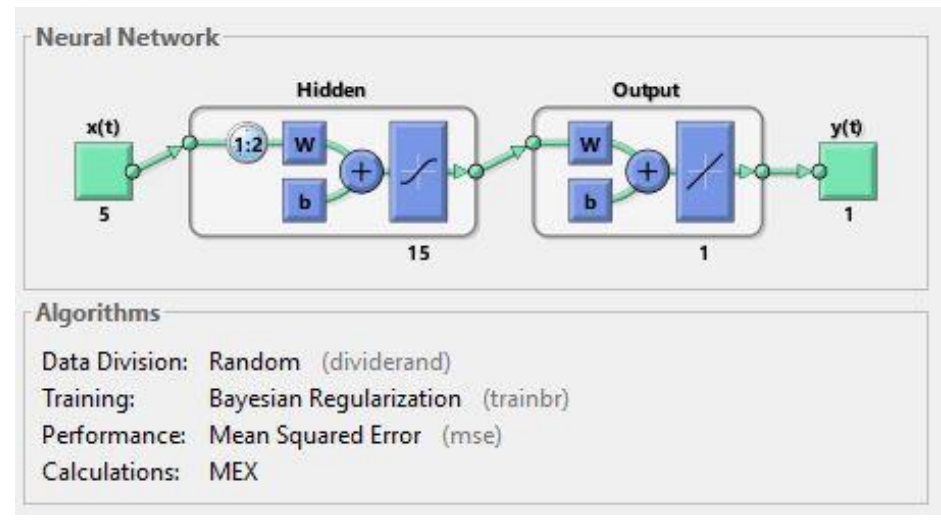

Figure 3 - Neural Network diagram

Training Input

Training Output

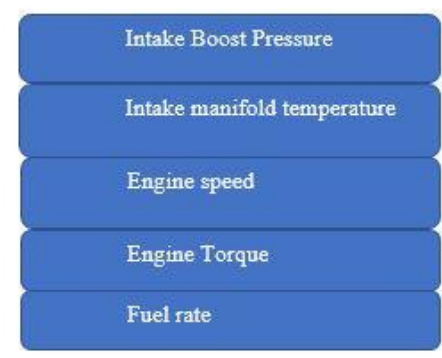

Correction Coefficients

Figure 4-parameters used for training the Neural Network

Figure 3, represents the structure of a neural network model with a Bayesian Regulation training algorithm containing 15 hidden layers with 5 input parameters as shown in Figure 4 i.e. Intake Boost pressure, Intake Temperature, Engine Speed, Torque and Fuel rate, and with provision for time-delay function. In the adopted back-propagation network with Bayesian Regularization (BR) model, estimates are obtained by variance learning process. The backpropagation network also uses an Error-based or supervised learning algorithm which depends on the availability of input and output data. Within the network, the training data acts as a teacher and 
provides the student (ANN) examples, then based on those examples the student receives inputs and reproduces the output and also makes extrapolations and interpolation from the provided data. During the training phase which is the first phase of the network, the training data which is made up of pairs of (' $\mathrm{x}$ ' and ' $\mathrm{y}$ '), where $\mathrm{x}$ is the input, typically a vector with n-dimensions ( $\overline{\mathrm{x}} \in R^{n}, \overline{\mathrm{x}}$ $\left.=\left[\mathrm{x}_{1}, \mathrm{x}_{2}, \ldots \mathrm{xn}\right]\right)$ and $\mathrm{y}$ is the output, typically a scalar $(y \in R)$. Synaptic weights are determined and are varied until cost function based on the error reaches it minimum value. The second phase is the prediction phase, during which no changes occur to the weights, and new outputs are obtained as the ANN is exposed to new input data. When exposed to the input data, the ANN generates the outputs that are compared to the training outputs by computing the errors, accordingly modifying the synaptic weights to reduce the errors.

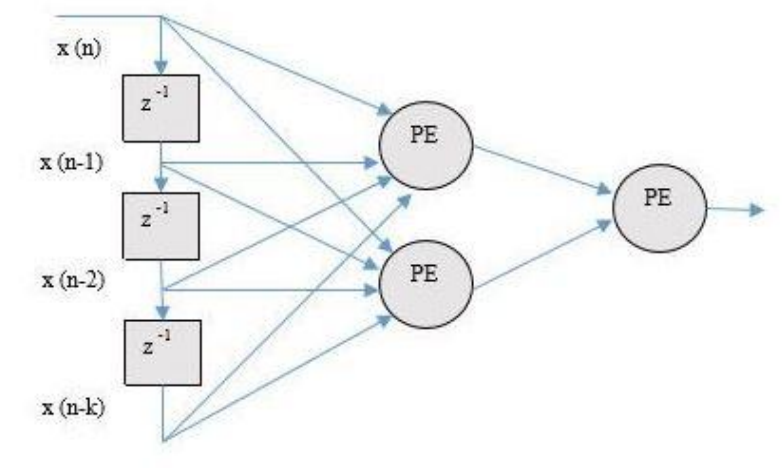

Figure 5 - Time-delay Network (Mishra n.d.)

Figure 5, represents a time-delay neural network where previous inputs are taken into consideration as the network progress. The time delay allows the network to operate at a different temporal resolution, as we go to higher layers of the network the more the wider the temporal context becomes. The layers get updated based on the gradient accumulated over all the time steps of the input temporal context. In simple terms, a time delay can be defined as the dependency of the network on the previous second's data to predict the output, the number of seconds to be considered for prediction can be varied based on the type of data set. In a transient data set where 
data changes over time, the time delay helps to make better estimates by taking into consideration the previous data points.

The Network was trained using the Input array with 5 parameters that have influence on the correction coefficients of an engine and which are logged by the engine OBD. The correction coefficients were calculated by diving the Semtech measured flow rate with the one calculated using Equation - (2). The input matrix made up of five parameters was used as an input training data set and the correction coefficients were used as the output of the training network. The network was trained till it achieved optimal Pearson correlation Coefficient (which defines the relation between actual and predicted values) where the performance was evaluated by a mean square error model for various combinations. Once the training was done, the network was used to predict the correction factor values which can be used in relation with the intake flow calculated from the flow equation and measured fuel flow, to estimate the exhaust flow values. ANN predicted correction factors help to correct the estimated exhaust flow rate values to exactly match the exhaust flow meter measured values. Figure 6 and Figure 67, represent the difference between Semtech measured flow and estimated flow before application of any correction factor. Figure 8 represents the correction coefficients developed across the engine speed range obtained from the combined data set, which are then used to train the neural network. 


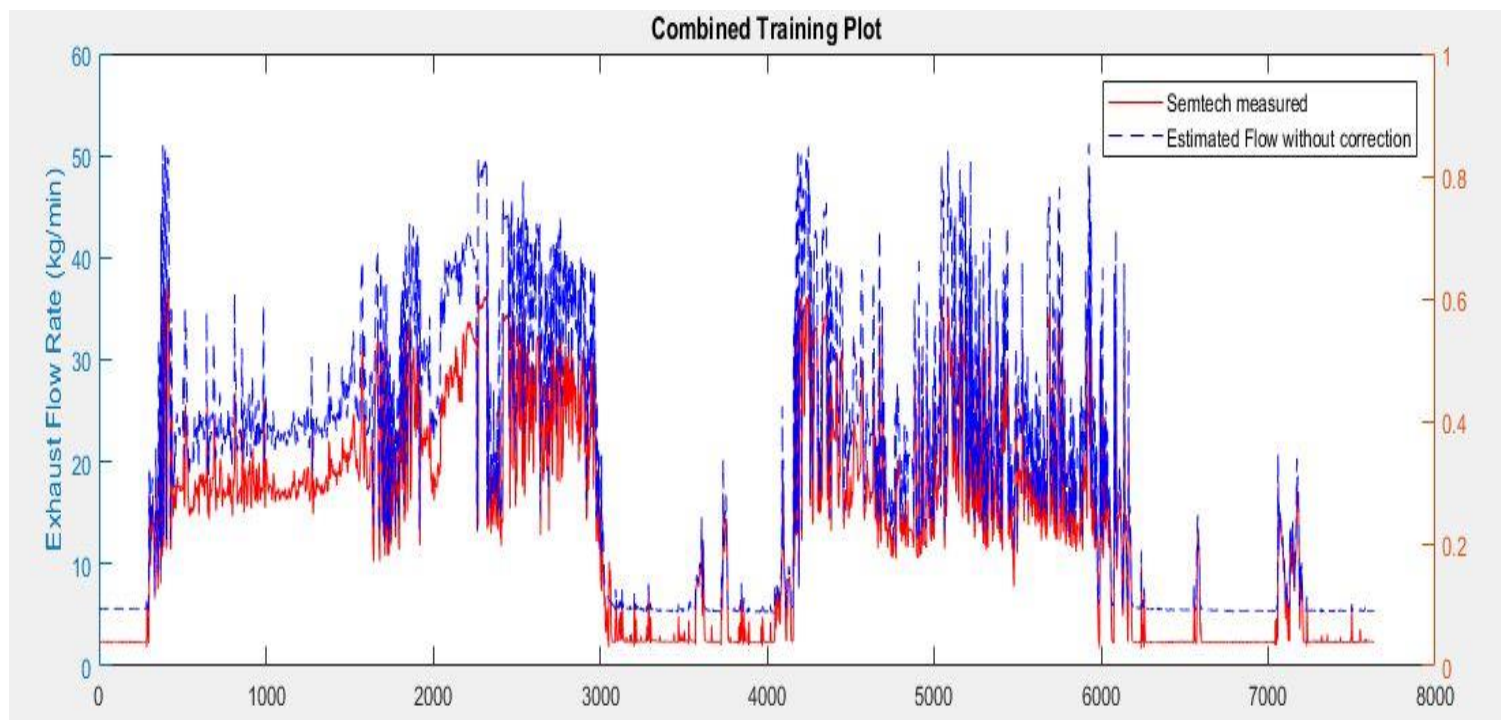

Figure 6 -Semtech measured flow (vs) estimated flow without any correction

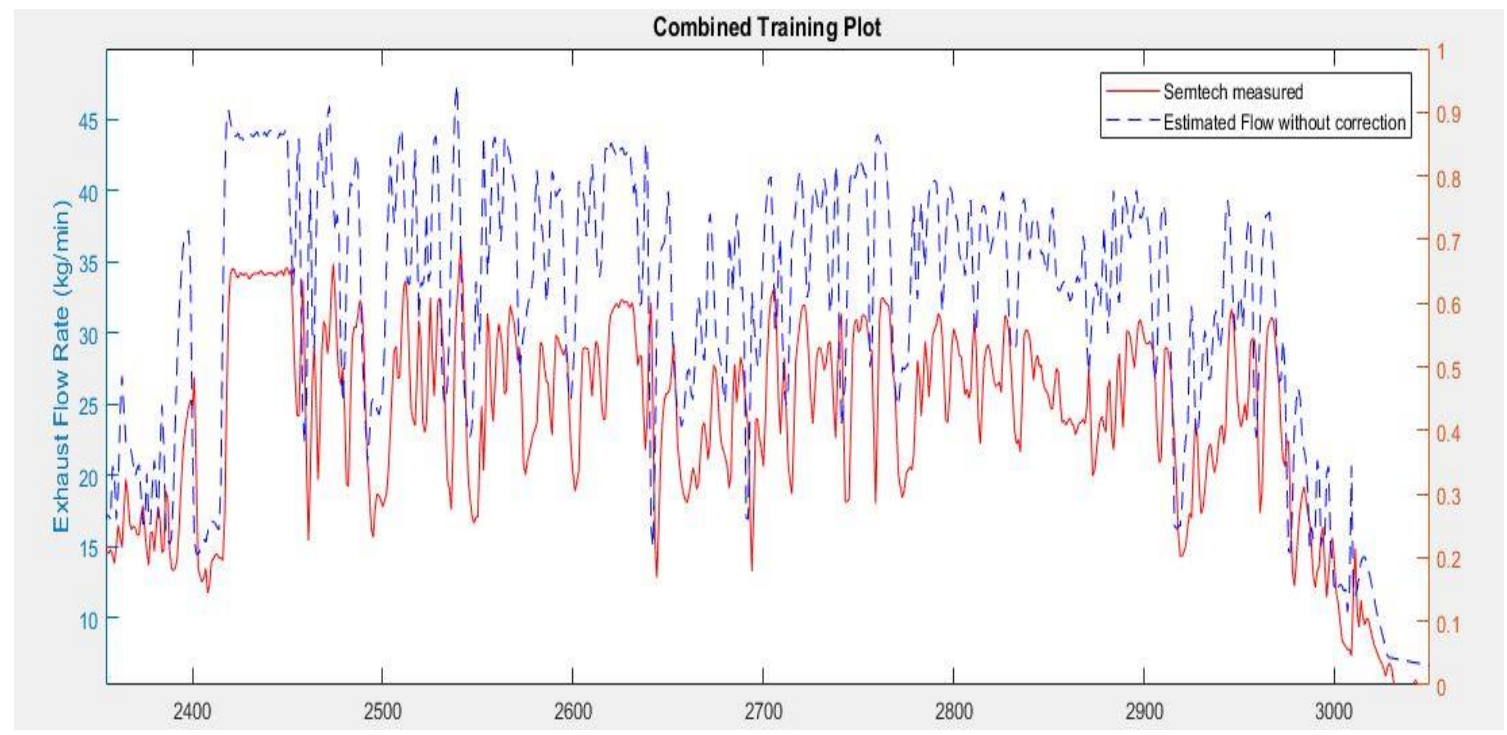

Figure 7 - Enlarged view of Semtech flow (vs) estimated flow without any correction 


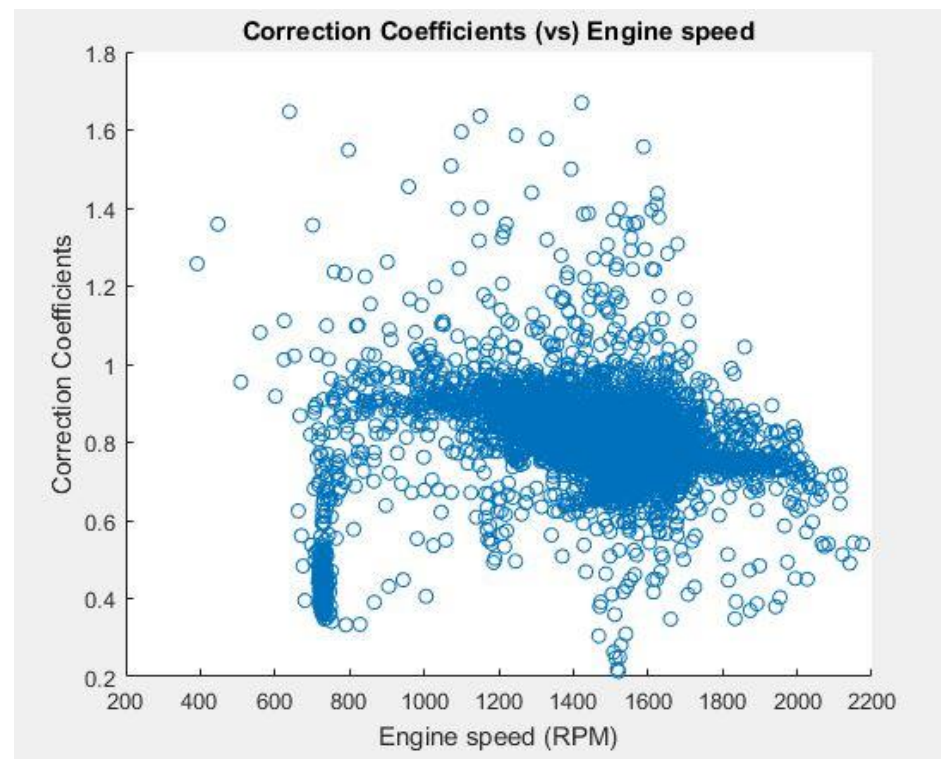

Figure 8 - Correction factors used in the training data set

Once the neural network was trained, it could predict the correction coefficients for any new test data. The only requirement of the neural network was that, the input data should be sufficient enough to allow the neural network to understand the pattern and the parameters being used should be available in all the OBD equipped vehicles.

Finally, the main purpose of flow prediction was achieved where the correction coefficients established either by Speed-density method or by neural network method were able to be used in relation with the estimated exhaust flow to help in correcting the estimated flow value. 


\subsubsection{DPF as an LFE method:}

The third method is more simplified than the other two methods and can be used only for diesel engines equipped with a Diesel Particulate filter (DPF), a differential pressure sensor that measures the pressure difference across the DPF element, and a temperature thermocouple to measures the temperature across the DPF element. To achieve the prediction of exhaust flow rate from the diesel vehicle a methodology was developed, in which the differential pressure sensor data was used to obtain the actual instantaneous estimates of exhaust flow rate.

The main principle behind this methodology was to consider the DPF as an internally compensated laminar unit (ICL). In an ICL internal restriction is created to the flow, which is known as laminar flow element. In the LFE, the gas molecules are forced to move through parallel paths along the length of the passage. This result in a laminar flow condition where all the flow turbulences are eliminated as the gas navigates through the porous channels, then the measured differential pressure is used along with Poiseuille equation, which quantifies the relation between pressure drop and volumetric flow rate. The operation principle of DPF seems similar to that of ICL. In the case of DPF, the exhaust gas from the engine is diverted into a fine pore ceramic filter, creating a substrate which has alternatively plugged channels and a porous wall separating each channel inside the filter, creating a structure which resembles a honeycomb with a checkerboard plugging pattern. The gas enters the DPF from the unclogged channels, then travels down the channel till it reaches the restriction plug. From here it is then forced via a porous wall (separating the channels) into an adjacent channel and travels down to the next and so on till it reaches the exit end of DPF. As the exhaust gas flows from one channel to other the soot particles in the exhaust get deposited on the walls of the channel. The soot particulates start to build up on the channel walls, which along with the porous wall and inlet-outlet flow contractions account for creating a 
flow restriction and pressure drop. To conclude, the DPF acts as an internally compensated laminar unit and the flow restriction occurring across the DPF resembles a laminar flow element.

From the literature review it was understood that the pressure drop of the diesel particulate trap under varying engine operation conditions behaves non-linearly during the initial wall loading phase and starts to behave linearly once particulate matter of sufficient quantity is accumulated forming a sooth cake layer. Further understandings from the literature review were, filters which are sized exactly for the turbocharged engines are designed perfectly to avoid excess soot buildup and allow a safe pressure margin that accounts for lesser pressure loss even during the higher volumetric flow rates of exhaust gas, and in most cases vary linearly with the flow. Based on the understandings from literature review, it was clear that the pressure drop across the particulate filter varies with the flow. So, the differential pressure measured across the DPF was used in relation with calculated proportionality constant values to obtain estimates of exhaust flow rate.

In the initial stages, when the DPF substrate is completely empty, the differential pressure is close to zero, which makes the measurement of exhaust flow difficult. Once the DPF starts accumulating the soot produced by the engine and, the differential pressure starts to build up, the differential pressure signal varies as the flow varies from the engine and it turns out that the signal varies linearly proportional to the exhaust flow rate. To establish better relation between the pressure drop and flow rate and to better predict the exhaust flow, the entire flow range was classified into six regimes and the coefficients were separately developed for each regime in all the vehicles that published differential pressure data. The first regime is one which has a differential pressure ranging from 0-1 KPa, the second was from 1-2 KPa, the third one has 2-2.5 $\mathrm{KPa}$, the fourth regime ranging from $2.5-3 \mathrm{KPa}$, the fifth one from 3-4 KPa, and the final regime covering a range of 4 - $6 \mathrm{KPa}$. Different regimes of pressure are observed during actual vehicle 
operation, i.e. during clean filter operation, immediately after a regeneration process, during vehicle idle condition, the start of a transient vehicle operation condition, and a higher regime condition observed when the filter gets sufficiently clogged with soot deposits. Figure $9-14$, represents the slope and intercept values of each regime when the differential pressure is plotted along $\mathrm{x}$-axis to match the Semtech measured flow plotted along the $\mathrm{y}$-axis, it acts as an example to represent the various regimes and how their corresponding slope and intercept values were obtained for Vehicle-3.

Additionally, from the data collected it was observed that most of the vehicle operation falls in the fourth and fifth regime. During regeneration, the temperature values increase drastically. This causes the differential pressure sensors to experience a drift necessitating temperature correction factors to be used in relation with the measured differential pressure. During regeneration, the vehicle is allowed to remain parked until the end of regeneration in the case of heavy-duty vehicle operations, and higher errors may be detected in estimated exhausted flow values as the Diesel particulate filter experiences low exhaust flow and high temperature conditions. This may result in non-uniform differential pressure and eventually result in a nonlinear relationship between differential pressure and the actual flow.

Also, as the sooth starts to accumulate across the porous wall, the differential pressure starts to vary non-linearly, which should be also taken into consideration while adopting the DPF-DP method for exhaust flow rate calculation. So, different correction factors need to be developed based on the sooth accumulated separately for period just before regeneration, during regeneration and immediately after the regeneration. 


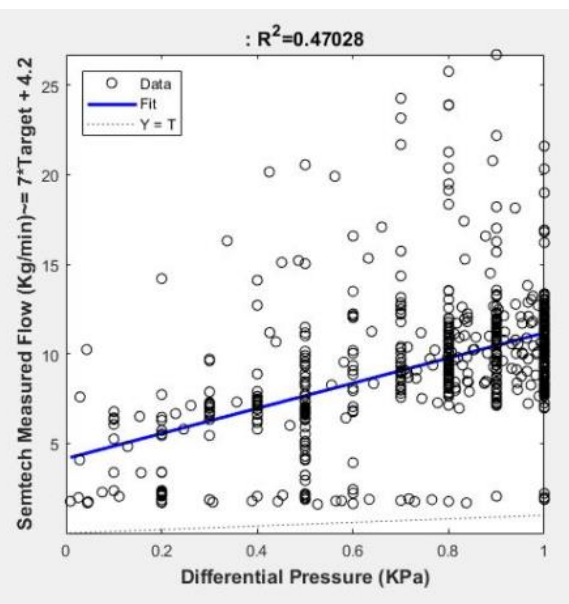

Figure 9 - DP range of $0-1 \mathrm{KPa}$

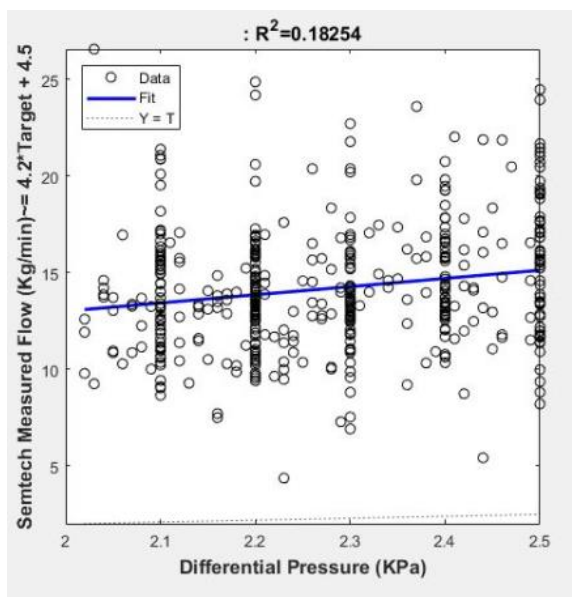

Figure 11 - DP range of 2-2.5 $\mathrm{KPa}$

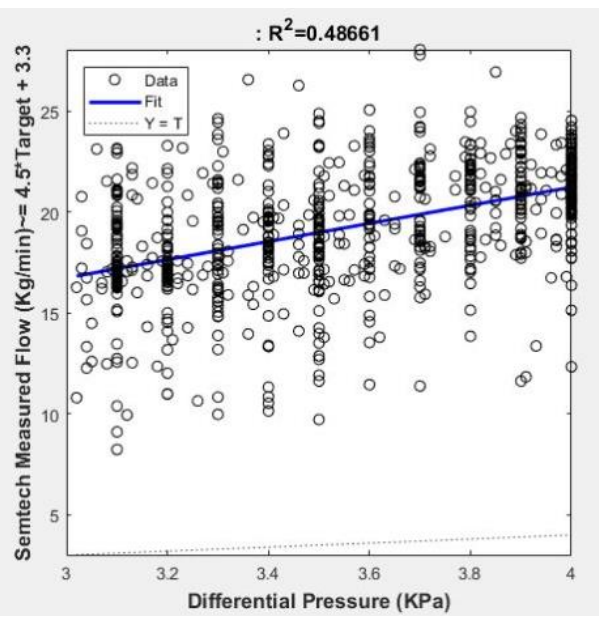

Figure 13 - DP range of 3-4 KPa

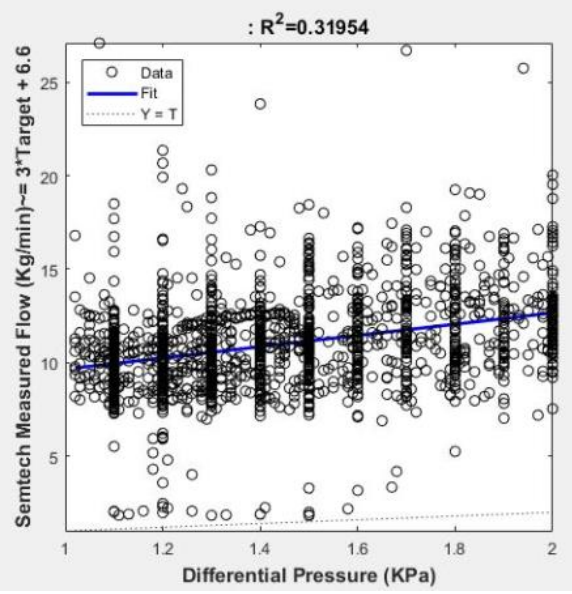

Figure 10 - DP range of 1-2 $\mathrm{KPa}$

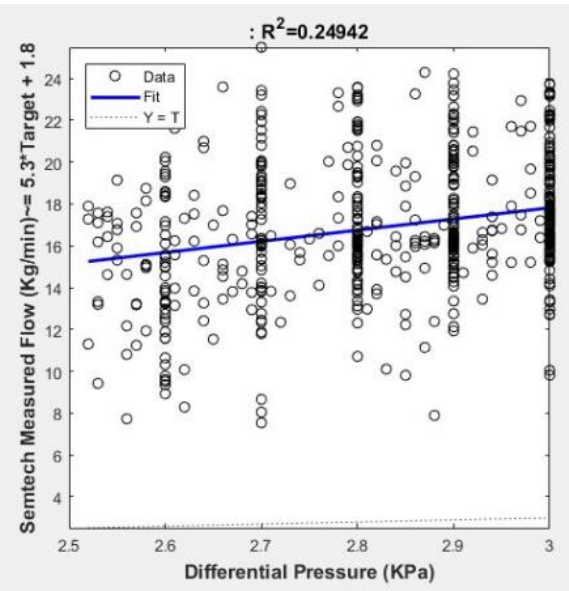

Figure 12 - DP range of 2.5-3 $\mathrm{KPa}$

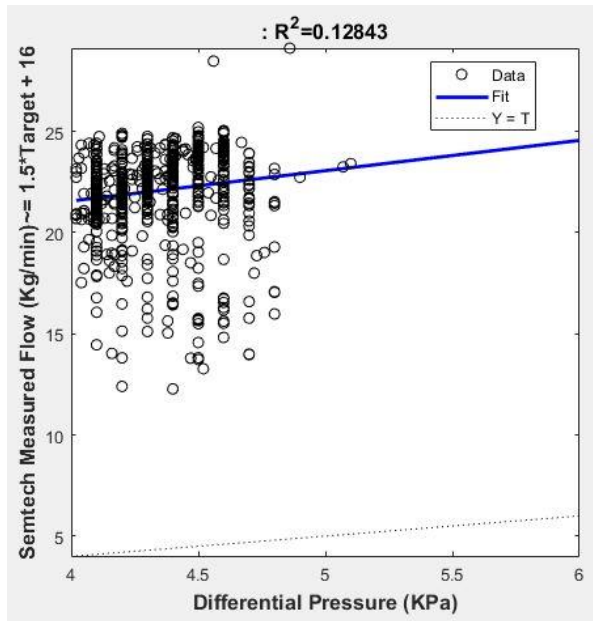

Figure 14 - DP range of 4-6 KPa 


\subsection{Experimental Test Vehicles and Data Collection Equipment:}

All the data used for this study was acquired in a research project conducted by the Center for Alternative Fuels, Engines and Emissions (CAFEE) lab at West Virginia University in the year 2015. The in-use data used for this study was recorded using a Semtech Flowmeter, while the vehicles were operated along various routes in California. The testing routes included operation of vehicle in Near-dock, Regional, Interstate, Urban, Local and Hill climb conditions with trips made around the Port of Los Angeles, Sacramento to Ontario and back from Ontario to Sacramento, driving in the town of Irvine, as well as along the Desert routes of Los Angeles. In all the test vehicles, the Semtech exhaust flow meter was connected to the tailpipe and the cables from the exhaust flow meter were ducted to the flow meter and to the Semtech instrument which has been housed inside the truck. The exhaust flow values were recorded along with other emission values by the Semtech portable emissions measurement system (PEMS).

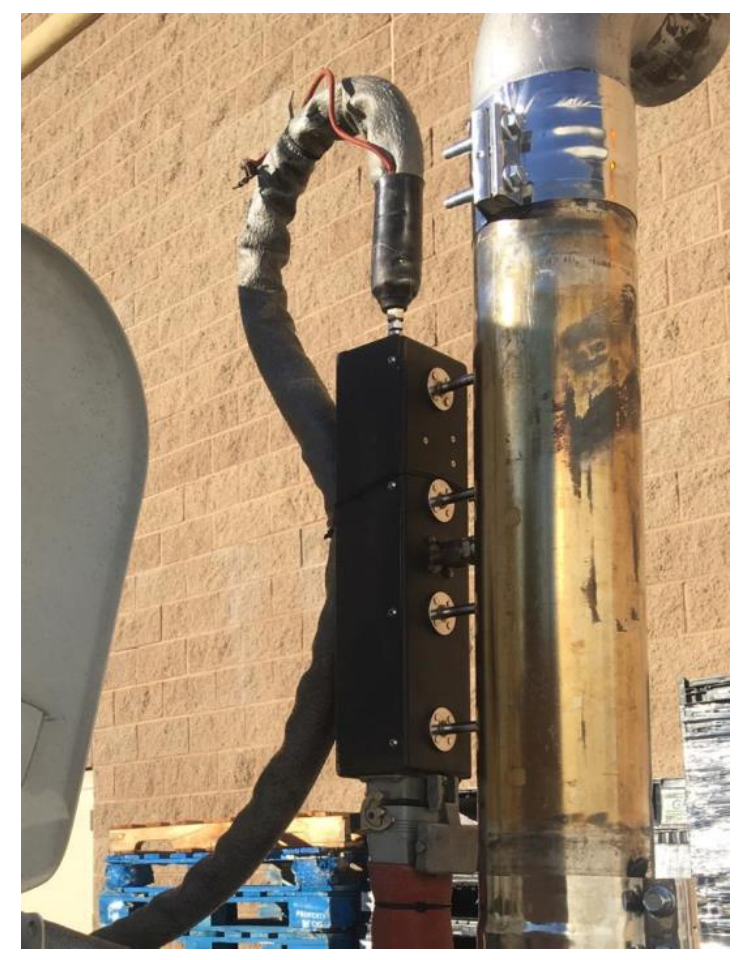

Figure 15 - Semtech exhaust gas flow meter connected to exhaust pipe 


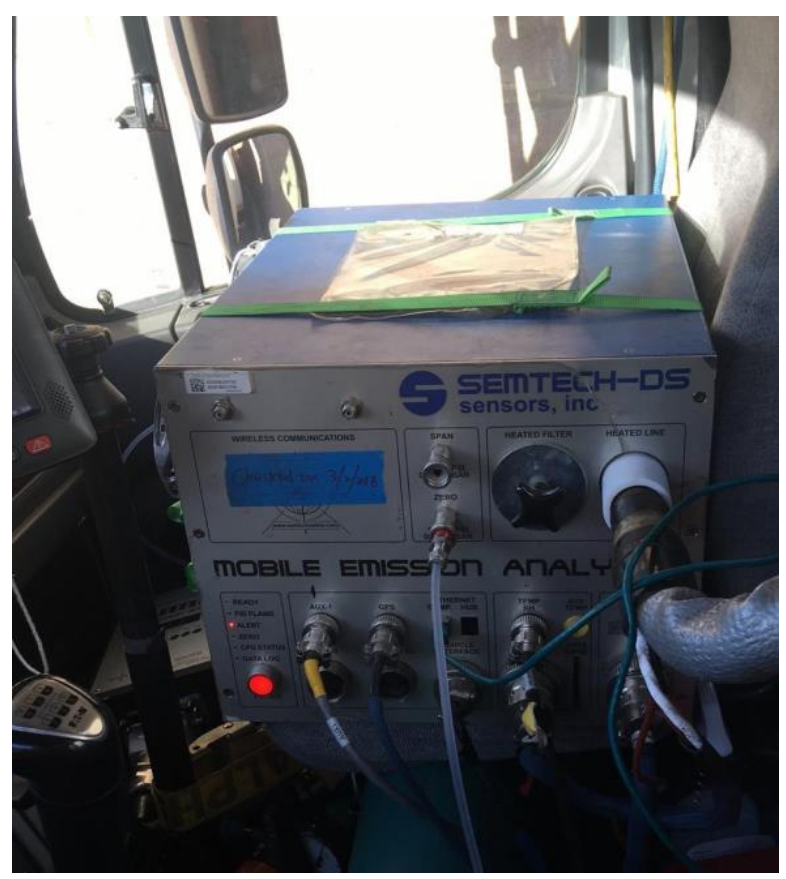

Figure 16 - Semtech instrument mounted inside the driver cabin

EFM4 front View

\section{EFM4 Front View}

(1) EFM4-SCS Port and Heated Line

2 Power Harness Connection

(3) Sample Purge Port

\section{EFM4 Side View}

(4) EFM4 Flow Tube

5) Averaging Pitot Tube (Delta P measurement point)

6) Sample Probe

Sample Inlet Port
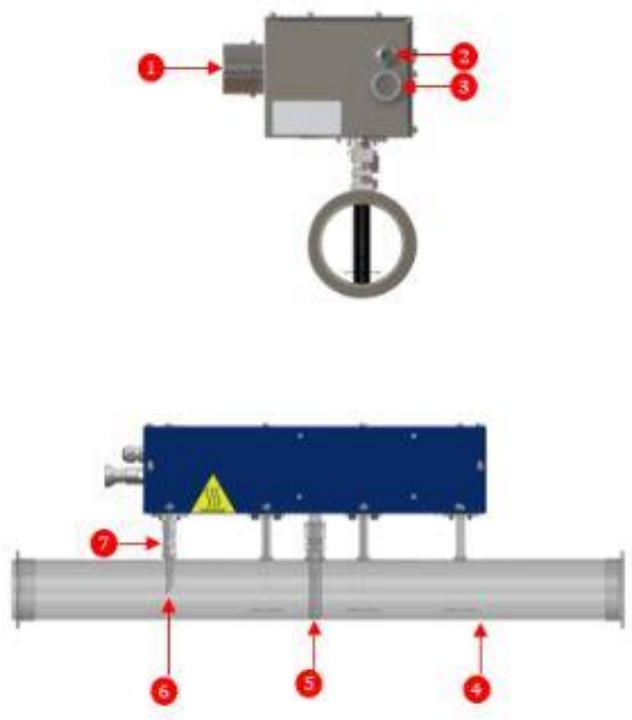

EFM4 Side View

Figure 17 - Components of Semtech exhaust gas flow tube (Sensors-inc n.d.) 


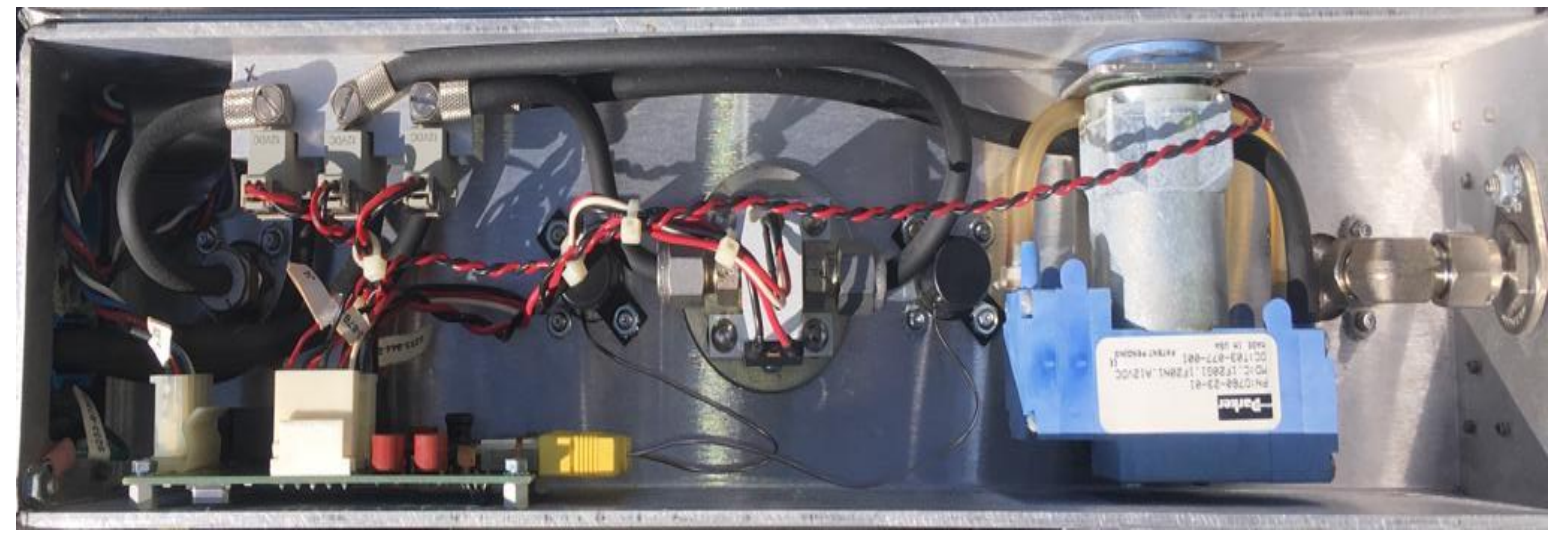

Figure 18 - Inside the Semtech exhaust gas flow tube box

The Semtech exhaust gas flow meter is designed for measurement of total raw exhaust flow from either compression or spark ignition engines and vehicles. It operates under the Bernoulli principle and laminar flow theory. The flowmeter employs five high performance, dual-stage, differential pressure transducers which allow operation even under extremely wide dynamic range. As shown in Figure 18 the measurement components are self-contained in a single module mounted on the flow tube and eliminates the need for lengthy transport lines.

The flow meter internally samples the differential pressure channels at up to $5 \mathrm{KHz}$, accounting for every pressure pulse from an engine, from idle to maximum rpm with a standard output rate of $1 \mathrm{~Hz}$. A software-controlled back purge pump is included in the heated sampling flow tube assembly, along with solenoids that route high pressure air backward through the Pitot tube, purging contaminants and any condensation in the pressure lines. The flow meter has internal solenoids that open the pressure sensors to ambient air, allowing fast and easy zeroing while the engine is still operating.

The exhaust flow tube is connected to the exhaust line of the vehicle as shown in Figure 15 , from where a heated exhaust line is routed to the Semtech instrument mounted inside the driver cabin or inside the trailer. 
A variety of engines from different manufacturers were tested. The data used in this study was collected from the vehicles as described in the Table 3-2, Table 3-3.

\section{Table 3-2 - Description of Vehicles used}

\begin{tabular}{|c|c|c|c|}
\hline \multicolumn{2}{|c|}{ Vehicle \# } & 1 & 2 \\
\hline \multicolumn{2}{|c|}{ Fuel } & ULSD & ULSD \\
\hline \multirow{6}{*}{ Engine } & Family & 7CEXH0912XAM & DCEXH0912XAT \\
\hline & OEM & Cummins & Cummins \\
\hline & MY & 2007 & 2013 \\
\hline & Model & & ISX15 \\
\hline & Disp. (L) & 15 & 15 \\
\hline & $\begin{array}{c}\text { Rated Power } \\
\text { HP @ rpm }\end{array}$ & $550 @$ & $450 @ 1800$ \\
\hline \multirow{4}{*}{ Vehicle } & MY & 2008 & 2014 \\
\hline & Make - Model & Kenworth - T800 & Freightliner - Cascadia \\
\hline & GVWR & 80,000 & 80,000 \\
\hline & ODO [miles] & 393,174 & 123,471 \\
\hline \multicolumn{2}{|c|}{ After-treatment System } & $\mathrm{DOC}+\mathrm{DPF}(\mathrm{EGR})$ & $\mathrm{DOC}+\mathrm{DPF}+\mathrm{SCR}(\mathrm{EGR})$ \\
\hline
\end{tabular}

Table 3-3 - Description of Vehicles used

\begin{tabular}{|c|c|c|c|}
\hline \multicolumn{2}{|c|}{ Vehicle \# } & 3 & 4 \\
\hline \multicolumn{2}{|c|}{ Fuel } & ULSD & ULSD \\
\hline \multirow{6}{*}{ Engine } & Family & EDDXH14.8EED & DNVXH07575SB \\
\hline & OEM & DDC & Navistar \\
\hline & MY & 2014 & 2013 \\
\hline & Model & DD15 TC & N13 \\
\hline & Disp. (L) & 14.8 & 12.4 \\
\hline & $\begin{array}{c}\text { Rated Power } \\
\text { HP @ rpm } \\
\end{array}$ & $505 @ 1800$ & $475 @ 1700$ \\
\hline \multirow{4}{*}{ Vehicle } & MY & 2014 & 2013 \\
\hline & Make - Model & Freightliner - PX125064ST & Prostar+ \\
\hline & GVWR & 80,000 & 80,000 \\
\hline & ODO [miles] & 110,680 & 186,389 \\
\hline \multicolumn{2}{|c|}{ After-treatment System } & $\mathrm{DOC}+\mathrm{DPF}+\mathrm{SCR}(\mathrm{EGR})$ & $\mathrm{DOC}+\mathrm{DPF}+\mathrm{SCR}(\mathrm{EGR})$ \\
\hline
\end{tabular}




\subsection{Artificial Neural Network Training Data:}

The test routes were categorized into four major arbitrary categories i.e. Idle, Rural, Urban and Freeway, based on the speed breakdown i.e. $<1 \mathrm{mph}, 1-25 \mathrm{mph}, 25-50 \mathrm{mph}$ and $>50 \mathrm{mph}$, as shown in Figure $19-22$.

Trip Summary of Training cycles

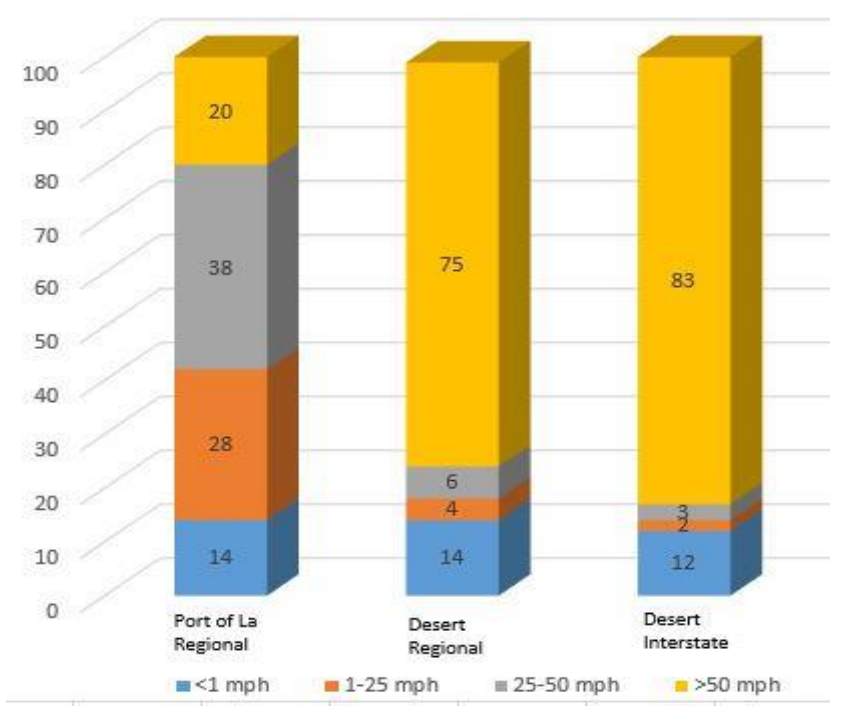

Figure 19 - Trip summary of vehicle-1 training data set

Trip Summary of Training cycles

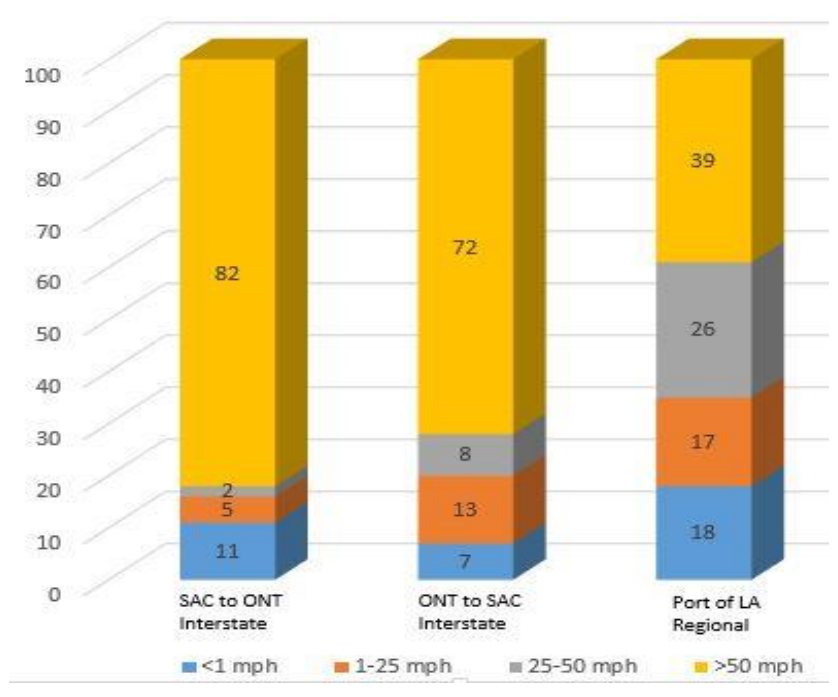

Figure 20 - Trip summary of vehicle-2 training data set 


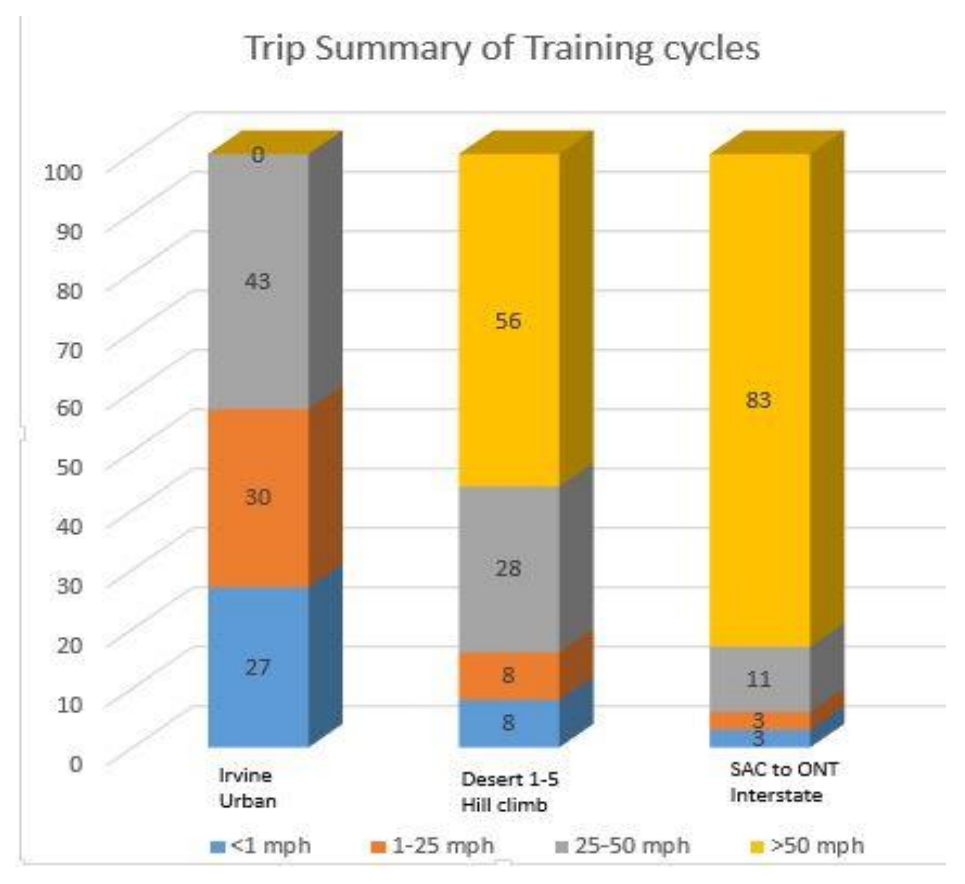

Figure 21 - Trip summary of vehicle-3 training data set

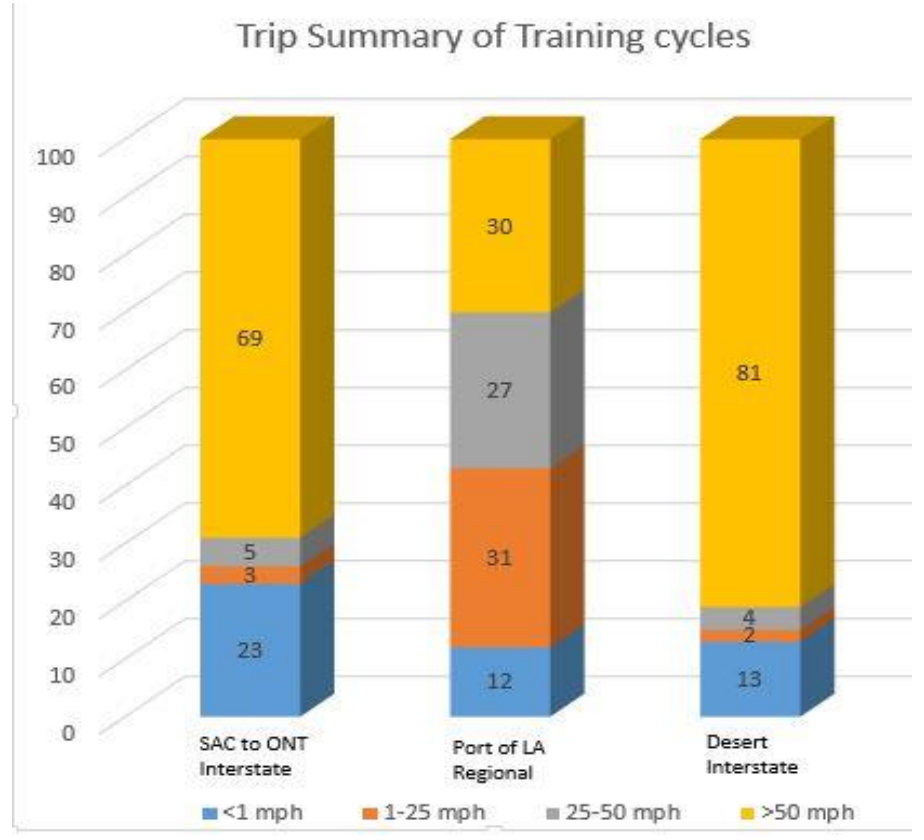

Figure 22 - Trip summary of vehicle-4 training data set 


\subsection{Routes Used for Validating the Developed Methodologies:}

Since, there is huge amount of data available from all the vehicles. The test routes were categorized into four major arbitrary categories i.e. Idle, Rural, Urban and Freeway, based on the speed breakdown i.e. $<1 \mathrm{mph}, 1-25 \mathrm{mph}, 25-50 \mathrm{mph}$ and $>50 \mathrm{mph}$, which facilitated the comparison of various engines models based on similar in-use operational conditions. Based on length of operation of vehicle in each range the tests were further grouped into four categories i.e. Regional, Highway, port: Local and Interstate. The validation routes for each vehicle were selected based on the length of operation of vehicle in any particular speed breakdown mode.

Trip Summary of Validation cycles

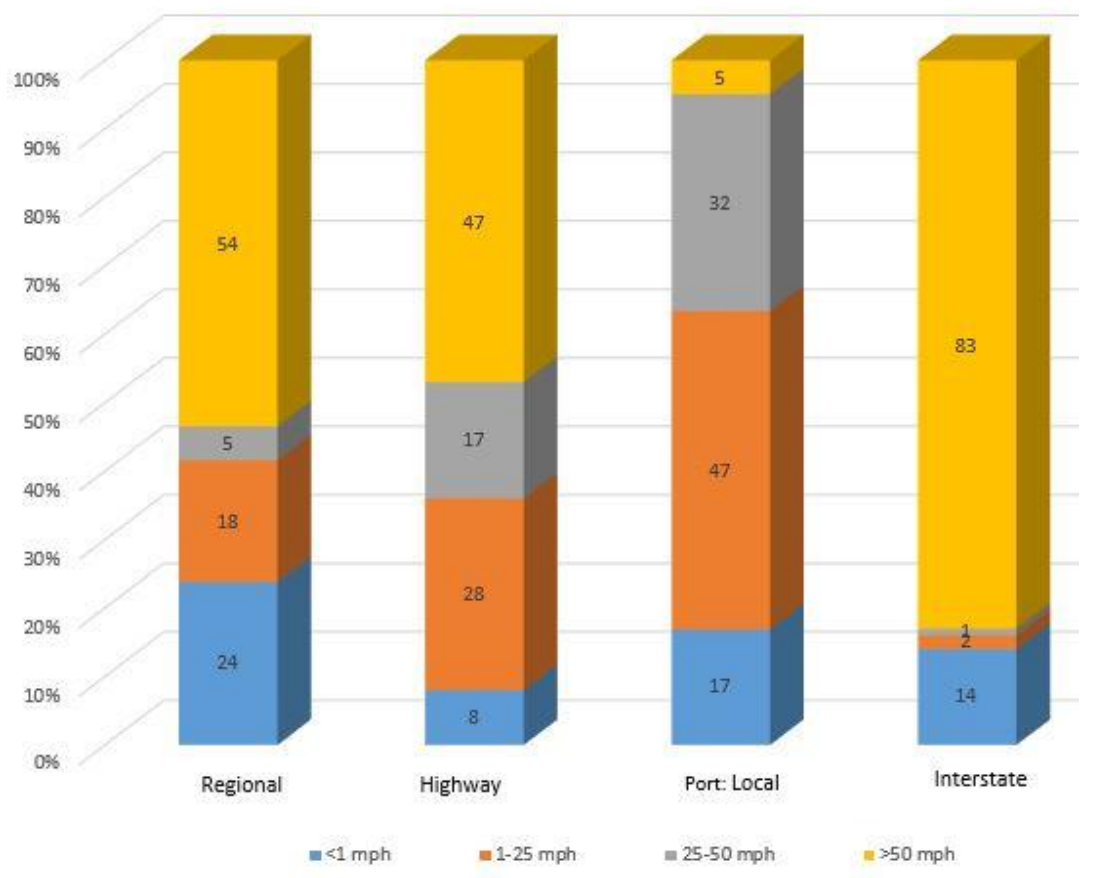

Figure 23 - Vehicle-1; Validation routes 
Trip Summary of Validation cycles

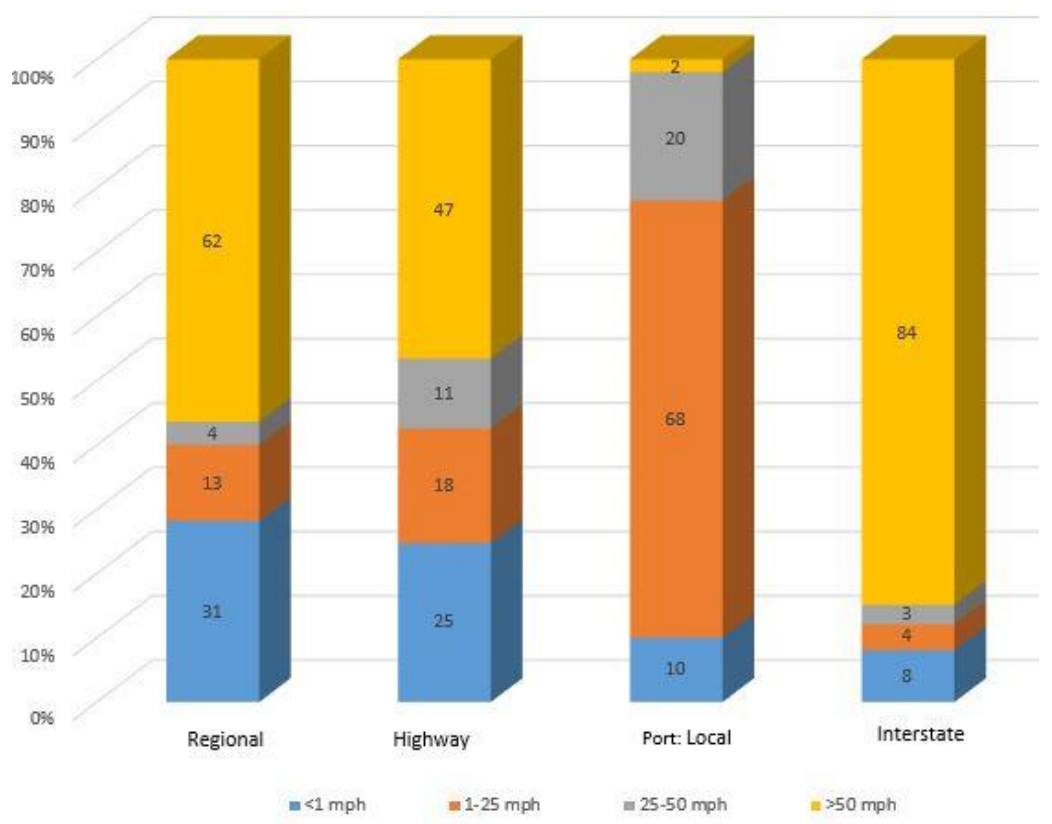

Figure 24 -Vehicle-2; Validation routes

Trip Summary of Validation cycles

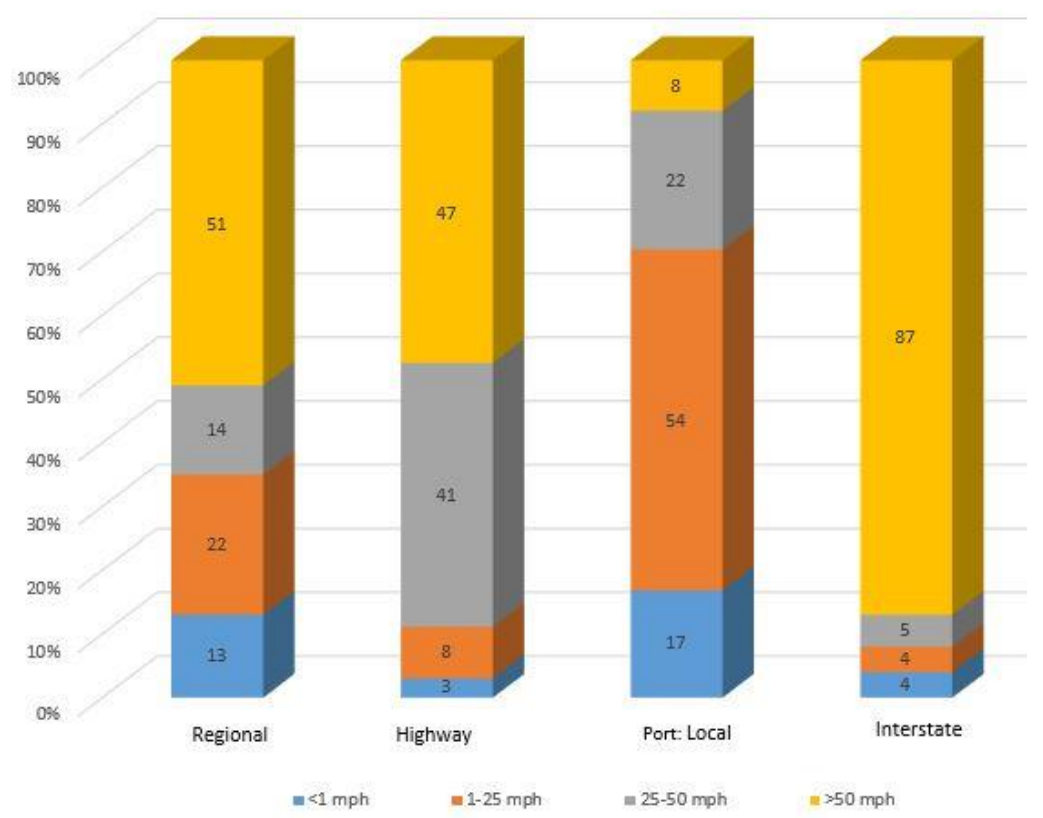

Figure 25 - Vehicle-3; Validation routes 


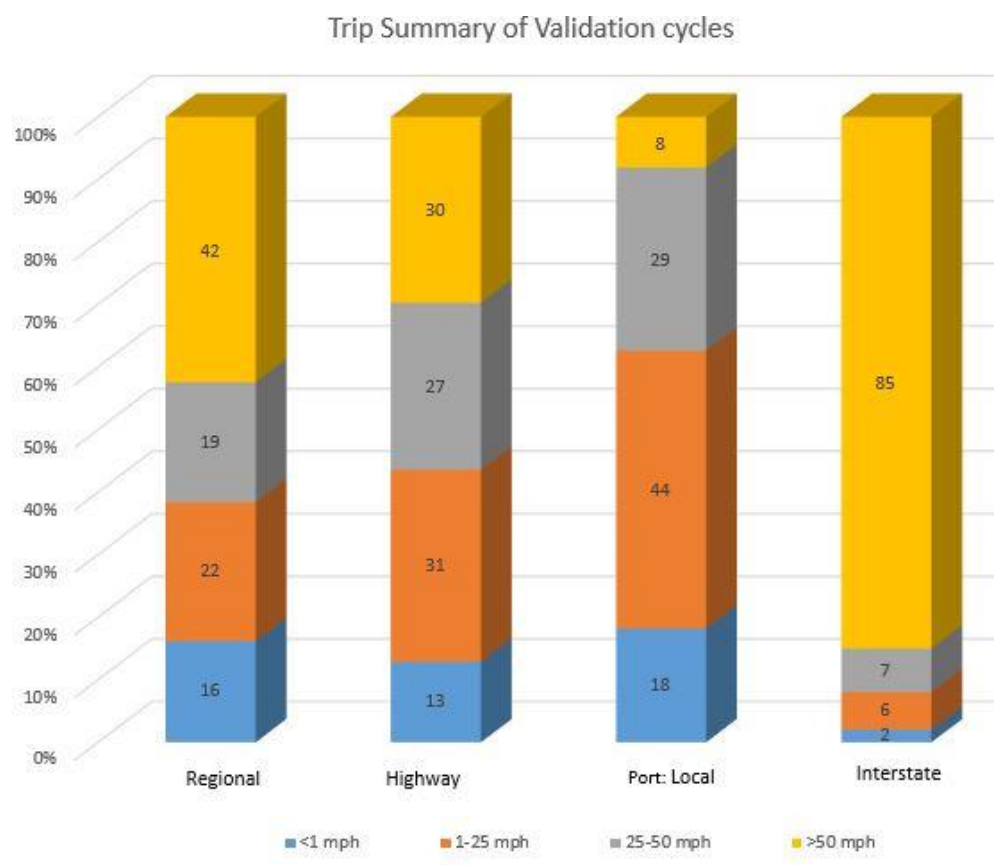

Figure 26 - Vehicle-4; Validation routes

The Validation of all the developed methods was limited to a few vehicles, because of some manufacturers' choice to not publish necessary channels which are desired to estimate the flow. The table below represents the vehicle and the corresponding methodologies used on that particular vehicle.

Table 3-4 - Information on application of validation methodologies

\begin{tabular}{|c|c|c|c|c|}
\hline & Speed density $-1 \mathrm{a}$ & Speed density $-1 \mathrm{~b}$ & ANN & DPF DP method \\
\hline Vehicle-1 & $\checkmark$ & $\checkmark$ & $\checkmark$ & $\checkmark$ \\
\hline Vehicle-2 & $\checkmark$ & $\checkmark$ & $\checkmark$ & $\checkmark$ \\
\hline Vehicle-3 & $\checkmark$ & $\checkmark$ & & $\mathrm{X}$ \\
\hline Vehicle-4 & $\checkmark$ & $\checkmark$ & $\checkmark$ & $\checkmark$ \\
\hline
\end{tabular}




\section{Results and Discussions}

In this section, firstly the correction coefficients that were obtained during the speed-density method are presented and then the regression plots of different routes, followed by Q-Q plots and run plots that were obtained when each methodology was applied are presented. The sequence starts with the speed-density method -1 a, followed by the speed -density method $-1 b$, then artificial neural network results, and finally with the DPF-DP method if available.

The use of regression plots were chosen because of their capability to aid in detecting outliers, unusual observations and influential criteria along with validating normality, linearity and equality of variances. The regression plots here serve to give a clear understanding and to identify the differences between estimated flow rate and the Semtech instrument measured flow rate values.

Secondly, Q-Q plots are presented. The Q-Q plots are used to compare the shapes of distribution; providing a graphical view of the properties such as location, scale and skewness, and how similar or different the quantiles are in the two distributions. The Q-Q plot help to graphically assess the strength of fit, rather than comparing them by numerical means or by comparing histograms of two samples.

The Q-Q plots are followed by line plots (or) run plots which provide a graphical representation and aids in the representation of trends in data over an interval of time, and in which the exhaust flow values estimated by different methods can be plotted together and compared to check the alignment of peaks across the test range which helps in further understanding the trends.

Finally, numerical results are then presented including the errors values and regression values, along with the values of estimated flow rate and Semtech measured flow rate values for all the vehicles tested.

The exhaust flow rate values in the entire report are in $\mathrm{kg} / \mathrm{min}$. 


\subsection{Vehicle 3:}

\subsubsection{Correction Coefficients of Vehicle-3 speed density method - 1 a}

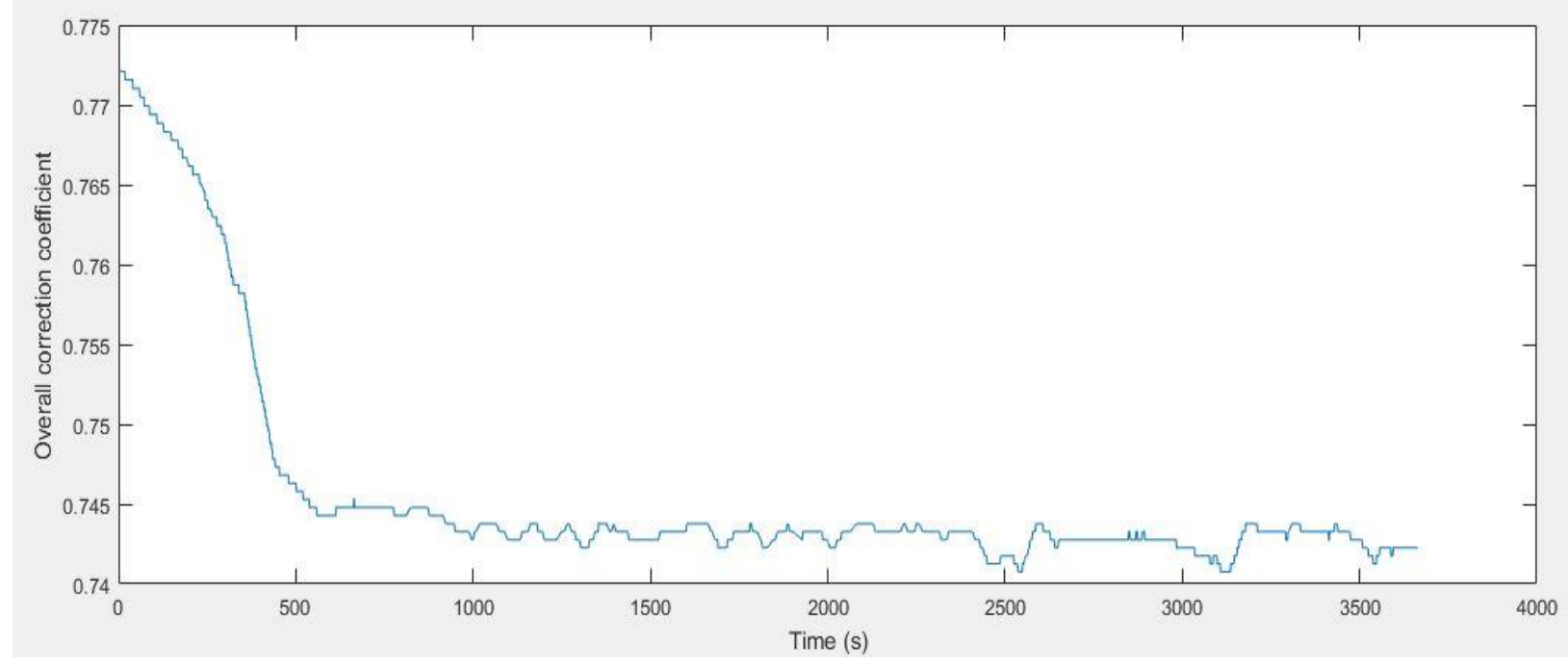

Figure 27 - Correction Coefficients of Regional Route of Vehicle-3

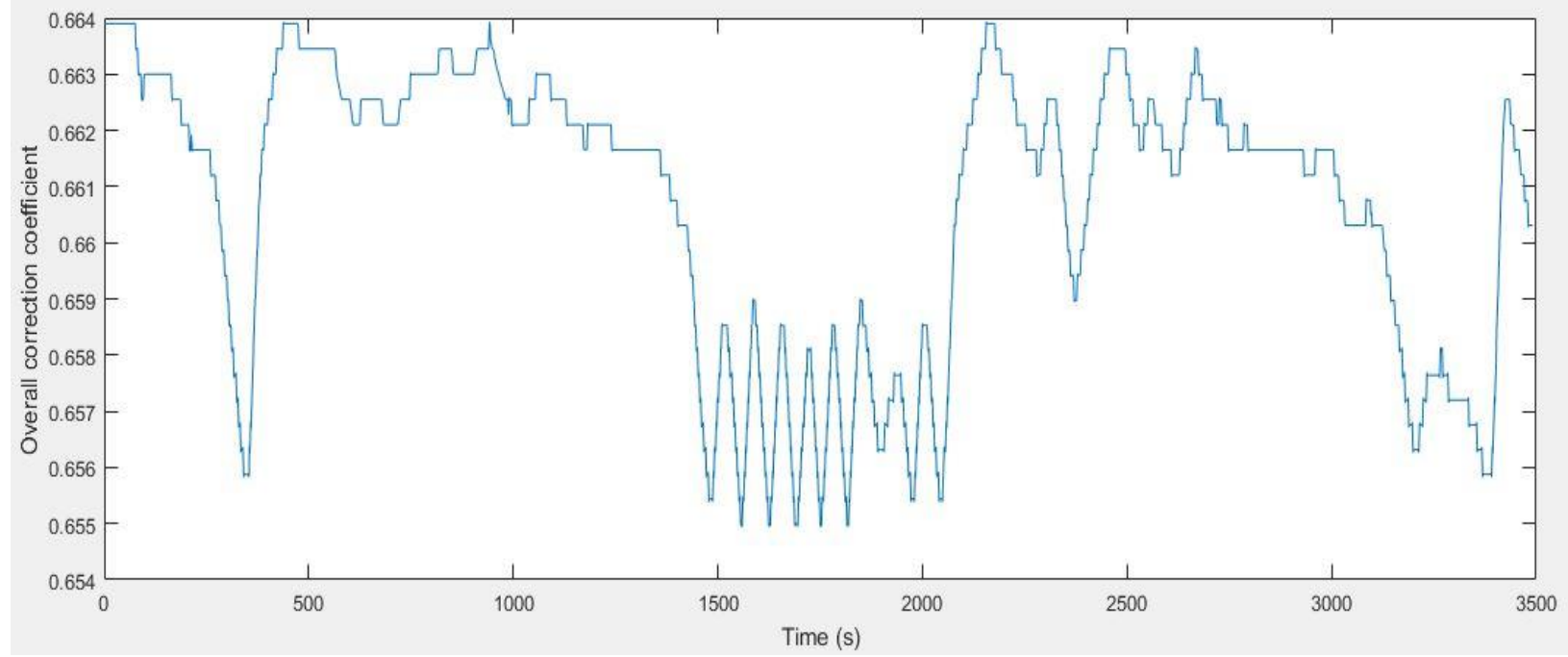

Figure 28-Correction Coefficients of Highway Route of Vehicle-3 


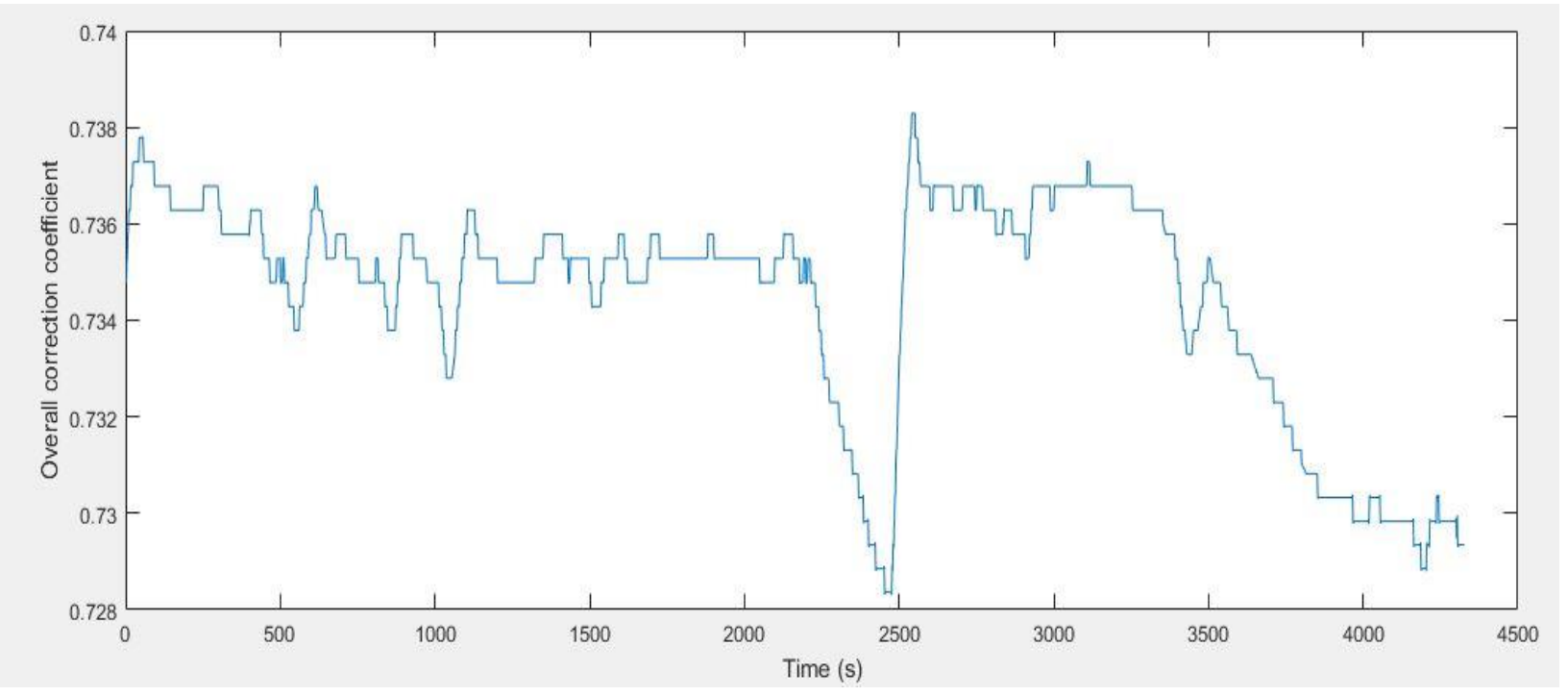

Figure 29 - Correction Coefficients of Port: Local Route of Vehicle-3

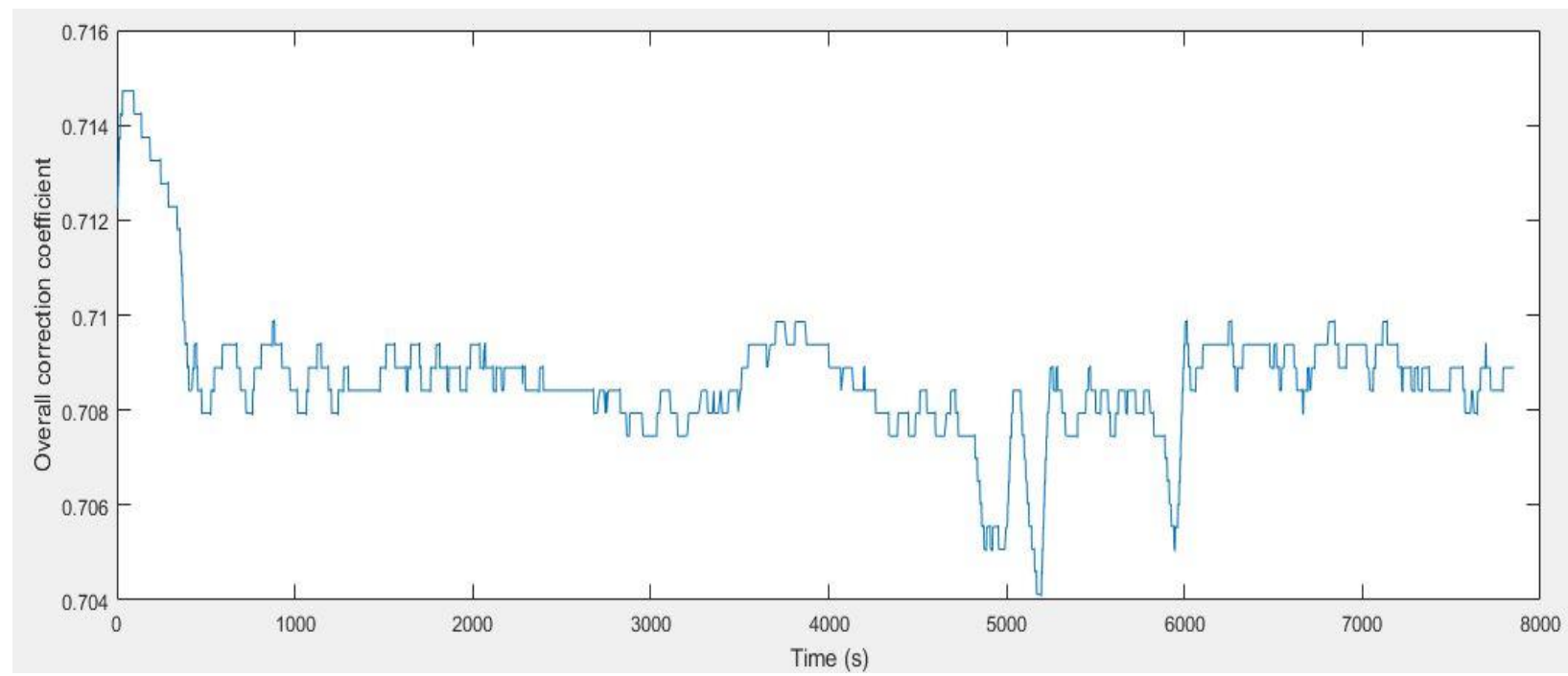

Figure 30- Correction Coefficients of Interstate Route of Vehicle-3

Figure 277-30 shows the overall correction coefficients obtained for different individual routes. The range of correction coefficients along different routes appears to differ and for any given length of the test, they appear not to vary by any more than 0.03 . 


\subsubsection{Regression Plots of Vehicle-3 speed density method - 1 a:}

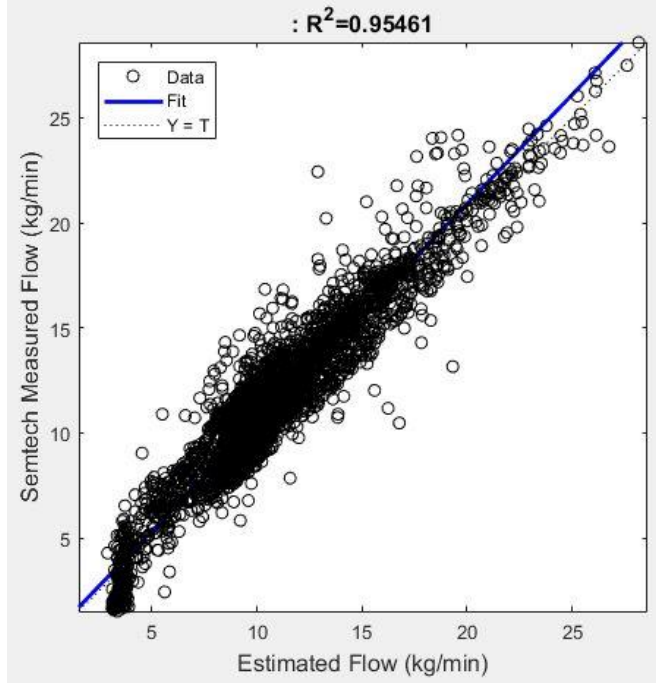

Figure 31 - Regional Route

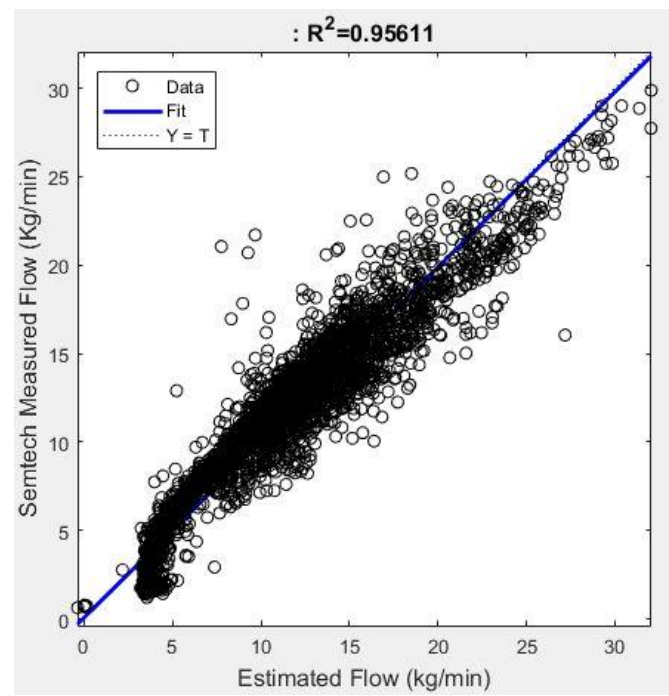

Figure 33 - Port: Local Route

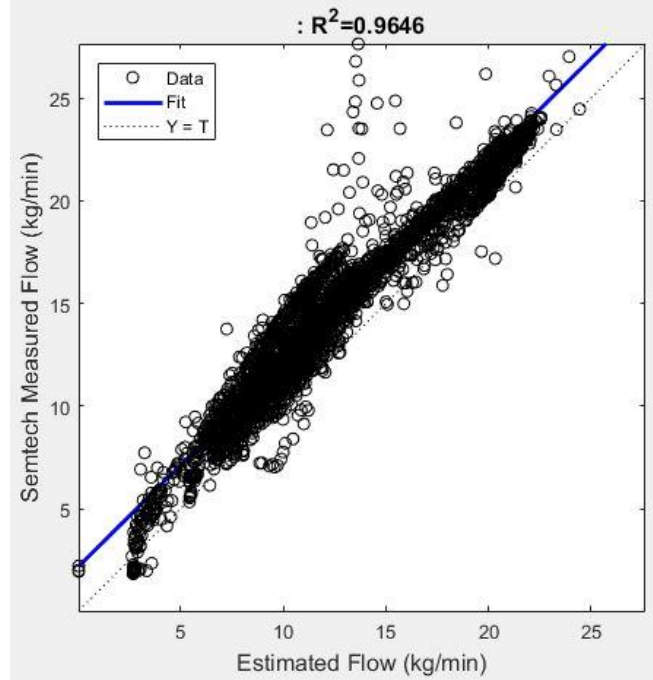

Figure 32 - Highway Route

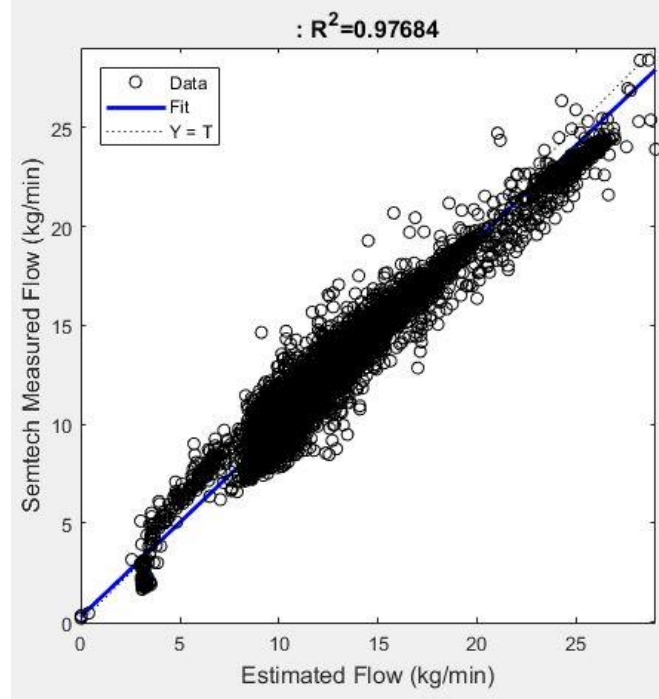

Figure 34 - Interstate Route

The above regression plots Figure 31 - 34, represent the correlation between speed density method-1a estimated flow rate values and the Semtech instrument measured flow rate values along different routes. The regression values and the plots obtained here imply that there is good amount of correlation between the estimated and actual flow rate values. 


\subsubsection{Quartile-Quartile Plots Vehicle-3 speed density method - 1 a:}

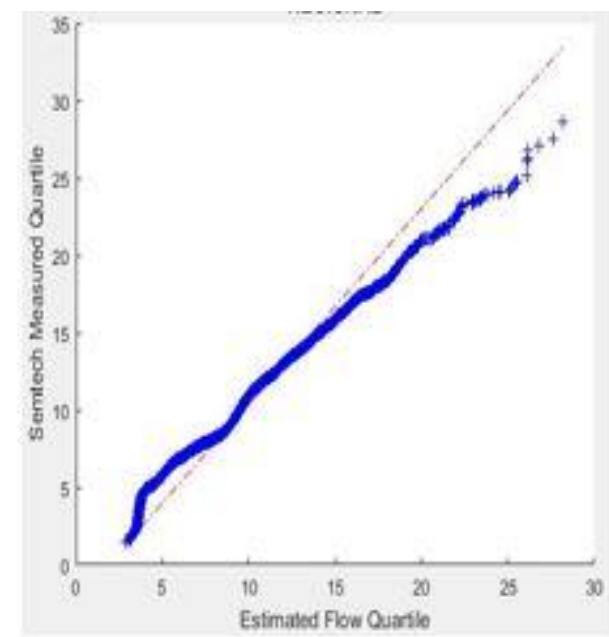

Figure 35 - Regional Route

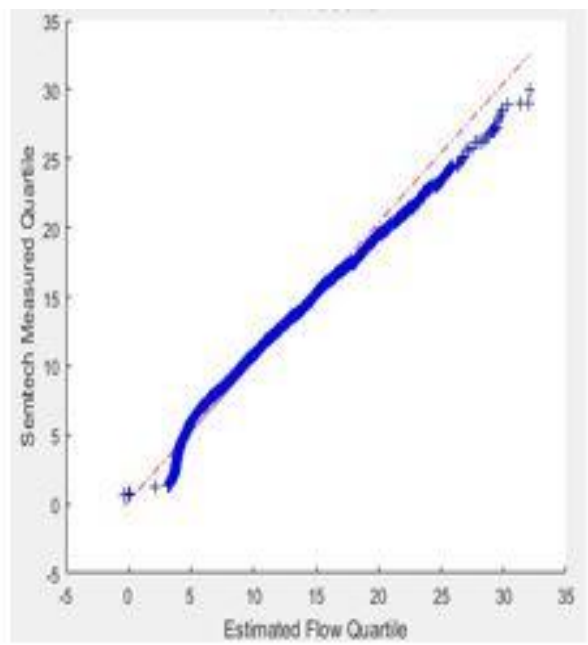

Figure 37 - port: Local Route

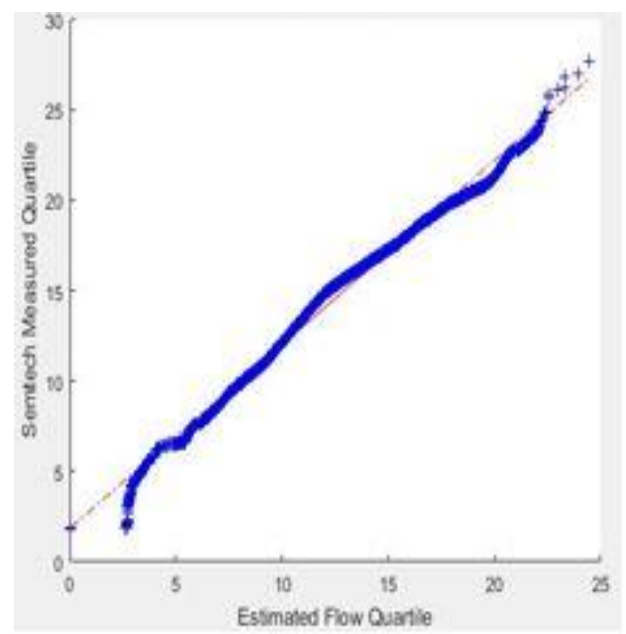

Figure 36 - Highway Route

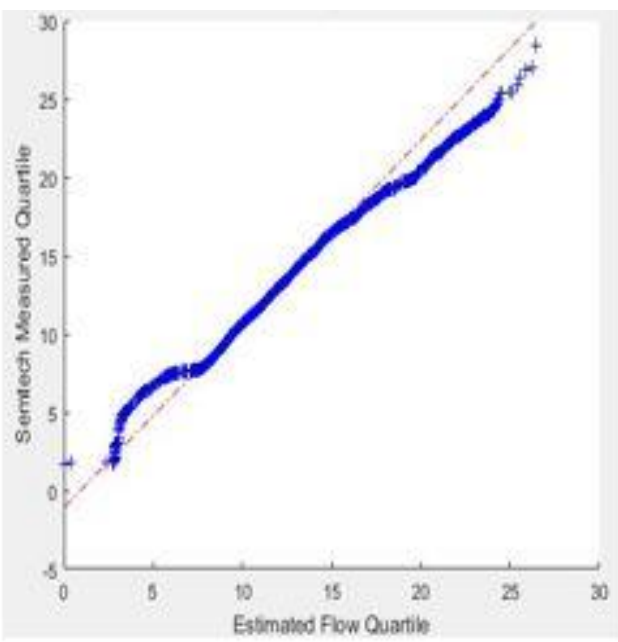

Figure 38 - Interstate Route

The above Q-Q plots Figure 35 - 38, represent the similarity between the two quantiles. Based on the linear alignment of points along the center line, it can be inferred from the generated plots that the two quantiles along different routes have similar normal distribution. 


\subsubsection{Line chart of Vehicle-3 speed density method - 1 a:}

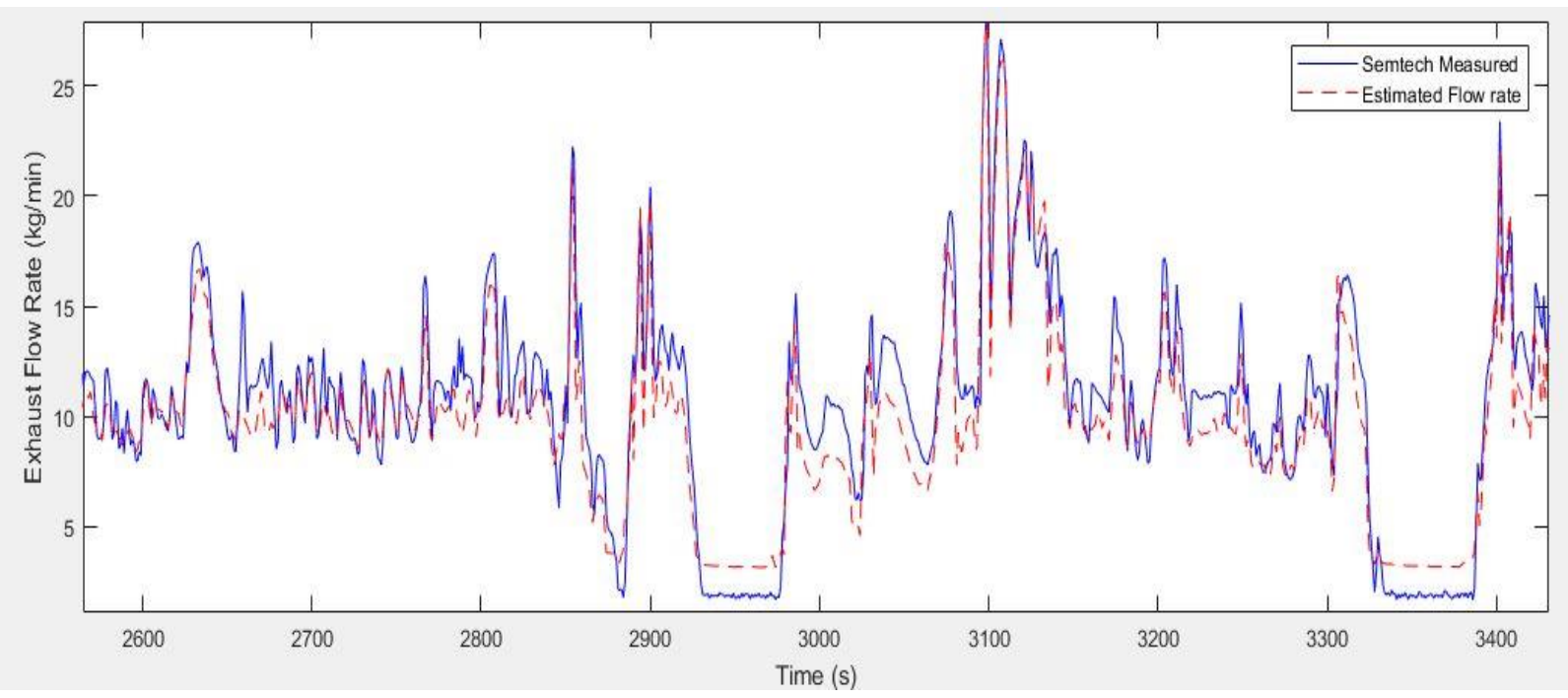

Figure 39 - Regional Route of Vehicle-3 speed density method - 1 a

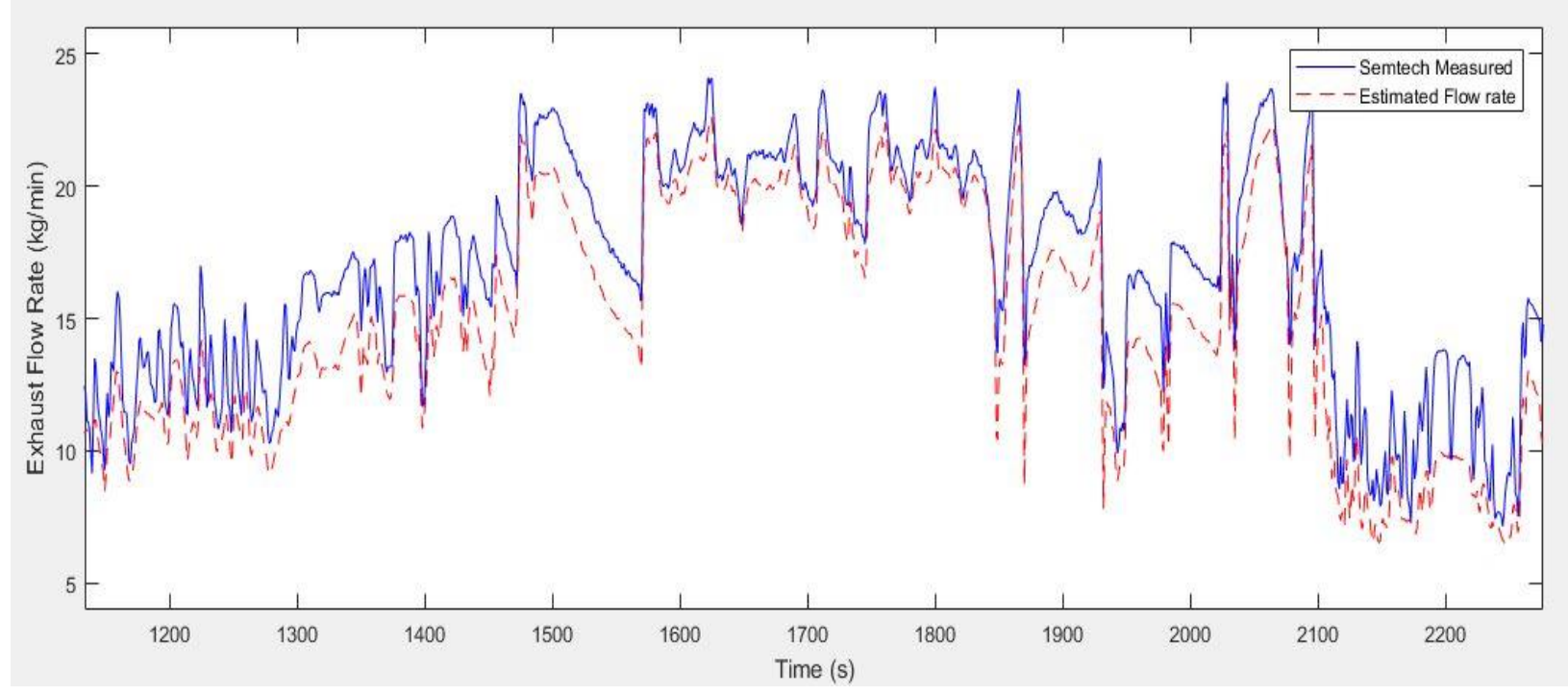

Figure 40 - Highway Route of Vehicle-3 speed density method - 1 a 


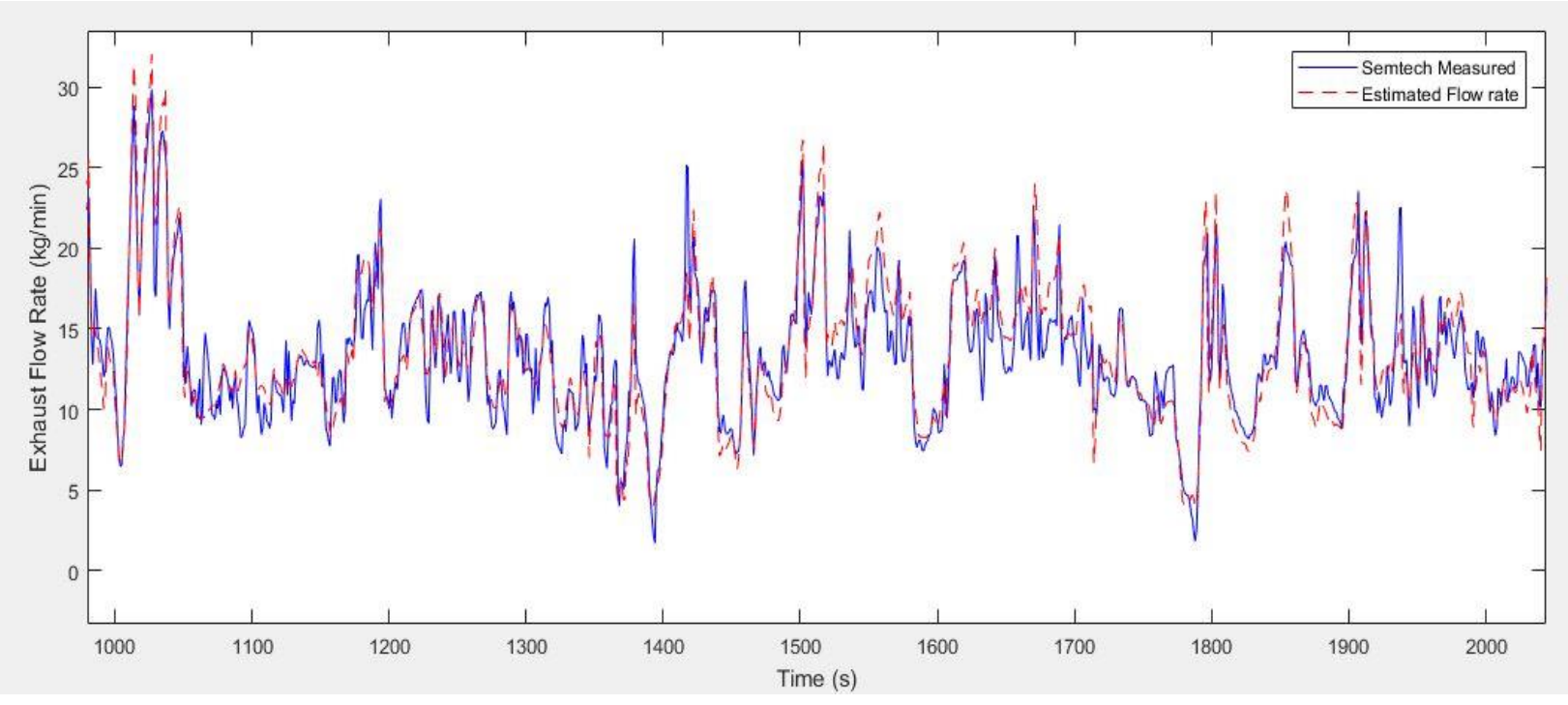

Figure 41 - Port: Local Route of Vehicle-3 speed density method - 1 a

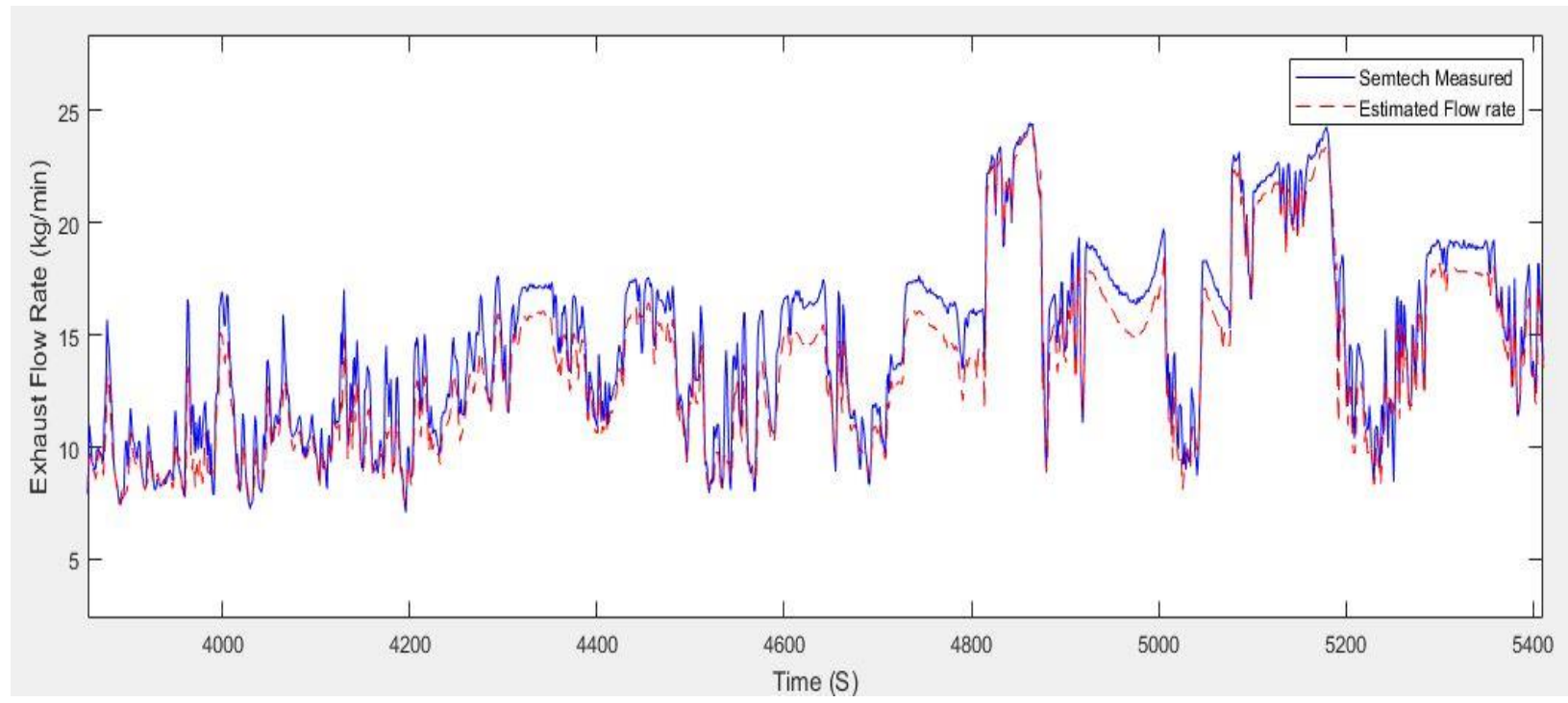

Figure 42 - Interstate Route of Vehicle-3 speed density method - 1 a

Figure $3939-42$, represent the run plots along different routes. It can be observed that the speed-density method-1a can estimate the values as accurately and effectively as the Semtech method, and based on the correction factors of each test, the values are either under predicted or over predicted across entire length of test, which can be clearly noticed in the above run plots. 


\subsubsection{Regression Plots of Vehicle-3 speed density method - 1 b:}

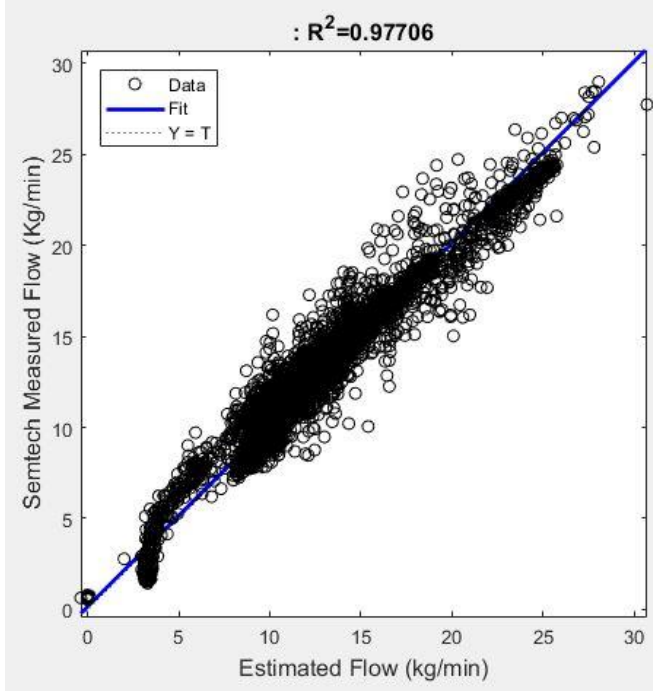

Figure 43 - Regional Route

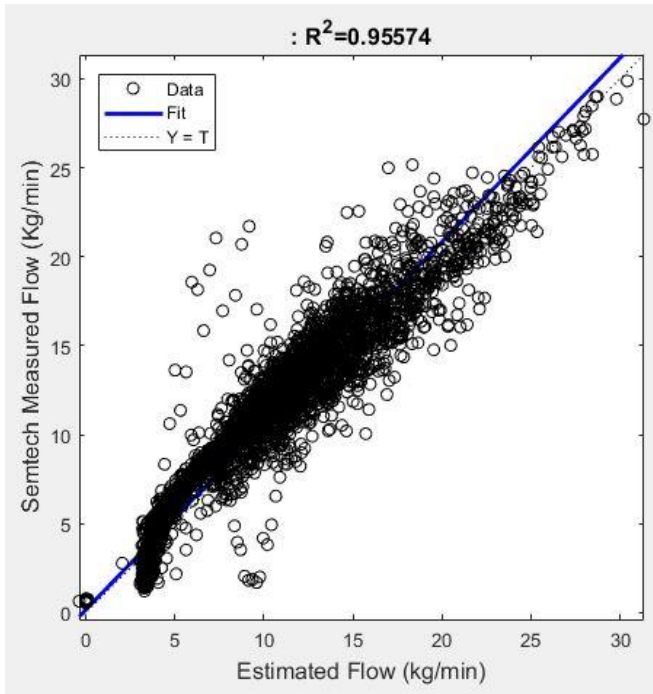

Figure 45 - Port: Local Route

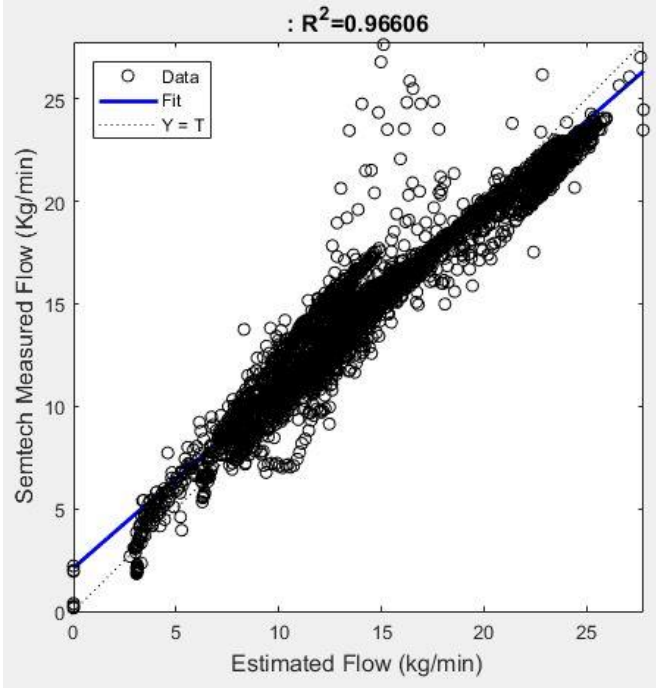

Figure 44 - Highway Route

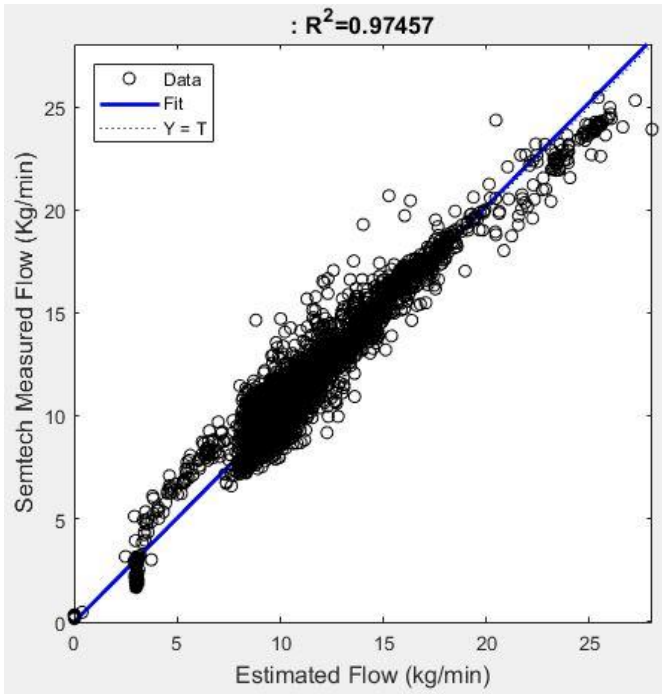

Figure 46- Interstate Route

The above regression plots Figure 4743 - 46, represent the correlation between speed density method-1b estimated flow rate values and the Semtech instrument measured flow rate values along different routes. The regression values and the plots obtained imply that the correlation between estimated values and Semtech measured values improved when the speed density method-1b was used. 


\subsubsection{Quartile-Quartile Plots Vehicle-3 speed density method - 1 b:}

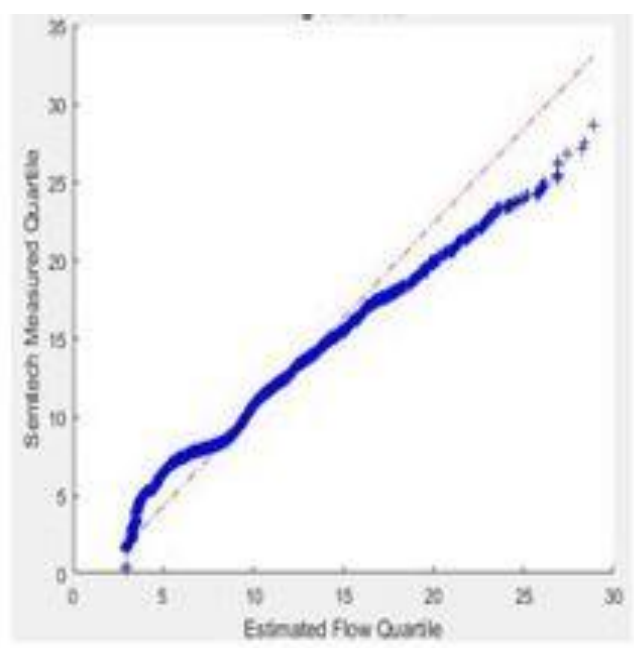

Figure 47 - Regional Route

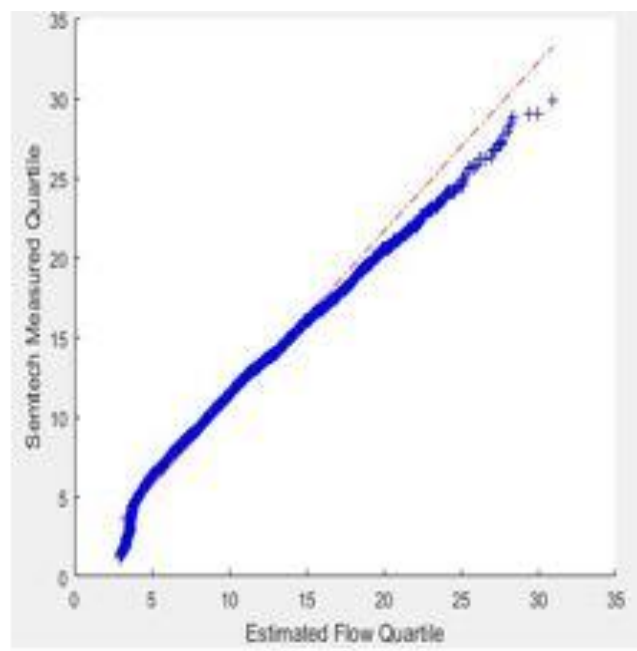

Figure 49 - port: Local Route

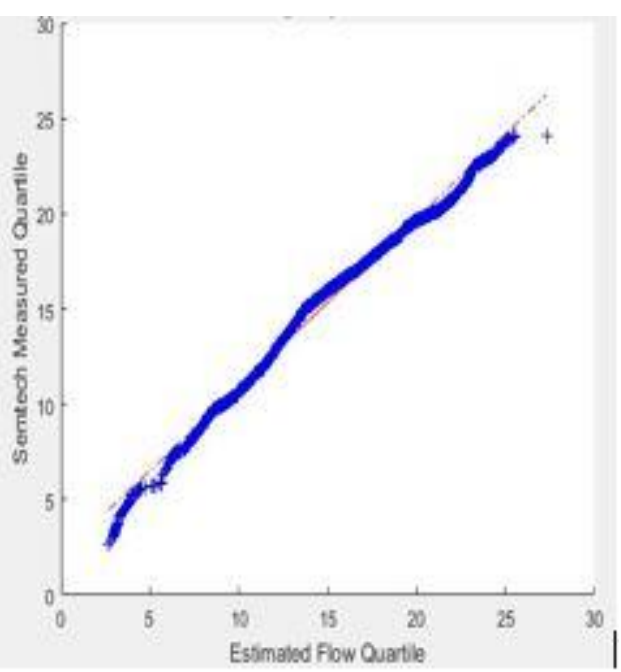

Figure 48 - Highway Route

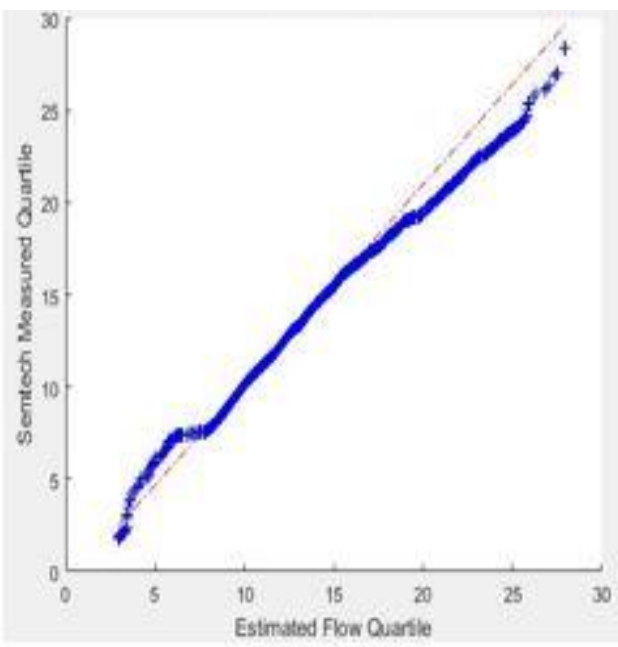

Figure 50 - Interstate Route

The above Q-Q plots Figure 47 - 50, represent the similarity between the two quantiles. Based on the linear alignment of points along the center line, it can be inferred from the generated plots that the two quantiles along different routes have similar normal distribution and the alignment of points along the center line increases by use of Speed-density method-1b. 


\subsubsection{Line chart of Vehicle-3 speed density method - 1 b:}

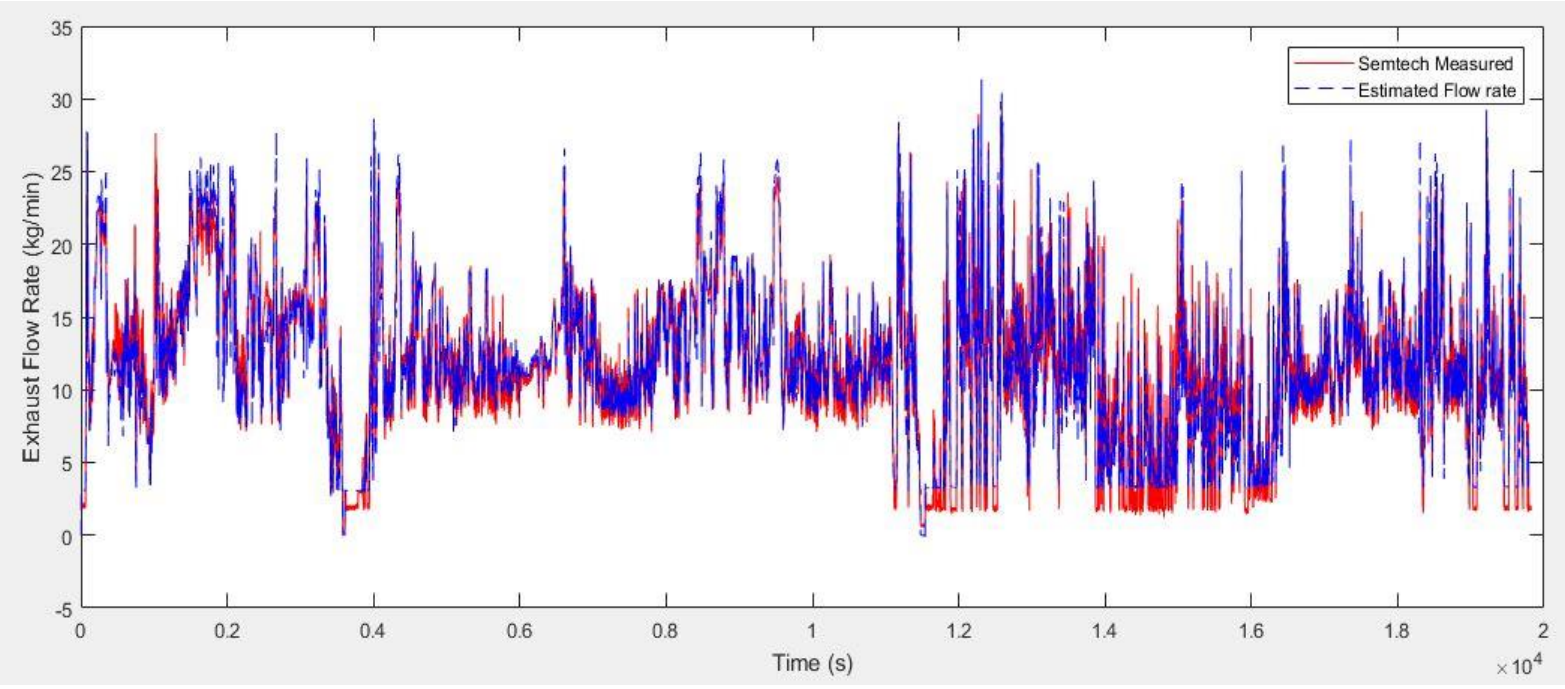

Figure 51 - Combined plot of Vehicle-3 speed density method - $1 \mathrm{~b}$

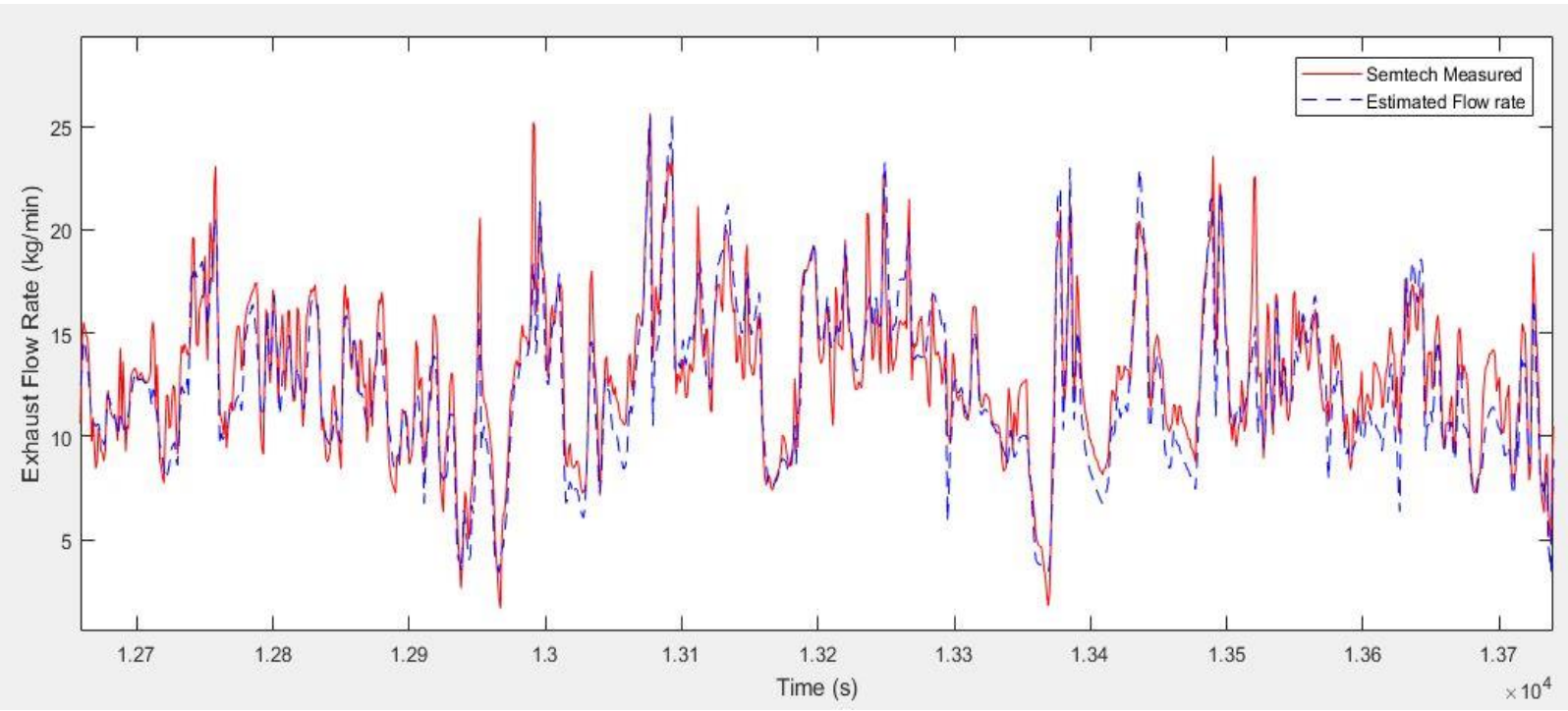

Figure 52 - Enlarged combined plot of Vehicle-3 speed density method - $1 \mathrm{~b}$

Figure 51 is the run plot of estimated values plotted along with the Semtech measured values for a combined test cycle whose data is a combination of regional, highway, Port: local and interstate routes. From Figure 52 it is evident that the estimated flow values align peak to peak with the Semtech measured values and there is almost no different between the two trends. 


\subsubsection{ANN Training Performance Results of Vehicle-3:}

Table 4-1 - Training performance of Vehicle-3 data

\begin{tabular}{|c|c|c|}
\hline Test Details & Regression (R) & Performance (P) \\
\hline Regional & 0.89958 & 0.0013081 \\
\hline Highway & 0.90129 & 0.0013444 \\
\hline Port Local & 0.89881 & 0.0013504 \\
\hline Interstate & 0.89855 & 0.0013506 \\
\hline
\end{tabular}
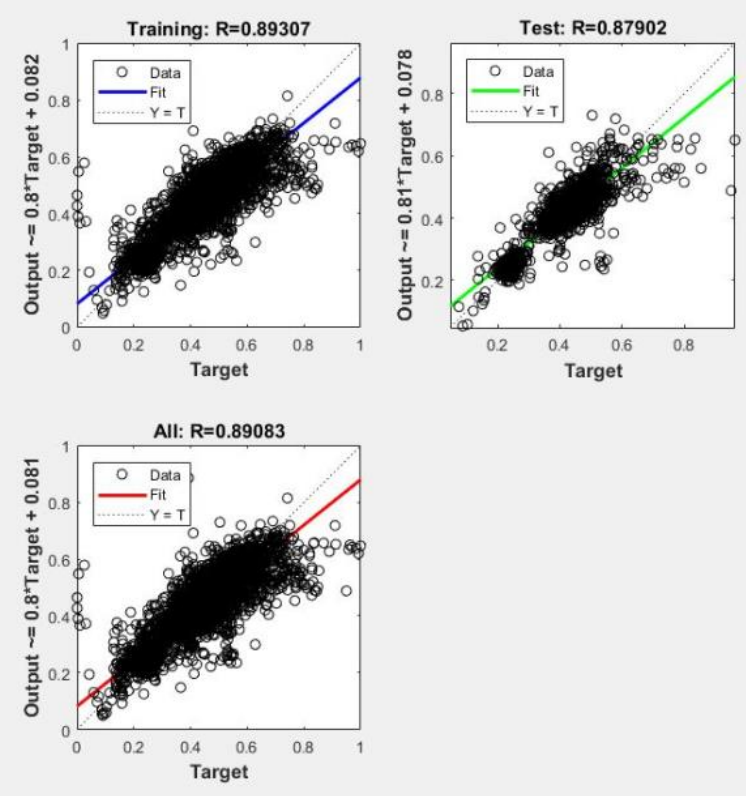

\section{Figure 53 - Training performance of Vehicle-3 data}

Table 4-1 shows the correlation and performance values attained as the ANN get trained before it starts estimating the values along each route. Figure 53 graphically represents the training phase, validation phase and overall correlation values, where the correlation is being made between the flow rate value obtained by adding input mass rate and fuel rate values and the Semtech Measured values. 


\subsubsection{Regression Plots of Vehicle-3 ANN Method:}
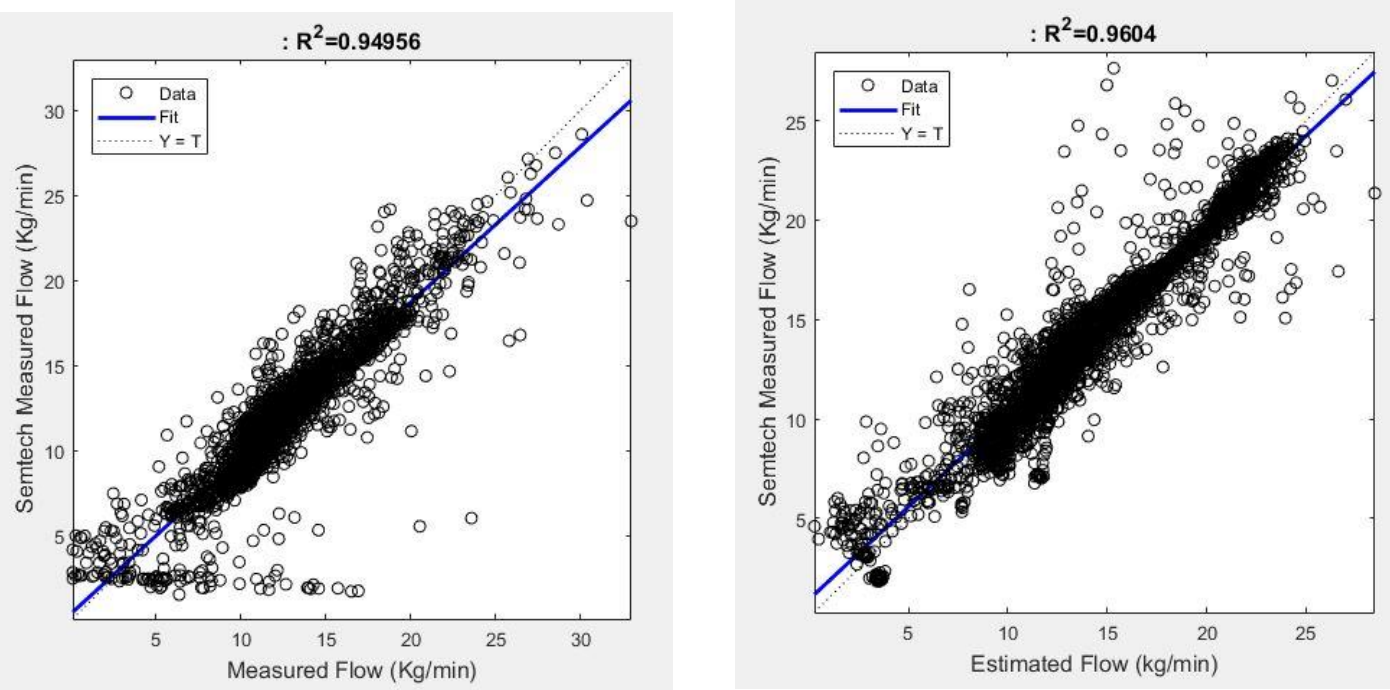

Figure 54 - Regional Route
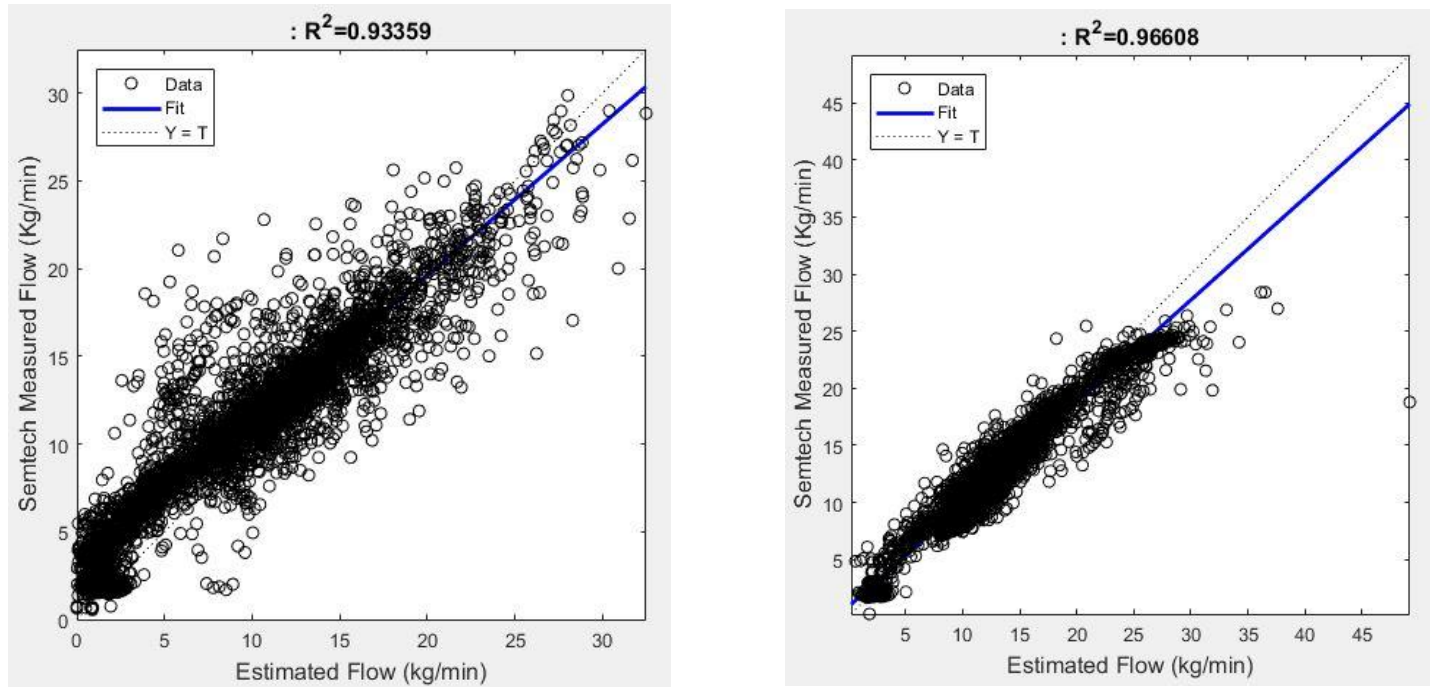

Figure 56 - Port: Local Route

Figure 57 - Interstate Route

The above regression plots Figure 54 - 57, represent the correlation between neural network estimated flow rate values and the Semtech instrument measured flow rate values along different routes. The regression values imply that the correlation between estimated values and Semtech measured Values was good, but was less correlated compared to those of the speeddensity methods. 


\subsubsection{Quartile-Quartile plots of Vehicle-3 ANN Method:}

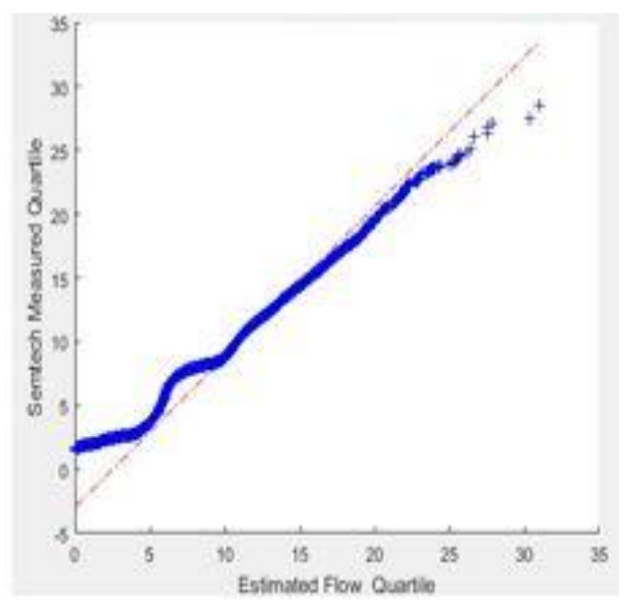

Figure 58-Regional Route

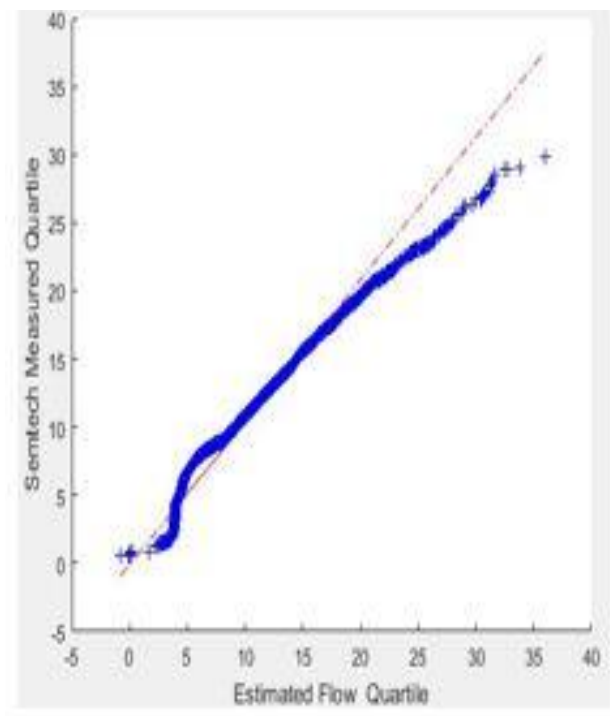

Figure 60 - Port: Local Route

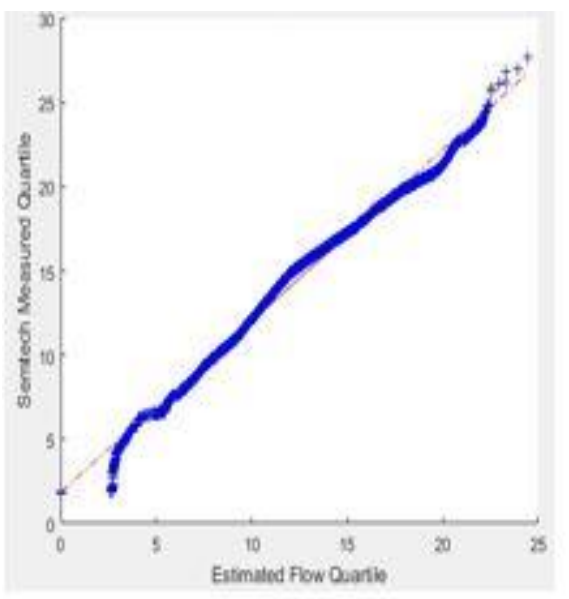

Figure 59-Highway Route

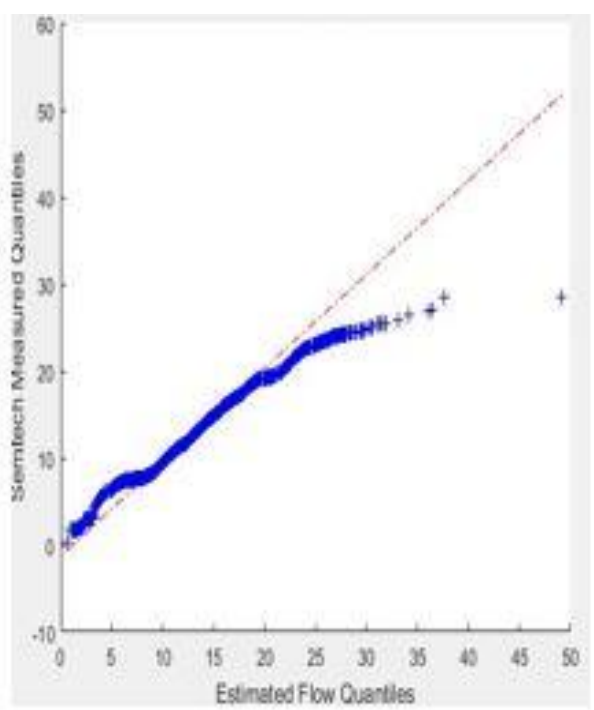

Figure 61 - Interstate Route

The above Q-Q plots Figure 58 - 61, depict the similarity between the two quantiles. The generated plots indicate that the two quantiles along different routes have similar normal distribution for most part. The Q-Q plots of ANN when compared to those of the speed-density method appear to be more spread, but in most part line up with the center line indicating the two quantiles are still in good agreement. 


\subsubsection{Line chart of Vehicle-3 ANN Method:}

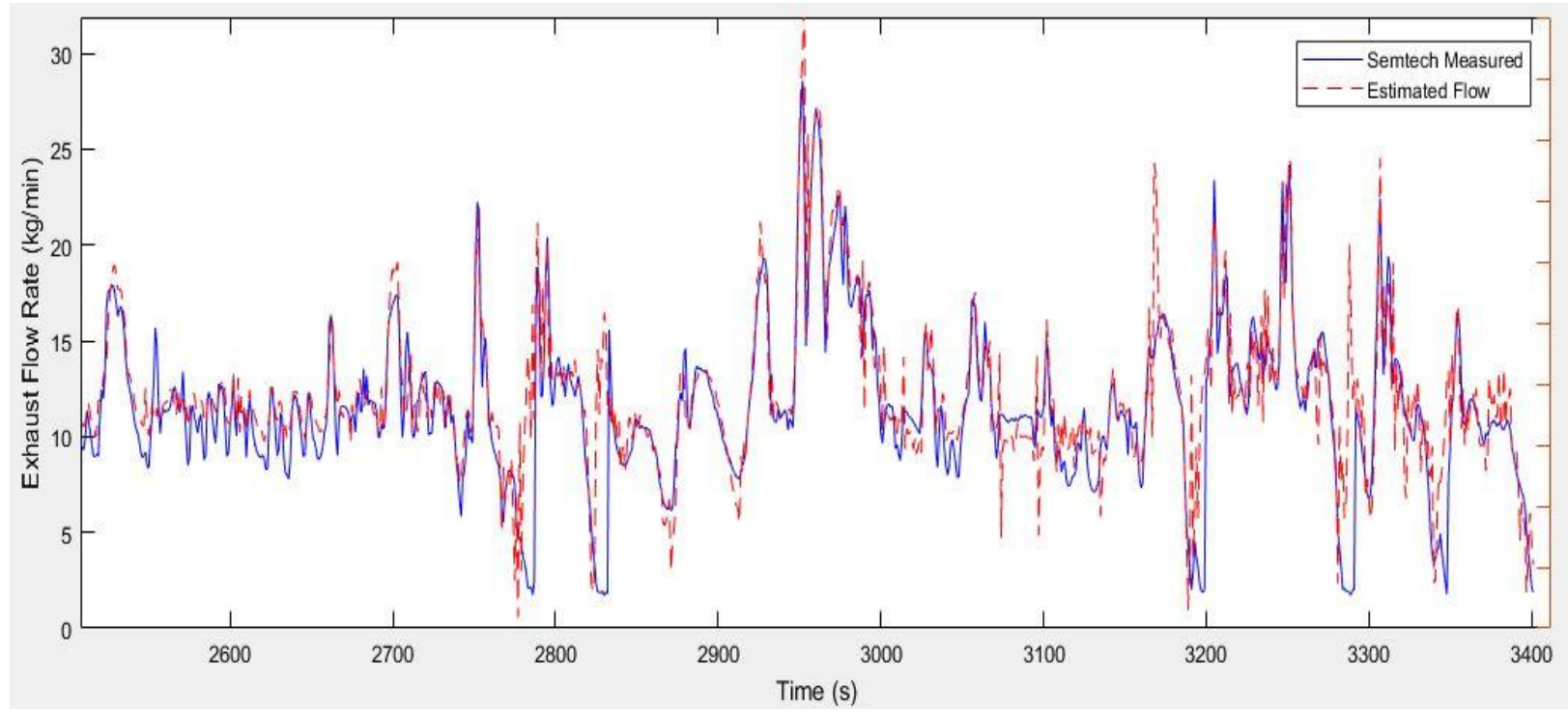

Figure 62 - Regional Route of Vehicle-3 ANN method

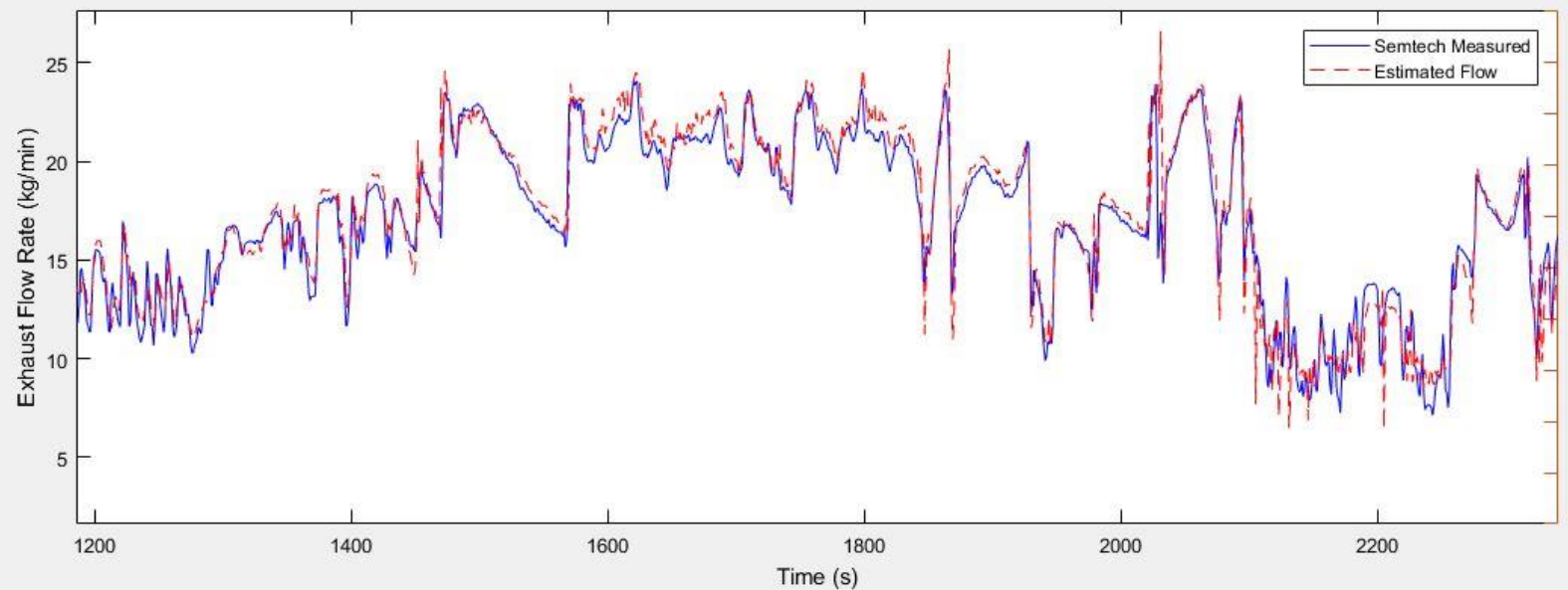

Figure 63 - Highway Route of Vehicle-3 ANN method 


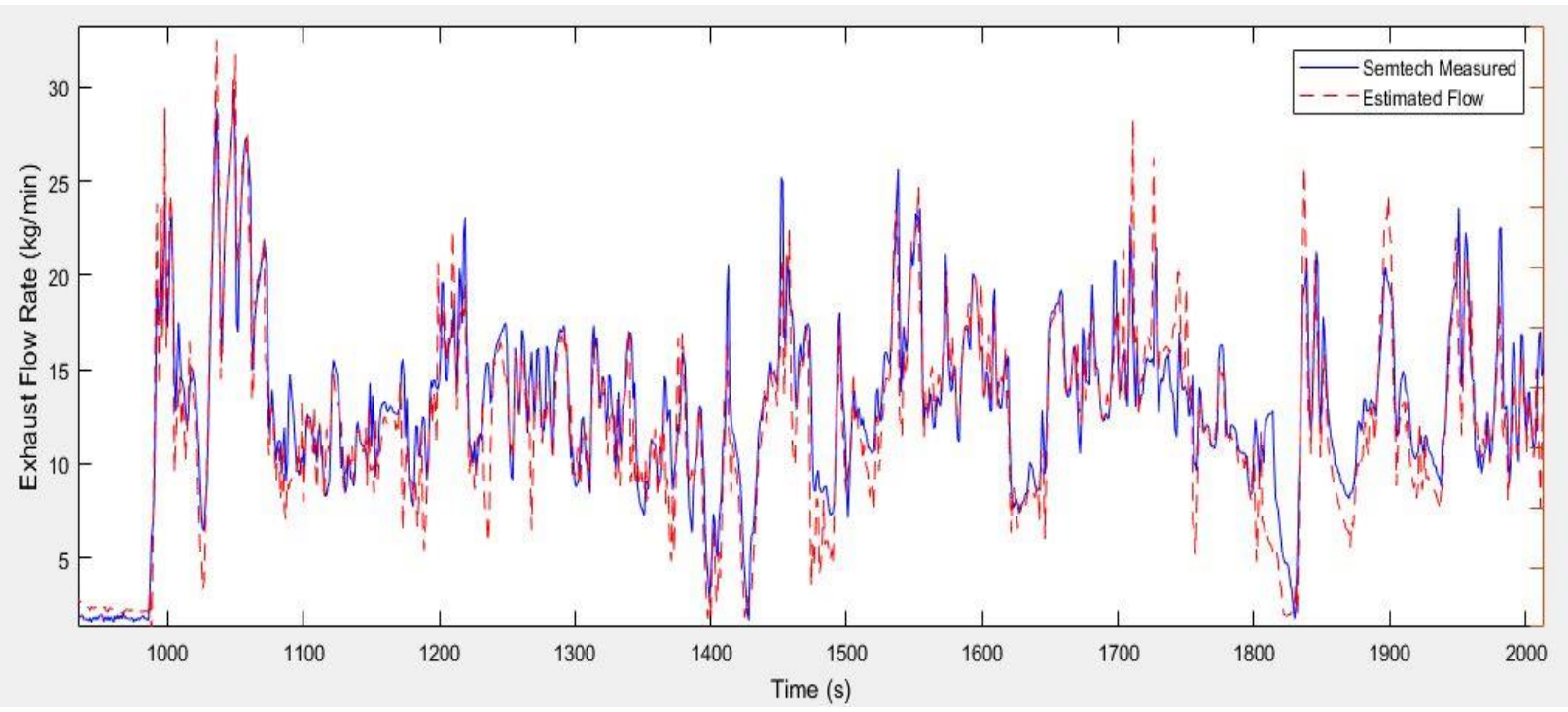

Figure 64 - Port: Local Route of Vehicle-3 ANN method

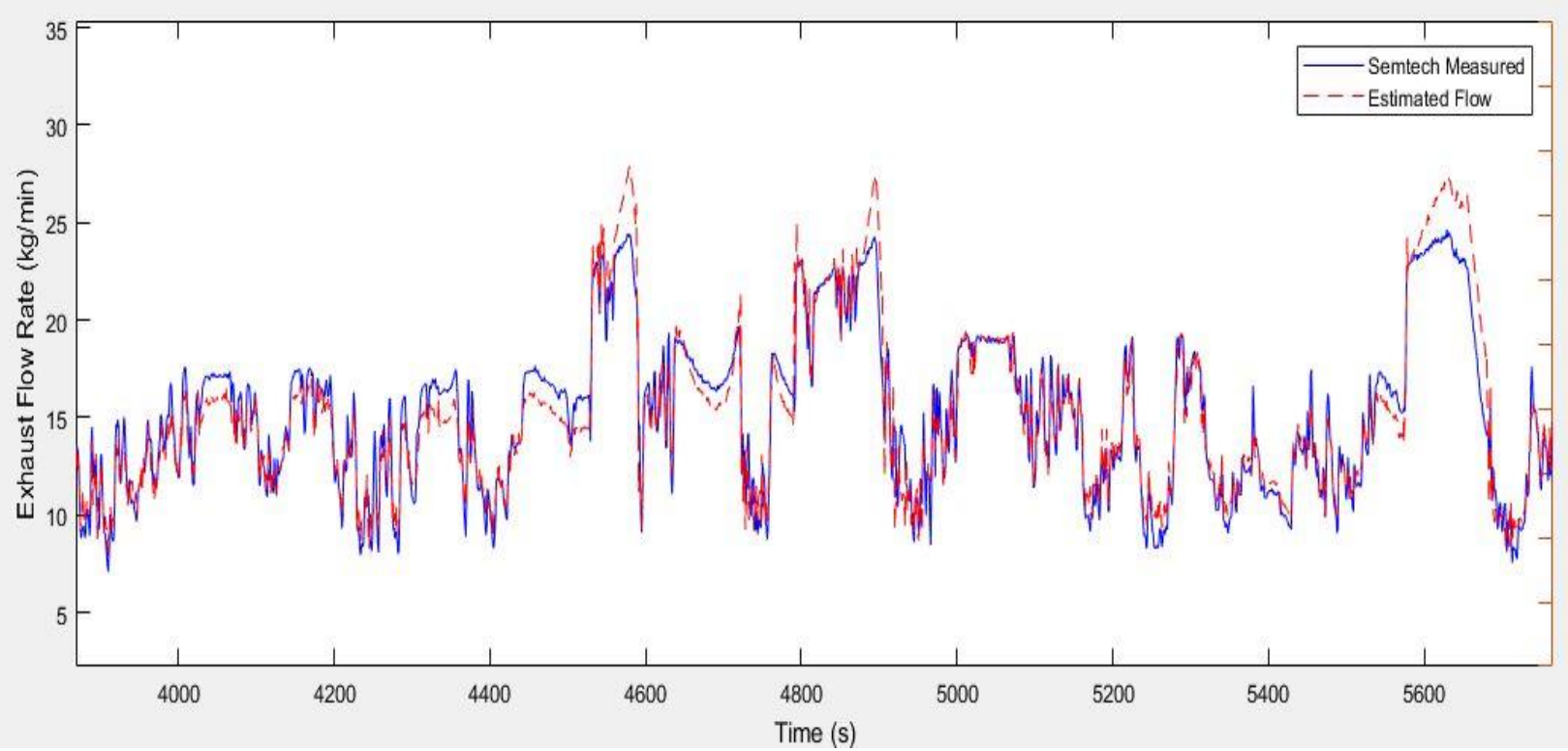

Figure 65 - Interstate Route of Vehicle-3 ANN method

Figure $3962-65$, represent the run plots of different routes. It can be seen that the ANN estimate were close to those of Semtech measured values, and that the values are under-estimated and over-estimated over different sections which is a totally different phenomenon, and which was not observed in either of the speed density methods. 


\subsubsection{Regression plots of Vehicle-3 DPF-DP Method:}

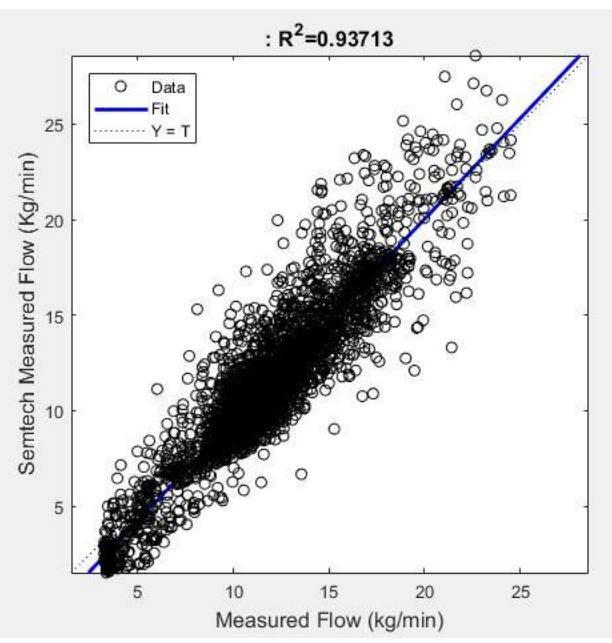

Figure 66-Regional Route

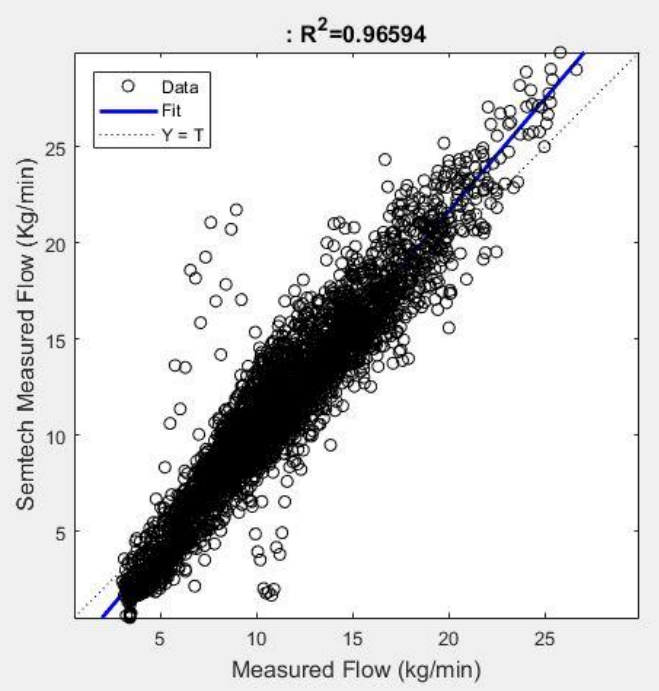

Figure 68 - Port: Local Route

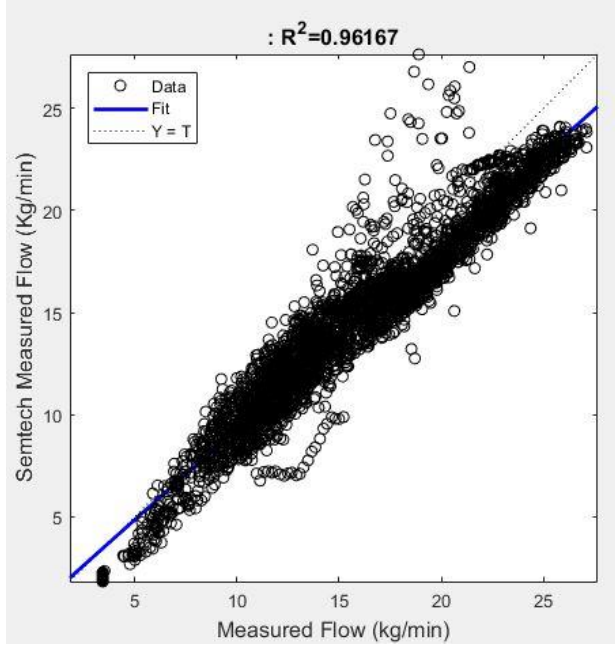

Figure 67 - Highway Route

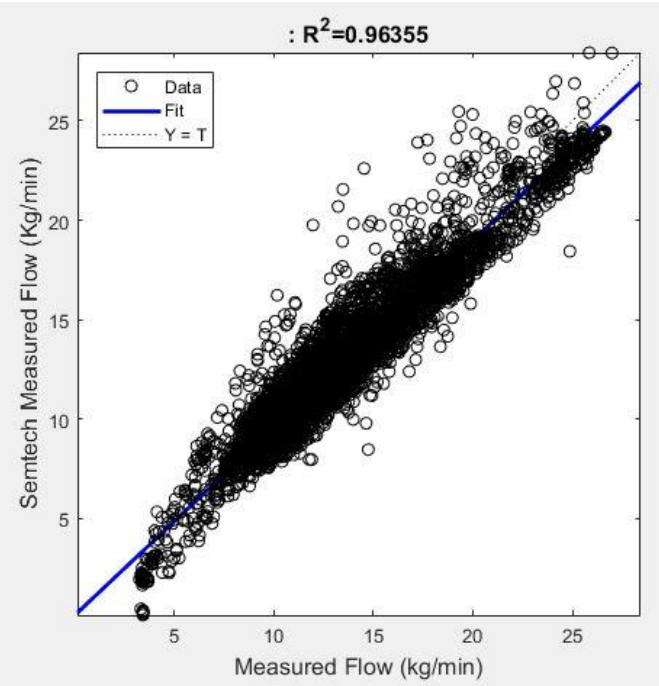

Figure 69 - Interstate Route

The above regression Figure 66 - 69, plots represent the correlation between the estimated

flow rate values obtained using the DPF-DP methodology and the Semtech instrument measured flow rate values along different routes. The regression value trend completely changed when compared to previous methodologies. Here the correlation value increased for those routes which had lesser value in other methods and decreased for routes which had good correlation in other methods. 


\subsubsection{Quartile-Quartile plots of Vehicle-3 DPF-DP Method:}

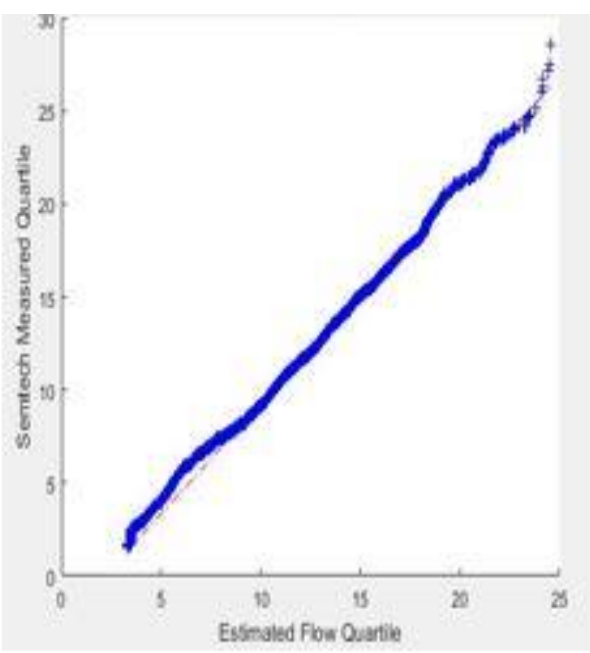

Figure 70 - Regional Route

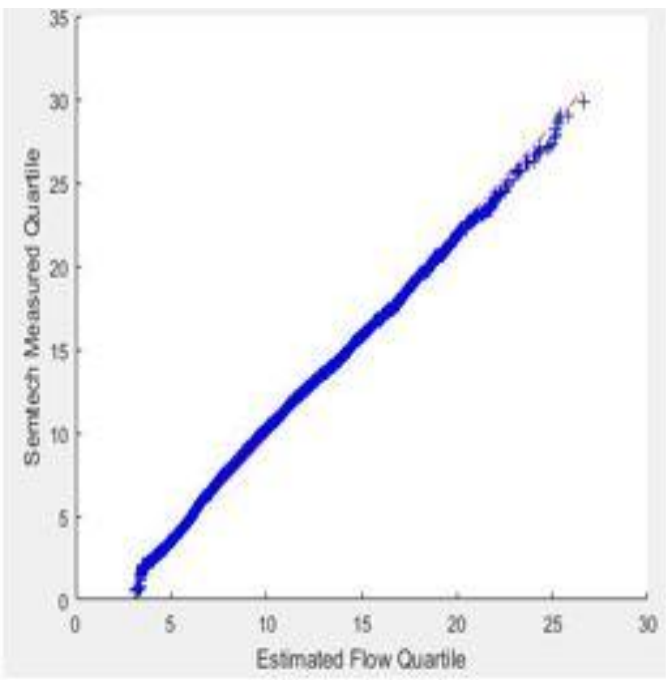

Figure 72 - Port: Local Route

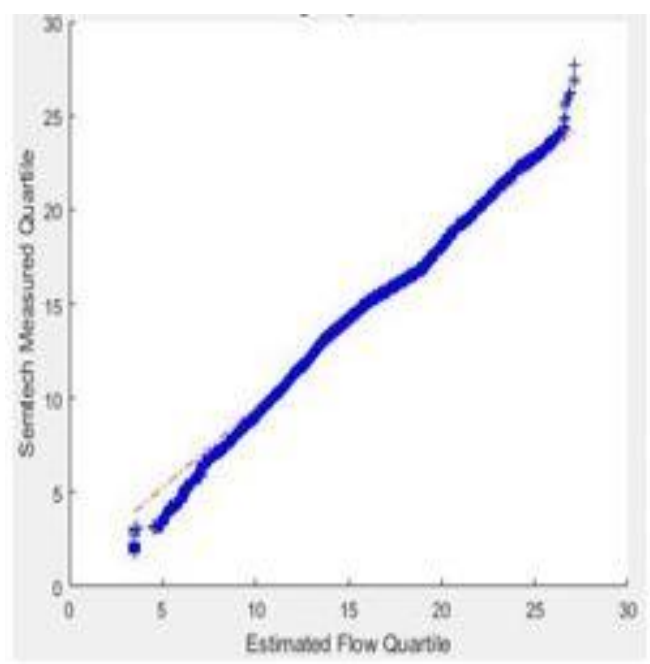

Figure 71 - Highway Route

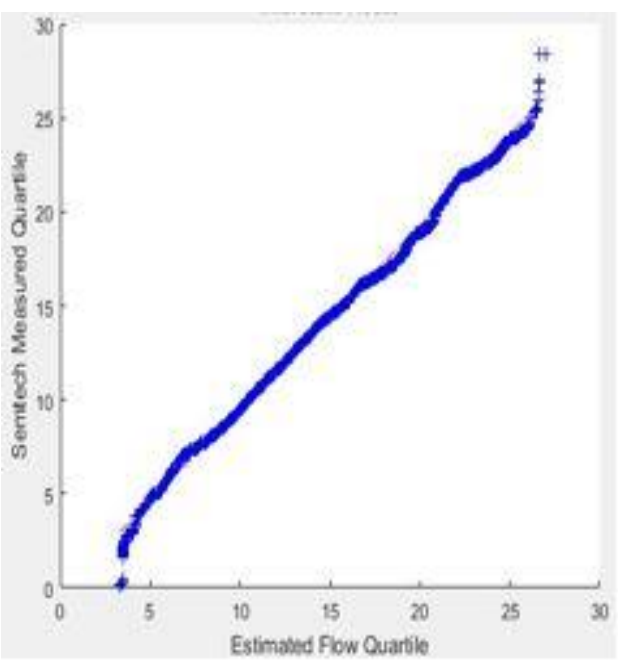

Figure 73 - Interstate Route

The above Q-Q plots Figure $70-73$, represent the similarity between the two quantiles.

The generated plots indicate that the two quantiles along different routes have similar normal distribution for almost the entire cycle. The Q-Q plots of DPF-DP, when compared to all the previous methods, appear to be less spread and for the most part line up with the center line indicating the two quantiles are in their best agreement. 


\subsubsection{Line chart of Vehicle-3 DPF-DP Method:}

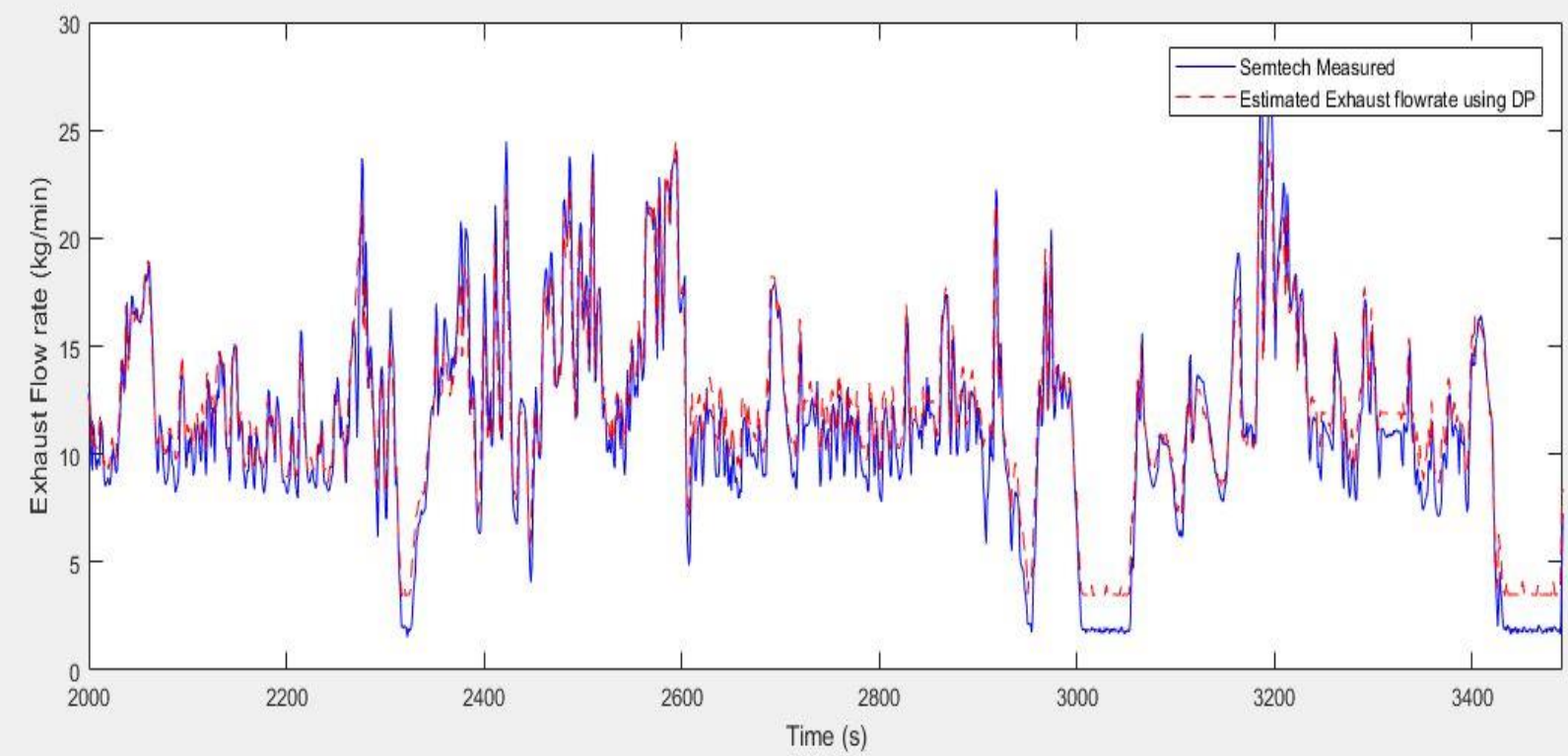

Figure 74 - Regional Route of Vehicle-3 DPF-DP method

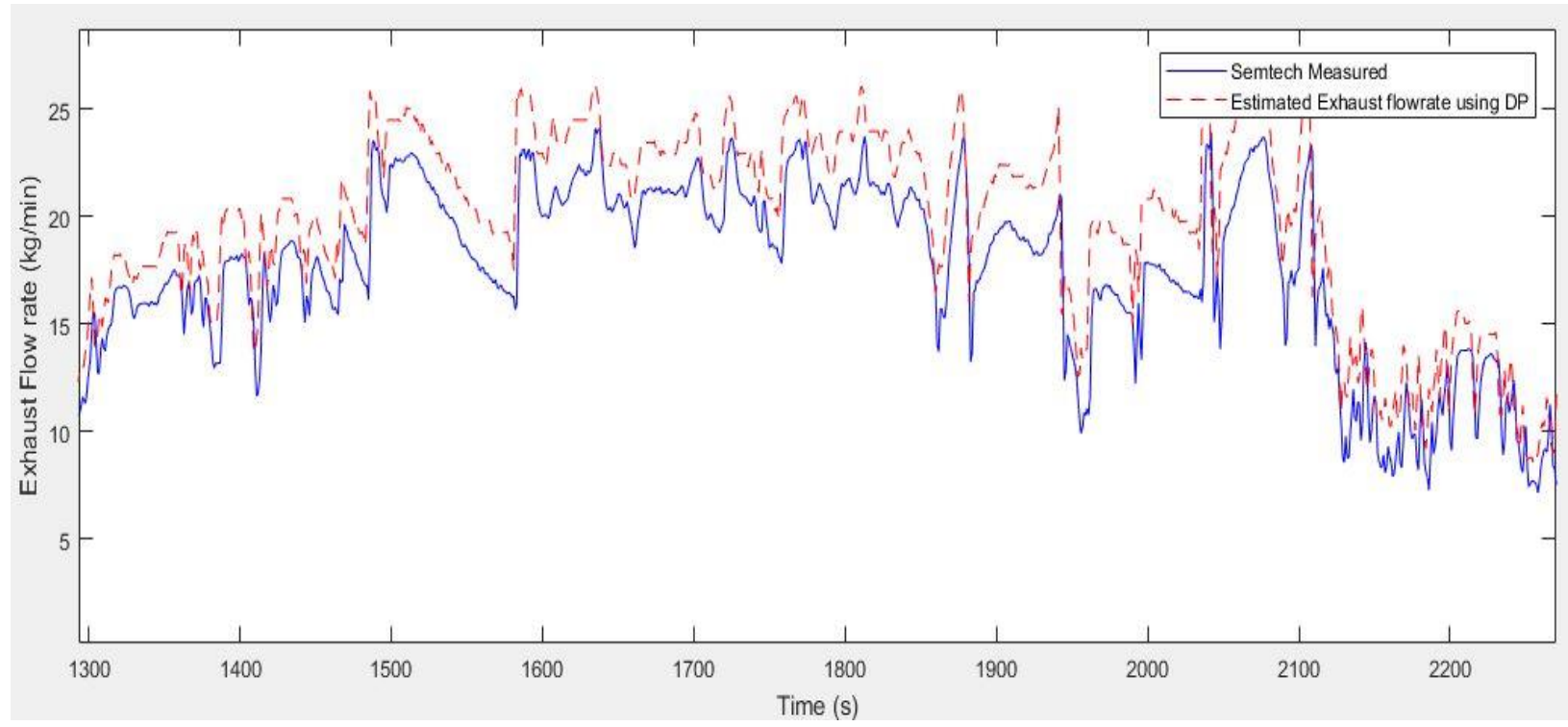

Figure 75 - Highway Route of Vehicle-3 DPF-DP method 


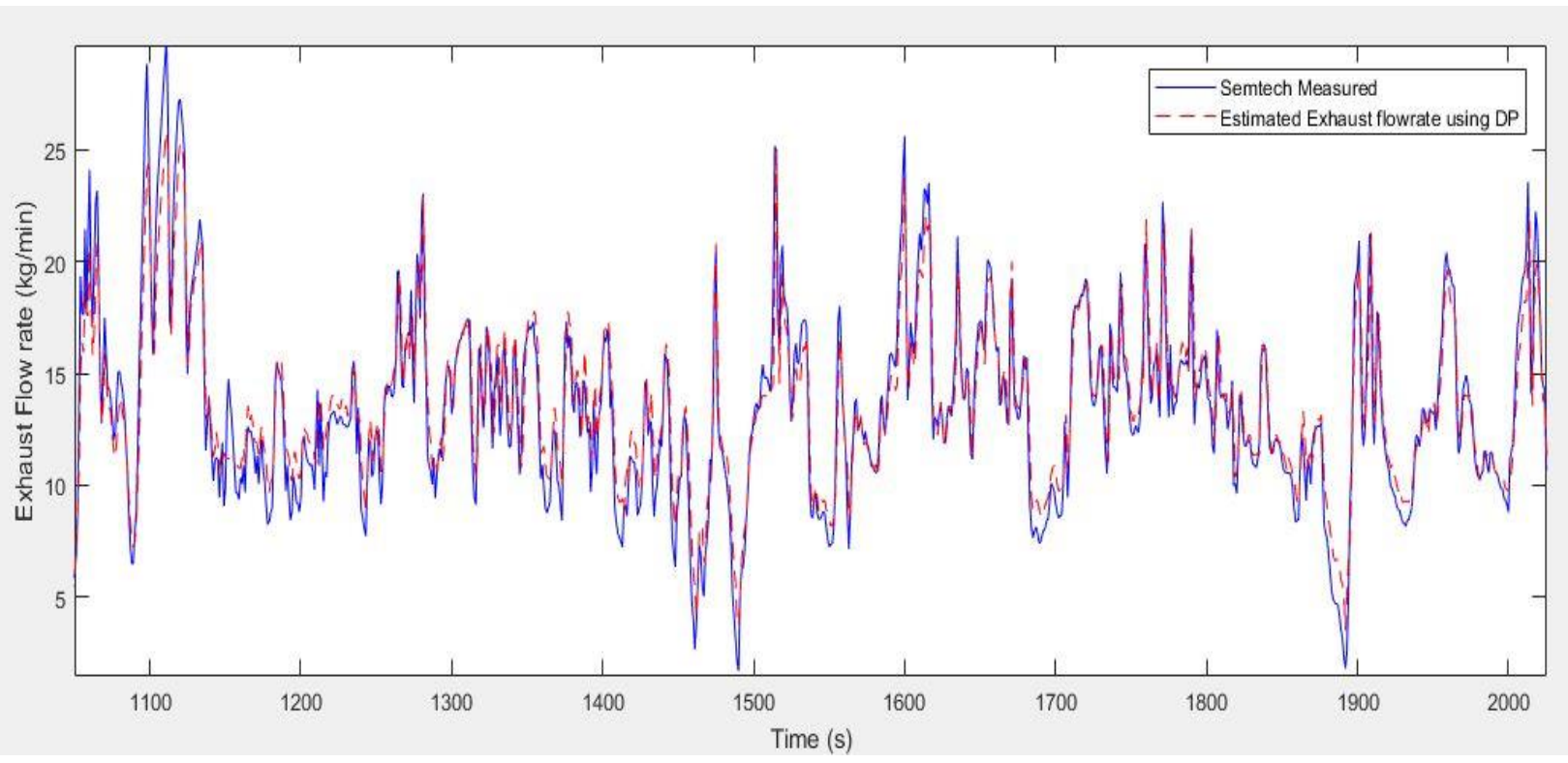

Figure 76 - Port: Local Route of Vehicle-3 DPF-DP method:

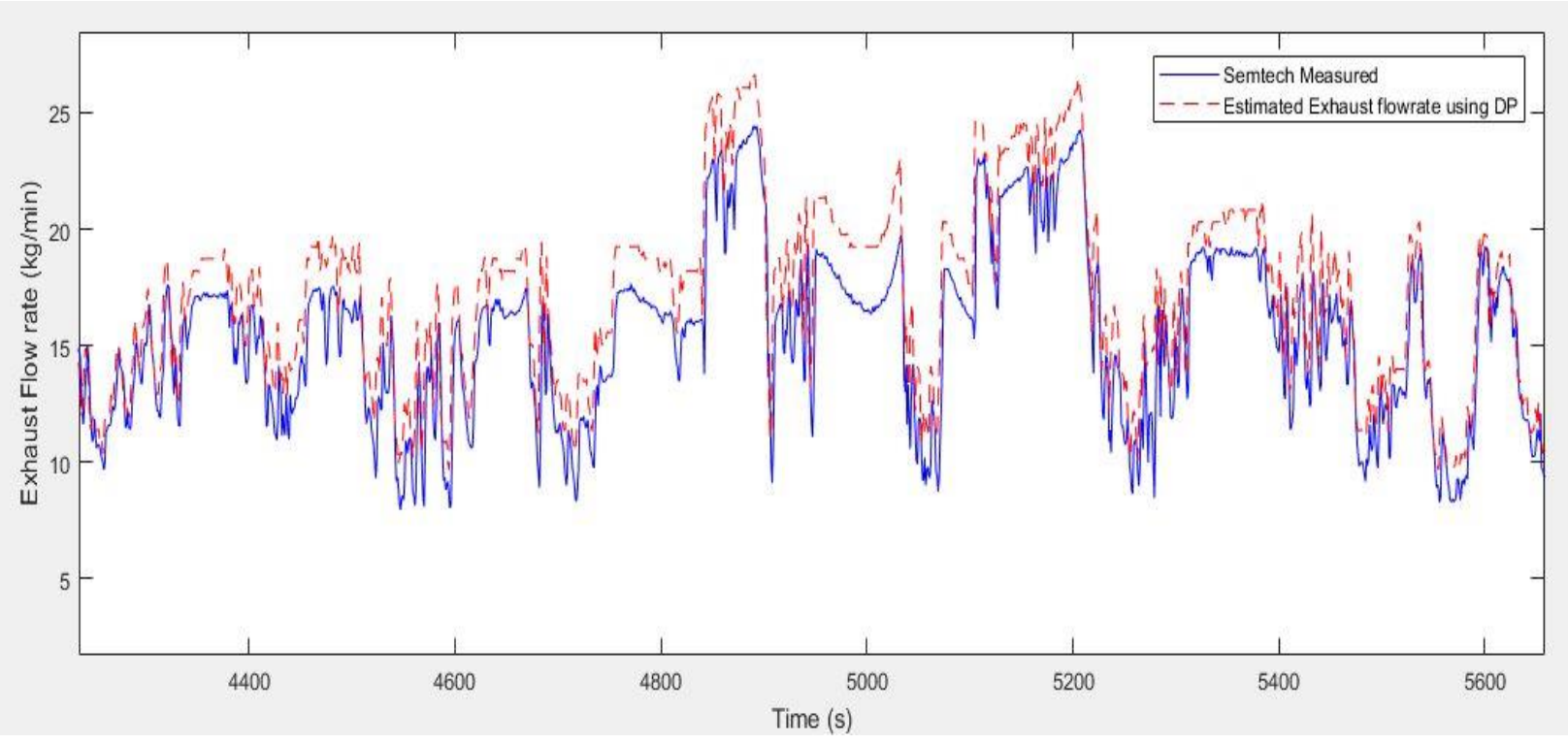

Figure 77 - Interstate Route of Vehicle-3 DPF-DP method

Figure $3974-77$, represent the run plots of different routes with estimated flow values obtained using DPF-DP. It can be seen that the estimates were close to those of Semtech measured for the Regional and Port: local routes, and the values are slightly over-estimated for Highway and Interstate routes. The estimated peak values perfectly align with the peaks of Semtech flow rate values in all the routes. 


\subsubsection{Combined Line chart of Vehicle-3 all Methods:}

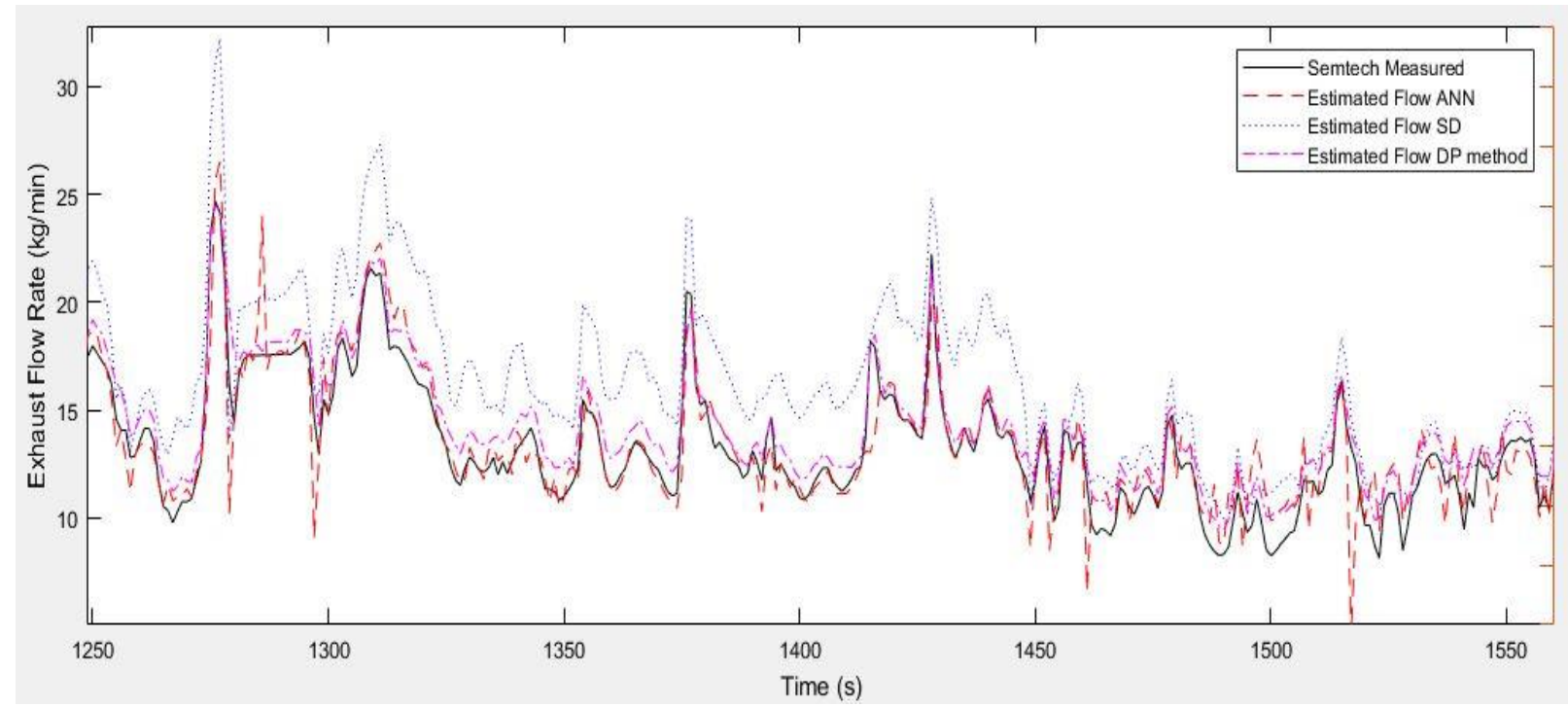

Figure 78 - Regional Route of Vehicle-3 all methods

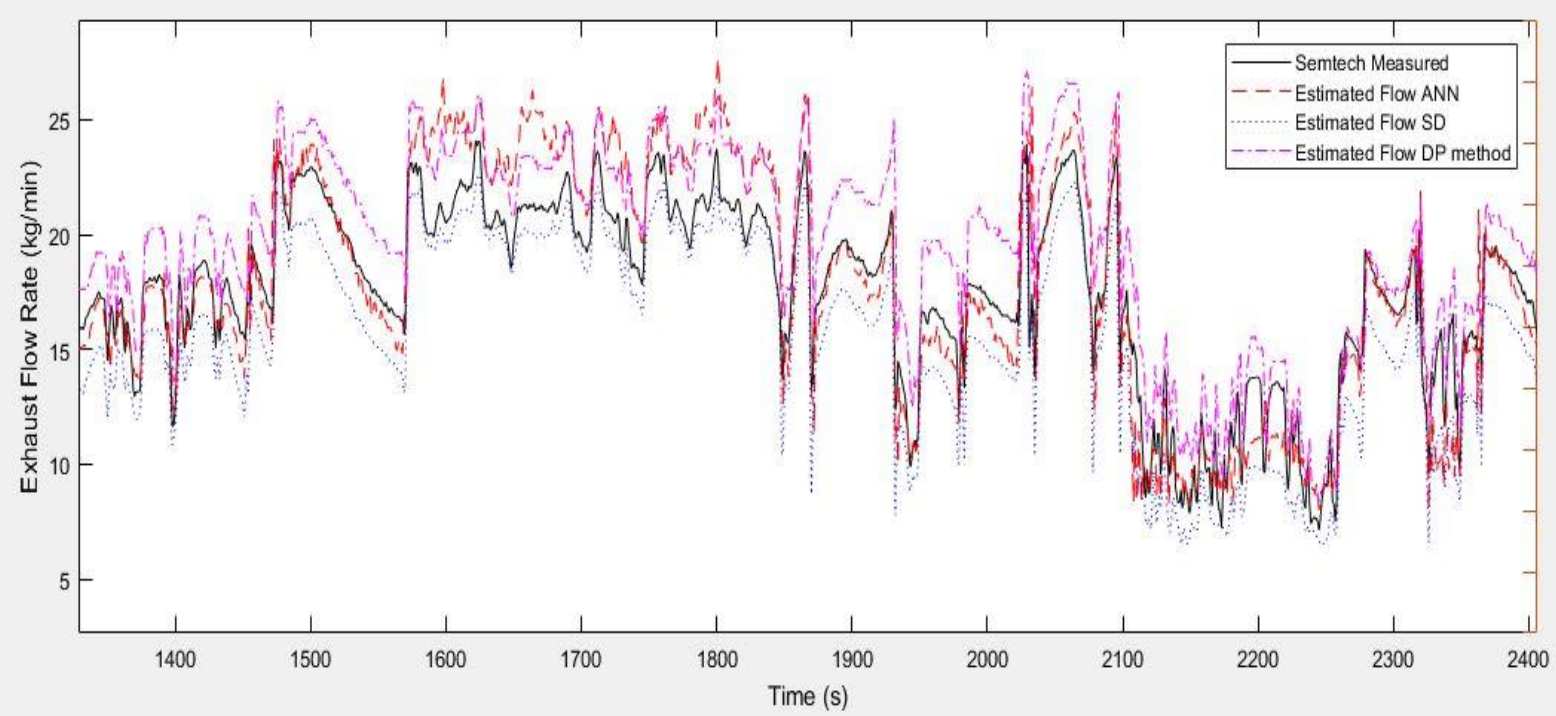

Figure 79 - Highway Route of Vehicle-3 all methods 


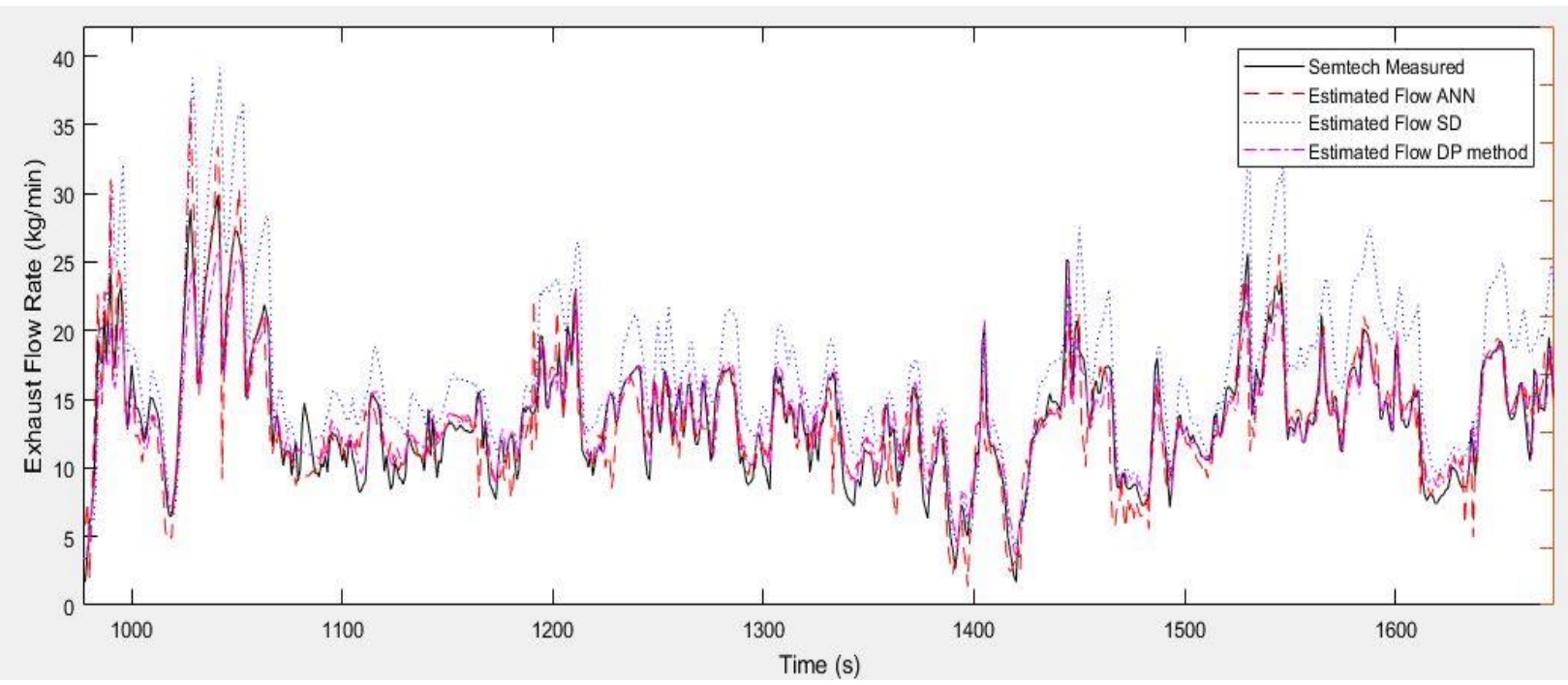

Figure 80 - Port: Local Route of Vehicle-3 all methods

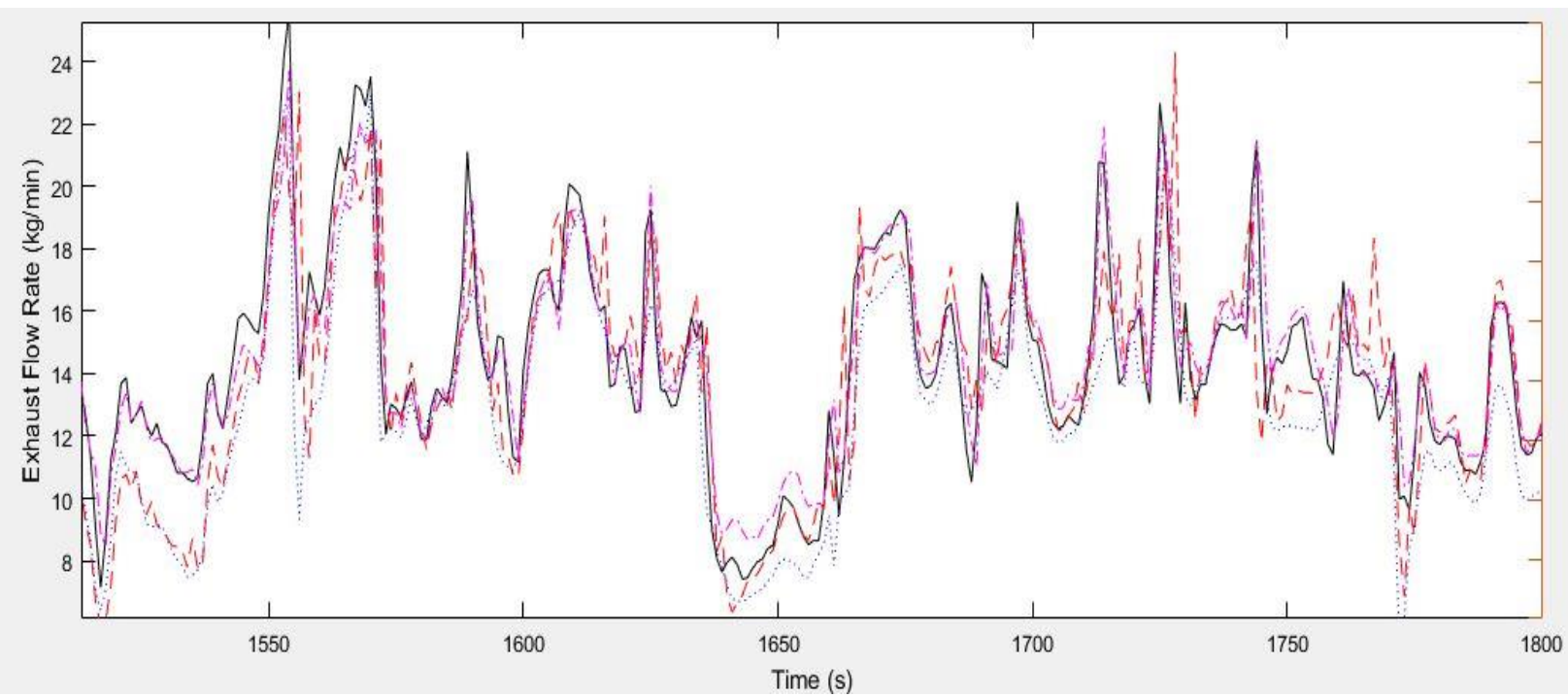

Figure 81 - Interstate Route of Vehicle-3 all methods

Figure $3978-81$, represent the run plots of different routes with estimated flow values obtained from all the three different methodologies. The differences between different methods can be clearly noticed and the phenomenon of over-estimated or under-estimated can be easily identified with these combined plots and the trends of different methods can also be easily compared. 
The data acquisition system used for recording the engine ECU data was developed at WVU and was designed in such a way that whenever there is a missing signal, the system interpolates the data between the last recorded and next recorded points. Efforts were made to eliminate those missing sections, however were ultimately reduced to best possible extent rather than being eliminated. In the case of vehicle-3 there were more interpolated points in the Regional route and Port: Local route compared to other routes, which can be clearly seen in the regression plots.

The speed density method with individual cycle to cycle correction factor accounted for a highest error of $-6.29 \%$ along the Highway route and a least error percentage of $-0.02 \%$ along the Port: Local route. When speed density method-1b was used, the error along the Highway route reduced to $1.91 \%$ and along the Port: Local route it further drifted to $4.93 \%$. The ANN estimates were also well within $\pm 6 \%$, with highest recorded error percentage of $-5.57 \%$ being along the regional route. The DPF-DP method also accounted for the highest error of $-9.32 \%$ along the Highway route, but for the Port; local route produced the least error which was $3.56 \%$.

Similarly, all the other three vehicles were validated along the Regional, Highway, Interstate and Port: local routes. The numerical results presented in the sections below provides clear information about the total estimated values and corresponding Semtech Measured values along various routes. Also, the tables contains information about the errors and regression values associated with each methodology along any given route. In the appendix section the plots of vehicle-1 are presented in similar format as those presented for vehcilce-3. 


\subsection{Numerical Results of Vehicle-1:}

Table 4-2 - Results of Vehicle-1 speed density method - 1 a

\begin{tabular}{|c|c|c|c|c|}
\hline Test Details & $\begin{array}{c}\text { Measured Flow } \\
(\mathrm{kg})\end{array}$ & $\begin{array}{c}\text { Estimated Flow } \\
(\mathrm{Kg})\end{array}$ & $\begin{array}{c}\text { Overall } \\
\text { Error } \\
(\%)\end{array}$ & $\begin{array}{c}\text { Regression } \\
\text { Between } \\
\text { Measured and } \\
\text { Estimated } \\
(\mathrm{R})\end{array}$ \\
\hline Regional & $1.0699 \mathrm{e}+05$ & $1.0623 \mathrm{e}+05$ & 0.093 & 0.98775 \\
\hline Highway & $9.6814 \mathrm{e}+04$ & $9.5245 \mathrm{e}+04$ & 7.91 & 0.97769 \\
\hline Port: Local & $4.9402 \mathrm{e}+04$ & $4.4910 \mathrm{e}+04$ & 6.57 & 0.93792 \\
\hline Interstate & $6.3495 \mathrm{e}+04$ & $6.1953 \mathrm{e}+04$ & 8.18 & 0.96087 \\
\hline
\end{tabular}

Table 4-3 - Results of Vehicle-1 speed density method - 1 b

\begin{tabular}{|c|c|c|c|c|}
\hline Test Details & $\begin{array}{c}\text { Measured Flow } \\
(\mathrm{kg})\end{array}$ & $\begin{array}{c}\text { Estimated Flow } \\
(\mathrm{Kg})\end{array}$ & $\begin{array}{c}\text { Overall } \\
\text { Error } \\
(\%)\end{array}$ & $\begin{array}{c}\text { Regression } \\
\text { Between } \\
\text { Measured and } \\
\text { Estimated } \\
(\mathrm{R})\end{array}$ \\
\hline Regional & $1.0696 \mathrm{e}+05$ & $1.0592 \mathrm{e}+05$ & 0.97 & 0.98746 \\
\hline Highway & $9.8605 \mathrm{e}+04$ & $9.6736 \mathrm{e}+04$ & 1.99 & 0.97871 \\
\hline Port: Local & $4.9351 \mathrm{e}+04$ & $4.9041 \mathrm{e}+04$ & 0.62 & 0.92507 \\
\hline Interstate & $6.3495 \mathrm{e}+04$ & $6.1496 \mathrm{e}+04$ & 3.12 & 0.97343 \\
\hline
\end{tabular}




\begin{tabular}{|c|c|c|c|c|}
\hline Test Details & $\begin{array}{c}\text { Measured Flow } \\
(\mathrm{kg})\end{array}$ & $\begin{array}{c}\text { Estimated Flow } \\
(\mathrm{Kg})\end{array}$ & $\begin{array}{c}\text { Overall } \\
\text { Error } \\
(\%)\end{array}$ & $\begin{array}{c}\text { Regression } \\
\text { Between } \\
\text { Measured and } \\
\text { Estimated } \\
(\mathrm{R})\end{array}$ \\
\hline Regional & $1.0427 \mathrm{e}+04$ & $1.0689 \mathrm{e}+04$ & 2.45 & 0.98228 \\
\hline Highway & $1.0411 \mathrm{e}+04$ & $1.0591 \mathrm{e}+04$ & 1.70 & 0.97747 \\
\hline Port: Local & $4.7623 \mathrm{e}+04$ & $4.9338 \mathrm{e}+04$ & 3.56 & 0.93792 \\
\hline Interstate & $5.9176 \mathrm{e}+04$ & $6.1816 \mathrm{e}+04$ & 4.27 & 0.95933 \\
\hline
\end{tabular}

\subsection{Numerical Results of Vehicle-2:}

Table 4-5 - Results of Vehicle-2 speed density method - 1 a

\begin{tabular}{|c|c|c|c|c|}
\hline Test Details & $\begin{array}{c}\text { Measured Flow } \\
(\mathrm{kg})\end{array}$ & $\begin{array}{c}\text { Estimated Flow } \\
(\mathrm{Kg})\end{array}$ & $\begin{array}{c}\text { Overall } \\
\text { Error } \\
(\%)\end{array}$ & $\begin{array}{c}\text { Regression } \\
\text { Between } \\
\text { Measured and } \\
\text { Estimated } \\
(\mathrm{R})\end{array}$ \\
\hline Regional & $3.6997 \mathrm{e}+04$ & $3.9267 \mathrm{e}+04$ & 9.61 & 0.95789 \\
\hline Highway & $8.6053 \mathrm{e}+04$ & $9.1634 \mathrm{e}+04$ & -6.57 & 0.95463 \\
\hline Port: Local & $4.4558 \mathrm{e}+04$ & $4.7495 \mathrm{e}+04$ & -6.48 & 0.8907 \\
\hline Interstate & $7.6037 \mathrm{e}+04$ & $6.8431 \mathrm{e}+04$ & -6.13 & 0.94401 \\
\hline
\end{tabular}


Table 4-6 - Results of Vehicle-2 speed density method - 1 b

\begin{tabular}{|c|c|c|c|c|}
\hline Test Details & $\begin{array}{c}\text { Measured Flow } \\
(\mathrm{kg})\end{array}$ & $\begin{array}{c}\text { Estimated Flow } \\
(\mathrm{Kg})\end{array}$ & $\begin{array}{c}\text { Overall } \\
\text { Error } \\
(\%)\end{array}$ & $\begin{array}{c}\text { Regression } \\
\text { Between } \\
\text { Measured and } \\
\text { Estimated } \\
(\mathrm{R})\end{array}$ \\
\hline Regional & $3.9040 \mathrm{e}+04$ & $3.9917 \mathrm{e}+04$ & -2.24 & 0.96134 \\
\hline Highway & $7.8612 \mathrm{e}+04$ & $8.0875 \mathrm{e}+04$ & -2.87 & 0.97668 \\
\hline Port: Local & $5.1051 \mathrm{e}+04$ & $5.0455 \mathrm{e}+04$ & 1.16 & 0.92272 \\
\hline Interstate & $6.1094 \mathrm{e}+04$ & $6.3557 \mathrm{e}+04$ & -4.03 & 0.9782 \\
\hline
\end{tabular}

Table 4-7 - Results of Vehicle-2 ANN method

\begin{tabular}{|c|c|c|c|c|}
\hline Test Details & $\begin{array}{c}\text { Measured Flow } \\
(\mathrm{kg})\end{array}$ & $\begin{array}{c}\text { Estimated Flow } \\
(\mathrm{Kg})\end{array}$ & $\begin{array}{c}\text { Overall } \\
\text { Error } \\
(\%)\end{array}$ & $\begin{array}{c}\text { Regression } \\
\text { Between } \\
\text { Measured and } \\
\text { Estimated } \\
(\mathrm{R})\end{array}$ \\
\hline Regional & $3.8355 \mathrm{e}+04$ & $3.6795 \mathrm{e}+04$ & 4.06 & 0.9611 \\
\hline Highway & $8.7531 \mathrm{e}+04$ & $9.3772 \mathrm{e}+04$ & -7.12 & 0.91726 \\
\hline Port: Local & $5.0205 \mathrm{e}+04$ & $4.8680 \mathrm{e}+04$ & 0.89 & 0.90809 \\
\hline Interstate & $7.0575 \mathrm{e}+04$ & $6.8833 \mathrm{e}+04$ & 2.46 & 0.9231 \\
\hline
\end{tabular}


Table 4-8 - Results of Vehicle-2 DPF-DP method

\begin{tabular}{|c|c|c|c|c|}
\hline Test Details & $\begin{array}{c}\text { Measured Flow } \\
(\mathrm{kg})\end{array}$ & $\begin{array}{c}\text { Estimated Flow } \\
(\mathrm{Kg})\end{array}$ & $\begin{array}{c}\text { Overall } \\
\text { Error } \\
(\%)\end{array}$ & $\begin{array}{c}\text { Regression } \\
\text { Between } \\
\text { Measured and } \\
\text { Estimated } \\
(\mathrm{R})\end{array}$ \\
\hline Regional & $3.8410 \mathrm{e}+04$ & $3.7838 \mathrm{e}+04$ & 1.49 & 0.96434 \\
\hline Highway & $8.7586 \mathrm{e}+04$ & $9.9243 \mathrm{e}+04$ & -13.30 & 0.94686 \\
\hline Port: Local & $5.0280 \mathrm{e}+04$ & $5.4693 \mathrm{e}+04$ & -8.75 & 0.93759 \\
\hline Interstate & $7.5999 \mathrm{e}+04$ & $7.3856 \mathrm{e}+04$ & 2.82 & 0.94393 \\
\hline
\end{tabular}

\subsection{Numerical Results of Vehicle-3:}

Table 4-9 - Results of Vehicle-3 speed density method - 1 a

\begin{tabular}{|c|c|c|c|c|}
\hline Test Details & $\begin{array}{c}\text { Measured Flow } \\
(\mathrm{kg})\end{array}$ & $\begin{array}{c}\text { Estimated Flow } \\
(\mathrm{Kg})\end{array}$ & $\begin{array}{c}\text { Overall } \\
\text { Error } \\
(\%)\end{array}$ & $\begin{array}{c}\text { Regression } \\
\text { Between } \\
\text { Measured and } \\
\text { Estimated } \\
(\mathrm{R})\end{array}$ \\
\hline Regional & $4.0265 \mathrm{e}+04$ & $4.1321 \mathrm{e}+04$ & -5.42 & 0.95461 \\
\hline Highway & $5.1868 \mathrm{e}+04$ & $5.2783 \mathrm{e}+04$ & -6.29 & 0.9646 \\
\hline Port: Local & $4.2404 \mathrm{e}+04$ & $4.3296 \mathrm{e}+04$ & -0.021 & 0.95611 \\
\hline Interstate & $9.6562 \mathrm{e}+04$ & $9.6709 \mathrm{e}+04$ & -3.14 & 0.97684 \\
\hline
\end{tabular}


Table 4-10 - Results of Vehicle-3 speed density method - $1 \mathrm{~b}$

\begin{tabular}{|c|c|c|c|c|}
\hline Test Details & $\begin{array}{c}\text { Measured Flow } \\
(\mathrm{kg})\end{array}$ & $\begin{array}{c}\text { Estimated Flow } \\
(\mathrm{Kg})\end{array}$ & $\begin{array}{c}\text { Overall } \\
\text { Error } \\
(\%)\end{array}$ & $\begin{array}{c}\text { Regression } \\
\text { Between } \\
\text { Measured and } \\
\text { Estimated } \\
(\mathrm{R})\end{array}$ \\
\hline Regional & $4.1187 \mathrm{e}+04$ & $4.0652 \mathrm{e}+04$ & 1.29 & 0.97706 \\
\hline Highway & $5.2758 \mathrm{e}+04$ & $5.17504 \mathrm{e}+04$ & 1.91 & 0.96606 \\
\hline Port: Local & $4.3963 \mathrm{e}+04$ & $4.1795 \mathrm{e}+04$ & 4.93 & 0.95574 \\
\hline Interstate & $9.6703 \mathrm{e}+04$ & $9.7755 \mathrm{e}+04$ & -1.08 & 0.97547 \\
\hline
\end{tabular}

Table 4-11 - Results of Vehicle-3 ANN method

\begin{tabular}{|c|c|c|c|c|}
\hline Test Details & $\begin{array}{c}\text { Measured Flow } \\
(\mathrm{kg})\end{array}$ & $\begin{array}{c}\text { Estimated Flow } \\
(\mathrm{Kg})\end{array}$ & $\begin{array}{c}\text { Overall } \\
\text { Error } \\
(\%)\end{array}$ & $\begin{array}{c}\text { Regression } \\
\text { Between } \\
\text { Measured and } \\
\text { Estimated } \\
(\mathrm{R})\end{array}$ \\
\hline Regional & $3.9676 \mathrm{e}+04$ & $4.1841 \mathrm{e}+04$ & -5.45 & 0.94956 \\
\hline Highway & $5.2725 \mathrm{e}+04$ & $5.3022 \mathrm{e}+04$ & -0.56 & 0.96041 \\
\hline Port: Local & $4.3520 \mathrm{e}+04$ & $4.978 \mathrm{e}+04$ & 3.54 & 0.93559 \\
\hline Interstate & $9.6667 \mathrm{e}+04$ & $9.8272 \mathrm{e}+04$ & -1.66 & 0.96608 \\
\hline
\end{tabular}

Table 4-12 - Results of Vehicle-3 DPF-DP method 


\begin{tabular}{|c|c|c|c|c|}
\hline Test Details & $\begin{array}{c}\text { Measured Flow } \\
(\mathrm{kg})\end{array}$ & $\begin{array}{c}\text { Estimated Flow } \\
(\mathrm{Kg})\end{array}$ & $\begin{array}{c}\text { Overall } \\
\text { Error } \\
(\%)\end{array}$ & $\begin{array}{c}\text { Regression } \\
\text { Between } \\
\text { Measured and } \\
\text { Estimated } \\
(\mathrm{R})\end{array}$ \\
\hline Regional & $4.1305 \mathrm{e}+04$ & $4.3162 \mathrm{e}+04$ & -4.49 & 0.93713 \\
\hline Highway & $5.2756 \mathrm{e}+04$ & $5.7675 \mathrm{e}+04$ & -9.32 & 0.96167 \\
\hline Port: Local & $4.3880 \mathrm{e}+04$ & $4.4675 \mathrm{e}+04$ & 3.56 & 0.96594 \\
\hline Interstate & $9.6693 \mathrm{e}+04$ & $1.0186 \mathrm{e}+05$ & 4.27 & 0.96355 \\
\hline
\end{tabular}

\subsection{Numerical Results of Vehicle-4:}

Table 4-13 - Results of Vehicle-4 speed density method - 1 a

\begin{tabular}{|c|c|c|c|c|}
\hline Test Details & $\begin{array}{c}\text { Measured Flow } \\
(\mathrm{kg})\end{array}$ & $\begin{array}{c}\text { Estimated Flow } \\
(\mathrm{Kg})\end{array}$ & $\begin{array}{c}\text { Overall } \\
\text { Error } \\
(\%)\end{array}$ & $\begin{array}{c}\text { Regression } \\
\text { Between } \\
\text { Measured and } \\
\text { Estimated } \\
(\mathrm{R})\end{array}$ \\
\hline Regional & $5.0678 \mathrm{e}+04$ & $5.0656 \mathrm{e}+04$ & 0.39 & 0.95702 \\
\hline Highway & $6.6404 \mathrm{e}+04$ & $6.6297 \mathrm{e}+04$ & 2.49 & 0.98263 \\
\hline Port: Local & $3.5881 \mathrm{e}+04$ & $3.5904 \mathrm{e}+04$ & -3.76 & 0.96983 \\
\hline Interstate & $3.5434 \mathrm{e}+04$ & $3.5518 \mathrm{e}+04$ & -3.19 & 0.98419 \\
\hline
\end{tabular}


Table 4-14 - Results of Vehicle-4 speed density method - 1 b

\begin{tabular}{|c|c|c|c|c|}
\hline Test Details & Measured Flow & Estimated Flow & $\begin{array}{c}\text { Overall } \\
\text { Error }\end{array}$ & $\begin{array}{c}\text { Regression } \\
\text { Between } \\
\text { Measured and } \\
(\mathrm{kg})\end{array}$ \\
& & $(\mathrm{Kg})$ & & $\begin{array}{c}\text { Estimated } \\
(\mathrm{R})\end{array}$ \\
\hline Regional & $5.0572 \mathrm{e}+04$ & $5.1123 \mathrm{e}+04$ & -1.08 & 0.95749 \\
\hline Highway & $6.6399 \mathrm{e}+04$ & $6.5368 \mathrm{e}+04$ & 1.55 & 0.9842 \\
\hline Port: Local & $3.5901 \mathrm{e}+04$ & $3.5362 \mathrm{e}+04$ & 1.50 & 0.96874 \\
\hline Interstate & $3.5468 \mathrm{e}+04$ & $3.5718 \mathrm{e}+04$ & -0.70 & 0.98574 \\
\hline
\end{tabular}

Table 4-15 - Results of Vehicle-4 ANN method

\begin{tabular}{|c|c|c|c|c|}
\hline Test Details & Measured Flow & Estimated Flow & $\begin{array}{c}\text { Overall } \\
\text { Error }\end{array}$ & $\begin{array}{c}\text { Regression } \\
\text { Between } \\
\text { Measured and } \\
\text { Estimated }\end{array}$ \\
& & $(\mathrm{kg})$ & $(\%)$ & $(\mathrm{R})$ \\
\hline Regional & $5.0633 \mathrm{e}+04$ & $4.9588 \mathrm{e}+04$ & 2.45 & 0.9466 \\
\hline Highway & $6.6258 \mathrm{e}+04$ & $6.8152 \mathrm{e}+04$ & -2.85 & 0.97954 \\
\hline Port: Local & $3.5864 \mathrm{e}+04$ & $3.6120 \mathrm{e}+04$ & -0.71 & 0.96309 \\
\hline Interstate & $3.5409 \mathrm{e}+04$ & $3.7245 \mathrm{e}+04$ & -5.18 & 0.96417 \\
\hline
\end{tabular}


Table 4-2 to Table 4-15, represent the numerical results, where the estimated flow rate and Semtech measured flow rate values are presented along with corresponding errors and regression values. 


\section{Conclusions and Recommendations}

\subsection{Conclusions}

The Speed density-1a method was able to estimate the exhaust flow rate accurately but also accounted for higher overall error percentage compared to other methodologies. This can be attributed to a relatively shorter test length, which resulted in a poor density correction coefficient. This in comparison to routes in which the test length was long enough in which case the correction coefficients were able to better correct the estimated flow obtained from the intake flow equation and fuel rate, which accurately matched with the actual Semtech Measured flow rate values. When the speed density-1b method was applied, the estimates were even more accurate due to correction coefficients being obtained from a longer length of test.

The estimations made by the ANN method were better correlated to the Semtech measured flow rate values. As the neural networks rely on training data and don't have a requirement for any correction coefficients that correct for density correction, the neural networks can be used when there is no possibility of using speed density method due to missing ambient pressure and ambient temperature sensor data. Also, when the neural network is employed the estimated values deviate less and therefore account for a reduced occurrence of huge errors.

In addition to the Speed density and ANN methodology, the DPF-DP methodology also proved to be a successive alternative to flow meters, as the pressure drop experienced across the differential flow element, which varies linearly, helped to estimate better flow rate values. The differential pressure range, which was divided into different flow regimes, helped to accurately obtain coefficients of each particular regime and eventually helped in obtaining an overall averaged value which could be used to effectively estimate the flow values. The highest error 
values were read during the rapid transient operations, due to tendency of pressure sensors to read comparatively higher values in those conditions, which eventually had an effect on the estimated flow rate values using the DPF-DP method.

All the three developed methodologies predicted the estimated results which appear to be in good correlation with those of actual measured results. The purpose of this study was achieved, where no additional instruments or devices were no longer required to measure exhaust flow rate values and the developed methodologies proved to be capable of estimating values of exhaust flow by just using the OBD data from the ECU.

\subsection{Limitations}

Each methodology is associated with at least one limitations. The speed density method is limited to conditions where ambient pressure and ambient temperature data are broadcasted correctly. If there is missing ambient sensor data, the correction coefficients calculated may overcorrect or under-correct the estimated data values which eventually leads to higher errors. The limitations of the artificial neural network method is that it needs a training data set in order to obtain estimates of a given data set. And finally, the limitation associated with the DPF-DP method is that the vehicle should be equipped with a differential pressure element and a differential pressure sensor which continuously monitors the pressure difference across the LFE, and is only valid for diesel engine equipped vehicles. Additionally, during the regeneration process the temperature of the element increases which could create an influence on the pressure sensor signal and may result in non-linear variation of pressure with the flow, under which circumstances accurate predictions cannot be made. 


\subsection{Recommendations}

To further develop the DPF-DP model, it is recommended that future work be conducted in a way that would result in data which could be employed to determine the effects of temperature changes during regeneration on the estimated exhaust flow rate values. The data available for this analysis was acquired via in-use testing in California; it is recommended that the methodologies be further tested with engines being operated in extreme environmental conditions in order to determine the impacts of severe weather conditions on the estimated flow rate values.

The recommendation is also made that as more in-use data becomes available for present technology engines, the ANN be trained with the available data, and employed to predict the data associated with different engine capacities that are in development or which are currently in production. 


\section{References}

Akita, Masanobu, and Tim Nevius. 2011. "Development of a High Temperature Exhaust Flowmeter for Diesel Emission Measurements." Feature Article, May, English ed.

Allen. 2016. On-Board Diagnostics (OBD) Program Overview. July 11. Accessed September 5, 2018. http://www.slideshare.net/tonnytran29/onboard-diagnostics-obd-programoverview.

Bai, Lu, Jianzhou Wang, and Xuejiao and Lu Haiyan Ma. 2018. "Air Pollution Forecasts: An Overview." International Journal of Environmental Research and Public Health.

Baltusis, Paul. 2004. "On Board Vehicle Diagnostics." SAE Technical Paper series.

Battermanb, Kai Zhanga and Stuart. 2013. "Air pollution and health risks due to vehicle traffic." PMC 307-316.

California Air Resources Board. n.d. OBD II Regulations and Rulemaking. https://www.arb.ca.gov/msprog/obdprog/pastregs.htm.

Caretto, Thomas C. Austin and L. S. 1998. "Improving the Calculation of Exhaust Gas Dilution During Constant Volume Sampling." SAE International: International Congress and Exposition (SAE International: International Congress and Exposition).

Changpu Zhao, Yayong Zhu, Yaohui Wang and Sirui Huang. 2017. "Pressure Drop and Soot Regeneration Characteristics through Hexaginal and Square Cell Diesel Partuculate Filters." SAE International.

Chase, William M. Silvis and Richard E. 1999. "Proportional Ambient Sampling: A CVS Improvement for ULEV and Lean Engine Operation." SAE International: International Congress and Exposition (SAE International: International Congress and Exposition).

Comte-Bellot, Genevieve. 2007. HOT-WIRE ANEMOMETRY. Technical, Ecully, France: ARjournals.

Czerwinski, J., Y. Zimmerli, and P. Comte and Th. Butler. 2016. "Experiences and Results with different PEMS." Journal of Earth Sciences and Geotechnical Engineering 91-106. 
DeFries, Timothy H., Michael Sabisch, Sandeep Kishan, Francisco Posada, and John and Bandivadekar, Anup German. 2014. "In-Use Fuel Economy and CO2 Emissions Measurement using OBD Data on US Light-Duty Vehicles." SAE Internations Journal of Engines 7 (3).

Gandhi, B K, S N Singh, V Seshadri, and Jeeot Singh. 2004. "(Akita and Nevius 2011)." Indian journal of Engineering \& Material Sciences 11: 378-384.

Gonzalez, Natalia Fonseca, Jesus Casanova Kindelan, and Jose Maria Lopez Martinez. n.d. "Methodology for instantaneous average exhaust gas mass flow rate measurement."

Gordon, Daniel Sperling and Deborah. 2009. "Natural Resources Forum 33." In Two Billion Cars: Driving towards Sustainability, by Daniel Sperling and Deborah Gordon, 250-254. New york,: Oxford University Press, Oxford, UK,.

Guenther, Mark, Mark Polster, and Larry Wroza. 2004. "Exhaust Flow Meter Calibration." SAE International.

Guenther, Mark, Travis Henney, William M. Silvis, and Shigeru Nakatani and Dien-Yeh Wu. 2000. "Improved Bag Mini-Diluter Sampling System for Ultra-Low Level Vehicle Exhaust Emissions." SAE 2000 World Congress (SAE 2000 World Congress).

Hadef, Jamil El, Guillaume Colin, Vincent Talon, and Yann Chamaillard. 2013. "Neural Model for Real-Time Engine Volumetric Efficiency Estimation." SAE International.

Hakansson, Evert, and Jerker Delsing. 1994. "Effects of pulsating flow on an ultrasonic gas flowmeter." Science Direct 5 (2): 93-101.

Hillier, V.A.W, and F.W. Pittuck. 1966. Fundamentals of Motor Vehicle Technology. London: Hutchinson Educational. .

Hornreich, W. Thiel and C., and O. Morsch and G. E. Seifert. 2003. "Problems of Partial Sample Systems for Modal Raw Exhaust Mass Emission Measurement." SAE International.

Chih-Chung, Jiun-Jih Miau, and Tzu-Liang Chen. 2006. "Determination of Real-time Vortex Shedding Frequency by a DSP." Journal of the Chinese Society of Mechanical Engineers 27 (3): 335-342. 
Hussain. J, Palaniradja. K, Alagumurthi. N, and Manimaran. R. 2012. "Effect of Exhaust Gas Recirculation (EGR) on Performance and Emission of a Compression Ignition Engine with Staged Combustion (Insertion of Unburned Hydrocarbon)." International Journal of Energy Engineering 285-292.

Heritage. 1989. "The performance of transit time ultrasonic flowmeters under good and disturbed flow conditions." Science Direct 1 (1): 24-30.

Laurantzon, Fredrik. 2010. Flow Measuring Techniques in Steady and Pulsating Compressible Flows. Technical Report, Sweden: Royal institute of Technology, KTH Mechanics, 2244.

Layhew, Zackery S. 2017. Investigation of a Neural Network Approach in Modeling and Diagnostics of an Engine-out NOx Sensor. Master's Thesis, Morgantown: West Virginia University.

Lee, Choong Hoon. 2017. A comparative study of the flow rate characteristics of flange embedded averaging Pitot tube (APT) flow meters for various cross section shapes. Research India Publications, International Journal of Applied Engineering Research.

Lee, Choong-Hoon. 2011. "A comparative study of flow rate characteristics of an averaging Pitot tube type flow meter according to $\mathrm{H}$ parameters based on two kinds of differential pressure measured at the flow meter with varying air temperature." Journal of Mechanical Science and Technology 25 (8): 1961-1967.

Mark Guenther, Travis Henney, William M. Silvis, Shigeru Nakatani and Dien-Yeh Wu. 2000. "Improved Bag Mini-Diluter Sampling System for Ultra-Low Level Vehicle Exhaust Emissions." SAE International (SAE International) 2000-01-0792.

Masoudi, Mansour. 2002. "Hydrodymaics of Diesel Particulate Filters." SAE Trechnical Paper Series.

Meriam Instruments Inc. n.d. Meriam LFE Laminar Flow Elements user manual. Cleveland, Ohio. 
Nevius, Tim, Dario Rauker, Masanobu Akita, Yoshinori Otsuki, Scott Porter, and Michael Akard. 2017. "Investigation of Ultrasonic Flow Measurement for CVS Dilution Air Volume." SAE INTERNATIONAL Journal of Engines 10 (4).

Ohtsuki, Satoshi, Kaori Inoue, and Yutaka Yamagishi and Kazuyoshi Namiyama. 2002. "Studies on Emission Measurement Techniques for Super-Ultra Low Emission Vehicles." SAE Intenrational.

HebrardL, Malard, and Strzelecki. 1992. "Experimental study of a vortex flowmeter in pulsatile flow conditions." Science Direct 3 (3): 173-186.

Pink, Alex, Adam Ragatz, Lijuan Wang, and Eric and Gonder, Jeffrey Wood. 2017. "Comparison of Vehicle-Broadcasted Fuel Consumption Rates against Precise Fuel Measurements for Medium- and Heavy-Duty Vehicles and Engines." SAE International Journal of Fuels and Lubricants 10 (2).

Regulations, Code of Federal. 2012. Electronic Code of Federal Regulations e-CFR. https://ecfr.io/Title-40/pt40.22.90\#se40.22.90_1420.

Robert.J.Howlett, Simon.D.Walters, Peter.A.Howson, and Ian.A.Park. n.d. Air-Fuel Ratio Measurement in an Internal Combustion Engine using a Neural Network. Technical Report, Brighton: University of Brighton,.

Santhosh K V, B K Roy. 2012. "An Intelligent Flow Measuring Technique Using Venturi." International multi Conference of Engineers and Computer Scientists 2.

sappok, Alexander, and Victor Wong. 2010. "Ash effects on Diesel Particulate Filter Pressure Drop Sensitivity to soot and Iplications for Regeneration Frequency and DPF control." SAE International .

Sato, Susumu, Toshiro Yamamoto, Yasuhiro Ogawa, and Yutaka Iizuka. 2007. "Research on Measurement Method of Exhaust Gas Flow Rate for On-board Measurement System." SAE Technical Paper Series (SAE Technical Paper Series).

Schroder, Andreas, Mario Kupnik, Paul O'Leary, Ewald Benes, and and Martin Gröschl. 2006. "A capacitance ultrasonic transducer for fast flow measurements in hot pulsating gases." IEEE Sensors Journal 6 (4): 898-905. 
Seller, Boeckmann and Eilts. 2008. "Performance of Undamaged and Damaged Diesel Particulate Filters." SAE Technical Paper Series.

Shin, Y G. n.d. "Estimation of instantaneous exhaust gas flowrate based on the assumption of a polytropic process." Proc Instn Mech Engineers 637-643.

Silvis, William M., Kay Steigerwald, Barbara Zelenka, and Günter Hohenberg. 2007. "Development of an Intake Flow Based Model Calculating Real Time Exhaust Flow by Accounting for Filling and Emptying of the Engine Manifolds." SAE TECHNICAL PAPER SERIES.

Stoltenkamp, P.W. 2007. Dynamics of turbine flow meters. Technische Universiteit Eindhoven.

Taubert, Sawomi, and Adam Majerczyk. 2013. "Some Aspects of Validation of the Fuel Consumption Measurement Method." Journal of KONES Powertrain and Transport 2014.

TetraTec. 2016. OPERATION MANUAL. Gewerbestrasse 8, 1214.

Vojtisek, Michael, and Martin Kotek. 2014. "ESTIMATION OF ENGINE INTAKE AIR MASS FLOW USING A GENERIC SPEED-DENSITY METHOD." MECCA 7-15.

Yamazaki, Satoshi, Kazuhiko Suzuki, Hiroshi Hirai, Yasuo Yoshikawa, Hitoshi Kunimi, and Shinji Kobayashi. 2003. "Modeling Study of Vehicle Emission Impacts." SAE International Spring Fuels \& Lubricants.

Yassine, Mahmoud, Rajinder Dhatt, Ron Berndt, Majed Marji, Dennis Blumke, and Thomas Laymac. 2004. "Development of Vehicle Exhaust Flow Measurement Calibration Device." SAE International . 


\section{Appendices}

\subsection{Vehicle 1:}

\subsubsection{Correction Coefficients of Vehicle-1 speed density method - 1 a:}

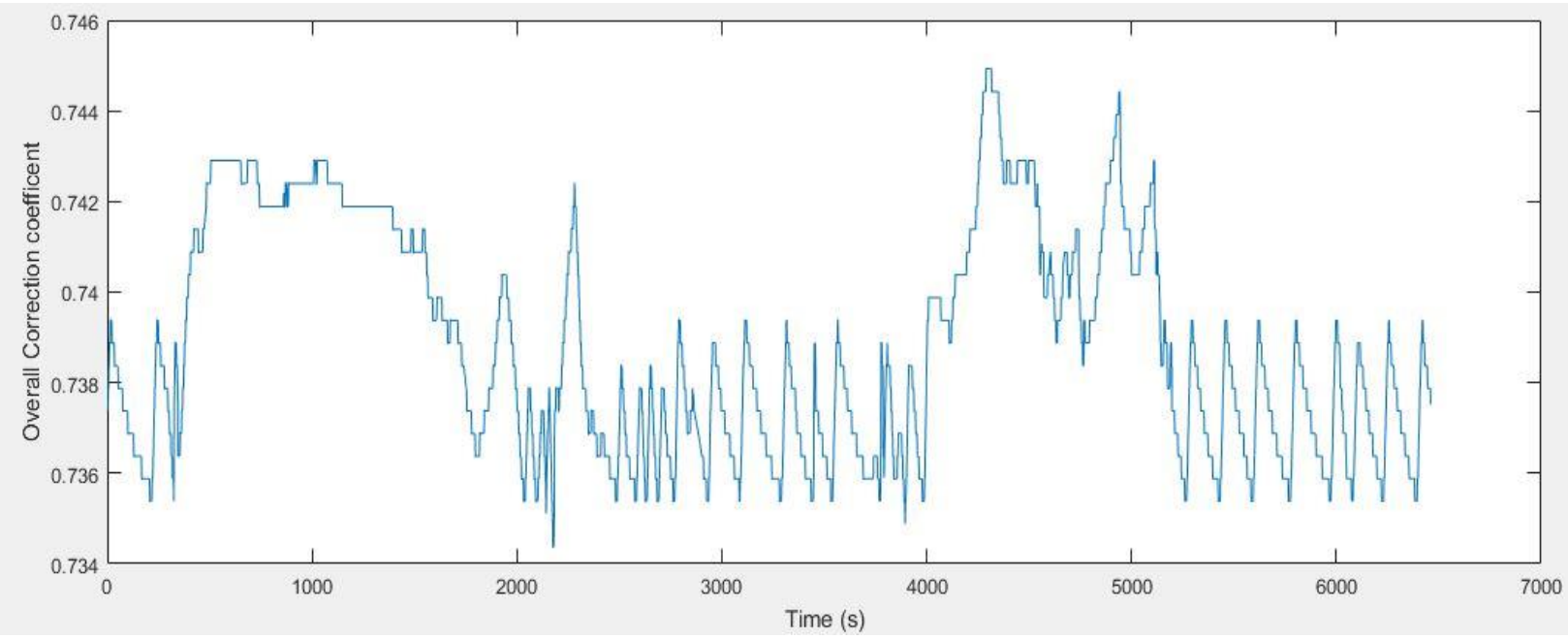

Figure 82 - Correction Coefficients of Regional Route of Vehicle-1

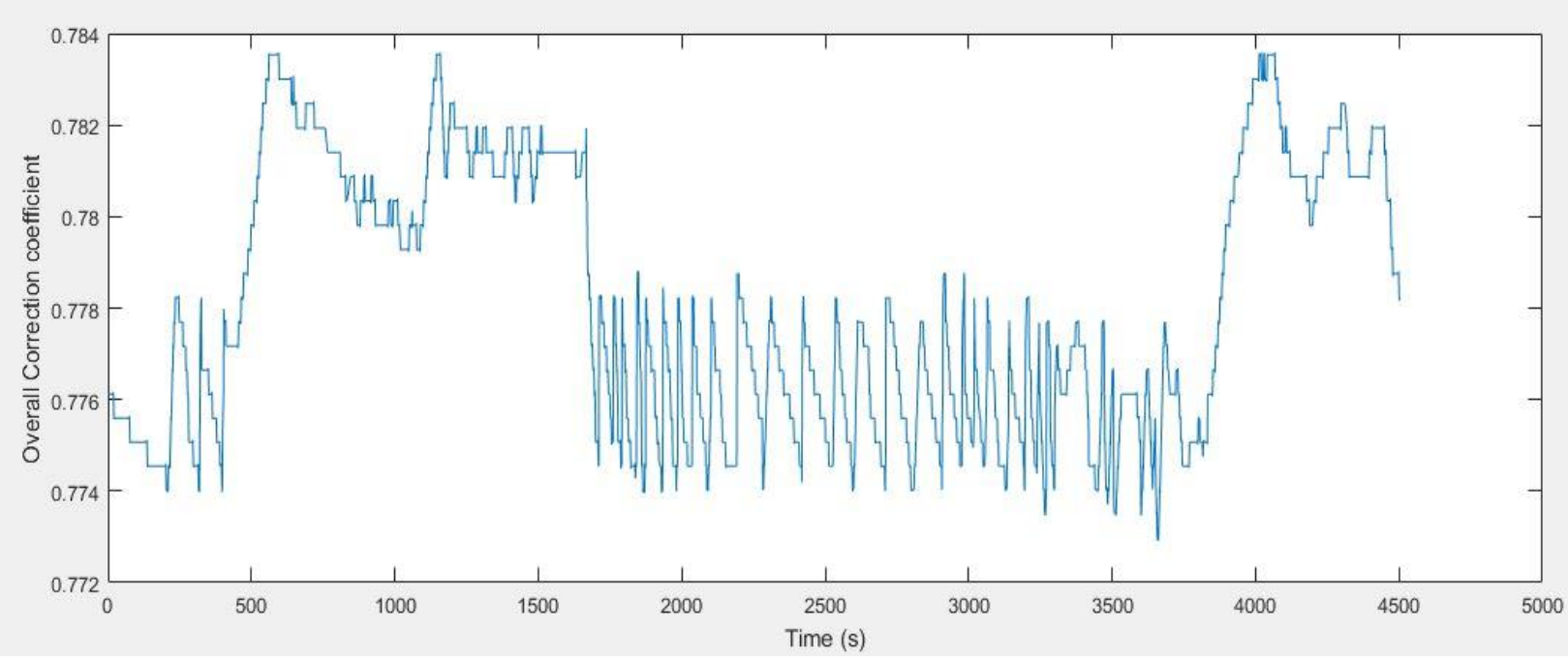

Figure 83 - Correction Coefficients of Highway Route of Vehicle-1 


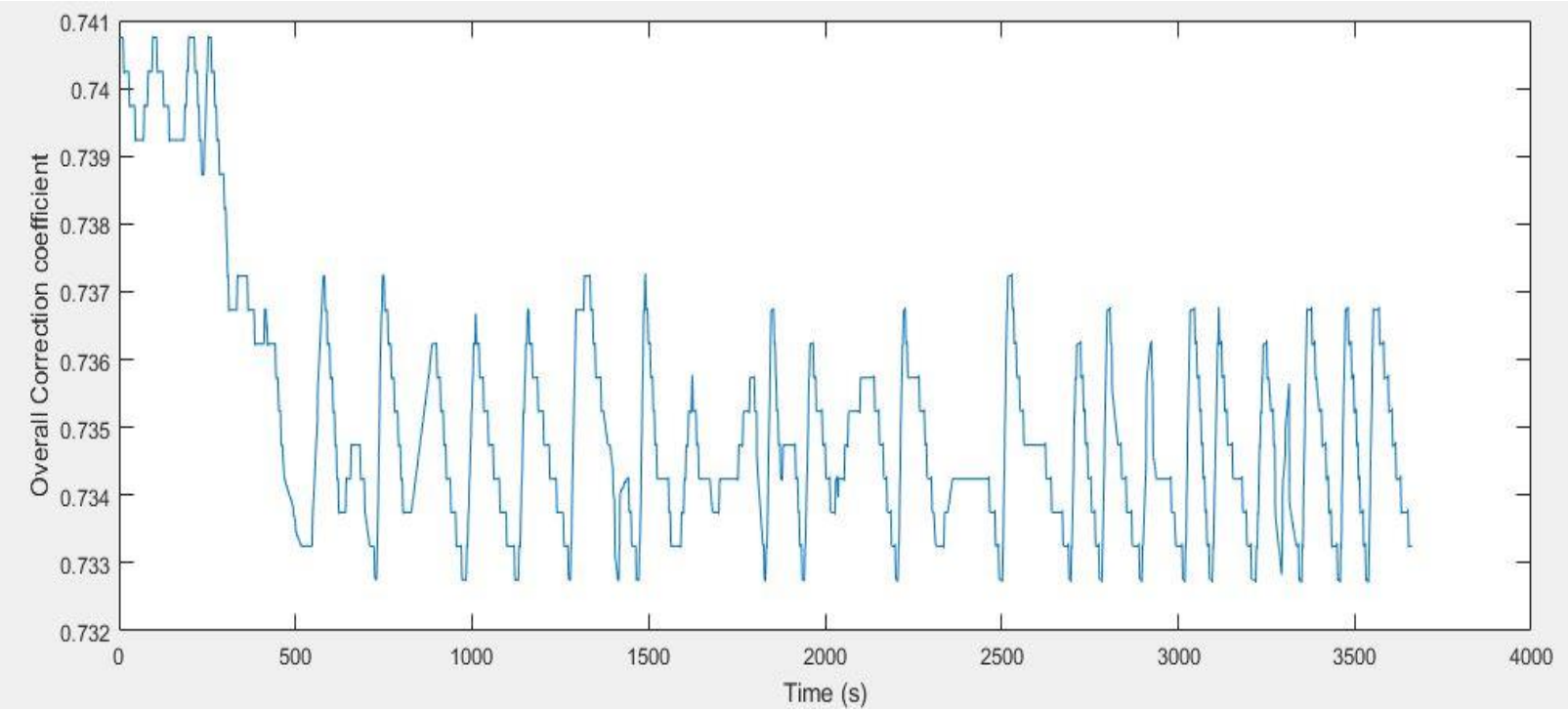

Figure 84 - Correction Coefficients of Port: Local Route of Vehicle-1

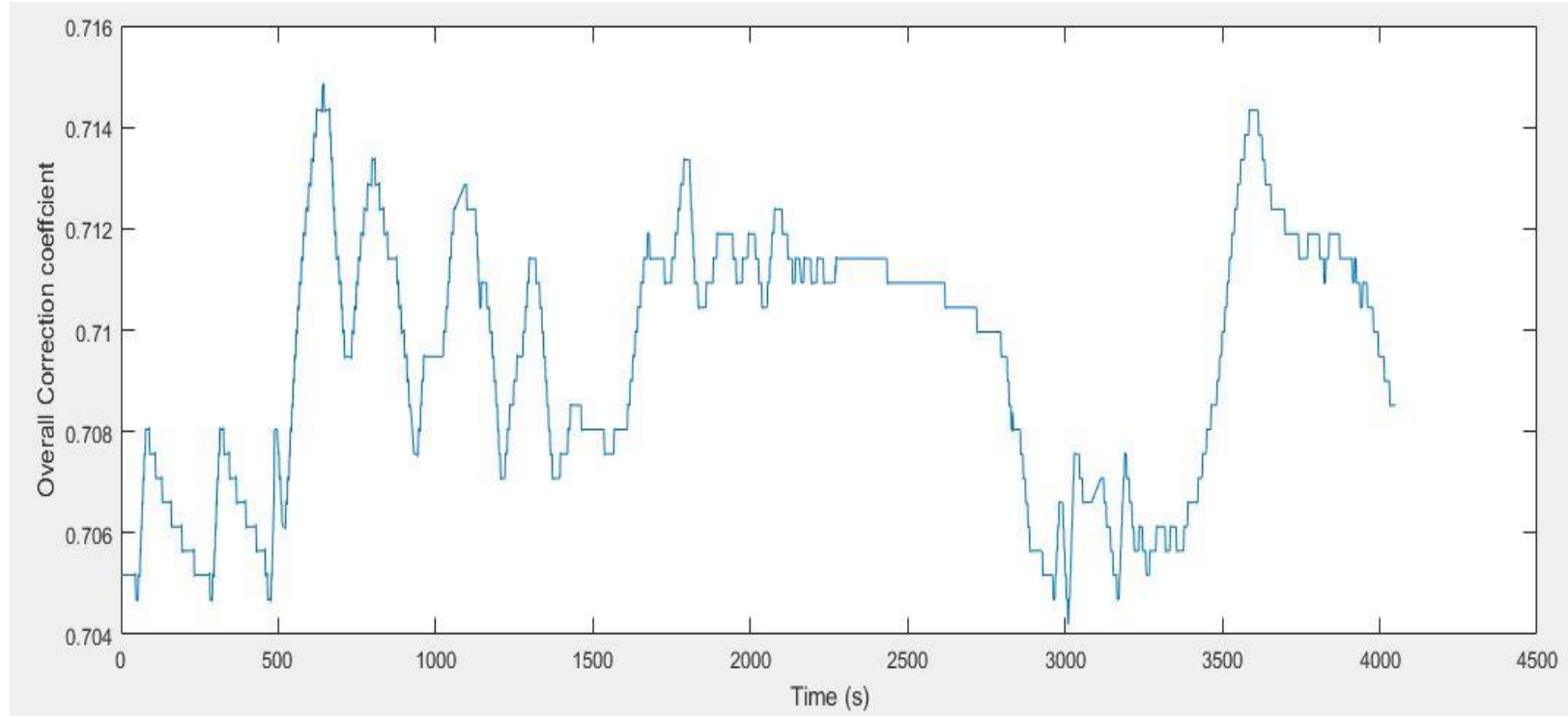

Figure 85- Correction Coefficients of Interstate Route of Vehicle-1 


\subsubsection{Regression Plots of Vehicle-1 speed density method - 1 a:}

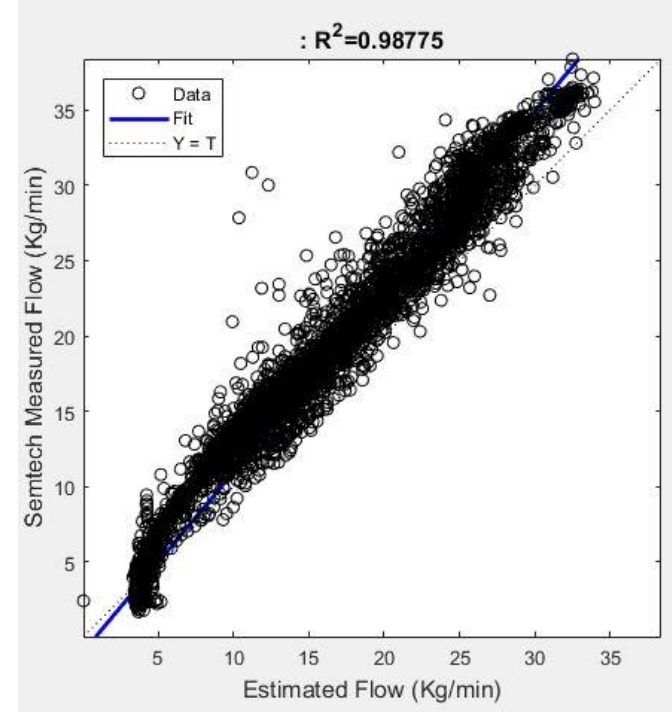

Figure 86 - Regional Route

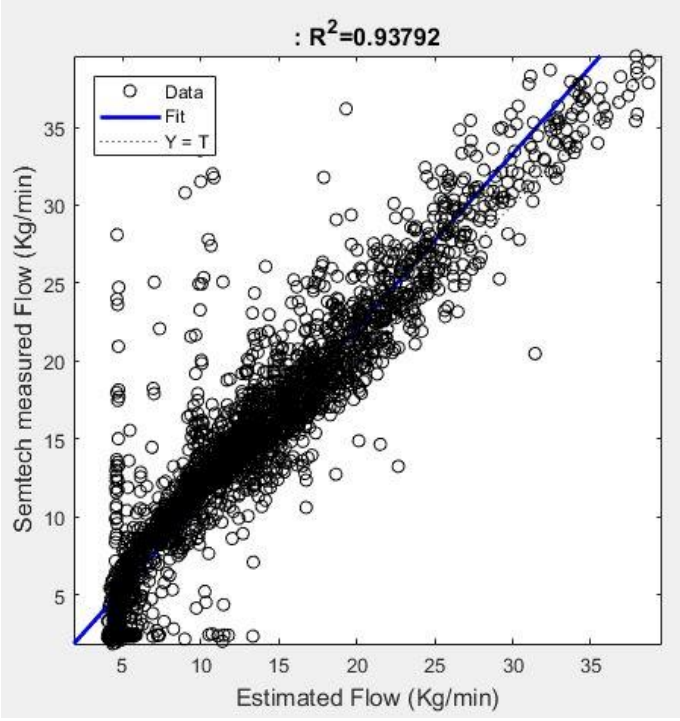

Figure 88 - Port: Local Route

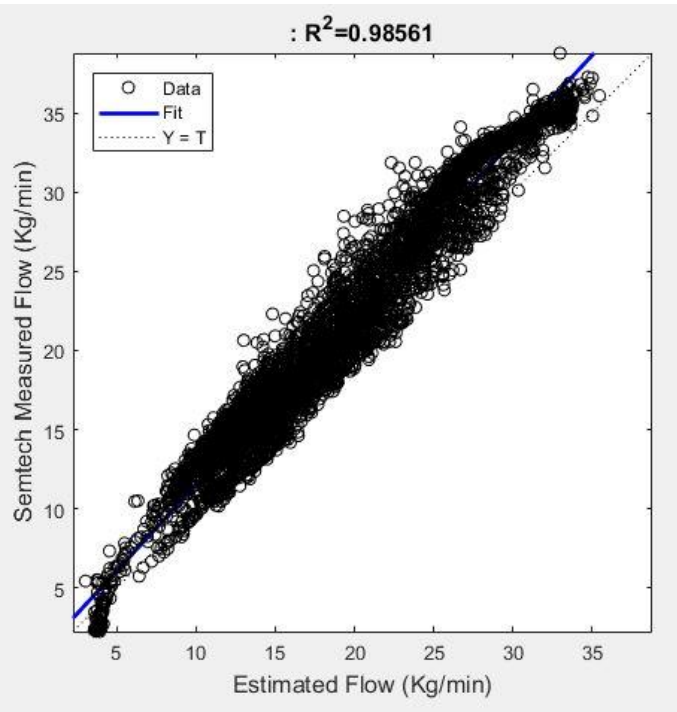

Figure 87 - Highway Route

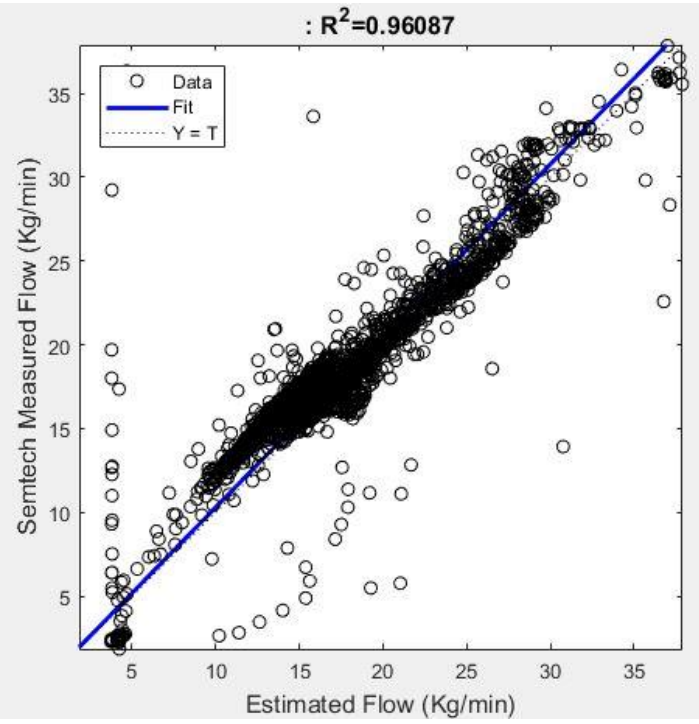

Figure 89 - Interstate Route 
7.1.3 Quartile-Quartile Plots Vehicle-1 speed density method - 1 a:

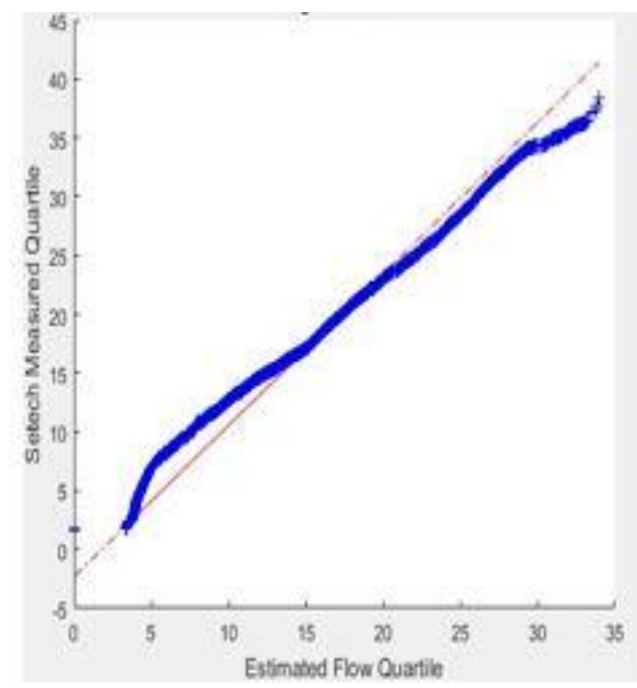

Figure 90 - Regional Route

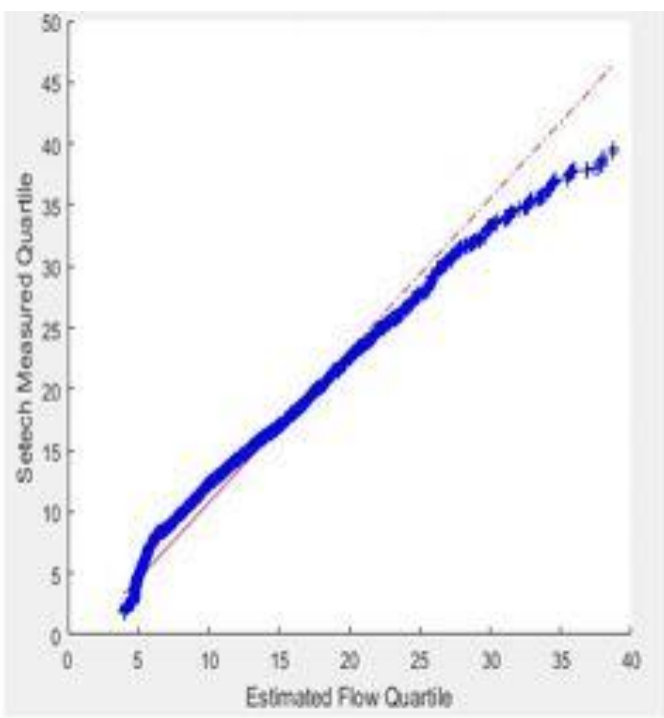

Figure 92 - Port: Local Route

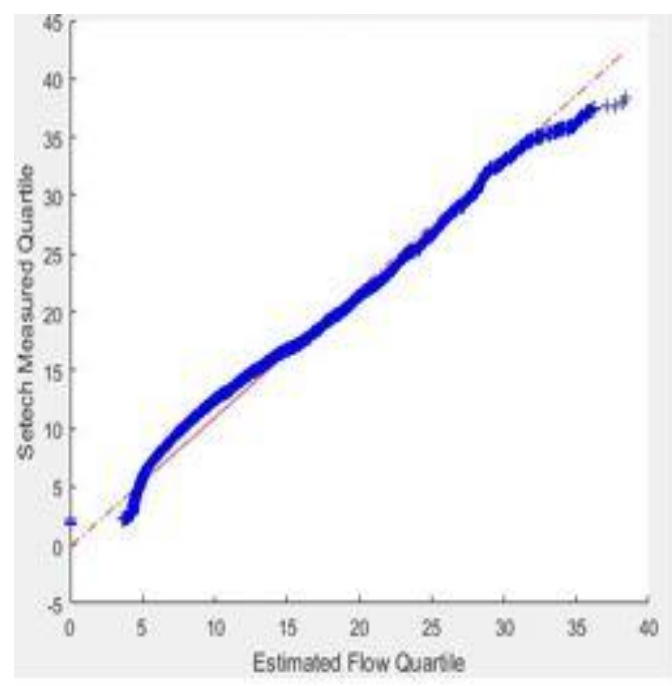

Figure 91 - Highway Route

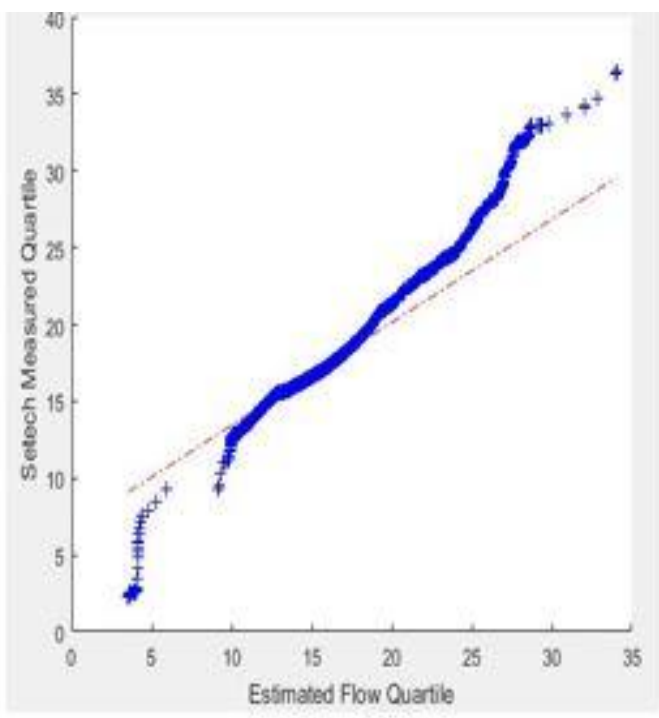

Figure 93 - Interstate Route 


\subsubsection{Line chart of Vehicle-1 speed density method - 1 a:}

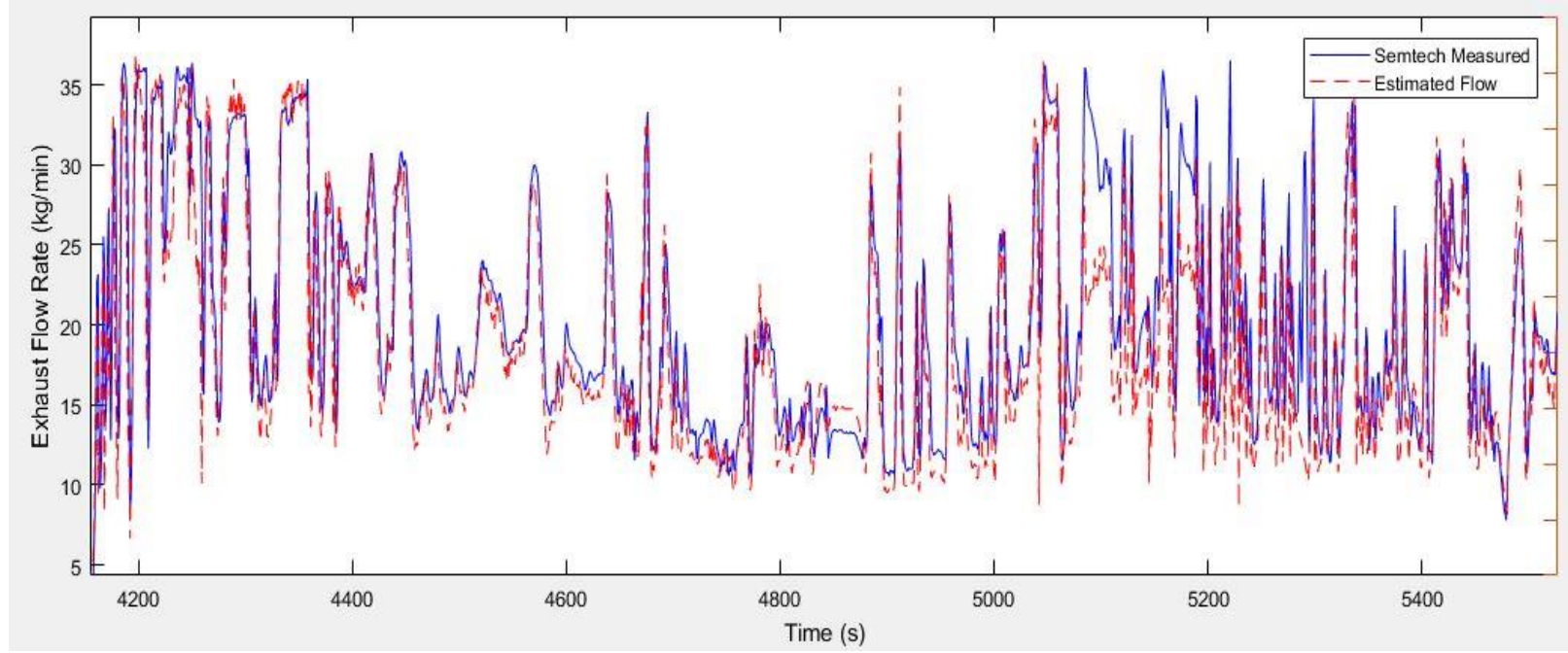

Figure 94 - Regional Route of Vehicle-1 speed density method - 1 a

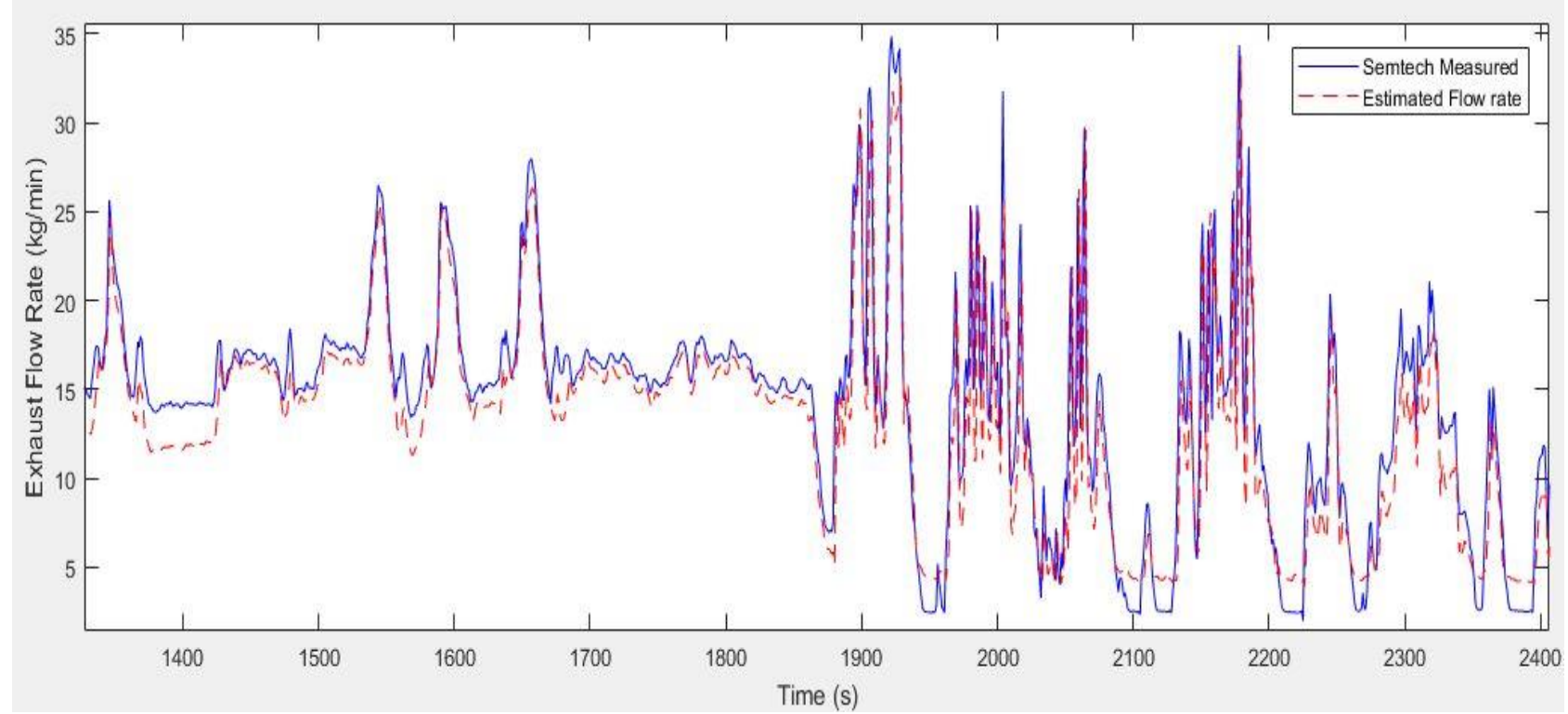

Figure 95 - Highway Route of Vehicle-1 speed density method - 1 a 


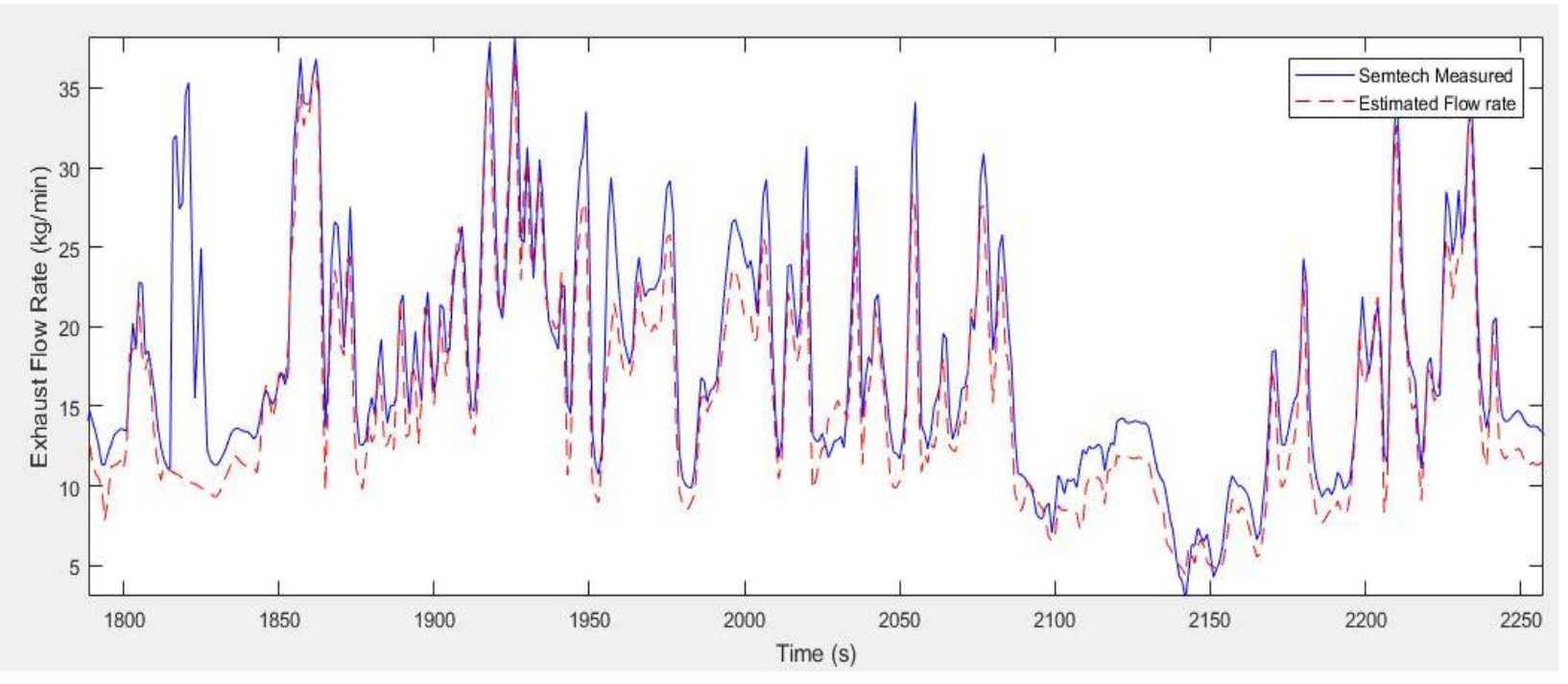

Figure 96-Port: Local Route of Vehicle-1 speed density method - 1 a

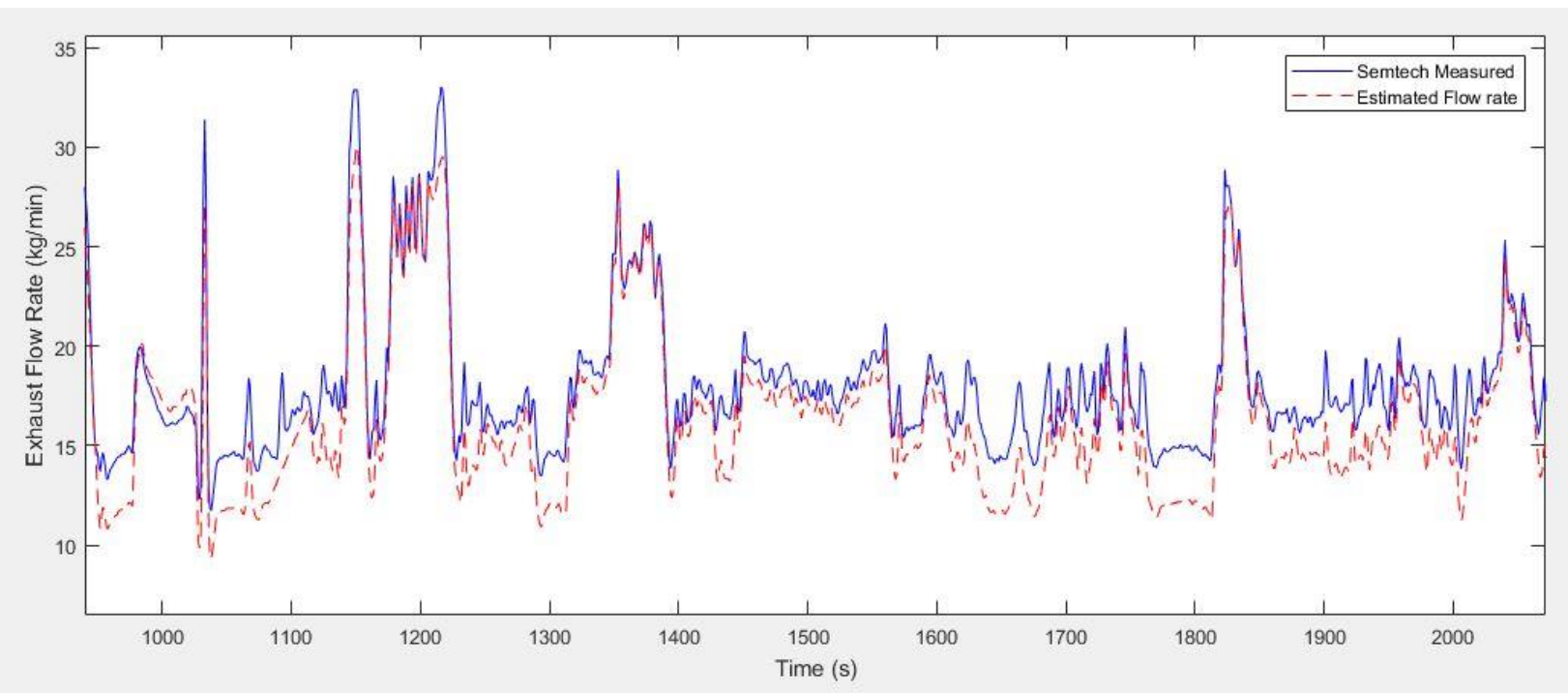

Figure 97 - Interstate Route of Vehicle-1 speed density method - 1 a 


\subsubsection{Regression Plots of Vehicle-1 speed density method - 1 b:}

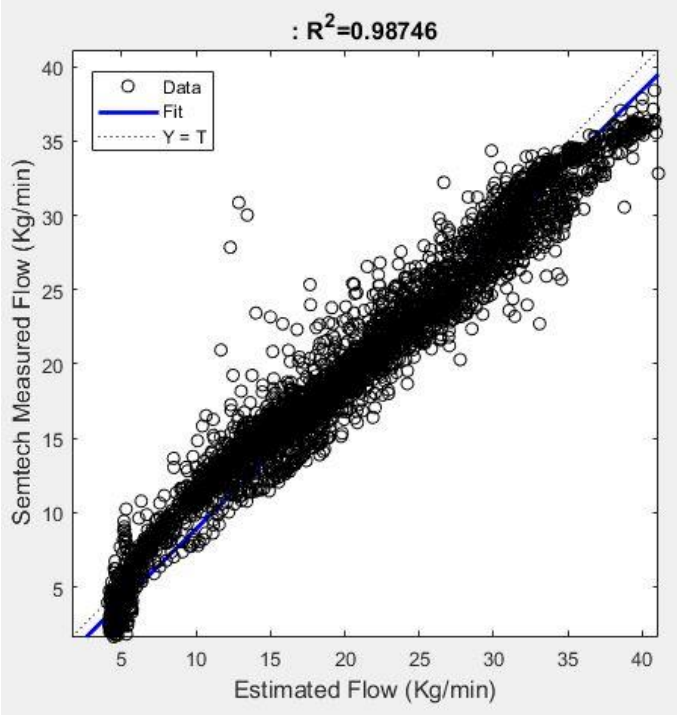

Figure 98 - Regional Route

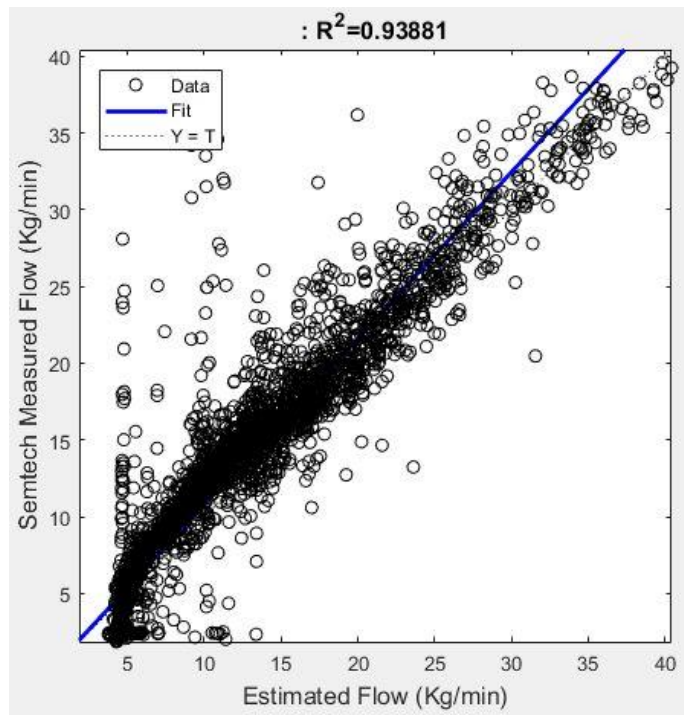

Figure 100 - Port: Local Route

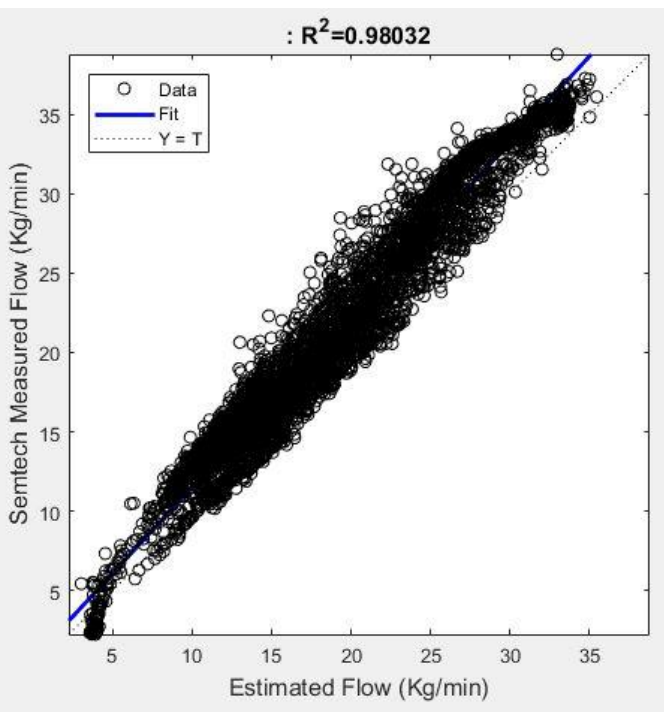

Figure 99 - Highway Route

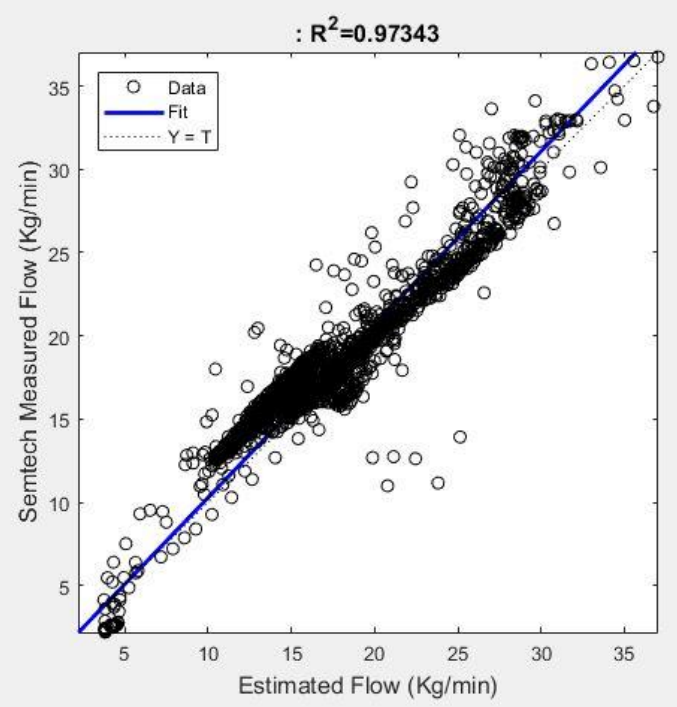

Figure 101 - Interstate Route 
7.1.6 Quartile-Quartile Plots Vehicle-1 speed density method - 1 b:

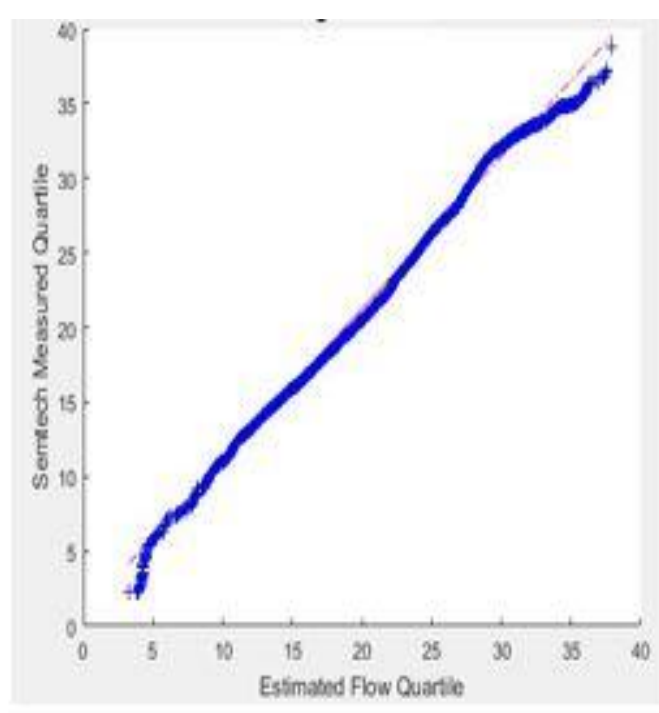

Figure 102 - Regional Route

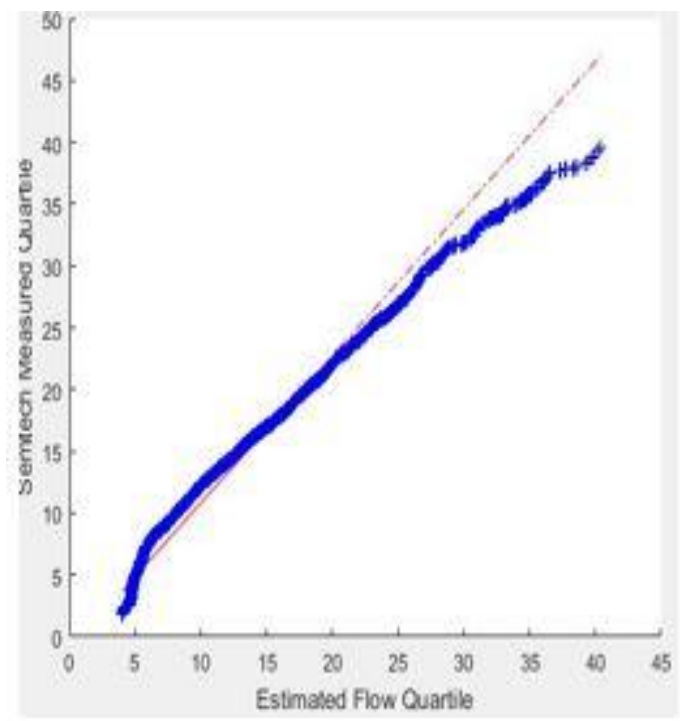

Figure 104 - Port: Local Route

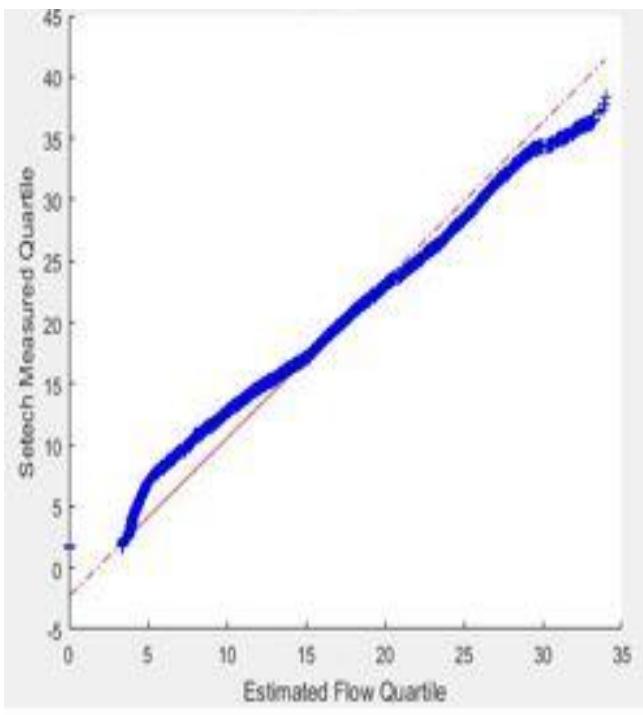

Figure 103 - Highway Route

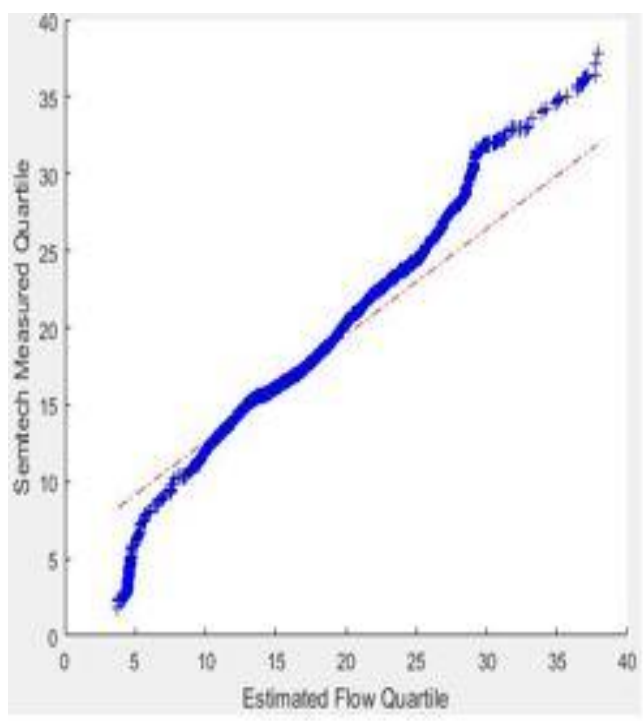

Figure 105 - Interstate Route 
7.1.7 Line chart of Vehicle-1 ANN Method:

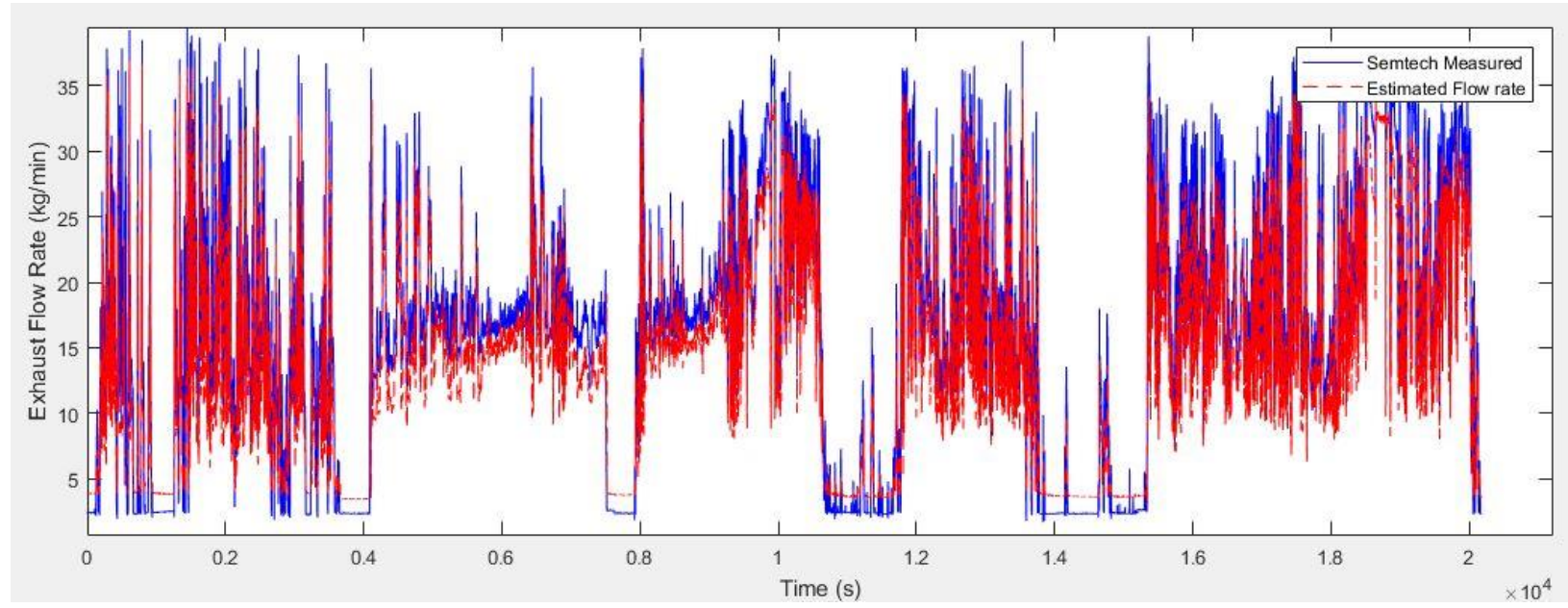

Figure 106-Combined plot of Vehicle-1 speed density method - 1 b

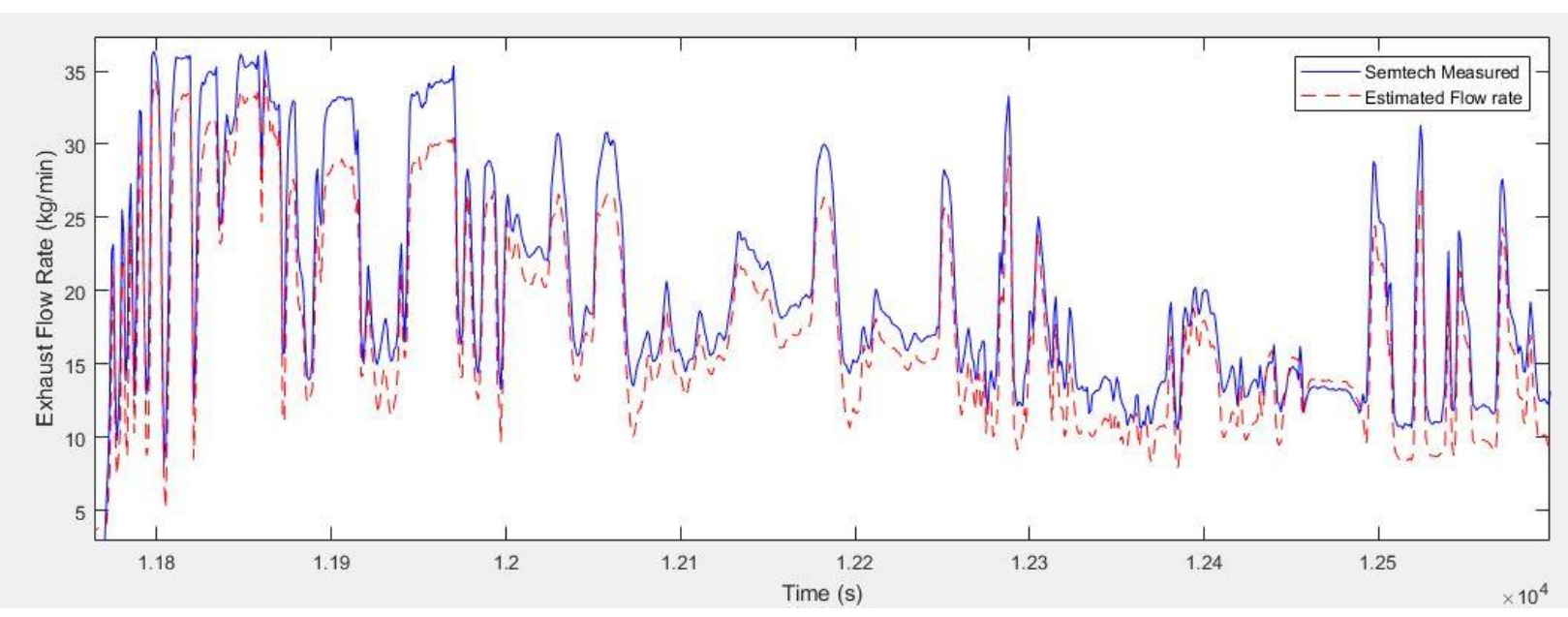

Figure 107- Enlarged combined plot of Vehicle-1 speed density method - 1 b 


\subsubsection{ANN Training Performance Results of Vehicle-1:}

Table 7-1 - Training performance of Vehicle-1 data

\begin{tabular}{|c|c|c|}
\hline Test Details & Regression & Performance \\
& $(\mathrm{R})$ & $(\mathrm{P})$ \\
\hline Regional & 0.92343 & 0.0016299 \\
\hline Highway & 0.92864 & 0.0015403 \\
\hline Port Local & 0.92886 & 0.0015097 \\
\hline Interstate & & 0.0016172 \\
\hline
\end{tabular}
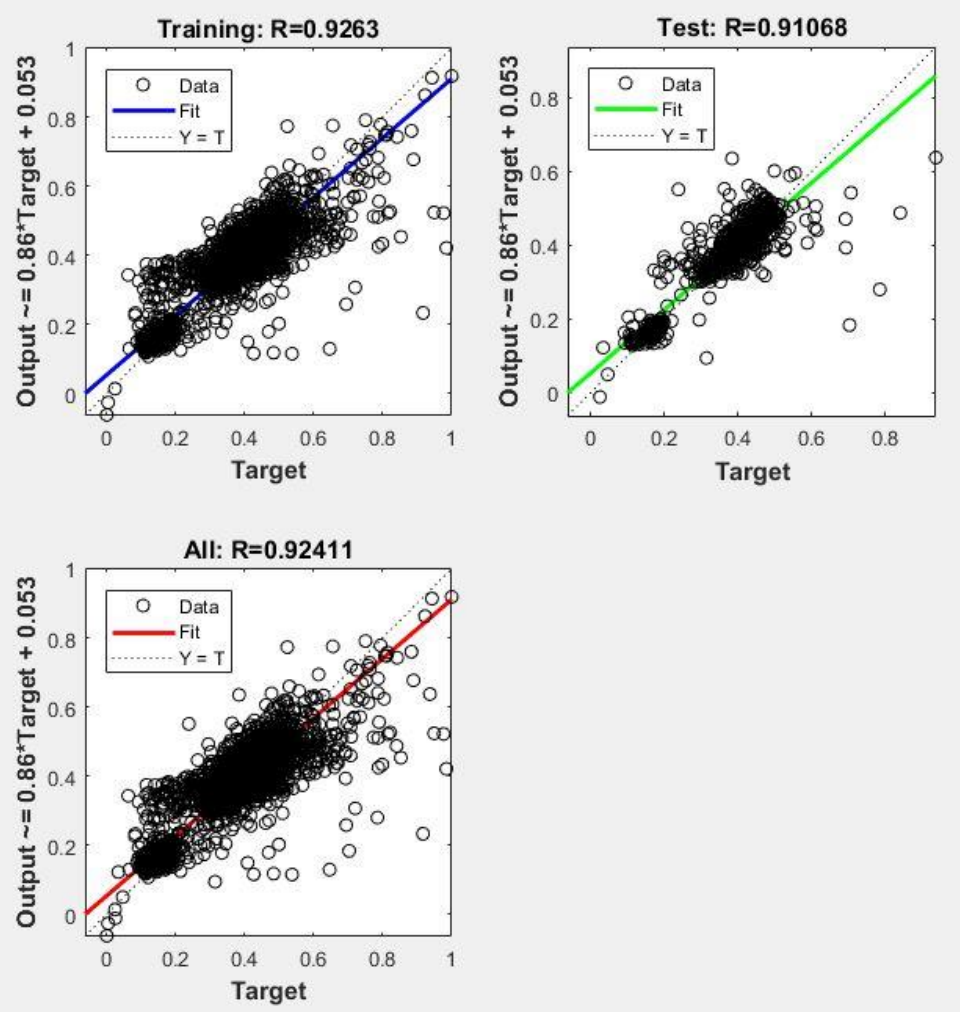

Figure 108 - Training performance of Vehicle-1 data 


\subsubsection{Regression Plots of Vehicle-1 ANN Method:}

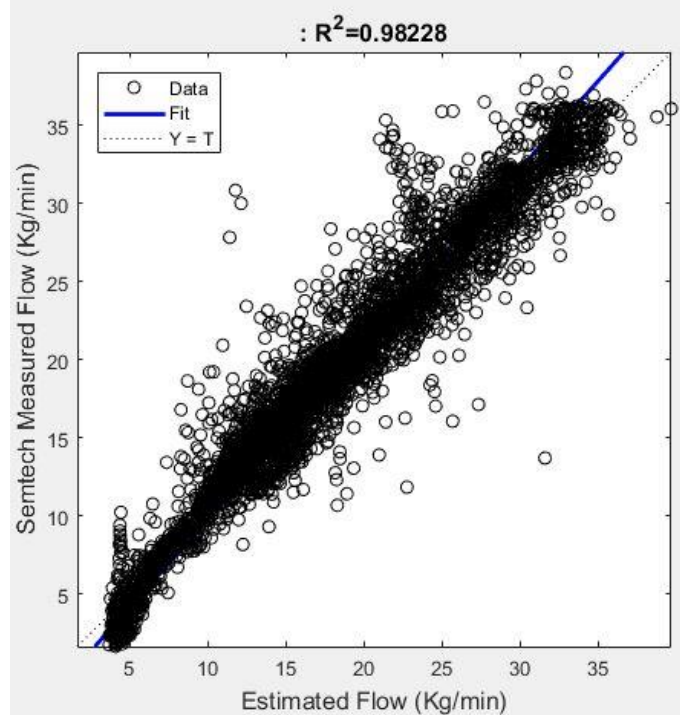

Figure 109 - Regional Route

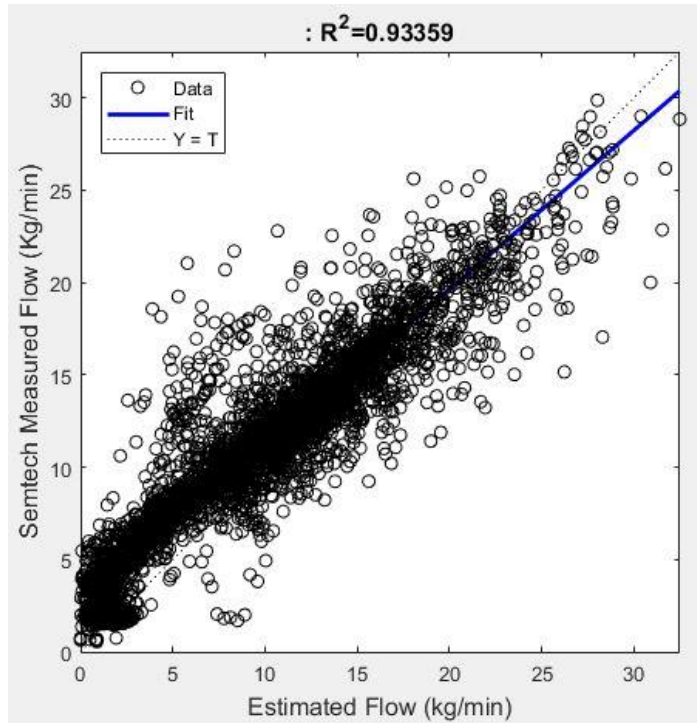

Figure 111 - Port: Local Route

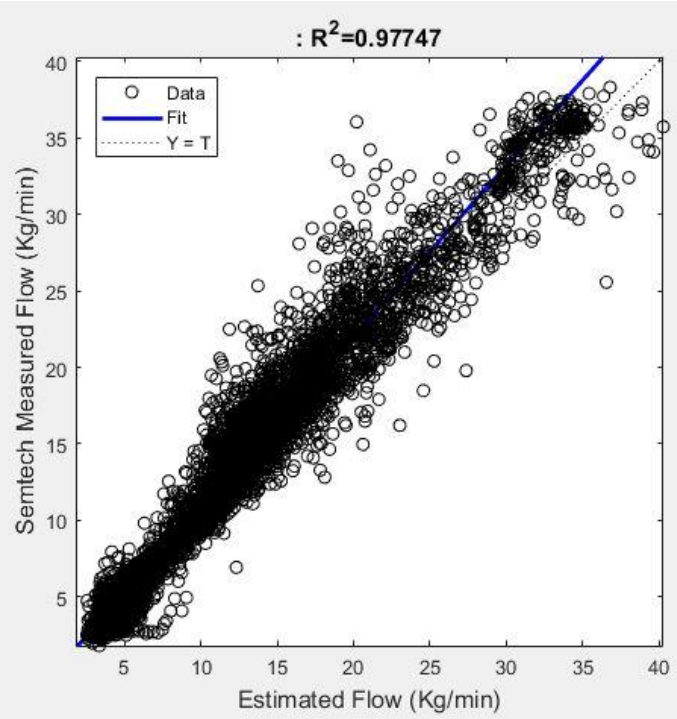

Figure 110- Highway Route

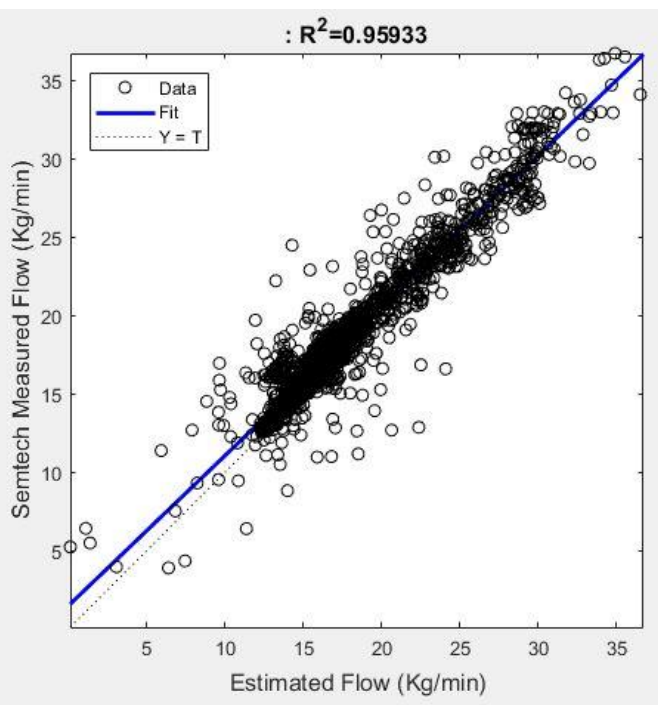

Figure 112 - Interstate Route 


\subsubsection{Quartile-Quartile Plots Vehicle-1 ANN Method:}

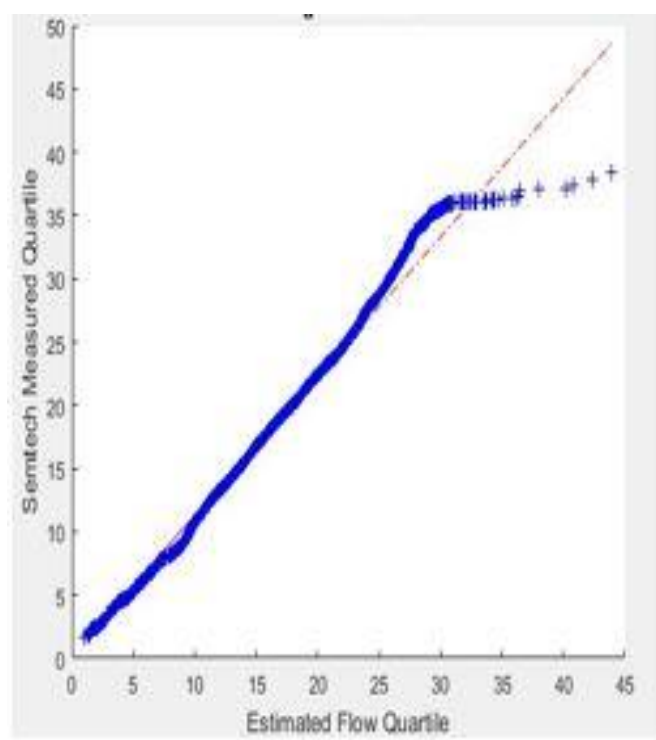

Figure 113 - Regional Route

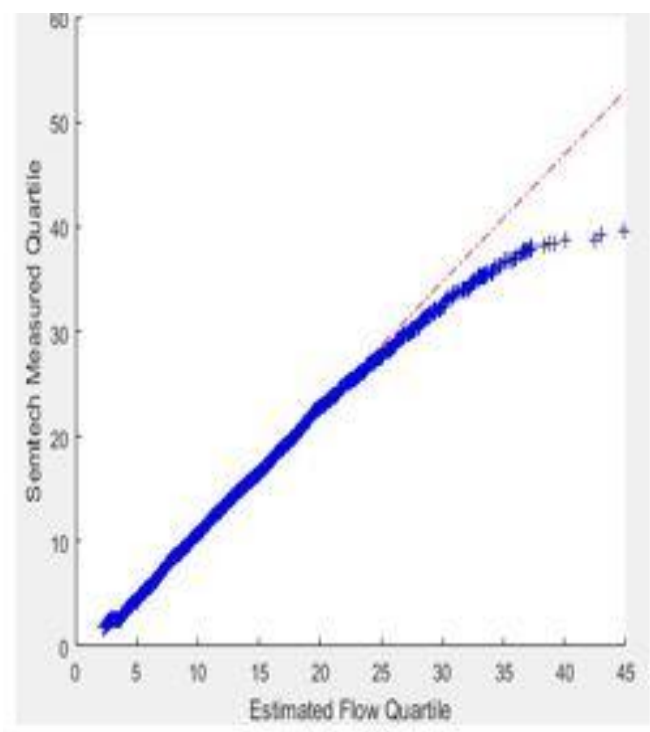

Figure 115 - Port: Local Route

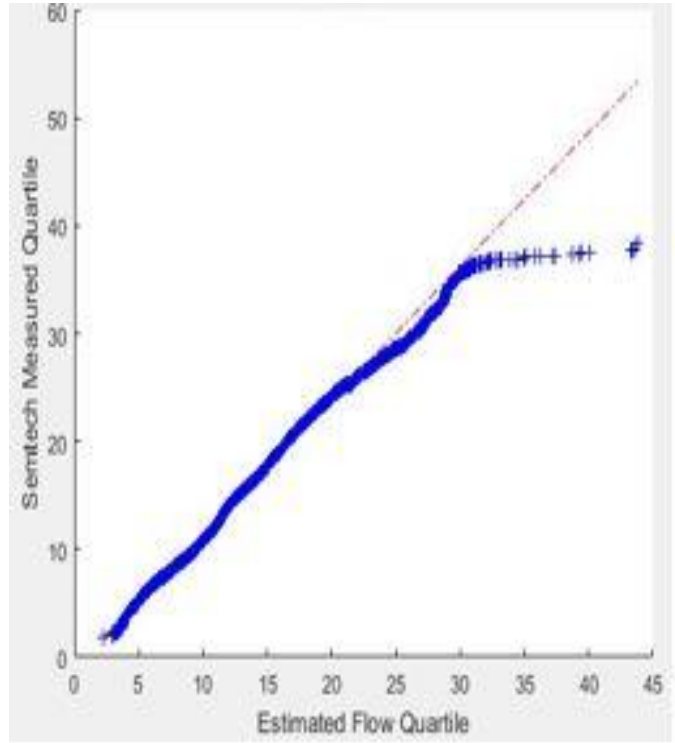

Figure 114 - Highway Route

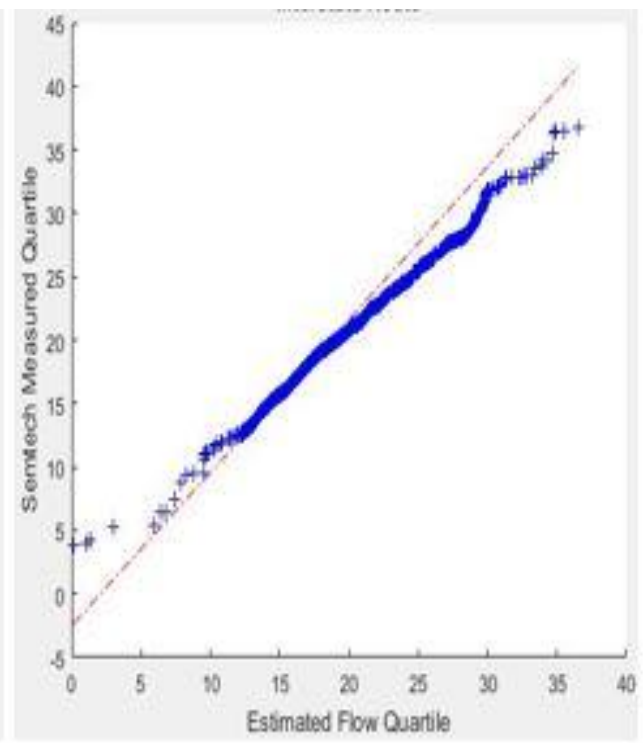

Figure 116 - Interstate Route 
7.1.11 Line chart of Vehicle-1 ANN Method:

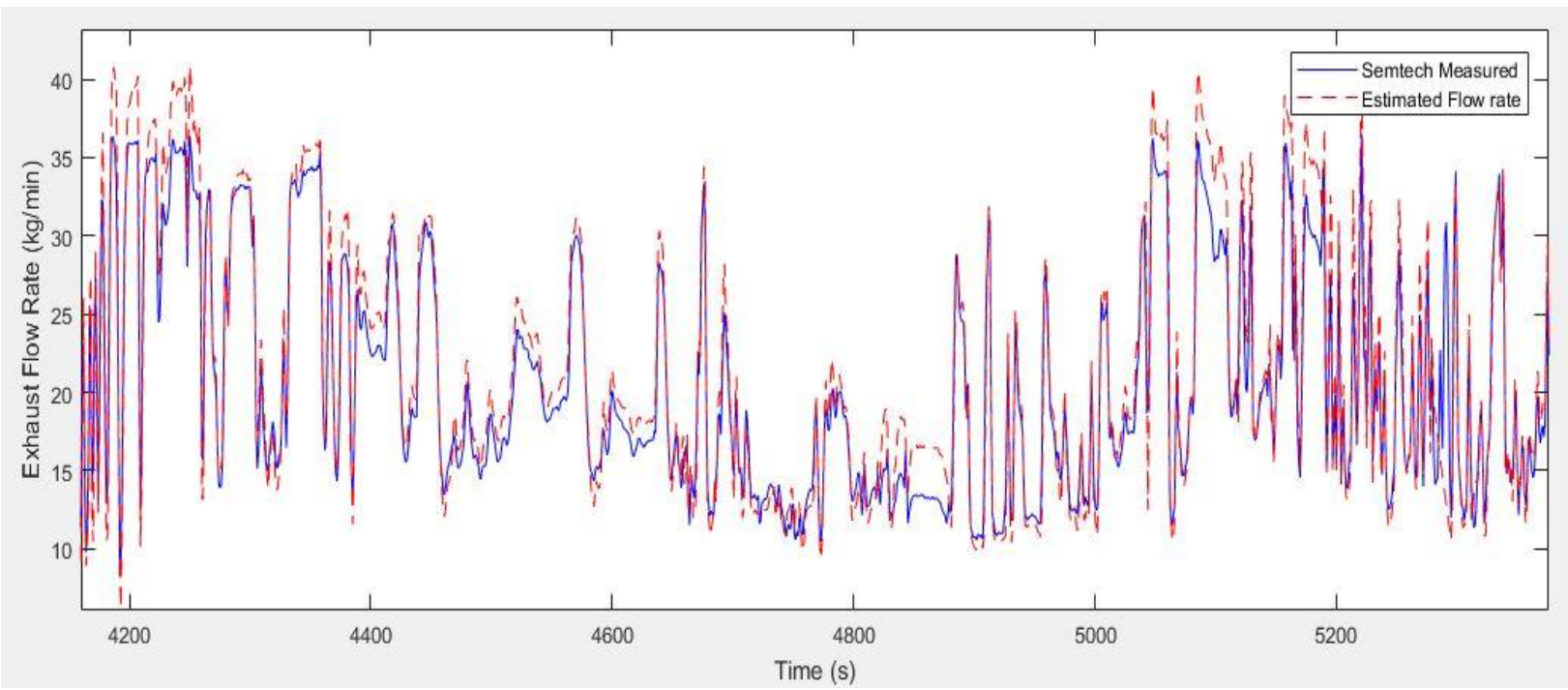

Figure 117 - Regional Route of Vehicle-1 ANN method

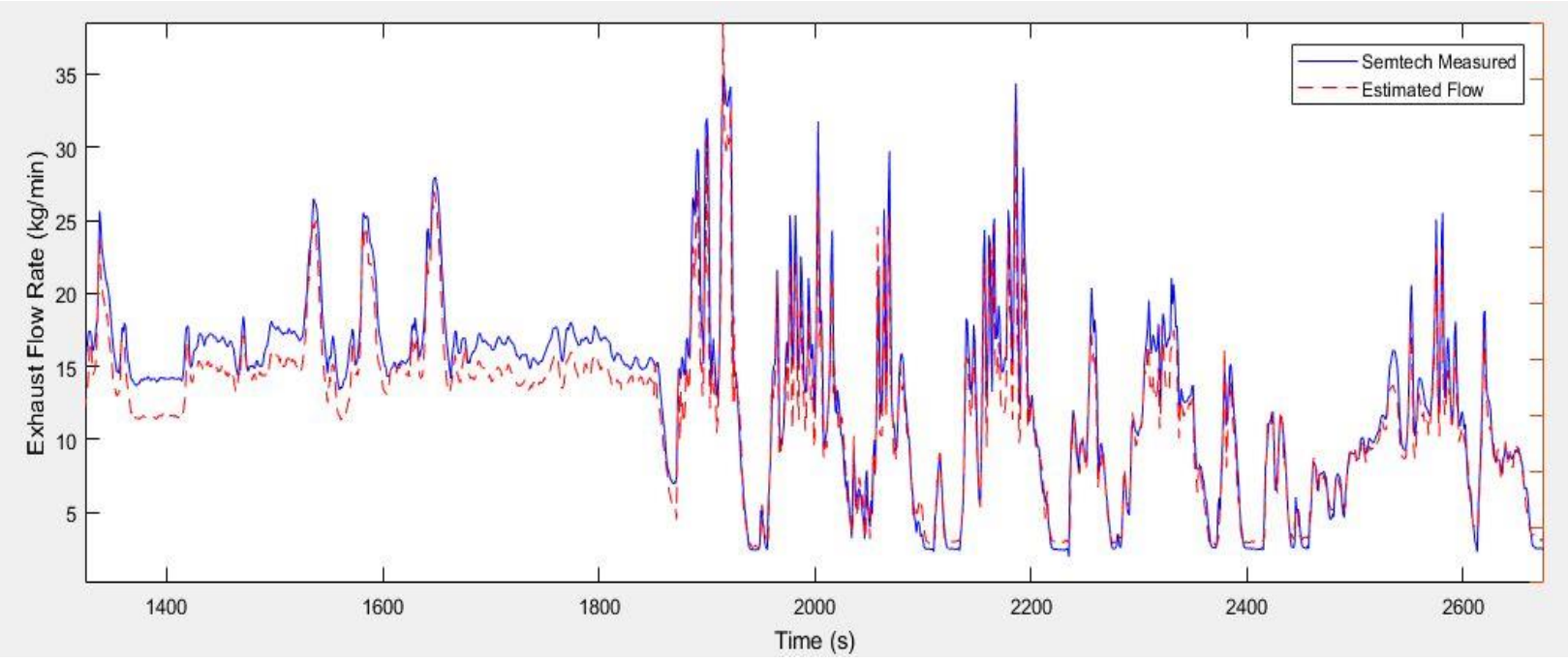

Figure 118 - Highway Route of Vehicle-1 ANN method 


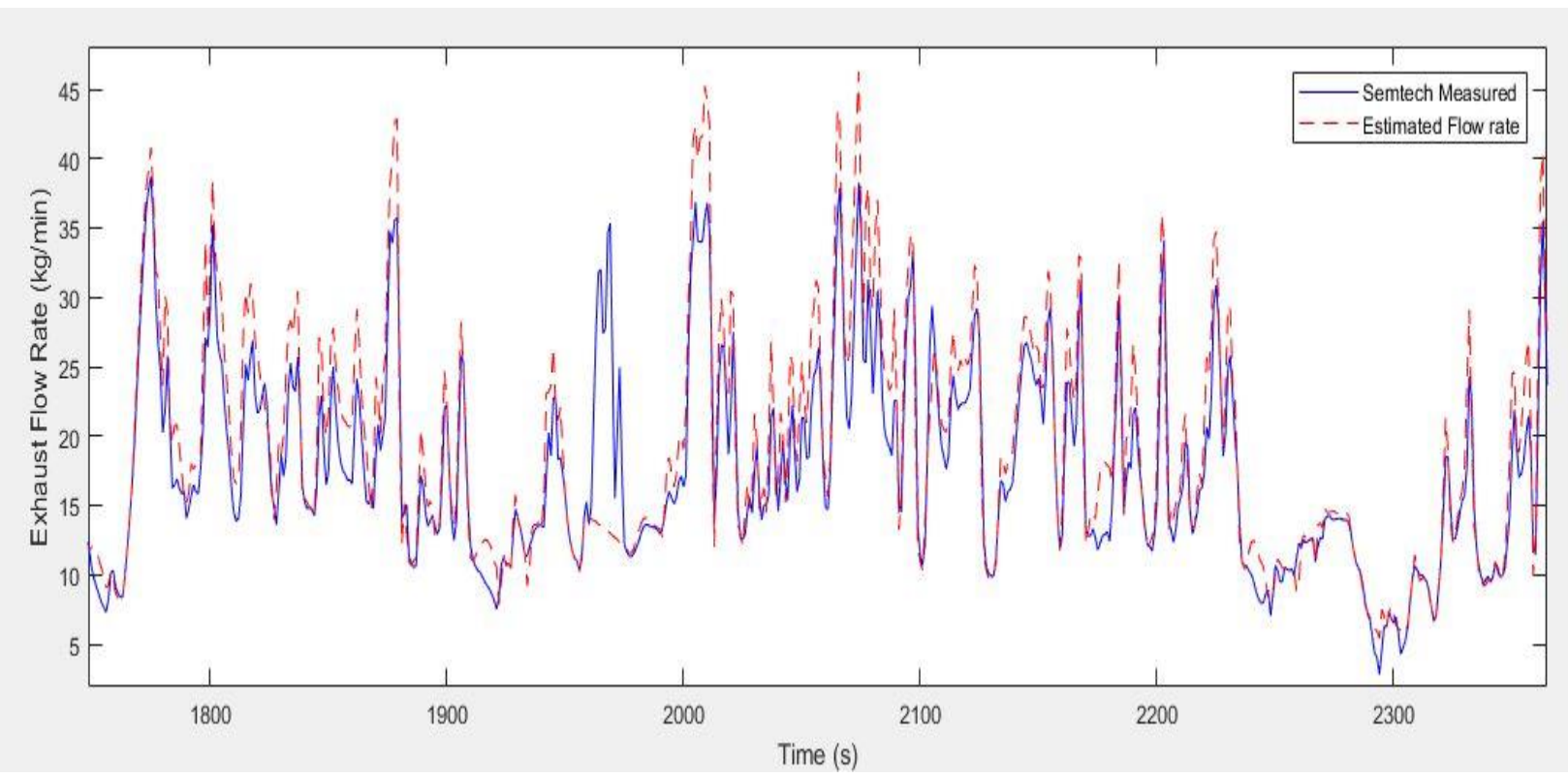

Figure 119 - Port: Local Route of Vehicle-1 ANN method

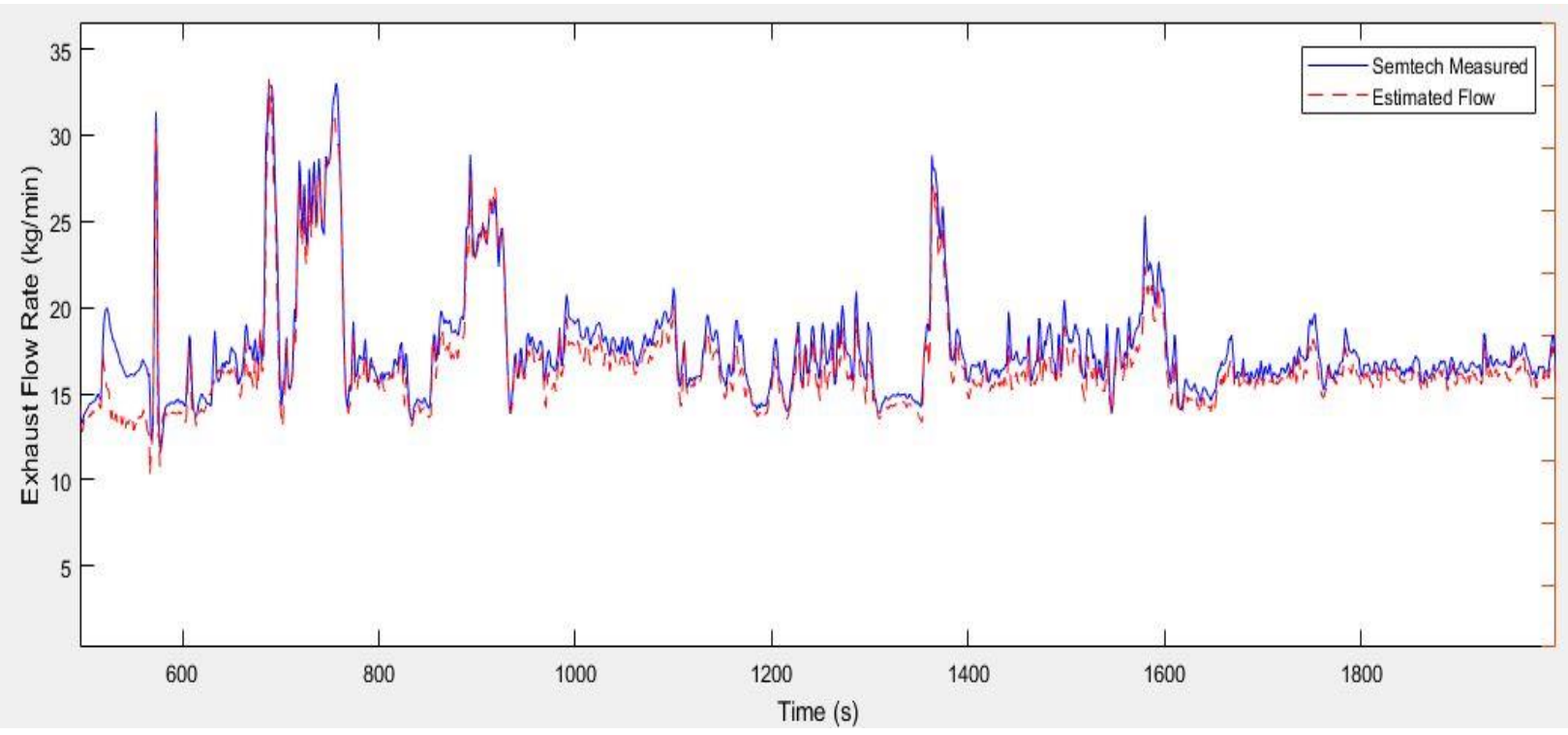

Figure 120 - Interstate Route of Vehicle-1 ANN method 


\subsubsection{Combined Line chart of Vehicle-1 all Methods:}

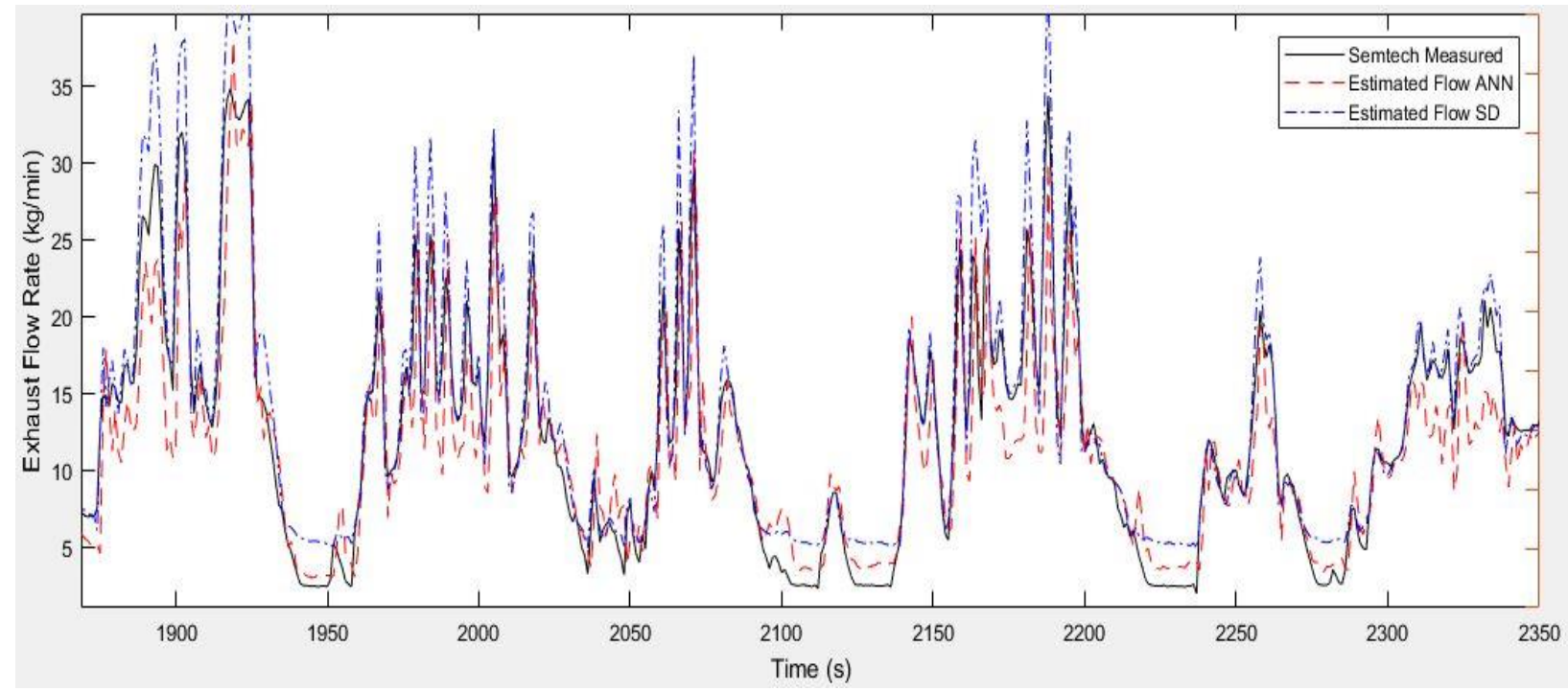

Figure 121 - Regional Route of Vehicle-1 all methods

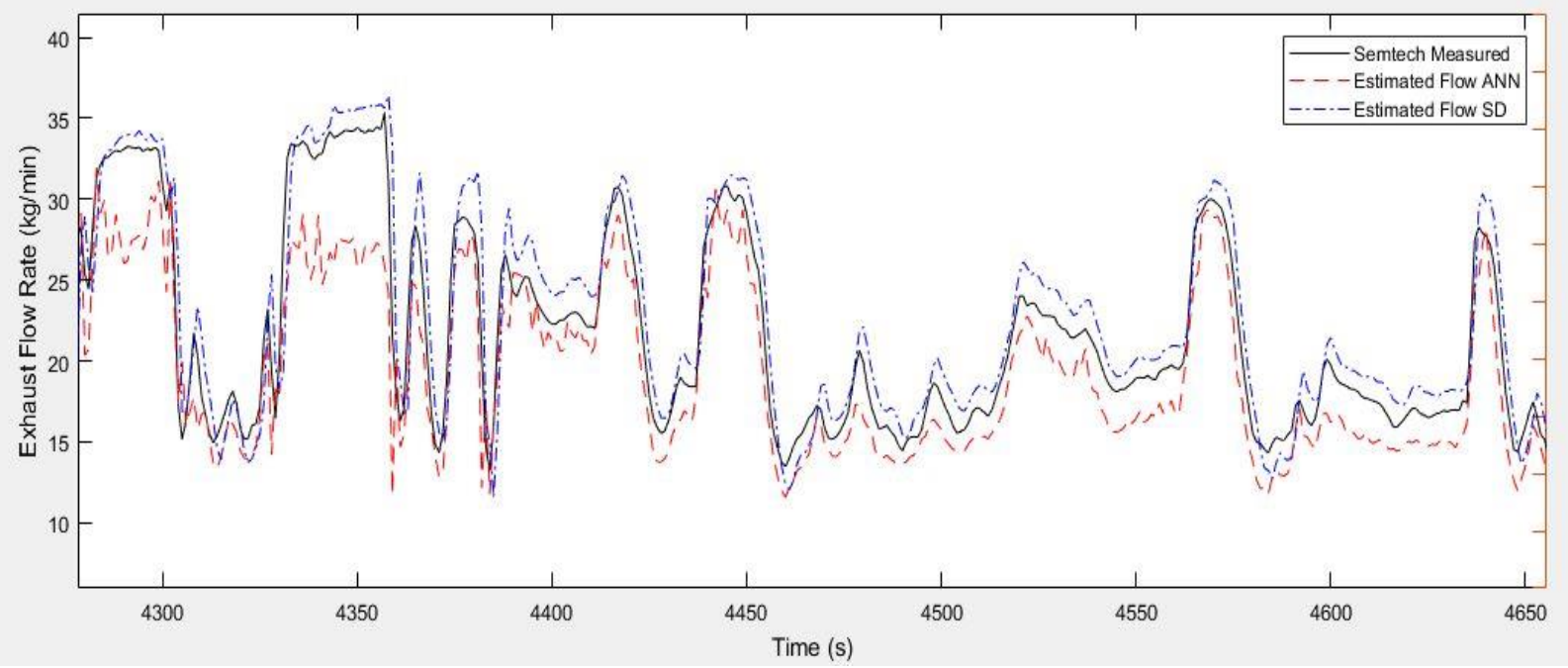

Figure 122 - Highway Route plot of Vehicle-1 all methods 